\title{
New developments in the field of retinal detachment
}

Citation for published version (APA):

Ricker, L. J. A. G. (2012). New developments in the field of retinal detachment. [Doctoral Thesis, Maastricht University]. Datawyse / Universitaire Pers Maastricht. https://doi.org/10.26481/dis.20120309Ir

Document status and date:

Published: 01/01/2012

DOI:

10.26481/dis.20120309lr

Document Version:

Publisher's PDF, also known as Version of record

\section{Please check the document version of this publication:}

- A submitted manuscript is the version of the article upon submission and before peer-review. There can be important differences between the submitted version and the official published version of record.

People interested in the research are advised to contact the author for the final version of the publication, or visit the DOI to the publisher's website.

- The final author version and the galley proof are versions of the publication after peer review.

- The final published version features the final layout of the paper including the volume, issue and page numbers.

Link to publication

\footnotetext{
General rights rights.

- You may freely distribute the URL identifying the publication in the public portal. please follow below link for the End User Agreement:

www.umlib.nl/taverne-license

Take down policy

If you believe that this document breaches copyright please contact us at:

repository@maastrichtuniversity.nl

providing details and we will investigate your claim.
}

Copyright and moral rights for the publications made accessible in the public portal are retained by the authors and/or other copyright owners and it is a condition of accessing publications that users recognise and abide by the legal requirements associated with these

- Users may download and print one copy of any publication from the public portal for the purpose of private study or research.

- You may not further distribute the material or use it for any profit-making activity or commercial gain

If the publication is distributed under the terms of Article $25 \mathrm{fa}$ of the Dutch Copyright Act, indicated by the "Taverne" license above, 


\section{New Developments in the Field of Retinal}

Detachment 
The printing of this thesis was financially supported by Alcon Nederland BV, Landelijke Stichting voor Blinden en Slechtzienden, Théa Pharma NV, Pfizer BV, Allergan BV, Novartis Pharma BV and Ursapharm Benelux BV.

(C) Lukas J.A.G. Ricker, Maastricht 2012

ISBN 9789461591111

Production: Datawyse | Universitaire Pers Maastricht 


\title{
New Developments in the Field of Retinal Detachment
}

\author{
PROEFSCHRIFT
}

ter verkrijging van de graad van doctor aan de Universiteit Maastricht, op gezag van de Rector Magnificus, Prof. mr. G.P.M.F. Mols, volgens het besluit van het College van Decanen,

in het openbaar te verdedigen, op vrijdag 9 maart 2012 om 12:00 uur

door

Lukas J.A.G. Ricker

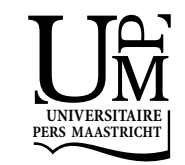




\section{Promotores}

Prof. dr. F. Hendrikse

Prof. dr. Ellen C. La Heij (Universiteit Utrecht)

\section{Beoordelingscommissie}

Prof. dr. H.W. Steinbusch (voorzitter)

Prof. dr. M.H. de Baets

Prof. dr. W.A. Buurman

dr. Martine J. Jager (Universiteit Leiden)

Prof. dr. P.J. Ringens (Vrije Universiteit Amsterdam) 


\section{Paranimfen}

Dennis Pluijmaekers

Jules Janssen 


\section{Table of Contents}

Chapter 1 General Introduction 9

Chapter 2 Persistent Subfoveal Fluid and Increased Preoperative Foveal $\quad 35$ Thickness Impair Visual Outcome After Macula-off Retinal Detachment Repair

Ricker LJAG, Noordzij LJ, Goezinne F, Cals DWJK, Berendschot TTJM, Liem ATA, Hendrikse F, La Heij EC.

Retina 2011;31(8):1505-1512

Chapter 3 High Subretinal Fluid Procoagulant Activity in Rhegmatogenous Retinal Detachment

Ricker LJAG, Al Dieri R, Beckers GJM, Pels E, Liem ATA, Hendrikse F, Kijlstra A, Hemker HC, La Heij EC.

Invest Ophthalmol Vis Sci 2010;51(10):5234-5239

Chapter 4 Soluble Apoptotic Factors and Adhesion Molecules in Rhegmatogenous Retinal Detachment

Ricker LJAG, Altara R, Goezinne F, Hendrikse F, Kijlstra A, La Heij EC. Invest Ophthalmol Vis Sci 2011;52(7):4256-4262

Chapter 5 Anti-angiogenic Isoforms of VEGF Predominate in Subretinal Fluid of Patients with Rhegmatogenous Retinal Detachment and Proliferative Vitreoretinopathy

Ricker LJAG, Dieudonné SC, Rennel ES, Berendschot TTJM, Hendrikse F, Kijlstra A, La Heij EC. Retina 2012;32(1):54-59

Chapter 6 Chemokine Levels in Subretinal Fluid Obtained during Scleral Buckling Surgery after Rhegmatogenous Retinal Detachment 
Chapter 7 Interleukin and Growth Factor Levels in Subretinal Fluid in Rhegmatogenous Retinal Detachment: a Case-control Study

Ricker LJAG, Kijlstra A, Kessels AGH, de Jager W, Liem ATA, Hendrikse F, La Heij EC.

PLOS ONE 2011;6(4):e19141

Chapter 8 Adipokine Levels in Subretinal Fluid from Patients with Rhegmatogenous Retinal Detachment

Ricker LJAG, de Jager W, Kessels AGH, Hendrikse F, Kijlstra A, La Heij EC. Exp Eye Res. In press (in revised form)

Chapter 9 Prediction of Proliferative Vitreoretinopathy after Retinal Detachment Surgery: Potential of Biomarker Profiling

Ricker LJAG, Kessels AGH, de Jager W, Hendrikse F, Kijlstra A, La Heij EC. Submitted

Chapter 10 General Discussion

Summary

Samenvatting

Dankwoord 

Chapter 1

General Introduction 


\section{Rhegmatogenous retinal detachment}

Rhegmatogenous retinal detachment (RRD) refers to detachment as a result of one or more breaks in the retina (rhegma means break in Greek). In general, it is an ophthalmologic urgency that leads to blindness of the affected eye if left untreated, since most detachments eventually involve the entire retina. Three distinct sequential stages can be distinguished in the development of a rhegmatogenous retinal detachment. First, a posterior vitreous detachment (PVD) develops due to an agedependent liquefaction of the vitreous. This phenomenon is rarely seen in patients younger than 50 years of age but increases considerably thereafter, eventually having occurred in almost two-third of patients who are in their $8^{\text {th }}$ decade of life. ${ }^{1}$ It develops earlier and more often in myopic patients, which makes them more prone to develop RRD. ${ }^{2}$ Second, a PVD may cause retinal breaks as a result of traction in areas of strong vitreoretinal adhesions, typically in the far periphery of the retina. Third, these retinal breaks provide the liquefied vitreous fluid access into the potential subretinal space, i.e. between the photoreceptor layer of the neuroretina and the retinal pigment epithelium (RPE). Normally, the retina is maintained in its attached position by an outward movement of fluid across the RPE into the choroid. If the RPE pump is overwhelmed by fluid passing through one or more retinal breaks, a RRD develops.

\section{Incidence}

Although PVD is very common in the elderly population and retinal breaks can be found in up to $15 \%$ of patients, ${ }^{1-4}$ the occurrence of RRD is quite rare. Many studies have been conducted on this topic in the past decades. The annual incidence of primary RRD was reported to be between 8 and 14 per 100.000 persons, with a peak incidence in the $7^{\text {th }}$ decade of life..$^{5-8}$ In a very recent prospective study on primary RRD, the authors found an annual incidence of 12.05 per 100.000 persons. ${ }^{9}$ If patients with previous cataract surgery, a common risk factor for RRD, were also included, the incidence tended to increase to about 18 per 100.000 persons. ${ }^{9}$ Interestingly, at the Annual Meeting of the Dutch Ophthalmologic Society, the annual incidence in the Netherlands was reported to approach 20 cases per 100.000 persons. ${ }^{10}$ These data implicate that, with a growing number of cataract procedures in a continuously aging population, the incidence and the number of primary RRD cases will keep on increasing, and so will the complications of RRD surgery. 


\section{Risk factors for retinal detachment}

Besides cataract surgery and myopia, several other risk factors for the development of RRD are known including trauma, a positive family history of RRD, inflammatory eye disease, and RRD in the fellow eye. ${ }^{11,12}$ Moreover, men were found to be at higher risk for developing RRD than women, ${ }^{13-16}$ even after having corrected for trauma and previous cataract surgery. ${ }^{9}$ It was suggested that men tend to underreport minor trauma that may have contributed to the risk of RRD, although an inherent difference in sex risk may also not be excluded. There are also few reports showing that women are more prone to RRD in a phakic, nontraumatic cohort of patients. ${ }^{6,17}$ Socio-economic status is known to be an important determinant of the risk of blindness. ${ }^{18,19}$ Retinal detachment, however, appeared to be associated with affluence. ${ }^{20}$ A sound explanation for this association was not found. Although cataract surgery and myopia are associated with higher income and socio-economic status, ${ }^{21-23}$ no more pseudophakic detachments or no higher prevalence of myopia were reported in the most affluent group. A higher risk of retinal detachment could also not be explained by a greater life expectancy in this group of patients. Retinopathy of prematurity and Stickler syndrome are also associated with an increased risk of retinal detachment.

\section{Treatment}

Since most retinal breaks occur in the far periphery of the retina, the detachment often causes loss of peripheral vision in the first place. Because the detachment may extend towards the macular region and thus may jeopardize central vision, treatment should in general be started within days in recent-onset cases. ${ }^{24}$ On the other hand, in patients with macular-off retinal detachments, the surgical procedure should preferably be performed within one week after the onset of macular involvement, ${ }^{25,26}$ suggesting that in this population surgical repair is a less urgent procedure. These recommendations appear to be in contrast with experimental models showing that within 24 hours after detachment many biological alterations unfold in all retinal layers. ${ }^{27}$ In longstanding detachments of several weeks, surgical repair becomes subject to an elective procedure. In a recent study on treatment delay in retinal detachment, it was demonstrated that the patients' unawareness and unfamiliarity with its symptoms are far more important than delay associated with referral and scheduling of the operating procedure. ${ }^{28}$

If one or more retinal breaks are detected without the occurrence of a detachment, they can be treated with cryotherapy or laser therapy. These interventions aim at the creation of scar tissue that seals the retinal break, thereby preventing the passage of liquefied vitreous into the subretinal space. If the neuroretina is de- 
tached from its underlying layers, reattachment surgery is inevitable. Three surgical methods can be distinguished: pneumatic retinopexy, scleral buckling surgery, and vitrectomy.

Pneumatic retinopexy is only performed in patients with local detachments. Retinal breaks are closed by the intravitreal injection of gas allowing the RPE pump to reattach the retina. Subsequently laser or cryotherapy is applied. Although this procedure has some advantages over the others (less invasive, less complications, avoidance of refractive errors), pneumatic retinopexy is rather impractical. Retinal breaks must be located in the superior parts of the fundus, since proper head positioning - during several days - must allow the gas bubble to close the break. Moreover, anatomic success rates are fairly low $(\sim 70 \%),{ }^{29,30}$ frequently necessitating additional interventions. On the other hand, a failed pneumatic retinopexy does not preclude high success rates following subsequent surgery. ${ }^{29,30}$

Scleral buckling surgery is often used for retinal detachments without complicating factors. The goal of this extraocular approach is to bring the underlying RPE, choroid, and sclera back in contact with the detached retina. During this procedure, silicone sponges are stitched on the external sclera in order to close the retinal break(s). An encircling band may also be applied to relieve traction at the level of the vitreous base, where vitreoretinal adhesions are strongest. To further enhance the apposition of the detached retina, subretinal fluid drainage may be performed. The use of intraoperative gas may also be helpful in case the breaks are located in the superior quadrants. Permanent closure of the retinal defects is achieved by cryotherapy or photocoagulation. Complications associated with scleral buckling surgery are diplopia, perforation of the sclera, and infection and extrusion of the buckle, among others. ${ }^{31,32}$

Vitrectomy is an intraocular procedure that involves the removal of some or all of the vitreous in order to relieve traction on the retina. Small instruments are inserted into the eye which allows cutting of the vitreous gel, removal of scar tissue, and the injection of gas to close the retinal break(s). In cases of complicated retinal detachments, the retina may be flattened by silicone oil which often needs to be removed after several months in a subsequent surgical procedure. The most common postoperative complication is cataract formation in phakic eyes, which develops within several years in the vast majority of patients older than 50 years of age. ${ }^{33}$ Posturing after vitrectomy with gas injection for retinal detachment remains a controversial issue. Randomized controlled trials showing that posturing improves anatomical or visual outcome after vitrectomy are currently lacking. Recently, avoidance of sudden head movements has been suggested to be much more important than restrictive posturing after vitrectomy. ${ }^{34}$ 


\section{Comparison of procedures}

Randomized controlled trials comparing pneumatic retinopexy, scleral buckling surgery, or vitrectomy are scarce. Since primary retinal detachments vary from relatively uncomplicated cases with only a local detachment to total detachments with severe scarring of the retina, vitreoretinal surgeons commonly tend to choose the surgical method according to the expected level of difficulty. Pneumatic retinopexy and scleral buckling surgery are the most popular surgical methods in relatively easy cases, whereas more complicated cases are most commonly treated by vitrectomy. However, in the middle of this spectrum of relatively easy and very complicated cases there is a large group of patients with retinal detachments of intermediate severity. The selection of one particular surgical procedure in this category of patients is still a matter of ongoing debate. In trials that have investigated pseudophakic eyes, no significant differences in anatomical and visual outcome were detected in one study between both surgical methods, ${ }^{35}$ whereas either the single-operation success rate ${ }^{36}$ or visual outcome ${ }^{37}$ was better in vitrectomized eyes as compared with buckling eyes in other studies. Data from recent case series however show a clear preference for vitrectomy in pseudophakic retinal detachments. ${ }^{38-41}$ A multicenter randomized controlled trial involving phakic eyes with primary RRD has shown similar results for single-operation success rates (64\%) as well as for final reattachment rates $(97 \%)$ between conventional surgery and vitrectomy. ${ }^{41}$ Although a clear advantage of vitrectomy over scleral buckling surgery has never been proven, and the latter remains a good choice for less severe retinal detachments, a shift towards vitrectomy has been observed in several countries including the Netherlands. The influence of the development of more refined instrumentation - such as $25 \mathrm{G}$ vitrectomy - on anatomic and functional outcome after retinal detachment must be evaluated in future trials.

\section{Functional recovery}

The degree of functional recovery after retinal detachment surgery is strongly associated with preoperative involvement of the macula. To illustrate, visual acuity was reported to be 0.5 or better in $78 \%$ of retinal detachments with a spared macula as compared with only $28 \%$ of eyes in macular-off detachments in a study in which scleral buckling surgery was the initial reattachment strategy. ${ }^{42}$ Other risk factors that have been shown to negatively influence visual outcome are the duration of macular detachment ${ }^{25,26}$ as well as the extent of macular elevation as shown in postoperative assessments using optical coherence tomography. ${ }^{43,44}$ Patients without macular involvement generally have a good visual prognosis, although in $10-$ $15 \%$ of cases postoperative visual acuity does not return to the preoperative level. ${ }^{24}$ 


\section{Failure of reattachment surgery}

Recurrent detachment after primary retinal detachment repair is one of the most challenging complications even though final reattachment rates are often $>95 \%$ after one or more reoperations (vitrectomies only). The majority of redetachments occur within 3-6 months after initial reattachment surgery. In a cohort of patients with a recurrent detachment, it was demonstrated that a substantial number of patients (19\%) still developed a redetachment after 12 months following scleral buckling surgery for primary retinal detachment. ${ }^{45}$ Proliferative vitreoretinopathy (PVR) is still the primary cause of failure of reattachment surgery, despite advances in surgical techniques in the past decades. Although new breaks or missed breaks are also a frequent cause of recurrent detachment, the remainder of this chapter will solely focus on the classification, clinical factors, pathogenesis, and treatment of PVR.

\section{Proliferative vitreoretinopathy}

Proliferative vitreoretinopathy is characterized by the development of contractile membranes that prevent the attachment of the neuroretina to the RPE. PVR is the latest in a series of terms that describes the fibrocellular cascade that takes place on both surfaces of the detached retina. It was initially thought that the formation of these membranes originated within the vitreous. Hence, this condition was referred to as massive vitreous retraction (MVR) or massive preretinal retraction (MPR). ${ }^{46}$ Later on, after the introduction of vitrectomy, the term massive periretinal proliferation (MPP) was used as it became clear that PVR was mainly a process of periretinal cellular proliferation. ${ }^{47}$ This term was subsequently changed to PVR by the Retina Society Terminology Committee in 1983 in an attempt to facilitate the communication between retinal surgeons and within the scientific community. ${ }^{48}$ In this classification, four stages of increasing severity are distinguished: vitreous haze and pigment clumps (PVR A); wrinkling of the retina and retinal stiffness (PVR B); fixed retinal folds (PVR C); and a funnel-shaped retinal detachment (PVR D). This classification has been further revised and updated by the Silicone Study Group, which resulted in subdivisions into anterior and posterior PVR and the identification of focal, diffuse, or subretinal proliferation. ${ }^{49,50}$ Although both classifications have certainly enhanced the communication in the literature, they are basically anatomic and do not address the biological activity of the PVR process. Furthermore, clinically important risk factors for the development or progression of PVR are not recorded. Ironically, the 1991 classification has nowadays been neglected by a majority of vitreoretinal surgeons. 


\section{Incidence of PVR}

The incidence of postoperative PVR has been reported to be between $5-10 \%$ in several reviews and papers but, without exception, references to the original articles are lacking. ${ }^{48,51-55}$ In studies comparing conventional scleral buckling surgery with vitrectomy, postoperative PVR rates vary considerably, ranging between 0 29.3\% after the former procedure and between 3.4\% - 35.4\% after the latter procedure. ${ }^{35-37,56-59}$ Recently, a prospective randomized multicenter trial showed postoperative PVR rates of $12.4 \%$ in the scleral buckling group and $16.4 \%$ in the vitrectomy group in the phakic subtrial, whereas in the pseudophakic/aphakic subtrial rates were somewhat higher in the scleral buckling group (22.6\%) as compared with the vitrectomy group (15.2\%). ${ }^{41}$ According to these numbers, an incidence of $5-10 \%$ as stated earlier appears to be an underestimation, and an incidence of postoperative PVR between $10-20 \%$ seems to be more reflective of its occurrence in everyday clinical practice. Also, preoperative PVR rates differ markedly between studies on retinal detachment surgery, ranging from almost no cases of preoperative PVR to an incidence of $100 \%{ }^{35,60-64}$ These apparently contradictory findings may be mostly due to differences in the definition of PVR, inclusion criteria, baseline characteristics of the study population, and study design. For example, well-controlled prospective studies tend to report considerably higher rates of both preoperative and postoperative PVR than retrospective studies. ${ }^{35,37,65,66}$

\section{Risk factors for PVR}

The identification of risk factors for the development of PVR may be useful for the selection of the appropriate surgical procedure after retinal detachment. Moreover, potentially toxic adjunct treatments could be targeted solely at patients at greatest risk. Many studies have investigated and identified a wide range of clinical risk factors for PVR. Among these are vitreous hemorrhage, ${ }^{60,62,67}$ aphakia, ${ }^{62,66}$ giant tears or large retinal breaks, ${ }^{62,67,68}$ use of cryopexy, ${ }^{68-70}$ preoperative and postoperative choroidal detachment, ${ }^{67,69}$ size of detachment, ${ }^{60,66,67,71}$ duration of detachment, ${ }^{60,62,71}$ young age, ${ }^{71}$ use of vitrectomy, ${ }^{69}$ use of silicone oil, ${ }^{66,72,76}$ use of air tamponade, $^{67,74}$ signs of uveitis, ${ }^{67}$ preoperative visual acuity, ${ }^{60}$ and preoperative PVR. ${ }^{66-70}$ At least some of the findings presented in these studies appear to be contradictory and inconclusive, and therefore their significance in everyday clinical practice and their contributions to PVR pathogenesis are difficult to assess. For example, some authors have found the use of silicone oil to be a risk factor for PVR, ${ }^{66,72,76}$ whereas others report no higher risk. ${ }^{67}$ The same yields for the use of air tamponade, that is associated with low risk of developing PVR in some studies ${ }^{74,75}$ and with high risk in others. ${ }^{67,76}$ Also, the preoperative presence of uveitis seems to 
be a plausible risk factor, since PVR is characterized by an exaggerated inflammatory response that is part of an anomalous wound healing reaction. However, Kon et al. ${ }^{66}$ did not find an increased risk in patients with preoperative uveitis. Interestingly, a study by Girard and colleagues ${ }^{67}$ showed preoperative PVR grade A, and, to a lesser extent, PVR grade $B$ predictive of postoperative PVR, whereas PVR grade C1 was not. The authors hypothesized that PVR grade $A$ represents an immature form of the disease with potential to go worse easily, whereas PVR grade C1 may represent a spontaneously arrested end-stage of the disease in some cases. In the same study, the amount of vitreous hemorrhage also had predictive value. In contrast to major hemorrhages occurring during or after surgery, only minor hemorrhages were associated with a higher prevalence of postoperative PVR. ${ }^{67}$ As with the incidence of PVR, it seems that all these clinical risk factor studies add more controversy to this challenging and complex eye disease.

Divergent risk factors have also been proposed for preoperative PVR and postoperative PVR, ${ }^{52}$ but - as is true for the contradictory results in the abovementioned studies - these discrepancies may be merely a result of differences between studies with respect to baseline characteristics, the number and choice of clinical risk factors studied, the study design and method of statistical analysis, and again, the definition of PVR. Of note, some risk factors for postoperative PVR may only be a marker with a strong association with a true risk factor. To illustrate, preoperative visual acuity may be an indirect risk factor for PVR because of its correlation with the extent and/or duration of retinal detachment.

One study determined the accuracy of a predictive risk formula for the development of PVR based on a combination of clinical parameters. Using this formula, $9.2 \%$ of predetermined low risk patients and $28 \%$ of high risk patients developed postoperative PVR. ${ }^{77}$ Even though this difference was highly statistically significant $(P<0.001)$, it is questionable whether this formula is valuable in everyday clinical practice. The associations that were found between a particular set of clinical parameters and postoperative PVR were too weak to predict an unfavorable outcome with high sensitivity and specificity. It seems that clinical variables do not completely explain the probability of PVR onset, suggesting that other, perhaps more objective parameters are needed.

Limb and Chignell $^{78}$ found vitreous levels of intercellular adhesion molecule (ICAM)-1 to be significantly higher in patients at high risk of developing PVR as compared with those at low risk. The same holds for interleukin (IL)- 6 and protein level in vitreous fluid, which were shown to be independent predictive risk factors for postoperative PVR in a large prospective study on vitrectomized eyes. ${ }^{79}$ Despite considerable overlap in cytokine levels between individuals of different risk groups, further research regarding the development of laboratory tests to identify high risk patients is warranted. 
The lack of accuracy of clinical risk factors for postoperative PVR may also be attributed to genetic differences between individuals. The potential contribution of a genetic component to PVR has however been neglected for many years. Cytokines play an important role in PVR pathogenesis, and genetic polymorphisms of some of these have recently been suggested to be contributing factors. ${ }^{55,80}$

\section{Pathogenesis of PVR}

After any tissue injury, an orderly but complex series of cellular and biochemical events takes place leading to regeneration of damaged tissue and wound repair. ${ }^{81}$ The formation of PVR membranes can be considered the resultant of an excessive wound healing response following retinal detachment. It has been suggested that the development of contractile PVR membranes parallels the three-phase cascade in wound repair, i.e. coagulation and inflammation, proliferation, and remodelling of scar tissue. ${ }^{52}$ This fierce reaction, which occurs more often on the inner surface of the retina (epiretinal membranes) than on the outer surface of the retina (subretinal membranes), ${ }^{82}$ is however undesired, since contraction of this fibrotic tissue leads to tractional retinal detachment with often a poor visual prognosis.

The identification of a key event that determines an unfavourable outcome in a minority of patients after retinal detachment has been the primary goal in PVR research. The triggering event has been suggested to be the breakdown of the bloodretinal barrier or the presence of a retinal break. ${ }^{51,83,84}$ These events may elicit an inflammatory response and lead to biochemical changes in the intraocular environment. Nevertheless, they do not appear to be crucial in the development of PVR. Blood-retinal barrier breakdown is also observed in many other intraocular conditions in which PVR is not a common complication and the occurrence of a retinal break is a constant in all patients with rhegmatogenous retinal detachment. On the other hand, the absence of PVR in exudative retinal detachment suggests that a retinal break is a precondition for progression of the disease, implicating that another - yet undetermined - event following retinal injury may trigger a fibrosis cascade. Whatever the exact cause may be, it has generally been accepted that PVR is a cell-mediated process in which a multitude of cytokines and growth factors mediate the events that lead to tractional retinal detachment. These events include attachment, migration, proliferation, and dedifferentiation of cells, deposition of extracellular matrix, and membrane contraction. 


\section{Cell types in PVR}

The dedifferentiation of several cell types after retinal detachment is a very common phenomenon and has some important implications for the identification of cells involved in the disease process. As a consequence of the displacement of cells from their normal microenvironment and the ensuing phenotypic changes, the identification of cells based on ultrastructural criteria is not always reliable. ${ }^{85,86}$ These observations are supported by results from immunohistochemical studies that significantly differed from those using ultrastructural criteria. ${ }^{87-89}$ Even the integration of ultrastructural and immunohistochemical data may yield inconclusive results, since an abundance of transitional cell types with very dedifferentiated phenotypes were observed in epiretinal membranes from various ocular conditions. ${ }^{90}$ The origin of cell types involved in the pathogenesis of PVR has mainly been retrieved from PVR membrane studies. Since vitrectomy allowed the removal of these specimens, a variety of cells has been identified, including RPE cells, glial cells, fibroblasts or fibroblast-like cells, and inflammatory cells.

RPE cells are pluripotent cells which express many proteins that are characteristic of other cell types. They have been attributed a very important role in the pathogenesis of PVR because of their uniform presence in contractile membranes. ${ }^{88,91-95}$ Animal studies have demonstrated that RPE cells already 24 hours after experimental retinal detachment start migrating and proliferating. ${ }^{96}$ These changes have been suggested to result from loss of signalling from or loss of contact with photoreceptor cells, ${ }^{97}$ or even loss of contact between RPE cells. ${ }^{98,99}$ The reason for this proliferative process may be an attempt to replace damaged retina, as is seen in amphibians. ${ }^{100}$ RPE cells may also undergo morphologic changes and take on the shape of macrophage-like or fibroblast-like cells. ${ }^{101}$ They may even synthesize collagen, ${ }^{102}$ promote extracellular matrix contraction, ${ }^{103}$ and express alpha-smooth muscle actin, ${ }^{104}$ thereby adopting myofibroblast-like characteristics.

Glial cells play a pivotal role in reparative processes in the brain and retina and may therefore be an important cell type in the pathogenesis of PVR. ${ }^{105}$ Glial cells have frequently been identified in PVR membranes ${ }^{87,89,95}$ and may also undergo migration, proliferation, and dedifferentiation after retinal detachment. ${ }^{106-109}$ Findings of a immunohistochemical study suggest that glial cells do not contribute significantly to the contractile forces generated by epiretinal membranes, since purely glial membranes were not associated with detachment. ${ }^{89}$ Therefore, other cell types have been suggested to be responsible for the tractional properties seen in PVR membranes.

Among the other cellular constituents of PVR membranes are fibroblasts or myofibroblasts. ${ }^{88,91-93,110}$ The latter are cells with contractile properties that seem crucial in the contraction of mature PVR membranes. ${ }^{111}$ Based on morphologic criteria, these have been shown to be the predominant cell types in some studies. ${ }^{88,93}$ 
Since it is these fibroblast-like cells that often do not stain for typical RPE cell and glial cell markers, i.e. cytokeratin and glial fibrillary acidic protein, their derivation remains obscure. They may originate from vascular epithelial cells, hyalocytes, glial cells, or RPE cells. ${ }^{47,88,92,93}$ Also fibrocytes have recently been argued to function as precursors of myofibroblasts. ${ }^{112}$ These are circulating cells that traffic to sites of injury, differentiate into myofibroblasts, and contribute to wound healing and fibrosis.

Inflammatory cells are a consistent component of PVR membranes throughout studies. ${ }^{93,94,113,114}$ The origin of macrophages, considered to be the most important inflammatory cell type in PVR, is controversial. Possible sources are the systemic circulation, retinal microglia, and transformed RPE cells. ${ }^{86}$ They may phagocytose cellular debris after retinal detachment and secrete several growth factors and cytokines that may stimulate processes important in PVR pathogenesis. ${ }^{83,115}$ Interestingly, direct contact of monocytes/macrophages with RPE cells in a coculture system significantly stimulated RPE cell growth. ${ }^{116}$ Whether lymphocytes are directly implicated in the development of PVR is unclear. T-lymphocytes have been identified in PVR membranes, ${ }^{117}$ whereas B-lymphocytes were only found in subretinal fluid and vitreous fluid samples obtained from patients with PVR. ${ }^{118}$

\section{Extracellular matrix and membrane contraction}

The formation of extracellular matrix components is considered to be an important step in PVR pathogenesis because attachment to its substratum is required for cell survival. ${ }^{119}$ Moreover, the extracellular matrix mediates several other cellular events including cell migration, cell differentiation, and tissue contraction. ${ }^{102}$ The composition of the extracellular matrix has been studied immunohistochemically in PVR membranes. ${ }^{94,95,120}$ The most important constituents are various subtypes of collagen, fibronectin, laminin, osteonectin, and tenascin. RPE cells, glial cells, and fibroblast-like cells have all been shown to produce various matrix components, including collagen and fibronectin, suggesting the intrinsic production by PVR tissue. ${ }^{95,102,121}$ Under the influence of growth factors and degrading enzymes, such as matrix metalloproteinases and serine proteases, the extracellular matrix is subject to continuous remodelling throughout the process of wound healing. ${ }^{122}$ Matrix components may thus play an active and pivotal role in the process of PVR by providing a scaffold for migrating and proliferating cells. It is the subsequent contraction of the formed membranes that lead to failure of retinal detachment surgery. In vitro studies have demonstrated that both RPE cells and fibroblasts, but not glial cells, are able to execute the contractile forces seen in tractional retinal detachment. ${ }^{123}$ It was suggested that RPE cells pull the collagen fibers toward them using alternating extension and retraction of their lamellipodia. ${ }^{103}$ 


\section{Growth factors/cytokines in PVR}

As already mentioned earlier, the development of PVR is reminiscent of the normal wound-healing response with inflammation, proliferation of retinal cells, and contraction of fibrotic membranes. It is likely that a complex network of growth factors and cytokines is involved in the various stages of the disease process. All the cell types involved are able to produce a multitude of these factors that influence each other in a scenario that is only poorly understood. Laboratory investigations, animal studies, and analyses of human specimens have been undertaken to unravel the role of these factors in the pathogenesis of PVR, but the exact roles often remain a matter of speculation. Nevertheless, it has generally been accepted that an imbalanced microenvironment of growth factors and cytokines may promote PVR development even though a key factor, such as in wet age-related macular degeneration, has never been found. Previous studies have mainly focused on specific cytokines, such as interleukin (IL)-1, ${ }^{79,124-126}$ IL-6, ${ }^{79,124,127,128}$ CXCL8 $^{124,129,130}$ (formerly known as IL-8), CCL2 ${ }^{129-134}$ (formerly known as MCP-1), vascular endothelial growth factor (VEGF), ${ }^{135-137}$ fibroblast growth factor (FGF), ${ }^{79,128,130}$ hepatocyte growth factor (HGF), ${ }^{138,139}$ platelet-derived growth factor (PDGF), ${ }^{140,141}$ intercellular adhesion molecule (ICAM)-1, ${ }^{78}$ tumor necrosis factor (TNF)- $\alpha,{ }^{130,142}$ and transforming growth factor (TGF)- $\beta 2 .{ }^{79,143,144}$ All these mediators have been shown to be elevated in ocular specimens obtained from eyes already affected by PVR, suggesting their involvement in the pathogenesis of PVR. Interestingly, TGF- $\beta 2$ can act as a negative regulator of cell proliferation in primary RPE cultures, ${ }^{144-146}$ whereas in passaged cells it is pro-fibrotic by stimulating matrix synthesis. ${ }^{146}$ In contradiction to earlier studies that focused on patients with established PVR, TGF- $\beta 2$ levels were lower in patients with primary RRD who developed PVR later on as compared with those who had an uncomplicated follow-up. ${ }^{139}$ Sampling at pre-clinical stages of PVR may thus yield divergent results, may provide clues as to which mediators initiate the formation of PVR membranes, and may identify those which are most predictive of its development.

\section{Treatment of PVR}

The goals of PVR surgery are similar to those of retinal detachment surgery in general, i.e. to seal the retinal breaks to prevent passage of fluid into the subretinal space, and to relieve traction on the retinal surface. Shortly after the introduction of pars plana vitrectomy anatomical success rates were reported to be less than $40 \%$, and less than $20 \%$ in severe cases. ${ }^{147}$ Advances in surgical techniques and instrumentation have increased the reattachment rate gradually. Nowadays a vast majority of retinal detachments complicated by PVR can be reattached. ${ }^{148}$ Functional 
results have however not run parallel to the improvements in surgical outcome, with only $11 \%$ to $25 \%$ of patients achieving a Snellen visual acuity of $0.2 .{ }^{149,150}$ Moreover, recurrent detachment after an initially successful surgical procedure is common and is mainly due to recurrent proliferation of cells. ${ }^{151,152}$ Therefore, a possible role for pharmacotherapeutical strategies as an adjunct to pars plana vitrectomy has been subject of investigation in recent years.

Corticosteroids are known to decrease intraocular inflammation, stabilize the blood-retinal barrier, suppress local growth factor synthesis, and, depending on the concentration, reduce cellular proliferation. ${ }^{153-155}$ Animal studies have shown that the use of intravitreal corticosteroids may be useful in the prevention or treatment of PVR. ${ }^{156-158}$ In a recent prospective randomized clinical trial one single preoperative subconjunctival injection of dexamethasone before retinal detachment surgery resulted in a significant decrease in laser flare measurements postoperatively, ${ }^{159}$ warranting the further study of steroid priming in the prevention of PVR. In another study on patients with established PVR, the outcome of vitreoretinal surgery was however not improved by adjunctive triamcinolone acetonide in silicone-filled eyes. ${ }^{160}$ The anthracycline antibiotic daunorubicin was shown to effectively arrest cell proliferation and cell migration in vitro and to stop traction retinal detachment in vivo in an experimental model of PVR. ${ }^{161-165}$ The results of a multicenter clinical trial were however somewhat disappointing. Although the intraoperative application of daunorubicin demonstrated some effect by reducing the number of reoperations, its use failed to show a significant increase in reattachment rate in patients with severe preoperative PVR. ${ }^{166}$

Retinoic acid may also be a candidate in the treatment of PVR. It has been shown to specifically inhibit RPE cell proliferation in cell cultures, to prevent the dedifferentiation of individual RPE cells, and to reduce the rate of traction retinal detachment in animal models of PVR. ${ }^{167-169}$ Small studies have demonstrated some effect of the postoperative administration of oral 13-cis-retinoic acid to increase the rate of retinal attachment after surgical repair, ${ }^{170,171}$ but large prospective randomized clinical trials are lacking. The administration of oral colchicine, an effective inhibitor of RPE cell migration and proliferation in vitro, ${ }^{172}$ significantly reduced the severity of traction retinal detachment in a rabbit model, ${ }^{173}$ but safe dosages of this drug did not significantly inhibit PVR in humans. ${ }^{174}$ Other drugs that have been evaluated in humans are heparin and 5-fluorouracil (5-FU). Heparin prevents fibrin formation after vitreoretinal surgery, binds to fibronectin and to several growth factors, and inhibits RPE cell proliferation, ${ }^{175,176}$ whereas 5-FU is a potent inhibitor of fibroblast proliferation. ${ }^{153}$ Both heparin and 5-FU have been shown to be effective in reducing the rate of traction retinal detachment in animal models. ${ }^{177,178}$ The socalled "British PVR cocktail" of heparin and 5-FU was initially thought to be a successful attempt to prevent the development of PVR in selected high-risk RRD patients. ${ }^{179}$ However, the intravitreal use of this cocktail did not show an improved 
outcome in patients with established PVR and in unselected RRD cases. ${ }^{180,181}$ The authors even discouraged the combined intravitreal use of heparin and 5-FU, since a worse visual acuity was observed in patients having received the adjuvant therapy. $^{181}$

To conclude, several anti-inflammatory and antiproliferative agents have been evaluated for their clinical use in the past decades, but many problems were encountered with regard to efficacy and retinal toxicity. The development of a medical treatment or prophylaxis will be a challenge for researchers to improve the functional outcome of patients with PVR. Attempts to treat the development of PVR membranes with pharmacological adjuncts have been very disappointing so far, and none of them is nowadays used in everyday clinical practice on a routine basis.

\section{Questions and hypotheses addressed in this thesis}

Visual recovery after successful reattachment surgery for macula-off retinal detachment is often incomplete. Important predictive clinical risk factors that have been shown to negatively influence macular recovery are a long duration of macular detachment and the extent of macular elevation..$^{25,43,44,182}$ In a considerable number of patients postoperative visual acuity remains poor despite a low-risk profile and an uncomplicated follow-up. Postoperative assessment with the use of OCT has shown persistent submacular fluid in a substantial number of patients in whom the macula was detached preoperatively. ${ }^{183}$ The aim of a prospective study was to determine the incidence and the pattern of subfoveal fluid and to investigate and quantify its association with visual outcome in patients who were undergoing successful scleral buckling surgery for primary RRD, as described in Chapter 2 .

Tissue factor (TF) is constitutively expressed by subendothelial cells and epithelia to prevent blood loss into extravascular spaces. ${ }^{184}$ Recently, it was shown that genes related to blood coagulation, including TF, were up-regulated in an experimental retinal detachment model in the pig. ${ }^{185}$ It was postulated that TF may be a critical determinant of the extent of tissue injury. Moreover, blood coagulation components may play an essential role in the development of PVR following RRD. ${ }^{186,187}$ The aim of our study, outlined in Chapter 3, was to confirm the presence of TF in human ocular specimens, to investigate the biological activity of the TF protein in subretinal and vitreous fluid samples collected from patients with RRD, and to compare TF activity between patients with and without PVR.

The RPE cell is considered to be the critical cell type in the formation of PVR membranes, since they start proliferating and migrating already shortly after the onset of retinal detachment. ${ }^{96}$ The mechanisms why PVR develops only in a small minority of patients after primary RRD are however unknown. We have previously suggested that PVR-affected individuals may have an impaired mechanism that 
stimulates apoptosis of uncontrolled RPE cells shortly after RRD onset. ${ }^{139}$ The Fas/FasL system has been shown to play a role in the induction of apoptosis in proliferating RPE cells. ${ }^{188}$ Therefore, we compared the levels of apoptosis-related factors such as sFas and sFasL between RRD patients who developed a redetachment due to PVR and those with an uncomplicated follow-up, as described in Chapter 4.

VEGF has been attributed an important role in ocular angiogenesis, such as in diabetic retinopathy and wet age-related macular degeneration. ${ }^{189}$ Surprisingly, elevated levels have also been demonstrated in nonangiogenic ocular diseases. For example, PVR is characterized by the formation of mainly avascular epiretinal membranes, but VEGF levels were found to be significantly higher in PVR samples compared with uncomplicated RRD controls. ${ }^{135,136}$ In Chapter 5, we have investigated whether the distribution of the proangiogenic and antiangiogenic VEGF isoforms in samples from patients with and without PVR could explain this finding.

As stated earlier, the development of PVR is reminiscent of the normal woundhealing response with inflammation, migration and proliferation of resident ocular cells and invading immune cells, and extracellular matrix deposition. In all these biological processes, cytokines function as signalling molecules between the different cell types involved in the disease process. Data from previous studies have indicated that not a single cytokine but a complex network of cytokines may underlie the development of contractile fibrotic membranes that are characteristic of PVR. ${ }^{78,79,124,130}$ In Chapters $6-8$ we have examined whether there is a role for certain interleukins, growth factors, chemokines, and adipokines in the pre-clinical stages of PVR using recently developed multiplex bead-based immunoassays. Pathological processes such as the breakdown of the blood-retinal barrier, the migration and proliferation of RPE cells and glial cells, and the influx of inflammatory cells into the subretinal space may produce PVR-specific cytokine profiles. In Chapter 9 we have therefore investigated whether specific cytokines could serve as PVR biomarkers that can be used as prognostic factors in patients with primary RRD.

In Chapter 10, the findings of this thesis are discussed and suggestions for future research are presented.

\section{References}

1. Foos RY, Wheeler NC. Vitreoretinal juncture: synchisis senilis and posterior vitreous detachment. Ophthalmology 1982;89:1502-12.

2. Jaffe NS. Complications of acute posterior vitreous detachment. Arch Ophthalmol 1968;79:568-71.

3. Tasman WS. Posterior vitreous detachment and peripheral retinal breaks. Trans Am Acad Ophthalmol Otolaryngol 1968;72:217-24.

4. Lindner B. Acute posterior vitreous detachment and its retinal complications: a clinical biomicroscopic study. Acta Ophthalmol Suppl 1966;87:1-108.

5. Wong TY, Tielsch JM, Schein OD. Racial difference in the incidence of retinal detachment in Singapore. Arch Ophthalmol 1999;117:379-83. 
6. Tornquist R, Stenkula S, Tornquist P. Retinal detachment: a study of a population-based patient material in Sweden 1971-1981. I. Epidemiology. Acta Ophthalmol (Copenh) 1987;65:213-22.

7. Algvere PV, Jahnberg P, Textorius O. The Swedish Retinal Detachment Register, I: a database for epidemiological and clinical studies. Graefes Arch Clin Exp Ophthalmol 1999;237:137-44.

8. Li X. Incidence and epidemiological characteristics of rhegmatogenous retinal detachment in Beijng, China. Ophthalmology 2003;110:2413-7.

9. Mitry D, Charteris DG, Yorston D, Siddiqui MA, Campbell H, Murphy AL, et al. The epidemiology and socioeconomic associations of retinal detachment in Scotland: a two-year prospective populationbased study. Invest Ophthalmol Vis Sci 2010;51:4963-8.

10. Van de Put MAJ, Hooymans JMM, Los LI. De incidentie van rhegmatogene ablatio retinae in Nederland. Meeting presentation NOG 2011, MECC Maastricht.

11. The Eye Disease Case-Control Study Group. Risk factors for idiopathic rhegmatogenous retinal detachment. Am J Epidemiol 1993;137:749-57.

12. Javitt JC, Vitale S, Canner JK, Krakauer H, McBean AM, Sommer A. National outcomes of cataract extraction. I. Retinal detachment after inpatient surgery. Ophthalmology 1991;98:895-902.

13. Limeira-Soares PH, Lira RP, Arieta CE, Kara-Jose N. Demand incidence of retinal detachment in Brazil. Eye 2007;21:348-52.

14. Ivanisevic M, Bojic L, Eterovic D. Epidemiological study of nontraumatic phakic rhegmatogenous retinal detachment. Ophthalmic Res 2000;32:237-9.

15. Polkinghorne PJ, Craig JP. Northern New Zealand Rhegmatogenous Retinal Detachment Study: epidemiology and risk factors. Clin Exp Ophthalmol 2004;32:159-63.

16. Mowatt L, Shun-Shin G, Price N. Ethnic differences in the demand incidence of retinal detachments in two districts in the West Midlands. Eye 2003;17:63-70.

17. Sasaki K, Ideta H, Yonemoto J, Tanaka S, Hirose A, Oka C. Epidemiologic characteristics of rhegmatogenous retinal detachment in Kumamoto, Japan. Graefes Arch Clin Exp Ophthalmol 1995;233:772-6.

18. Tielsch JM, Sommer A, Katz J, et al. Socioeconomic status and visual impairment among urban Americans. Baltimore Eye Survey Research Group. Arch Ophthalmol 1991;109:637-41.

19. Dandona L, Dandona R, Srinivas M, et al. Blindness in the Indian State of Andhra Pradesh. Invest Ophthalmol Vis Sci 2001;42:908-16.

20. Saidkasimova S, Mitry D, Singh J, Yorston D, Charteris DG. Retinal detachment in Scotland is associated with affluence. Br J Ophthalmol 2009;93:1591-4.

21. Yorston D. High-volume surgery in developing countries. Eye 2005;19:1083-9.

22. Williams C, Miller LL, Gazzard G, et al. A comparison of measures of reading and intelligence as risk factors for the development of myopia in a UK cohort of children. Br J Ophthalmol 2008;92:111721.

23. Saw SM, Tan SB, Fung D, et al. IQ and the association with myopia in children. Invest Ophthalmol Vis Sci 2004;45:2943-8.

24. Hartz AJ, Burton TC, Gottlieb MS, et al. Outcome and cost analysis of scheduled versus emergency scleral buckling surgery. Ophthalmology 1992;99:1358-63.

25. Diederen RM, La Heij EC, Kessels AGH, Goezinne F, Liem ATA, Hendrikse F. Scleral buckling surgery after macula-off retinal detachment: worse visual outcome after more than 6 days. Ophthalmology 2007;114:705-9.

26. Liu F, Meyer $\mathrm{CH}$, Mennel S, Hoerle S, Kroll P. Visual recovery after scleral buckling surgery in macula-off rhegmatogenous retinal detachment. Ophthalmology 2006;220:174-80.

27. Nakazawa T, Matsubara A, Noda K, et al. Characterization of cytokine responses to retinal detachment in rats. Mol Vis 2006;12:867-78.

28. Goezinne F, La Heij EC, Berendschot TTJM, et al. Patient ignorance is the main reason for treatment delay in primary rhegmatogenous retinal detachment in The Netherlands. Incidence of redetachment 6 months after scleral buckling surgery. Eye 2009;23:1393-9. 
29. Tornambe PE, Hilton GF. Pneumatic retinopexy: a multicenter randomized controlled clinical trial comparing pneumatic retinopexy with scleral buckling. Ophthalmology 1989;96:772-83.

30. Tornambe PE. Pneumatic retinopexy: the evolution of case selection and surgical technique: a twelve-year study of 302 eyes. Trans Am Ophthalmol Soc 1997;95:551-78.

31. Langmann A, Gruber A, Lindner S, Langmann G. Diplopia after encircling procedure for retinal detachment. Ophthalmologe 2003;100:623-7.

32. La Heij EC, Hendrikse F. Netvliesloslatingen en netvlieschirurgie. Ned Tijdschr Geneeskd 1999;143:781-5.

33. Heimann $\mathrm{H}$, Bornfeld $\mathrm{N}$, Friedrichs W, Helbig $\mathrm{H}$, Kellner U, Korra A. Primary vitrectomy without scleral buckling for rhegmatogenous retinal detachment. Graefes Arch Clin Exp Ophthalmol 1996;234:561-8.

34. Angunawela R, Azarbadegan A, Aylward G, Eames I. Intraocular fluid dynamics and retinal shear stress after vitrectomy and gas tamponade. Invest Ophthalmol Vis Sci. In press.

35. Ahmadieh $\mathrm{H}$, Moradian S, Faghihi $\mathrm{H}$, et al. Anatomic and visual outcomes of scleral buckling versus primary vitrectomy in pseudophakic and aphakic retinal detachment: six-month follow-up results of a single operation: report no. 1. Ophthalmology 2005;112:1421-9.

36. Brazitikos PD, Androudi S, Christen WG, Strangos NT. Primary pars plana vitrectomy versus scleral buckle surgery for the treatment of pseudophakic retinal detachment: a randomized clinical trial. Retina 2005;25:957-64.

37. Sharma YR, Karunanithi S, Azad RV, et al. Functional and anatomic outcome of scleral buckling versus primary vitrectomy in pseudophakic retinal detachment. Acta Ophthalmol Scand 2005;83:293-7.

38. Mendrinos E, Dang-Burgener NP, Stangos AN, Sommerhalder J, Pournaras CJ. Primary vitrectomy without scleral buckling for pseudophakic rhegmatogenous retinal detachment. Am J Ophthalmol 2008;145:1063-70.

39. Arya AV, Emerson JW, Englebert M, Hagedorn CL, Adelman RA. Surgical management of pseudophakic retinal detachments: a meta-analysis. Ophthalmology 2006;113:1724-33.

40. Weichel ED, Martidis A, Fineman MS, et al. Pars plana vitrectomy versus combined pars plana vitrectomy-scleral buckle for primary repair of pseudophakic retinal detachment. Ophthalmology 2006;113:2033-40.

41. Heimann H, Bartz-Schmidt KU, Bornfeld N, Weiss C, Hilgers RD, Foerster MH. Scleral buckling versus primary vitrectomy in rhegmatogenous retinal detachment: a prospective randomized multicenter clinical study. Ophthalmology 2007;114:2142-54.

42. Salicone A, Smiddy WE, Ventkatraman A, Feuer W. Visual recovery after scleral buckling procedure for retinal detachment. Ophthalmology 2006;113:1734-42.

43. Hagimura N, lida T, Suto K, Kishi S. Persistent foveal retinal detachment after successful rhegmatogenous retinal detachment surgery. Am J Ophthalmol 2002;133:516-20.

44. Lecleire-Collet A, Muraine M, Menard JF, Brasseur G. Predictive visual outcome after macula-off retinal detachment surgery using optical coherence tomography. Retina 2005;25:44-53.

45. Goezinne F, La Heij EC, Berendschot TTJM, Kessels AGH, Liem ATA, Diederen RMH, Hendrikse F. Incidence of redetachment 6 months after scleral buckling surgery. Acta Ophthalmol 2010;88:199206.

46. Machemer R. Proliferative vitreoretinopathy (PVR): a personal account of its pathogenesis and treatment. Invest Ophthalmol Vis Sci 1988;29:1771-83.

47. Machemer R, Laqua H. Pigment epithelium proliferation in retinal detachment (massive periretinal proliferation). Am J Ophthalmol 1975;80:1-23.

48. The Retina Society Terminology Committee. The classification of retinal detachment with proliferative vitreoretinopathy. Ophthalmology 1983;90:121-5.

49. Lean JS, Stern WH, Irvine A, Azen SP. The Silicone Study Group. Classification of proliferative vitreoretinopathy used in the Silicone Study. Ophthalmology 1989;96:756-71. 
50. Machemer R, Aaberg TM, Freeman M, et al. An updated classification of retinal detachment with proliferative vitreoretinopathy. Am J Ophthalmol 1991;112:159-65.

51. Pastor JC. Proliferative vitreoretinopathy: an overview. Surv Ophthalmol 1998;43:3-18.

52. Pastor JC, Rodriguez de la Rua E, Martin F. Proliferative vitreoretinopathy: risk factors and pathobiology. Prog Retin Eye Res 2002;21:127-44.

53. Charteris DG. Proliferative vitreoretinopathy: pathobiology, surgical management, and adjunctive treatment. Br J Ophthalmol 1995;79:953-60.

54. Asaria RH, Charteris DG. Proliferative vitreoretinopathy: developments in pathogenesis and treatment. Compr Ophthalmol Update 2006;7:179-85.

55. Rojas J, Fernandez I, Pastor JC, et al. A strong genetic association between the tumor necrosis factor locus and proliferative vitreoretinopathy: The Retina 4 Project. Ophthalmology 2010;117:2417-23.

56. Oshima Y, Yamanishi S, Sawa M, et al. Two-year follow-up study comparing primary vitrectomy with scleral buckling for macula-off rhegmatogenous retinal detachment. Jpn J Ophthalmol 2000;44:538-49.

57. Miki D, Hida T, Hotta K, et al. Comparison of scleral buckling and vitrectomy for retinal detachment resulting from flap tears in superior quadrants. Jpn J Ophthalmol 2001;45:187-91.

58. Roider J, Hoerauf $\mathrm{H}$, Hager A, et al. Conventional ablation surgery or primary vitrectomy in complicated retinal holes [in German]. Ophthalmologe 2001;98:887-91.

59. Afrasi F, Erakgun T, Akkin C, et al. Conventional buckling surgery or primary vitrectomy with silicone oil tamponade in rhegmatogenous retinal detachment with multiple breaks. Graefes Arch Clin Exp Ophthalmol 2004;242:295-300.

60. Tseng W, Cortez RT, Ramirez G, et al. Prevalence and risk factors for proliferative vitreoretinopathy in eyes with rhegmatogenous retinal detachment but no previous vitreoretinal surgery. Am J Ophthalmol 2004;137:1105-15.

61. Nagasaki H, Ideta H, Uemura A, Morita H, Ito K, Yonemoto J. Comparative study of clinical factors that predispose patients to proliferative vitreoretinopathy in aphakia. Retina 1991;11:204-7.

62. Yoshino $\mathrm{Y}$, Ideta $\mathrm{H}$, Nagasaki $\mathrm{H}$, Uemura A. Comparative study of clinical factors predisposing patients to proliferative vitreoretinopathy. Retina 1989;9:97-100.

63. Malbran E, Dodds RA, Hulsbus R, Charles DE, Buonsanti JL, Adrogue E. Retinal break type and proliferative vitreoretinopathy in nontraumatic retinal detachment. Graefes Arch Clin Exp Ophthalmol 1990;228:423-5.

64. Capeans C, Lorenzo J, Santos L, et al. Comparative study of incomplete posterior vitreous detachment as a risk factor for proliferative vitreoretinopathy. Graefes Arch Clin Exp Ophthalmol 1998;236:481-5.

65. Tewari HK, Kedar S, Kumar, A, et al. Comparison of scleral buckling with combined scleral buckling and pars plana vitrectomy in the management of rhegmatogenous retinal detachment with unseen retinal breaks. Clin Exp Ophthalmol 2003;31:403-7.

66. Kon CH, Asaria RHY, Occleston NL, Khaw PT, Aylward GW. Risk factors for proliferative vitreoretinopathy after primary vitrectomy: a prospective study. Br J Ophthalmol 2000;84:506-11.

67. Girard P, Mimoun G, Karpouzas I, Montefiore G. Clinical risk factors for proliferative vitreoretinopathy after retinal detachment surgery. Retina 1994;14:417-24.

68. Duquesne N, Bonnet M, Adeleine P. Preoperative vitreous hemorrhage associated with rhegmatogenous retinal detachment: a risk factor for postoperative proliferative vitreoretinopathy? Graefes Arch Clin Exp Ophthalmol 1996;234:677-82.

69. Cowley M, Conway BP, Campochiaro PA, Kaiser D, Gaskin H. Clinical risk factors for proliferative vitreoretinopathy. Arch Ophthalmol 1989;107:1147-51.

70. Bonnet $M$, Guenoun S. Surgical risk factors for severe postoperative proliferative vitreoretinopathy (PVR) in retinal detachment with grade B PVR. Graefes Arch Clin Exp Ophthalmol 1995;233:789-91.

71. Miura $\mathrm{M}$, Ideta $\mathrm{H}$. Factors related to subretinal proliferation in patients with primary rhegmatogenous retinal detachment. Retina 2000;20:465-8. 
72. Lambrou FH, Burke JM, Aaberg TM. Effect of silicone oil on experimental traction retinal detachment. Arch Ophthalmol 1987;105:1269-72.

73. Lewis $\mathrm{H}$, Burke JM, Abrams GW, et al. Perisilicone proliferation after vitrectomy for proliferative vitreoretinopathy. Ophthalmology 1988;95:583-91.

74. Algvere PV, Gjotterberg M, Olivestedt G, Fituri S. Results of pneumatic retinopexy with air. Acta Ophthalmol 1992;70:632-6.

75. Sebag J, Tang M. Pneumatic retinopexy using only air. Retina 1993;13:8-12.

76. Guerra A, Manzanas L, Giraldo A, et al. Resultados de las inyecciones de SF6 como tratamiento del desprendimiento de retina. Arch Soc Esp Oftalmol 1987;53:393-8.

77. Asaria $\mathrm{RHY}$, Kon $\mathrm{CH}$, Bunce $\mathrm{C}$, et al. How to predict proliferative vitreoretinopathy: a prospective study. Ophthalmology 2001;108:1184-6.

78. Limb GA, Chignell AH. Vitreous levels of intercellular adhesion molecule 1 (ICAM-1) as a risk indicator of proliferative vitreoretinopathy. Br J Ophthalmol 1999;83:953-6.

79. Kon CH, Occleston NL, Aylward GW, Khaw PT. Expression of vitreous cytokines in proliferative vitreoretinopathy: a prospective study. Invest Ophthalmol Vis Sci 1999;40:705-12.

80. Sanabria Ruiz-Colmenares MR, Pastor Jimeno JC, Garrote Adrados JA, et al. Cytokine gene polymorphisms in retinal detachment patients with and without proliferative vitreoretinopathy: a preliminary study. Acta Ophthalmol Scand 2006;84:309-13.

81. Wilkins RB, Kulwin DR. Wound healing. Ophthalmology 1979;86:507-10.

82. Wallyn R, Hilton G. Subretinal fibrosis in retinal detachment. Arch Ophthalmol 1979;97:2128-9.

83. Nagasaki H, Shinagawa K, Mochizuki M. Risk factors for proliferative vitreoretinopathy. Prog Retin Eye Res 1998;17:77-98.

84. Ryan SJ. Traction retinal detachment. Am J Ophthalmol 1993;115:1-20.

85. Mandelcorn M, Machemer R, Fineberg E, Hersh S. Proliferation and metaplasia of intravitreal retinal pigment epithelium cell autotransplants. Am J Ophthalmol 1975; 80:227-37.

86. Mueller-Jensen K, Machemer R, Azarnia R. Autotransplantation of retinal pigment epithelium in intravitreal diffusion chamber. Am J Ophthalmol 1975;80:530-7.

87. Rodrigues MM, Newsome D, Machemer R. Further characterization of epiretinal membranes in human massive periretinal proliferation. Curr Eye Res 1981;1:311-5.

88. Hiscott PS, Grierson I, McLeod D. Retinal pigment epithelial cells in epiretinal membranes: an immunohistochemical study. Br J Ophthalmol 1984;68:708-15.

89. Hiscott PS, Grierson I, Trombetta CJ, Rahi AHS, Marshall J, McLeod D. Retinal and epiretinal glia: an immunohistochemical study. Br J Ophthalmol 1984;68:698-707.

90. Vinores SA, Campochiaro PA, Conway BP. Ultrastructural and electron-immunocytochemical characterization of cells in epiretinal membranes. Invest Ophthalmol Vis Sci 1990;31:14-28.

91. Clarkson JG, Green WR, Massof D. A histopathological review of 168 cases of preretinal membrane. Am J Ophthalmol 1977;84:1-17.

92. Machemer R, van Horn DL, Aaberg TM. Pigment epithelial proliferation in human retinal detachment with massive periretinal proliferation. Am J Ophthalmol 1978;85:181-91.

93. Kamplik A, Kenyon KR, Michels RG. Epiretinal and vitreous membranes. Comparative study of 56 cases. Arch Ophthalmol 1981;99:1445-54.

94. Jerdan JA, Pepose JS, Michels RG, Hayashi H, de Bustros S, Sebag M, et al. Proliferative vitreoretinopathy membranes. An immunohistochemical study. Ophthalmology 1989;96:801-10.

95. Morino I, Hiscott PS, McKechnie N, Grierson I. Variation in epiretinal membrane components with clinical duration of the proliferative tissue. Br J Ophthalmol 1990;74:393-9.

96. Anderson DH, Stern W, Fisher SK, Erickson PA, Borgula GA. The onset of pigment epithelial proliferation after retinal detachment. Invest Ophthalmol Vis Sci 1981;21:10-16.

97. Anderson DH, Stern WH, Fisher SK, Erickson PA, Borgula GA. Retinal detachment in the cat: the pigment epithelial-photoreceptor interface. Invest Ophthalmol Vis Sci 1983;24:906-26.

98. Heriot WJ, Machemer R. Pigment epithelial repair. Graefes Arch Clin Exp Ophthalmol 1992;230:91100. 
99. Del Priore LV, Hornbeck R, Kaplan HJ, et al. Débridement of the pig retinal pigment epithelium in vivo. Arch Ophthalmol 1995;113:939-44.

100. Campochiaro PA, Hackett SF, Vinores SA, Tobe T. The retinal pigmented epithelium and retinal wound repair. Great Basin Vis Sci Symp 1996;2:28-34.

101. Casaroli R, Pagan R, Vilaró S. Epithelial-mesenchymal transition in proliferative vitreoretinopathy : intermediate filament protein expression in RPE. Invest Ophthalmol Vis Sci 1999;40:2062-72.

102. Hiscott P, Sheridan C, Magee RM, Grierson I. Matrix and the retinal pigment epithelium in proliferative retinal disease. Prog Retin Eye Res 1999;18:167-90.

103. Glaser BM, Cardin A, Biscoe B. Proliferative vitreoretinopathy. The mechanism of development of vitreoretinal traction. Ophthalmology 1987;94:327-32.

104. Stocks SZ, Taylor SM, Shiels IA. Transforming growth factor-beta 1 induces alpha-smooth muscle actin expression and fibronectin synthesis in cultured human retinal pigment epithelial cells. Clin Exp Ophthalmol 2001;29:33-7.

105. Fisher SK, Erickson PA, Lewis GP, Anderson DH. Intraretinal proliferation induced by retinal detachment. Invest Ophthalmol Vis Sci 1991;32:1739-48.

106. van Horn DL, Aaberg TM, Machemer R, Fenzl R. Glial cell proliferation in human retinal detachment with massive periretinal proliferation. Am J Ophthalmol 1977;84:383-93.

107. Lewis GP, Matsumoto B, Fisher SK. Changes in the organisation and expression of cytoskeletal proteins during retinal degeneration induced by retinal detachment. Invest Ophthalmol Vis Sci 1995;36:2404-16.

108. Laqua $H$, Machemer R. Glial cell proliferation in retinal detachment (massive periretinal proliferation). Am J Ophthalmol 1975;80:602-18.

109. Francke M, Faude F, Pannicke T, et al. Electrophysiology of rabbit Müller (glial) cells in experimental retinal detachment and PVR. Invest Ophthalmol Vis Sci 2001;42:1072-9.

110. Walshe R, Esser $\mathrm{P}$, Wiedemann $\mathrm{P}$, Heimann K. Proliferative retinal diseases: myofibroblasts cause chronic vitreoretinal traction. Br J Ophthalmol 1992;76:550-2.

111. Pournaras CJ, Donati G, Kapetanios AD, Redard M, Bochatay-Piallat ML, Gabbiani G. Myofibroblasts and retinal fibrovascular membranes. Klin Monatsbl Augenheilkd 1998;212:356-8.

112. Abu El-Asrar AM, Struyf S, Van Damme J, Geboes K. Circulating fibrocytes contribute to the myofibroblast population in proliferative vitreoretinopathy epiretinal membranes. $\mathrm{Br} J$ Ophthalmol 2008;92:699-704.

113. Hiscott PS, Grierson I, McLeod D. Natural history of fibrocellular epiretinal membranes: a quantitative, autoradiographic, and immunohistochemical study. Br J Ophthalmol 1985;69:810-23.

114. Baudouin C, Fredj-Reygrobellet D, Gordon WC, Baudouin F, Peyman G, Lapalus P, et al. Immunohistologic study of epiretinal membranes in proliferative vitreoretinopathy. Am J Ophthalmol 1990;110:593-8.

115. Wiedemann P. Growth factors in retinal diseases: proliferative vitreoretinopathy, proliferative diabetic retinopathy, and retinal degeneration. Surv Ophthalmol 1992;36:373-84.

116. Osusky R, Ryan SJ. Retinal pigment epithelial cell proliferation: potentiation by monocytes and serum. Graefes Arch Clin Exp Ophthalmol 1996;234 Suppl 1:S76-82.

117. Charteris DG, Hiscott P, Grierson I, Lightman SL. Proliferative vitreoretinopathy: lymphocytes in epiretinal membranes. Ophthalmology 1992;99:1364-7.

118. Baudouin C, Hofman P, Brignole F, Bayle J, Loubiere R, Gastaud P. Immunocytology of cellular components in vitreous and subretinal fluid from patients with proliferative vitreoretinopathy. Ophthalmologica 1991;203:38-46.

119. Meredith JE Jr, Fazeli B, Schwartz MA. The extracellular matrix as a cell survival factor. Mol Biol Cell 1993;4:953-61.

120. Scheifforth OF, Kamplik A, Gunther H, van der Mark K. Protein of the extracellular matrix in vitreoretinal membranes. Graefes Arch Clin Exp Ophthalmol 1988;226:357-61.

121. Casaroli R, Vilaró $S$. The role of fibronectin, laminin, vitronectin and their receptors on cellular adhesion in proliferative vitreoretinopathy. Invest Ophthalmol Vis Sci 1994;35:2791-2803. 
122. Sethi CS, Bailey TA, Luthert PJ, Chong NHV. Matrix metalloproteinase biology applied to vitreal disorders. Br J Ophthalmol 2000;84:654-66.

123. Mazure A, Grierson I. In vitro studies of the contractility of cell types involved in proliferative vitreoretinopathy. Invest Ophthalmol Vis Sci 1992;33:3407-16.

124. El-Ghrably IA, Dua HS, Orr GM, Fischer D, Tighe PJ. Intravitreal invading cells contribute to vitreal cytokine milieu in proliferative vitreoretinopathy. Br J Ophthalmol 2001;85:461-70.

125. Kirchhof B, Kirchhof E, Ryan SJ, Dixon JF, Barton BE, et al. Macrophage modulation of retinal pigment epithelial cell migration and proliferation. Graefes Arch Clin Exp Ophthalmol 1989;227:60-6.

126. Ferrick MR, Thurau SR, Oppenheim MH, Herbort CP, Ni M, et al. Ocular inflammation stimulated by intravitreal interleukin-8 and interleukin-1. Invest Ophthalmol Vis Sci 1991;32:1534-9.

127. Kauffmann DJH, Van Meurs JC, Mertens DAE, Peperkamp E, Master C, et al. Cytokines in vitreous humor: interleukin-6 is elevated in proliferative vitreoretinopathy. Invest Ophthalmol Vis Sci 1994;35:900-6.

128. La Heij EC, Van de Waarenburg MP, Blaauwgeers HG, Kessels AGH, Liem ATA, et al. Basic fibroblast growth factor, glutamine synthetase, and interleukin- 6 in vitreous fluid from eyes with retinal detachment complicated by proliferative vitreoretinopathy. Am J Ophthalmol 2002;134:367-75.

129. Elner SG, Elner VM, Jaffe GJ, Stuart A, Kunkel SL, Strieter RM. Cytokines in proliferative diabetic retinopathy and proliferative vitreoretinopathy. Curr Eye Res 1995;14:1045-53.

130. Banerjee S, Savant V, Scott RAH, Curnow SJ, Wallace GR, Murray PI. Multiplex bead analysis of vitreous humor of patients with vitreoretinal disorders. Invest Ophthalmol Vis Sci 2007;48:2203-7.

131. Abu El-Asrar AM, Struyf S, Kangave D, Geboes K, Van Damme J. Chemokines in proliferative diabetic retinopathy and proliferative vitreoretinopathy. Eur Cytokine Netw 2006;17:155-65.

132. Capeans C, De Rojas MV, Lojo S, Salorio MS. C-C chemokines in the vitreous of patients with proliferative vitreoretinopathy and proliferative diabetic retinopathy. Retina 1998;18:546-50.

133. Abu El-Asrar AM, Van Damme J, Put W, et al. Monocyte chemotactic protein-1 in proliferative vitreoretinal disorders. Am J Ophthalmol 1997;123:599-606.

134. Mitamura Y, Takeuchi S, Yamamoto S, et al. Monocyte chemotactic protein-1 levels in the vitreous of patients with proliferative vitreoretinopathy. Jpn J Ophthalmol 2002;46:218-21.

135. Su CY, Chen MT, Wu WS, Wu WC. Concentration of vascular endothelial growth factor in the subretinal fluid of retinal detachment. J Ocul Pharmacol Ther 2000;16:463-9.

136. Ogata N, Nishikawa M, Nishimura T, Mitsuma Y, Matsumura M. Inverse levels of pigment epithelium-derived factor and vascular endothelial growth factor in the vitreous of eyes with rhegmatogenous retinal detachment and proliferative vitreoretinopathy. Am J Ophthalmol 2002;133:851-2.

137. Dieudonné SC, La Heij EC, Diederen RMH, Kessels AGH, Liem ATA, et al. Balance of vascular endothelial growth factor and pigment epithelial growth factor prior to development of proliferative vitreoretinopathy. Ophthalmic Res 2007;39:148-54.

138. Mitamura Y, Takeuchi S, Matsuda A, Tagawa Y, Mizue Y, et al. Hepatocyte growth factor levels in the vitreous of patients with proliferative vitreoretinopathy. Am J Ophthalmol 2000;129:678-80.

139. Dieudonné SC, La Heij EC, Diederen R, Kessels AGH, Liem ATA, et al. High TGF- $\beta 2$ levels during primary retinal detachment may protect against proliferative vitreoretinopathy. Invest Ophthalmol Vis Sci 2004;45:4113-8.

140. Lei $H$, Hovland $P$, Velez $G$, et al. A potential role for PDGF-C in experimental and clinical proliferative vitreoretinopathy. Invest Ophthalmol Vis Sci 2007;48:2335-42.

141. Lei H, Rheaume MA, Kazlauskas A. Recent developments in our understanding of how plateletderived growth factor (PDGF) and its receptors contribute to proliferative vitreoretinopathy. Exp Eye Res 2010;90:376-81.

142. Rasier R, Gormus U, Artunay O, Yuzbasioglu E, Oncel M, et al. Vitreous levels of VEGF, IL-8, and TNFalpha in retinal detachment. Curr Eye Res 2010;35:505-9.

143. Connor TB Jr, Roberts AB, Sporn MB, et al. Correlation of fibrosis and transforming growth factor- $\beta$ type 2 levels in the eye. J Clin Invest 1989;83:1661-6. 
144. Esser P, Heimann K, Bartz-Schmidt KU, et al. Apoptosis in proliferative vitreoretinal disorders: possible involvement of TGF- $\beta$-induced RPE cell apoptosis. Exp Eye Res 1997;65:365-78.

145. Leschey KH, Hackett SF, Singer JH, Campochiaro PA. Growth factor responsiveness of human retinal pigment epithelial cells. Invest Ophthalmol Vis Sci 1990;31:839-46.

146. Lee SC, Kwon OW, Seong GJ, Kim SH, Ahn JE, Kay ED. Epitheliomesenchymal transdifferentiation of cultured RPE cells. Ophthalmic Res 2001;33:80-86.

147. Michels RG, Wilkinson CP, Rice TA. Retinal detachment, St. Louis: Mosby, 1990;680-705.

148. Campochiaro PA. Pathogenic mechanisms in proliferative vitreoretinopathy. Arch Ophthalmol 1997;115:237-41.

149. Lewis $\mathrm{H}$, Aaberg TM. Causes of failure after repeat vitreoretinal surgery for recurrent proliferative vitreoretinopathy. Am J Ophthalmol 1991;111:15-9.

150. Silicone Study Group. Vitrectomy with silicone oil or sulphur hexafluoride gas in eyes with severe proliferative vitreoretinopathy: results of a randomized clinical trial. Silicone Study Report 1. Arch Ophthalmol 1992;110:770-9.

151. Lewis H, Aaberg TM, Abrams GW. Causes of failure after initial vitreoretinal surgery for severe proliferative vitreoretinopathy. Am J Ophthalmol 1991;111:8-14.

152. Silicone Study Group. Vitrectomy with silicone oil or perfluoropropane gas in eyes with severe proliferative vitreoretinopathy: results of a randomized clinical trial. Silicone Study Report 2. Arch Ophthalmol 1992;110:780-92.

153. Guidetti B, Azéma J, Malet-Martino M, Martino R. Delivery systems for the treatment of proliferative vitreoretinopathy: materials, devices and colloidal carriers. Current Drug Delivery 2008;5:7-19.

154. Rubsamen PE, Cousins SW. Therapeutic effect of periocular corticosteroids in experimental proliferative vitreoretinopathy. Retina 1997;17:44-50.

155. Ando N, Sen HA, Berkowitz BA, et al. Localization and quantitation of blood-retinal barrier breakdown in experimental proliferative vitreoretinopathy. Arch Ophthalmol 1994;112:117-22.

156. Tano Y, Chandler D, Machemer R. Treatment of intraocular proliferation with intravitreal injection of triamcinolone acetonide. Am J Ophthalmol 1980;90:810-6.

157. Chandler D, Rozakis G, de Juan E Jr, Machemer R. The effect of triamcinolone acetonide on a refined experimental model of proliferative vitreoretinopathy. Am J Ophthalmol 1985;99:686-90.

158. Chandler DB, Hida T, Sheta S, et al. Improvement in efficacy of corticosteroid therapy in an animal model of proliferative vitreoretinopathy by pretreatment. Graefes Arch Clin Exp Ophthalmol 1987;225:259-65.

159. Bali E, Feron EJ, Peperkamp E, Veckeneer M, Mulder PG, et al. The effect of a preoperative subconjunctival injection of dexamethasone on blood-retinal barrier breakdown following scleral buckling retinal detachment surgery: a prospective randomized placebo-controlled double blind clinical trial. Graefes Arch Clin Exp Ophthalmol 2010;248:957-62.

160. Ahmadieh H, Feghhi M, Tabatabaei H, Shoeibi N, Ramezani A, Mohebbi MR. Triamcinolone acetonide in silicone-filled eyes as adjunctive treatment for proliferative vitreoretinopathy: a randomized clinical trial. Ophthalmology 2008;115:1938-43.

161. Verdoorn C, Renardel de Lavalette VW, Dalma-Weizhausz J, Orr GH, Sorgente N, Ryan SJ. Cellular migration, proliferation, and contraction: an in vitro approach to a clinical problem-proliferative vitreoretinopathy. Arch Ophthalmol 1986;108:1216-9.

162. Wiedemann P, Kirmani M, Santana M, Sorgente N, Ryan SJ. Control of experimental massive periretinal proliferation by daunomycin: dose-response relation. Graefes Arch Clin Exp Ophthalmol 1983;220:233-5.

163. Kirmani M, Santana M, Sorgente N, Wiedemann P, Ryan SJ. Antiproliferative drugs in the treatment of experimental proliferative vitreoretinopathy. Retina 1983;3:269-72.

164. Khawly JA, Saloupis P, Hatchell DL, Machemer R. Daunorubicin treatment in a refined experimental model of proliferative vitreoretinopathy. Graefes Arch Clin Exp Ophthalmol 1991;229:464-7. 
165. Chen E, Steinhorst U, Samsa G, Saloupis PT, Hatchell DL. The effect of combined daunorubicin and triamcinolone acetonide treatment on a refined experimental model of proliferative vitreoretinopathy. Invest Ophthalmol Vis Sci 1992;33:2160-4.

166. Wiedemann $P$, Hilgers RD, Bauer $P$, Heimann K. Adjunctive daunorubicin in the treatment of proliferative vitreoretinopathy: results of a multicenter clinical trial. Daunomycin Study Group. Am J Ophthalmol 1998;126:550-9.

167. Campochiaro PA, Hackett SF, Conway BP. Retinoic acid promotes density-dependent growth arrest in human retinal pigment epithelial cells. Invest Ophthalmol Vis Sci 1991;32:65-72.

168. Araiz JJ, Refojo MF, Arroyo MH, Leong FL, Albert DM, Tolentino FI. Antiproliferative effect of retinoic acid in intravitreous silicone oil in an animal model of proliferative vitreoretinopathy. Invest Ophthalmol Vis Sci 1993;34:522-30.

169. Giordano GG, Refojo MF, Arroyo MH. Sustained delivery of retinoic acid from microspheres of biodegradable polymer in PVR. Invest Ophthalmol Vis Sci 1993;34:2743-51.

170. Fekrat S, de Juan E Jr, Campochiaro PA. The effect of oral 13-cis-retinoic acid on retinal detachment after surgical repair in eyes with proliferative vitreoretinopathy. Ophthalmology 1995;102:412-8.

171. Chang YC, Hu DN, Wu WC. Effect of oral 13-cis-retinoic acid treatment on postoperative clinical outcome of eyes with proliferative vitreoretinopathy. Am J Ophthalmol 2008;146:440-6.

172. Lemor M, de Bustros S, Glaser BM. Low-dose colchicine inhibits astrocyte, fibroblast, and retinal pigment epithelial cell migration and proliferation. Arch Ophthalmol 1986;104:1223-5.

173. Lemor $\mathrm{M}$, Yeo $\mathrm{JH}$, Glaser BM. Oral colchicine for the treatment of experimental traction retinal detachment. Arch Ophthalmol 1986;104:1226-9.

174. Berman DH, Gombos GM. Proliferative vitreoretinopathy: does oral low-dose colchicine have an inhibitory effect? A controlled study in humans. Ophthalmic Surg 1989;20:268-72.

175. Blumenkranz MS, Hartzer MK. Pharmacologic treatment of proliferative vitreoretinopathy: interrelationship with the coagulation cascade. In: Lewis $\mathrm{H}$, Ryan SJ, eds. Medical and surgical retina, advances, controversies and management. St Louis: Mosby,1993:172.

176. Iverson DA, Katsura H, Hartzer MK, Blumenkranz MS. Inhibition of intraocular fibrin formation following infusion of low-molecular-weight heparin during vitrectomy. Arch Ophthalmol 1991;109:405-9.

177. Blumenkranz MS, Ophir A, Claflin AJ, Hajek A. Fluorouracil for the treatment of massive periretinal proliferation. Am J Ophthalmol 1982;94:458-67.

178. Stern WH, Lewis GP, Erickson PA, Guerin CJ, Anderson DH, Fisher SK, et al. Fluorouracil therapy for proliferative vitreoretinopathy after vitrectomy. Am J Ophthalmol 1983;96:33-42.

179. Asaria $\mathrm{RHY}$, Kon $\mathrm{CH}$, Bunce $\mathrm{C}$, et al. Adjuvant 5-fluorouracil and heparin prevents proliferative vitreoretinopathy. Results from a randomized, double-blind, controlled clinical trial. Ophthalmology 2001;108:1179-83.

180. Charteris DG, Aylward GW, Wong D, et al. PVR Study Group. A randomized controlled trial of combined 5-fluorouracil and low-molecular-weight heparin in management of established proliferative vitreoretinopathy. Ophthalmology 2004;111:2240-5.

181. Wickham L, Bunce C, Wong D, et al. Randomized controlled trial of combined 5-fluorouracil and low-molecular-weight heparin in the management of unselected rhegmatogenous retinal detachments undergoing primary vitrectomy. Ophthalmology 2007;114:698-704.

182. Abouzeid H, Wolfensberger TJ. Macular recovery after retinal detachment. Acta Ophthalmol Scand 2006;84:597-605.

183. D’Amico DJ. Clinical practice. Primary retinal detachment. N Engl J Med 2008;359:2346-54.

184. Koyama T, Nishida K, Ohdama S, et al. Determination of plasma tissue factor antigen and its clinical significance. Br J Haematol 1994;87:343-7.

185. Hollborn M, Francke M, landiev I, et al. Early activation of inflammation- and immune responserelated genes after experimental detachment of the porcine retina. Invest Ophthalmol Vis Sci 2008;49:1262-73. 
186. Cleary PE, Ryan SJ. Experimental posterior penetrating eye injury in the rabbit, I: Method of production and natural history. Br J Ophthalmol 1979;63:306-11.

187. García-Layana A, Pastor JC, Saornil MA, Gonzalez G. Porcine model of proliferative vitreoretinopathy with platelets. Curr Eye Res 1997;16:556-63.

188. Chang JH, Kang SW, Ham DI. Sensitivity of CD95-induced apoptosis in different proliferative status of human retinal pigment epithelial cells. Korean J Ophthalmol 2001;15:74-80.

189. Witmer AN, Vrensen GF, Van Noorden CJ, Schlingemann RO. Vascular endothelial growth factors and angiogenesis in eye disease. Prog Retin Eye Res 2003;22:1-29. 

Chapter 2

Persistent Subfoveal Fluid and Increased Preoperative Foveal Thickness Impair Visual Outcome after Macula-off Retinal Detachment Repair

L.J.A.G. Ricker, L.J. Noordzij, F. Goezinne, D.W.J.K. Cals, T.T.J.M. Berendschot, A.T.A. Liem, F. Hendrikse, E.C. La Heij 


\section{Abstract}

Purpose: To investigate the influence of subfoveal fluid and foveal thickness on visual outcome in patients who underwent reattachment surgery for rhegmatogenous retinal detachment (RRD).

Methods: This prospective study included 53 patients who were undergoing successful scleral buckling surgery for primary RRD. A thorough ophthalmologic examination including best-corrected visual acuity, slit-lamp biomicroscopy, binocular indirect ophthalmoscopy, and optical coherence tomography scanning was performed preoperatively and during all subsequent follow-up visits at $1,3,6,9,12$, and 24 months postoperatively.

Results: Preoperative foveal thickness was significantly higher in the macula-off group ( $n=38)$ compared with the macula-on group $(n=15)(P<0.0001)$, whereas postoperative measurements were normal in both the groups. Linear mixed-model analysis revealed that persistent subfoveal fluid $(P=0.0004)$ was an independent predictor of a worse visual outcome after scleral buckling surgery for primary macula-off RRD, although the effect on visual outcome was small (0.1 logarithm of the minimal angle of resolution units). Moreover, increased preoperative foveal thickness was associated with a worse visual prognosis in macula-off $\operatorname{RRD}(P=0.010)$.

Conclusions: Persistent subfoveal fluid and increased preoperative foveal thickness were associated with a worse visual prognosis in macula-off RRD patients, albeit the effect of persistent subfoveal fluid was small and temporary. 


\section{Introduction}

For many decades debate is ongoing why visual recovery after successful reattachment surgery for macula-off rhegmatogenous retinal detachment (RRD) is often incomplete. Several pre- and postoperative factors that possibly compromise visual outcome have been investigated throughout the years. Important predictive clinical risk factors that have been shown to negatively influence macular recovery are a low preoperative visual acuity and a long duration of macular detachment. ${ }^{1}$ To illustrate, we showed in a previous study that a rapid worsening of the best-corrected postoperative visual acuity (BCVA) occurred when the duration of macular detachment exceeded 6 days. ${ }^{2}$ Moreover, the extent of macular elevation has been shown to correlate with impaired functional recovery. ${ }^{3,4}$ However, in a considerable number of patients postoperative visual acuity remains poor despite a low-risk profile and an uncomplicated follow-up.

Postoperative assessment with the use of optical coherence tomography (OCT) has shown persistent submacular fluid in a substantial number of patients in whom the macula was detached preoperatively and in a minority of patients in whom the macula was not detached. ${ }^{5}$ Optical coherence tomography studies revealed that it usually requires several months before this submacular fluid has resolved. The delayed absorption of subretinal fluid has been associated with a worse visual outcome by some authors, ${ }^{3,6-9}$ whereas others did not find any influence on postoperative visual acuity. ${ }^{10,11}$ These contradictory results may be mostly because of small case numbers, a short follow-up period or an inappropriate case selection. For instance, preoperative OCT images are often lacking, which makes a proper distinction between macula-off and macula-on RRDs impractical. In addition, the studies that showed an influence of persistent submacular fluid on postoperative visual outcome did not reveal to what extent visual outcome was affected. ${ }^{3,6-9}$ This clinical information may have important implications for the patient's prognosis and treatment. Therefore, the aims of this prospective study were to determine the incidence and the pattern of subfoveal fluid and to investigate and quantify its association with visual outcome in patients who were undergoing successful scleral buckling surgery for primary RRD. Furthermore, we measured the height of foveal detachment and preoperative and postoperative foveal thickness on OCT in these patients and investigated their influence on postoperative visual acuity. We report that persistent subfoveal fluid and increased preoperative foveal thickness are both significantly associated with a worse visual outcome in patients who underwent successful scleral buckling surgery for primary macula-off RRD. 


\section{Materials and Methods}

\section{Patients}

Fifty-three consecutive eyes of 53 patients who were undergoing scleral buckling surgery for primary RRD between January 2007 and December 2007 at the Maastricht University Eye Clinic were enrolled in the study. Patients with preexisting macular disease, failed scleral buckling surgery, a history of ocular trauma or ocular surgery other than uncomplicated cataract surgery and those whose fovea was hidden behind a bullous retinal detachment were excluded from the study. We further excluded patients in whom no preoperative OCT was obtained and those who did not want to participate in the study because more than regular visits at the outpatient clinic were needed. One of the 40 patients who were phakic at the time of reattachment surgery underwent cataract surgery during follow-up. Three experienced vitreoretinal surgeons performed all scleral buckling procedures. The study was performed with the agreement of the University Hospital Ethics Committee. All patients gave informed consent before inclusion in the study and after the nature of the study had been explained. The study adhered to the tenets of the Declaration of Helsinki.

All patients underwent thorough ophthalmologic examination preoperatively, including BCVA according to Snellen visual acuity chart, slit-lamp biomicroscopy, binocular indirect ophthalmoscopy, and OCT scanning. Duration of macular detachment was defined as the interval between the onset of symptoms of macular detachment and the surgical procedure and was estimated according to a precise history of patients' symptoms. Best-corrected visual acuity measurements were performed by three different masked operators. Follow-up with repeat of the ophthalmologic examinations was scheduled at 1, 3, 6, 9, and 12 months after the surgical procedure. Thirty patients (macula-off, $n=19$; macula-on, $n=11$ ) were also examined 24 months postoperatively, and OCT measurements of the healthy fellow eye were obtained in 18 of these patients (macula-off, $n=13$; macula-on, $n=5$ ).

\section{Optical Coherence Tomography}

The 6-mm x 6-mm radial line scan protocol was performed using a Stratus OCT Model 3000 OCT scanner (Carl Zeiss Ophthalmic System, Dublin, CA). If fixation was problematic, external fixation was used, and scans were repeated until good fixation was obtained. Maximal height of foveal detachment was measured by calipers in "retinal thickness analysis mode" 1 day before the surgical procedure. The height of foveal detachment was defined as the distance between the middle of the outer surface of the detached fovea and the inner surface of the underlying retinal pigment epithelium. ${ }^{4}$ In two patients in whom the retinal pigment epithelium was not 
visible on the OCT image because of a high foveal detachment, the distance between the outer surface of the detached fovea and the bottom of the OCT imaging area was measured. ${ }^{12}$ One day preoperatively and at each follow-up visit, foveal thickness was measured on OCT by calipers, where foveal thickness reaches its minimum value, that is, between the center between both foveal crests and the outer surface of the photoreceptor layer (Figure 1). Preoperative foveal thickness measurements mainly reflected an index corresponding to the amount of intraretinal edema. In case that foveal architecture was lost $(n=7)$, preoperative foveal thickness measurements were excluded from the analysis. The height of foveal detachment and foveal thickness measurements were performed for all six radial line scans. Their mean values were calculated and used for analysis. All measurements were performed by one experienced resident. As far as the postoperative OCT scans are concerned, this person was masked for preoperative macular status and follow-up time after the surgical procedure. The accumulation of subretinal fluid was defined as a clear space between the photoreceptor layer and the retinal pigment epithelium on $\mathrm{OCT}^{3,6,10}$ We defined persistent subfoveal fluid as subretinal fluid within a diameter of $1,000 \mu \mathrm{m}$ from the center of the fovea. The pattern of subretinal fluid was identified as a single bleb, multiple blebs, or a confluent bleb that extended beyond the edge of the $6-\mathrm{mm}$ scan (Figure 2 ). ${ }^{8}$

\section{Statistical Analysis}

For statistical analysis, Snellen visual acuity was transformed into logarithm of the minimal angle of resolution (logMAR) visual acuity. Comparisons of demographic or

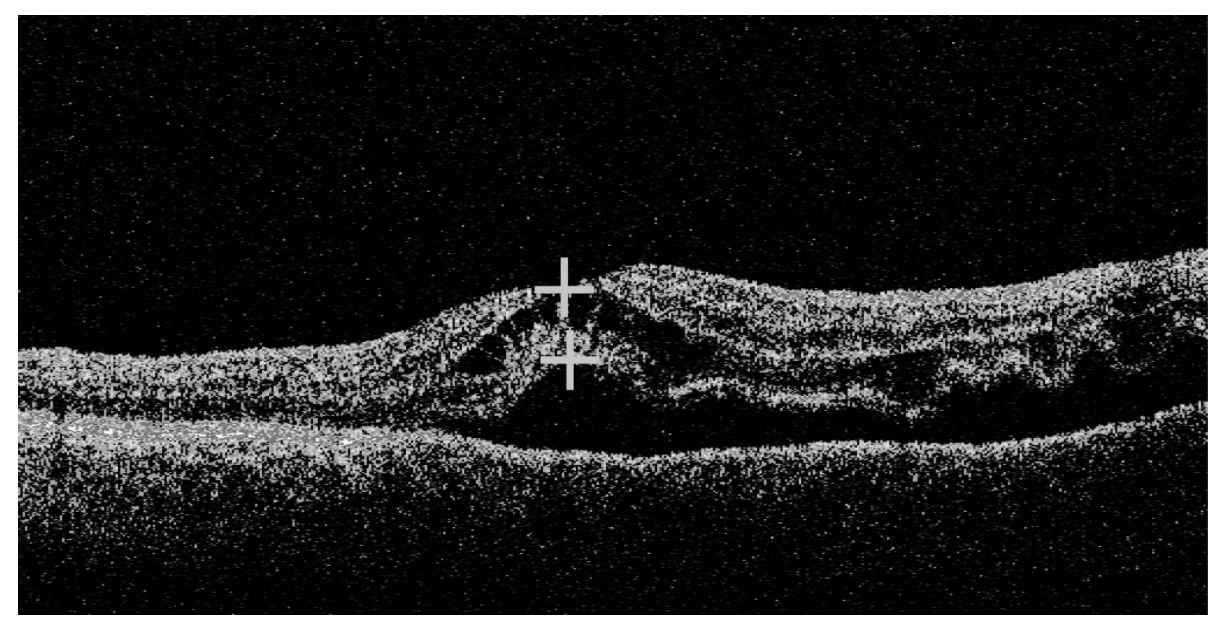

Figure 1 Preoperative optical coherence tomography image of a patient with macula-off rhegmatogenous retinal detachment. Foveal thickness was measured by the use of calipers in "retinal thickness analysis mode". Note extensive intrafoveal edema in this patient. 

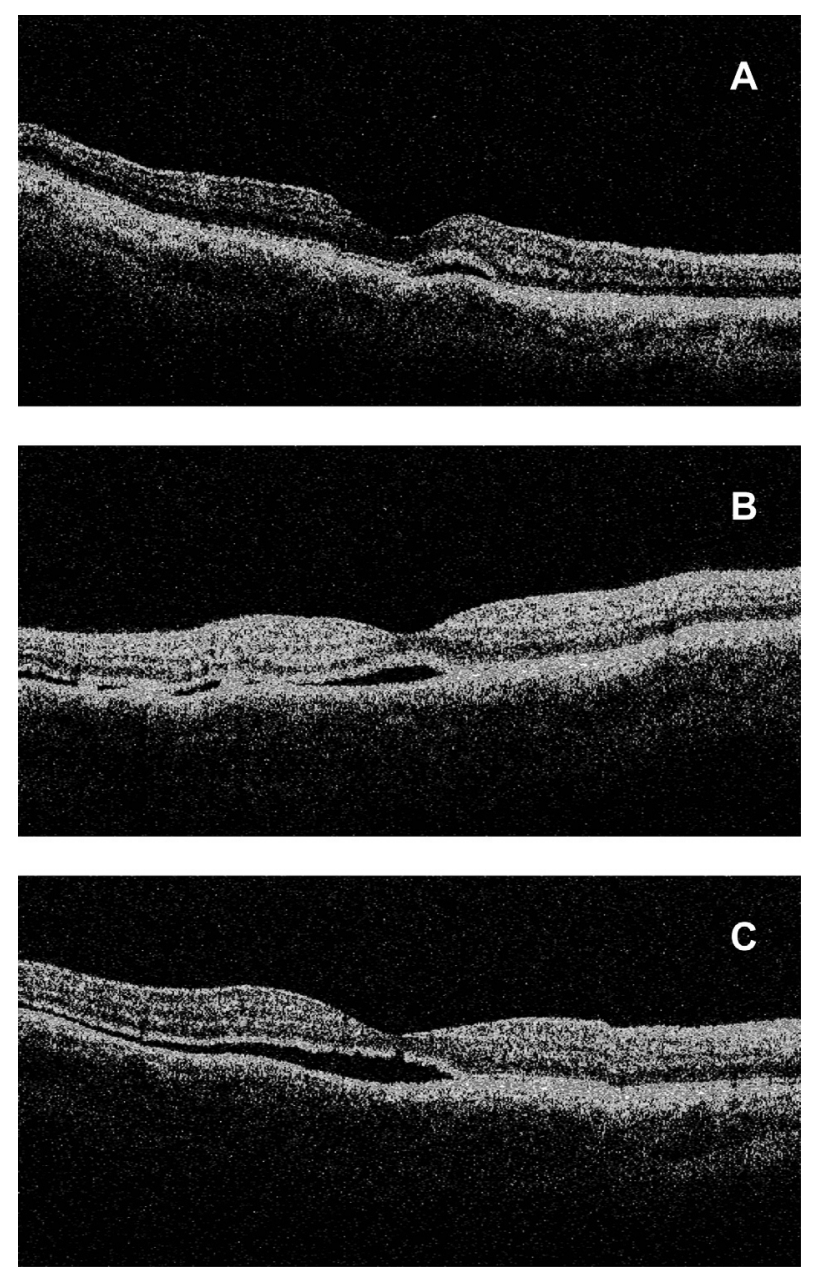

Figure 2 The pattern of subretinal fluid was identified as $(A)$ a single bleb, (B) multiple blebs, or (C) a confluent bleb.

clinical variables between macula-off and macula-on patients were assessed using the Student's $t$-test or the chi-square test as appropriate. The paired $t$-test was used to compare preoperative values with postoperative values (including BCVA and foveal thickness) and to compare foveal thickness of the affected eye with that of the unaffected healthy eye. To assess visual acuity over time, a linear mixed-model analysis was applied. ${ }^{13}$ Subjects were considered as a random-effect factor, whereas clinical variables such as the presence of subfoveal fluid, preoperative foveal thickness, preoperative logMAR visual acuity, and time after the surgical procedure were taken as fixed-effect factors. Data are presented as mean $\pm \mathrm{SD}$, unless stated else. $P$ values of $<0.05$ were considered to be statistically significant. SPSS Version 16.0 software (SPSS Inc, Chicago, IL) was used for statistical analysis. 


\section{Results}

Fifty-three eyes of 53 patients were included in this study. All patients underwent anatomically successful scleral buckling surgery for primary RRD. There were 33 male patients (62.3\%) and 20 female patients (37.7\%). Their median age was 55 years, ranging from 21 years to 84 years. Demographics and characteristics of RRD surgery of the study population are shown in Table 1. Preoperative OCT scans showed a macula-on RRD in 15 patients and a macula-off RRD in 38 patients. In the latter group, 13 patients (34.2\%) would have been misclassified as macula-on RRD based on clinical assessment without the performance of preoperative OCT. The mean duration of macular detachment in the macula-off group was $6.1 \pm 5.6$ days. In patients with preoperative macular detachment, the mean number of quadrants involved (1.76 \pm 0.54 vs. $1.33 \pm 0.49)(P=0.010$, Student's $t$-test) and the number of patients in whom subretinal fluid drainage was performed $(97.4 \%$ vs. $66.7 \%)(P=$ 0.001 , chi-square test) was higher compared with those in the macula-on group.

Table 1 Demographic and Clinical Data on 53 Rhegmatogenous Retinal Detachment Patients

\begin{tabular}{|c|c|c|c|}
\hline Clinical Variable & $\begin{array}{l}\text { Macula-off RRD } \\
\qquad(n=38)\end{array}$ & $\begin{array}{l}\text { Macula-on RRD } \\
\qquad(n=15)\end{array}$ & $P$ value \\
\hline \multicolumn{4}{|l|}{ Age (years) } \\
\hline Mean \pm SD & $55 \pm 14$ & $55 \pm 10$ & $P=0.990$ \\
\hline \multicolumn{4}{|l|}{ Gender } \\
\hline Male & $26(68.4 \%)$ & $7(46.7 \%)$ & $P=0.141$ \\
\hline Female & $12(31.6 \%)$ & $8(53.3 \%)$ & \\
\hline \multicolumn{4}{|l|}{ Laterality } \\
\hline Right eye & $20(52.6 \%)$ & $8(53.3 \%)$ & $P=0.963$ \\
\hline Left eye & $18(47.4 \%)$ & $7(46.7 \%)$ & \\
\hline \multicolumn{4}{|c|}{ Preoperative logMAR visual acuity } \\
\hline Mean \pm SD & $1.10 \pm 0.94$ & $0.15 \pm 0.23$ & $P<0.0001$ \\
\hline \multicolumn{4}{|c|}{ Duration of macular detachment } \\
\hline (days) & $6.1 \pm 5.6$ & - & - \\
\hline \multicolumn{4}{|l|}{ Mean $\pm S D$} \\
\hline Macula-on RRD clinically & $13(34.2 \%)$ & - & - \\
\hline \multicolumn{4}{|l|}{ Quadrants involved } \\
\hline Mean \pm SD & $1.76 \pm 0.54$ & $1.33 \pm 0.49$ & $P=0.010$ \\
\hline \multicolumn{4}{|l|}{ Lens status } \\
\hline Phakia & $29(76.3 \%)$ & $11(73.3 \%)$ & $P=0.820$ \\
\hline Pseudophakia & $9(23.7 \%)$ & $4(26.7 \%)$ & \\
\hline Intraoperative cryotherapy & $22(57.9 \%)$ & $10(66.7 \%)$ & $P=0.556$ \\
\hline Intraoperative SF6 gas & $29(76.3 \%)$ & $11(73.3 \%)$ & $P=0.820$ \\
\hline Subretinal fluid drainage & 37 (97.4\%) & $10(66.7 \%)$ & $P=0.001$ \\
\hline
\end{tabular}

RRD, rhegmatogenous retinal detachment; SD, standard deviation; logMAR, logarithm of minimal angle of resolution 
At 1 month postoperatively, subfoveal fluid was detected on OCT in $94 \%$ of eyes of patients with macula-off RRD. At 3, 6, 9, and 12 months after scleral buckling surgery, OCT scans revealed subfoveal fluid in $72 \%, 55 \%, 24 \%$, and $17 \%$ of cases, respectively. None of the 19 patients who were measured at 24-month follow-up, however, had any subfoveal fluid left on OCT (Figure 3). In comparison, 1 patient (7\%) with macula-on RRD had subfoveal fluid on OCT at 1 month after scleral buckling surgery $(P<0.0001$, chi-square test). None of the macula-on patients showed subfoveal fluid on OCT during any of the subsequent follow-up visits.

The mean preoperative logMAR visual acuity was worse in the macula-off group compared with the macula-on group $(1.10 \pm 0.94$ vs. $0.15 \pm 0.23)(P<0.0001$, Student's $t$-test). Except for a worse visual acuity in patients with preoperative macular detachment at 1-month follow-up $(0.34 \pm 0.20$ vs. $0.20 \pm 0.12)(P=0.016$, Student's $t$ - test), no significant differences in postoperative BCVAs were reached between both the groups during the subsequent follow-up visits (Figure 4). Best-corrected visual acuities at all follow-up visits were significantly better than preoperative BCVA for patients with macula-off RRD ( $P<0.0001$ for all comparisons, paired $t$-test), whereas no significant improvement in visual outcome was seen in the macula-on group ( $P>0.05$, paired $t$-test).

The mean preoperative foveal thickness was $226 \pm 42 \mu \mathrm{m}$ for the macula-off group and $177 \pm 14 \mu \mathrm{m}$ for the macula-on group. This difference was highly statistically significant $(P<0.0001$, Student's $t$-test). There were no significant differences

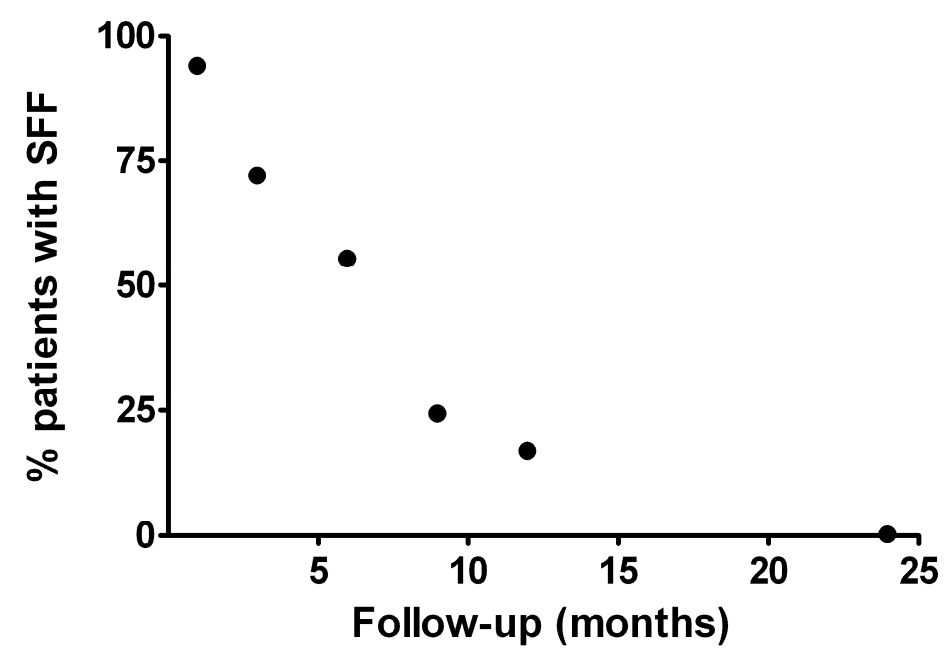

Figure $3 \mathrm{~A}$ graph illustrating the percentage of macula-off rhegmatogenous retinal detachment patients with persistent subfoveal fluid detected on optical coherence tomography (OCT). At 1 month $94 \%$ of patients; at 3 months $72 \%$ of patients; at 6 months 55\% of patients; at 9 months $24 \%$ of patients; and at 12 months $17 \%$ of patients had persistent subfoveal fluid on OCT. At final follow-up at 24 months, none of the patients had any subfoveal fluid left on OCT. SFF, subfoveal fluid. 
in postoperative foveal thickness between both the groups during the follow-up period ( $P>0.05$ for all comparisons, Student's $t$-test) (Fig. 5). In the macula-off group, the mean postoperative foveal thickness decreased significantly at 1-month follow-up compared with preoperative values $(P=0.014$, paired $t$-test) and remained stable thereafter during the whole follow-up period. In the macula-on group, no significant changes in postoperative foveal thickness were detected compared with preoperative measurements ( $P>0.05$ for all comparisons, paired $t$-test). The mean foveal thickness of the nonaffected fellow eye at 24-month follow-up was $188 \pm 20 \mu \mathrm{m}$ in the macula-off group and $187 \pm 18 \mu \mathrm{m}$ in the macula-on group $(P=$ 0.961 , Student's $t$-test). No significant differences in mean foveal thickness betweenthe affected and the nonaffected healthy fellow eye were found for both the groups at 24-month follow-up ( $P>0.05$ for both comparisons, paired $t$-test).

\section{Predictors of Visual Outcome after Macula-off Rhegmatogenous Retinal Detachment}

To evaluate the influence of a wide range of clinical variables on postoperative visual outcome in patients with macula-off RRD, we applied linear mixed-model analy sis. This analysis revealed that the presence of postoperative subfoveal fluid, preop-

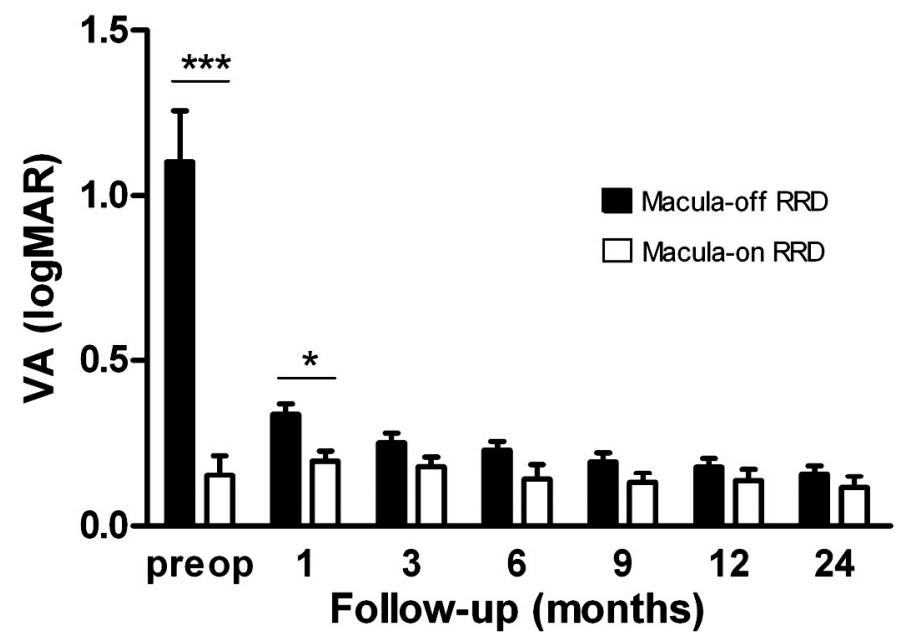

Figure 4 Preoperative best-corrected visual acuity and the course of postoperative best-corrected visual acuity in patients with macula-off (closed bars) and macula-on (open bars) rhegmatogenous retinal detachment (RRD). The mean preoperative logMAR visual acuity was significantly worse in patients with macula-off RRD compared to patients with macula-on RRD, whereas worse postoperative visual acuities in the macula-off group only reached significance at 1 month follow-up. Error bars represent the standard error of the mean. ${ }^{* * *} P<0.001, * P<0.05$; VA, visual acuity; logMAR, logarithm of minimal angle of resolution; preop, preoperative. 
erative foveal thickness, preoperative logMAR visual acuity, time after the surgical procedure, and the pattern of postoperative subretinal fluid were each independent predictors of postoperative visual outcome after scleral buckling surgery for primary macula-off RRD (Table 2). About the latter, it is shown that multiple blebs $(P=$ $0.020)$ and the presence of a confluent bleb $(P=0.006)$ but not a single bleb $(P=-$ $0.734)$ contributed to a worse postoperative visual outcome in these patients. Although intraoperative $\mathrm{SF}_{6}$ gas injection was also an independent predictor of postoperative visual outcome, further analysis showed that this was solely because of a worse mean preoperative logMAR visual acuity in patients who received $\mathrm{SF}_{6}$ gas compared with those who did not $(1.25 \pm 0.95$ vs. $0.62 \pm 0.77)$. Age, gender, the number of quadrants involved, the duration of macular detachment, the application of cryotherapy intraoperatively, lens status, and the height of retinal detachment, however, did not reach statistical significance ( $P>0.05$ for all comparisons) and thus did not predict visual outcome after macula-off RRD surgery in our patient population.

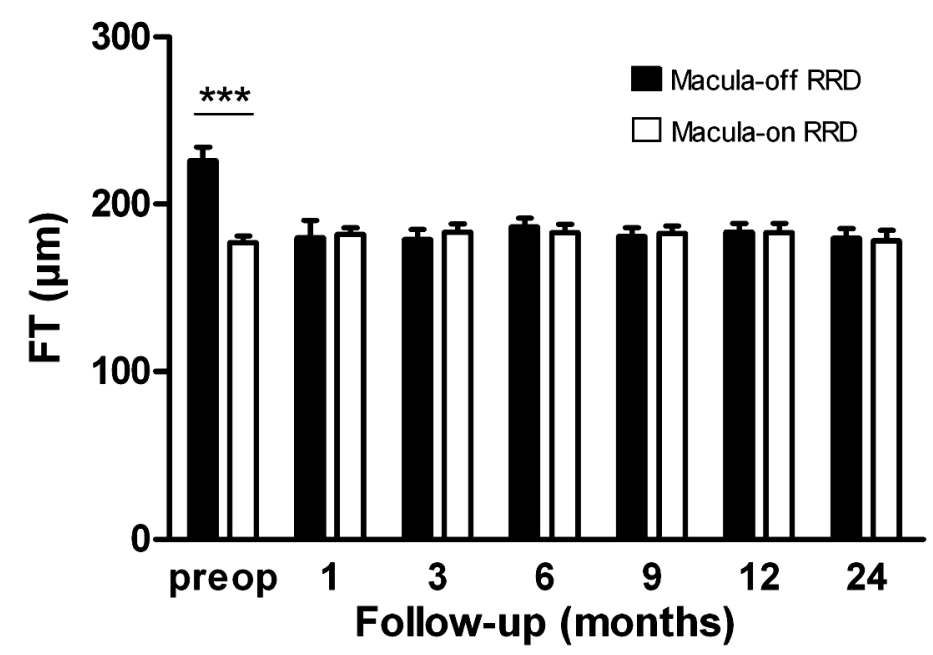

Figure 5 Preoperative foveal thickness and the course of postoperative foveal thickness in patients with macula-off (closed bars) and macula-on (open bars) rhegmatogenous retinal detachment. The mean preoperative foveal thickness was significantly higher in the macula-off group than in the macula-on group, whereas there were no significant differences in postoperative foveal thickness between both groups at each follow-up visit. Error bars represent the standard error of the mean. $* * * P<0.001 ; \mathrm{FT}$, foveal thickness; preop, preoperative. 
Table 2 Independent Predictors of Postoperative Visual Outcome According to Linear Mixed-Model Analysis

\begin{tabular}{lcccc}
\hline Variable & $\begin{array}{c}\text { Estimate (logMAR } \\
\text { Visual Acuity) }\end{array}$ & $\begin{array}{c}\text { 95\% Confidence } \\
\text { Interval }\end{array}$ & $\boldsymbol{t}$ & $\boldsymbol{P}$ value \\
\hline $\begin{array}{l}\text { Subfoveal fluid } \\
\quad \text { Absence }\end{array}$ & 0 & & & \\
$\quad \begin{array}{l}\text { Presence } \\
\text { Preoperative foveal thickness }\end{array}$ & 0.092 & $0.044-0.140$ & 3.821 & $P=0.0002$ \\
( $\mu$ m) & 0.0015 & $0.0003-0.003$ & 2.650 & $P=0.014$ \\
$\begin{array}{l}\text { Preoperative visual acuity } \\
\text { (logMAR) }\end{array}$ & 0.054 & $0.010-0.098$ & 2.475 & $P=0.018$ \\
Pattern subretinal fluid & & & & \\
$\quad$ Absence & 0 & & & \\
$\quad$ Single bleb & 0.011 & $-0.052-0.074$ & 0.340 & $P=0.734$ \\
$\quad$ Multiple blebs & 0.071 & $0.011-0.130$ & 2.346 & $P=0.020$ \\
$\quad$ Confluent bleb & 0.112 & $0.033-0.191$ & 2.805 & $P=0.006$ \\
Time after surgery (months) & -0.0082 & $-0.011--0.006$ & -6.885 & $P<0.0001$ \\
\hline
\end{tabular}

logMAR, logarithm of minimal angle of resolution

When combining the significant predictors in a linear mixed model, the presence of subfoveal fluid $(P=0.0004)$, preoperative foveal thickness $(P=0.010)$, and time after the surgical procedure $(P=0.009)$ remained significant predictors of visual outcome after macula-off RRD. As a result, the following equation can be computed:

$y_{i}(t)=-0.134+0.106 \times \mathrm{SFF}+0.0015 \times$ pre-FT $-0.0051 \times t+\varepsilon_{i}$

where $y_{i}(t)$ is the logMAR visual acuity of a patient $i$ after a follow-up of $t$ months; SFF represents the effect of subfoveal fluid (yes $=1$ and no $=0$ ); pre-FT represents the effect of preoperative foveal thickness (in micrometers); $t$ is the effect of time after the surgical procedure (in months follow-up); and $\varepsilon_{i}$ is the residual error. According to this linear mixed model, it is estimated that patients with persistent subfoveal fluid have a worse postoperative visual outcome of $0.106 \log$ MAR units. Furthermore, it can be deducted from the formula that an increased preoperative foveal thickness is associated with a worse visual prognosis after macula-off RRD and that there is a gradual improvement in visual acuity over time. For example, after 6 month follow-up, the estimated $\log$ MAR visual acuity of a patient with persistent subfoveal fluid and a preoperative foveal thickness of $318 \mu \mathrm{m}$ is $0.42(-0.134+0.106$ x $1+0.0015 \times 318-0.0051 \times 6)$. 


\section{Discussion}

In this prospective study, we investigated the influence of several OCT parameters on visual outcome in patients who underwent successful scleral buckling surgery for RRD. We found that persistent subfoveal fluid and increased preoperative foveal thickness impaired postoperative visual outcome in eyes of patients with primary macula-off RRD, whereas these preoperative and postoperative OCT characteristics and their influence on visual outcome were not seen in the macula-on group. At final follow-up at 24 months, however, there was only a small nonsignificant difference in visual acuity between both the groups, indicating that the effect of persistent subfoveal fluid and increased preoperative foveal thickness on long-term visual outcome is minor.

Patients with macula-off RRD were greatly outnumbered by those with maculaon RRD. Based on clinical examination, 13 macula-off RRD patients would have been misclassified as macula-on RRD patients. Without preoperative OCT scanning 25 of 53 patients (47\%) were classified as macula-off patients, whereas this number increased to 38 of 53 patients ( $72 \%$ ) with the performance of preoperative OCT scanning. These figures stress the importance of preoperative OCT scanning in the allocation of RRD patients. Obviously, there was a significant difference in preoperative visual acuity and in the number of quadrants involved between both the groups. Subretinal fluid drainage occurred less frequently in the macula-on group because this is not routinely performed in our clinic if $<1$ quadrant is involved.

Our series demonstrated that $94 \%$ of eyes of patients with macula-off RRD had persistent subfoveal fluid on OCT at 1-month follow-up. This finding is higher than the incidence reported by previous studies. For instance, Benson et al $^{8}$ found persistent subretinal fluid on OCT in $82.5 \%$ of patients with macula-off RRD at 6-week follow-up, whereas Wolfensberger and Gonvers ${ }^{6}$ demonstrated residual subretinal fluid in $81.3 \%$ of patients 1 month postoperatively. Some authors reported even lower incidences of persistent subfoveal fluid after reattachment surgery for macula-off RRD., ${ }^{9,10}$ A possible explanation for the high incidence of persistent subfoveal fluid in our case series may be ascribed to the operating procedure. In our population, all patients underwent scleral encircling, while in other studies, scleral encircling was only performed in a part of the patients. There is evidence that scleral encircling reduces choroidal blood flow, and as a consequence, this procedure may contribute to the persistence of subfoveal fluid after RRD surgery. ${ }^{14-16}$ Moreover, differences in baseline demographics and patient characteristics among studies may have yielded variations in the incidence of persistent subfoveal fluid.

At 12 -month follow-up, still $17 \%$ of patients showed subfoveal fluid on OCT, indicating that subfoveal fluid takes 1 year to 2 years to resolve in a substantial number of macula-off RRD patients. Interestingly, 1 of the 15 macula-on RRD patients in our case series had postoperative subfoveal fluid on OCT. Persistent submacular 
fluid in a preoperatively uninvolved macula has also been reported by Theodossiadis et al. ${ }^{7}$ This is possibly the result of subretinal fluid movement from the periphery to the macular region during or after the surgical procedure.

So far, only very few studies have focused on foveal thickness in RRD patients. To our knowledge, this is the first study that compared foveal thickness measurements before and after scleral buckling surgery, which was possible because we only included patients with preoperative OCT imaging. Considering possible segmentation error in Stratus OCT software, ${ }^{17,18}$ foveal thickness was measured manually using the OCT electronic calipers. We found that preoperative foveal thickness was significantly higher in patients with macula-off RRD compared with those with macula-on RRD, which was mainly caused by extensive edema with cystoid spaces in the macula. One month after successful scleral buckling surgery intraretinal edema had disappeared in all patients, which was supported by our finding that foveal thickness had returned to normal values in these patients. In the macula-on group, preoperative foveal thickness and postoperative foveal thickness at all follow-up visits did not differ and were similar to the foveal thickness measured in the nonaffected fellow eyes. On the contrary, a small retrospective study reported a significant increase in foveal thickness after macula-off RRD. ${ }^{19}$ However, no preoperative OCT images were available in this study to make a direct comparison between preoperative and postoperative foveal thickness measurements. In patients with macula-off RRD, the authors found a mean foveal thickness of $249 \mu \mathrm{m} 2$ years postoperatively compared with that of $180 \mu \mathrm{m}$ in our study at 24-month follow-up. This difference may be explained by the fact that the authors of this study measured the foveal thickness within $500 \mu \mathrm{m}$ from the center of the fovea, whereas we measured the minimal foveal thickness at the center of the fovea.

We used linear mixed-model analysis to evaluate and quantify the influence of a wide range of OCT parameters and clinical variables on postoperative visual outcome. We found that the presence of persistent subfoveal fluid, preoperative foveal thickness, preoperative visual acuity, the pattern of persistent subretinal fluid, and time after the surgical procedure were each independent predictors of visual outcome after successful scleral buckling surgery for macula-off RRD. When we combined these predictors in one model, the presence of persistent subfoveal fluid, preoperative foveal thickness, and time after the surgical procedure remained significant predictors. In general, there was a gradual improvement in visual acuity over time in the macula-off group, whereas subfoveal fluid and preoperative foveal thickness negatively influenced postoperative visual outcome. Importantly, the prediction of visual acuity by this model is confined to our patient population for no longer than the duration of the follow-up period (i.e., 24 months).

Because several studies have reported a compromised visual acuity because of persistent subfoveal fluid after scleral buckling surgery for macula-off RRD, some authors have successfully tried to facilitate subretinal fluid reabsorption. Both selec- 
tive retina therapy, in which multiple short laser pulses cause a thermo-mechanical disintegration of retinal pigment epithelial cells, and the intravitreal injection of $\mathrm{SF}_{6}$ gas 3 months to 5 months after successful scleral buckling surgery have been performed in a few patients with persistent subfoveal fluid after RRD repair. ${ }^{20,21} \mathrm{Al}-$ though our model showed that the effect of persistent subfoveal fluid on visual outcome was highly significant, the effect was also small ( 0.1 logMAR units) and temporary. For that reason, we would not recommend to routinely intervene and accelerate the reabsorption of persistent subfoveal fluid after reattachment surgery. We do not think that the risk of an intervention outweighs the benefit of a small gain in visual acuity.

The present study has some limitations. First, our results are based on a cohort of eyes with favorable preoperative factors associated with macula-off RRD. Patients were relatively young and had a short duration of macular detachment. Moreover, we were not able to implement the influence of highly elevated macular detachments in our model, a well-known risk factor for a lower visual outcome after reattachment surgery, ${ }^{1}$ because we excluded these patients from the study. Second, we did not measure bleb width or bleb height to investigate whether its size influenced visual outcome. However, we showed that the presence of a confluent bleb or multiple blebs but not a single bleb contributed to a worse visual prognosis in patients who were successfully operated for macula-off RRD. Third, the use of highspeed Fourier-domain OCT would have yielded more information on the intraretinal morphologic changes, such as photoreceptor disruption after macula-off RRD repair. ${ }^{22}$ Last, BCVA was not assessed by Early Treatment Diabetic Retinopathy Study chart with standardized correction.

In conclusion, this prospective study showed that subretinal fluid occasionally takes $>12$ months to resolve in patients who underwent scleral buckling surgery for macula-off RRD. Furthermore, persistent subfoveal fluid and increased preoperative foveal thickness were associated with a worse visual prognosis in macula-off RRD patients, although it is important to remark that the effect of persistent subfoveal fluid on visual outcome was only small ( $0.1 \log$ MAR units) and temporary. Because we think that the risk of an intervention outweighs the benefit of a small gain in visual acuity, we do not recommend to routinely intervene to accelerate the reabsorption of this fluid.

\section{References}

1. Abouzeid H, Wolfensberger TJ. Macular recovery after retinal detachment. Acta Ophthalmol Scand 2006;84:597-605.

2. Diederen RMH, La Heij EC, Kessels AGH, Goezinne F, Liem ATA, Hendrikse F. Scleral buckling surgery after macula-off retinal detachment: worse visual outcome after more than 6 days. Ophthalmology 2007;114:705-9. 
3. Hagimura N, lida T, Suto K, Kishi S. Persistent foveal retinal detachment after successful rhegmatogenous retinal detachment surgery. Am J Ophthalmol 2002;133:516-20.

4. Lecleire-Collet A, Muraine M, Menard JF, Brasseur G. Predictive visual outcome after macula-off retinal detachment surgery using optical coherence tomography. Retina 2005;25:44-53.

5. D'Amico DJ. Clinical practice. Primary retinal detachment. N Engl J Med 2008;359:2346-54.

6. Wolfensberger TJ, Gonvers M. Optical coherence tomography in the evaluation of incomplete visual acuity recovery after macula-off retinal detachments. Graefes Arch Clin Exp Ophthalmol 2002;240:85-9.

7. Theodossiadis PG, Georgalas IG, Emfietzoglou J, et al. Optical coherence tomography findings in the macula after treatment of rhegmatogenous retinal detachments with spared macula preoperatively. Retina 2003;23:69-75.

8. Benson SE, Schlottmann PG, Bunce C, Xing W, Charteris DG. Optical coherence tomography analysis of the macula after scleral buckle surgery for retinal detachment. Ophthalmology 2007;114:108-12.

9. Cavallini GM, Masini C, Volante V, Pupino A, Campi L, Pelloni S. Visual recovery after scleral buckling for macula-off retinal detachments: an optical coherence tomography study. Eur J Ophthalmol 2007;17:790-6.

10. Baba T, Hirose A, Moriyama M, Mochizuki M. Tomographic image and visual recovery of acute macula-off rhegmatogenous retinal detachment. Graefes Arch Clin Exp Ophthalmol 2004;242:57681.

11. Seo JH, Woo SJ, Park KH, Yu YS, Chung H. Influence of persistent submacular fluid on visual outcome after successful scleral buckle surgery for macula-off retinal detachment. Am J Ophthalmol 2008;145:915-22.

12. Puliafito CA, Hee MR, Lin CP, et al. Imaging of macular diseases with optical coherence tomography. Ophthalmology 1995;102:217-29.

13. Cnaan A, Laird NM, Slasor P. Using the general linear mixed model to analyse unbalanced repeated measures and longitudinal data. Stat Med 1997;16:2349-80.

14. Diddie KR, Ernest JT. Uveal blood flow after 360 degrees constriction in the rabbit. Arch Ophthalmol 1980;98:729-30.

15. Yoshida A, Feke GT, Green GJ, et al. Retinal circulatory changes after scleral buckling procedures. Am J Ophthalmol 1983;95:182-8.

16. Bird AC. Pathogenesis of serous detachment of the retina and pigment epithelium. Retina 1994;2:1019-26.

17. Patel PJ, Chen FK, da Cruz L, Tufail A. Segmentation error in Stratus optical coherence tomography for neovascular age-related macular degeneration. Invest Ophthalmol Vis Sci 2009;50:399-404.

18. Taban M, Sharma S, Williams DR, Waheed N, Kaiser PK. Comparing retinal thickness measurements using automated fast macular thickness map versus six-radial line scans with manual measurements. Ophthalmology 2009;116:964-70.

19. Christensen U, Sander B, Villumsen J. Retinal thickening after successful surgery for macula-off retinal detachment. Curr Eye Res 2007;32:65-9.

20. Koinzer S, Elsner H, Klatt C, et al. Selective retina therapy (SRT) of chronic subfoveal fluid after surgery of rhegmatogenous retinal detachment: three case reports. Graefes Arch Clin Exp Ophthalmol 2008;246:1373-8.

21. Itakura H, Kishi S. Intravitreal injection of $0.3 \mathrm{ml}$ of SF6 gas for persistent subfoveal fluid after scleral buckling for rhegmatogenous retinal detachment. Graefes Arch Clin Exp Ophthalmol 2009;247:1147-50.

22. Smith AJ, Telander DG, Zawadzki RJ, et al. High-resolution Fourier-domain optical coherence tomography and microperimetric findings after macula-off retinal detachment repair. Ophthalmology 2008;115:1923-9. 



\section{Chapter 3}

\section{High Subretinal Fluid Procoagulant Activity in Rhegmatogenous Retinal Detachment}

L.J.A.G. Ricker, R. Al Dieri, G.J.M. Beckers, E. Pels, A.T.A. Liem, F. Hendrikse, A. Kijlstra, H.C. Hemker, E.C. La Heij 


\section{Abstract}

Purpose: An increased mRNA expression of genes related to blood coagulation has been demonstrated in an experimental retinal detachment model but has not yet been confirmed in human clinical specimens. Tissue factor (TF), the initiating factor of blood coagulation, may be a determinant of the extent of tissue injury following rhegmatogenous retinal detachment (RRD). We therefore investigated whether subretinal fluid and vitreous fluid collected from patients with RRD exerted any procoagulant activity.

Methods: Calibrated thrombin generation (CAT) was utilized to investigate the thrombogenic properties of 28 subretinal fluids collected during scleral buckling surgery for RRD. Further, the thrombogenic properties of vitreous fluids from RRD $(n=12)$, macular pucker $(n=5)$, macular hole $(n=6)$, and proliferative diabetic retinopathy $(n=5)$ were compared with eye bank eyes $(n=11)$, which served as controls. Identification of the procoagulant activity as TF was performed using Western blotting.

Results: The addition of subretinal fluid from all RRD patients $(28 / 28,100 \%)$ induced thrombin generation in normal and severe factor XII deficient plasma. Contrary to subretinal fluid, the addition of vitreous fluids from various ocular disorders hardly provoked thrombin generation in normal and severe factor XII deficient plasma (4/12, 33\% RRD; 1/5, 20\% macular pucker; 0/6, 0\% macular hole; 0/5, 0\% proliferative diabetic retinopathy; and $2 / 11,18 \%$ eye bank eyes). The procoagulant activity in subretinal fluid was almost completely neutralized by antibodies against human TF. The presence of TF in subretinal fluid was confirmed by Western blotting.

Conclusions: Subretinal fluid from patients with RRD exerts high procoagulant activity by the action of tissue factor. 


\section{Introduction}

Tissue factor (TF), a transmembrane glycoprotein, is the major initiating factor of blood coagulation in normal haemostasis in vivo. Upon complex formation of coagulation factor VII with TF, coagulation factor $\mathrm{X}$ and IX further activate downstream proteases. ${ }^{1}$ Ultimately, this leads to the generation of thrombin, the key enzyme in the conversion of fibrinogen into fibrin. ${ }^{2}$ TF is ubiquitous throughout the human body in order to maintain haemostasis when blood vessels are injured. Therefore, TF is constitutively expressed by subendothelial cells and epithelia to prevent blood loss into extravascular spaces. ${ }^{3}$

In the human eye, TF is mostly expressed in the retinal vessel walls but only faintly in anterior segmental tissue. ${ }^{4}$ Recently, it was shown that genes related to blood coagulation were up-regulated in an experimental retinal detachment model in the pig. ${ }^{5}$ In this study, TF gene expression showed a threefold change in expression level and was considered to be up-regulated in detached and peridetached neural retinas and in retinal pigment epithelial (RPE) cells compared to control retinas. It is postulated that TF may be a critical determinant of the extent of tissue injury mediated by an ongoing inflammatory response. ${ }^{6}$ For instance, it was suggested that plasma TF levels may reflect endothelial cell injury and/or destruction of TF-containing cells in patients with diabetes mellitus with retinopathy or nephropathy. ${ }^{7}$ Since the blood-retinal barrier with its TF-containing RPE cells may be damaged during rhegmatogenous retinal detachment (RRD), it is conceivable that TF will be released into the subretinal space. Moreover, blood coagulation components may play an essential role in the development of proliferative vitreoretinopathy (PVR) following RRD, as is shown in animal models. ${ }^{8,9}$

The aim of our study was to confirm the presence of TF in human clinical specimens, to investigate the biological activity of the TF protein in subretinal and vitreous fluid samples collected from patients with RRD, and to compare TF activity between patients with and without PVR. Therefore, we investigated whether subretinal fluid and vitreous fluid collected from patients who underwent reattachment surgery for RRD exerted any procoagulant activity, using calibrated automated thrombography (CAT). This functional test, developed by Hemker et al., ${ }^{10,11}$ allows for the measurement of the composite effect of the multiple factors that determine coagulation capacity. In a similar way, we examined the procoagulant abilities of vitreous fluids from patients with various ocular conditions, including macular pucker, macular hole, and proliferative diabetic retinopathy. We report that subretinal fluid collected from RRD patients exerts high procoagulant activity by the action of TF, although we were not able to demonstrate a higher TF activity in eyes of patients with PVR. On the other hand, procoagulant activity in vitreous fluids from other ocular conditions was negligible. 


\section{Methods}

\section{Chemicals}

Phospholipid vesicles consisted of 20 mol\% phosphatidylserine (PS), 20 mol\% phosphatidyl-ethanolamine (PE) and $60 \mathrm{~mol} \%$ phosphatidylcholine (PC) and were obtained from Avanti (Alabaster, AL, USA). Recombinant relipidated tissue factor (r.TF) not containing polybrene or $\mathrm{Ca}^{2+}$ was a kind gift from Dade Behring (Marburg, Germany). Hepes-buffered saline comprised $20 \mathrm{mM}$ Hepes, $140 \mathrm{mM} \mathrm{NaCl}, \mathrm{pH}$ 7.35. Fluorogenic substrate, Z-Gly-Gly-Arg-AMC, was obtained from Bachem (Bubendorf, Switzerland). Upon splitting by thrombin, it releases the fluorescent AMC (7-amino4-methylcoumarin), which is measured by a $390 \mathrm{~nm}$ excitation and a $460 \mathrm{~nm}$ emission filter set. A fresh mixture of fluorogenic substrate and $\mathrm{CaCl}_{2}$ was prepared for each experiment as follows: to $875 \mu \mathrm{l}$ of buffer (Hepes $20 \mathrm{mM}, \mathrm{pH}$ 7.35) containing $60 \mathrm{~g} / \mathrm{l} \mathrm{BSA}$ (Sigma, A-7030), $100 \mu \mathrm{l}$ of $1 \mathrm{M} \mathrm{CaCl}_{2}$ was added. At $37^{\circ} \mathrm{C}, 25 \mu \mathrm{l}$ of a 100 $\mathrm{mM}$ DMSO solution of the fluorogenic substrate was squirted in and immediately vigorously mixed. The resulting clear solution, referred to as FluCa, thus is $2.5 \mathrm{mM}$ in fluorogenic substrate and $100 \mathrm{mM}$ in $\mathrm{CaCl}_{2}$. Calibrator was prepared in-house and consists of $\alpha_{2}$ macrogobulin-thrombin $\left(\alpha_{2} \mathrm{M}-\mathrm{T}\right)$ complex with an activity that is equal to that of $600 \mathrm{nM}$ human thrombin in buffer. Severe FXII-deficient plasma was obtained from Siemens (Marburg-Germany). Antibodies against TF were purchased from American Diagnostica (Stamford, CT, USA).

\section{Subjects}

In our department, subretinal fluid and vitreous fluid samples are routinely collected during scleral buckling surgery and pars plana vitrectomy, respectively. From samples stored in our BioBank we selected 28 subretinal fluids from patients with primary RRD. Eighteen patients had an uncomplicated postsurgical follow-up and ten patients developed a re-detachment due to PVR within 2 months. In the former group, two different collection techniques were applied. To investigate whether vitreous fluids of various ocular disorders exerted any procoagulant activity, we selected 12 patients with primary RRD, 5 patients with macular pucker, 6 patients with macular hole, and 5 patients with proliferative diabetic retinopathy. Eleven human vitreous samples obtained from 11 eye bank eyes with consent for research were used as controls. Vitreous fluid was isolated within 24 hours postmortem. These patients did not suffer from any known eye disease and deceased due to trauma, cerebrovascular event, or respiratory or cardiac failure.

This study was performed with the agreement of the University Hospital ethics committee. All patients gave informed consent before the surgical procedure and 
after the nature of the study was explained. The study adhered to the tenets of the Declaration of Helsinki.

\section{Sample Collection}

Subretinal fluid samples were obtained during scleral buckling surgery for primary RRD by two different techniques. In 20 patients, subretinal fluid was obtained by making a small incision through the sclera and choroid. Before the incision, scleral and choroidal vessels were carefully cauterized. The sclera surrounding the incision opening was cleaned from any macroscopic blood with a cotton tip. After cautiously giving some pressure on the eye, the subretinal fluid was collected from the surface of the sclera with a 25-gauge bent needle without touching the eye. Samples that were contaminated with macroscopic hemorrhage were discarded. In 8 patients, subretinal fluid was collected by the use of a needle attached to a pipette. Under biomicroscopical guidance the tip of the needle was inserted into the middle of the subretinal space. Releasing pressure on the pipette resulted in fluid collection. Macroscopic hemorrhage was avoided in any case using this technique. Samples were centrifuged at 1,200 rpm for 7 minutes to obtain supernatants.

Undiluted vitreous samples were obtained by conventional three-port, closed vitrectomy by manual suction at the start of the surgical procedure before opening the infusion line. Samples were taken out of the core of the vitreous body. Vitreous samples from eye bank eyes were obtained from the Cornea Bank Amsterdam. All samples were collected in sterile tubes and immediately stored at -80 ㅇ $\mathrm{C}$ until assayed. Sample volumes ranged between $50-250 \mu \mathrm{L}$ for subretinal fluid and between $100-1,500 \mu \mathrm{L}$ for vitreous fluid.

\section{Blood and Plasma}

Blood was obtained through antecubital venapuncture (1 volume trisodium citrate $0.13 \mathrm{M}$ to 9 volumes blood) from healthy individuals who consented to participate in this study. Free flow or minimal suction was employed; vacuum containers were avoided. The blood was centrifuged at $1,000 \mathrm{~g}$ for 10 minutes at room temperature and the plasma was aspirated. This procedure was repeated once. The plasma was stored at $-80^{\circ} \mathrm{C}$ in $1 \mathrm{~mL}$ aliquots.

\section{The Automated Calibrated Thrombogram (CAT)}

The thrombograms were measured in a 96-well plate fluorometer (Ascent reader, Thermolabsystems OY, Helsinki Finland) equipped with a 390/460 filter set (excitation/emission) and a dispenser. Flat-bottom 96-well plates (Thermo, MA, USA) were used. Each experiment needs two sets of readings, one from a well in which throm- 
bin generation takes place (TG well) and a second one from a well to which the calibrator has been added ( $C L$ well). Experiments were carried out in duplicate, i.e. a set of 2 TG wells was compared to a set of $2 \mathrm{CL}$ wells. A dedicated software program (Thrombinoscope, Synapse BV, Maastricht, The Netherlands) enables the identification of the (sets of) wells and determines the duration of the experiment and the sampling rate (usually $4 / \mathrm{min}$ ). To each well, $80 \mu \mathrm{l}$ of plasma (PPP) was added. The TG wells received $20 \mu$ of buffer, containing the trigger (including $5 \mu$ l of the ocular fluid $\pm 5 \mu$ l of antibodies against TF) but no $\mathrm{Ca}^{2+}$, whereas the $\mathrm{CL}$ wells received $20 \mu \mathrm{l}$ of the $\alpha_{2} \mathrm{M}-\mathrm{T}$ solution. The trigger was the subretinal fluid or vitreous fluid obtained during ocular surgery together with $24 \mu \mathrm{M}$ PS/PC/PE vesicles in Hepes-buffered saline, in the absence of TF. The plate was placed in the fluorometer and allowed to warm to $37^{\circ} \mathrm{C}$ (minimally 5 minutes). The dispenser of the fluorometer was flushed with warm $100 \mathrm{mM} \mathrm{CaCl}_{2}$ solution, emptied, and then flushed with warm FluCa. At the start of the experiment, the instrument dispenses $20 \mu \mathrm{l}$ of FluCa to all the wells to be measured, registers this as zero time, shakes them for 10 s and starts reading. During the measurement, the program compares the readings from the TG and the $\mathrm{CL}$ wells, calculates thrombin concentration and displays the thrombin concentration in time.

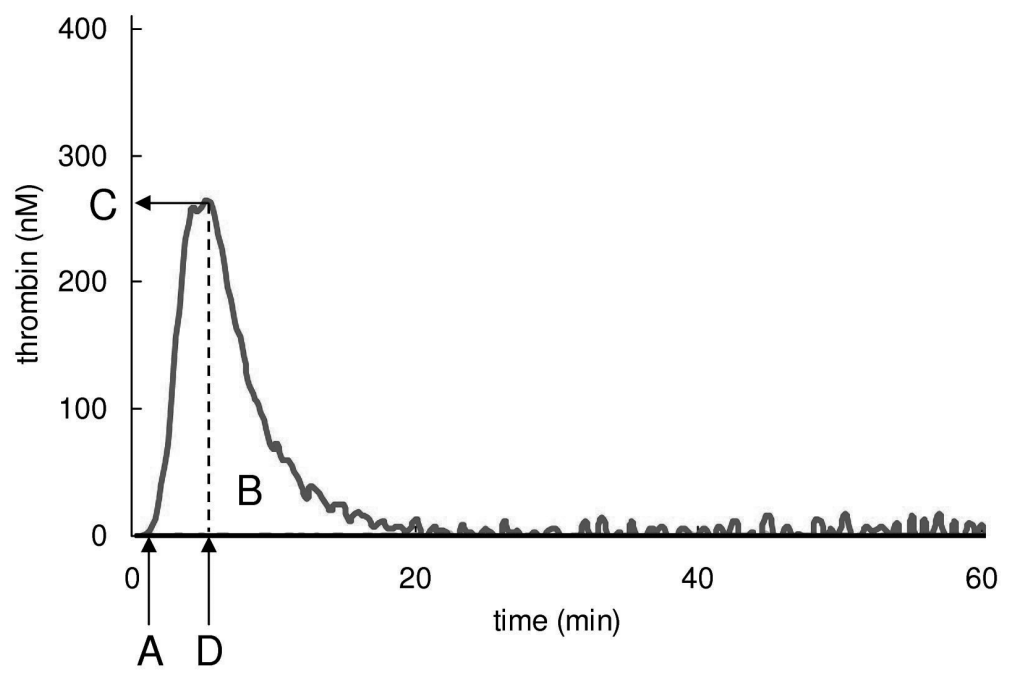

Figure 1 Typical course of a thrombogram with its parameters. (A) Lag time, (B) Endogenous Thrombin Potential (ETP), (C) Peak height, and (D) Time to peak. 
A typical course of a thrombogram is illustrated in Fig. 1. The period in which no observable thrombin is formed reflects the lag time. After this phase, the concentration of thrombin formed increases rapidly until a peak is reached, and then decreases again. The area under the curve is called the endogenous thrombin potential (ETP) and is obtained by adding a thrombin substrate in excess, so that the total amount of substrate converted is proportional to the area under the thrombogram. Other parameters of the thrombogram are the peak height and the time it takes until the peak is reached. Evident thrombin generation is defined as the peak height being $>50 \mathrm{nM}$ thrombin.

In any experimental setting, the intrinsic pathway of the coagulation cascade will be activated due to contact activation. To rule out the contribution of contact activation to the amount of thrombin generated, severe factor XII deficient plasma was used besides normal plasma in all the experiments. As a result, the use of severe factor XII deficient plasma prevented any thrombin to be generated in the absence of a trigger of the coagulation system.

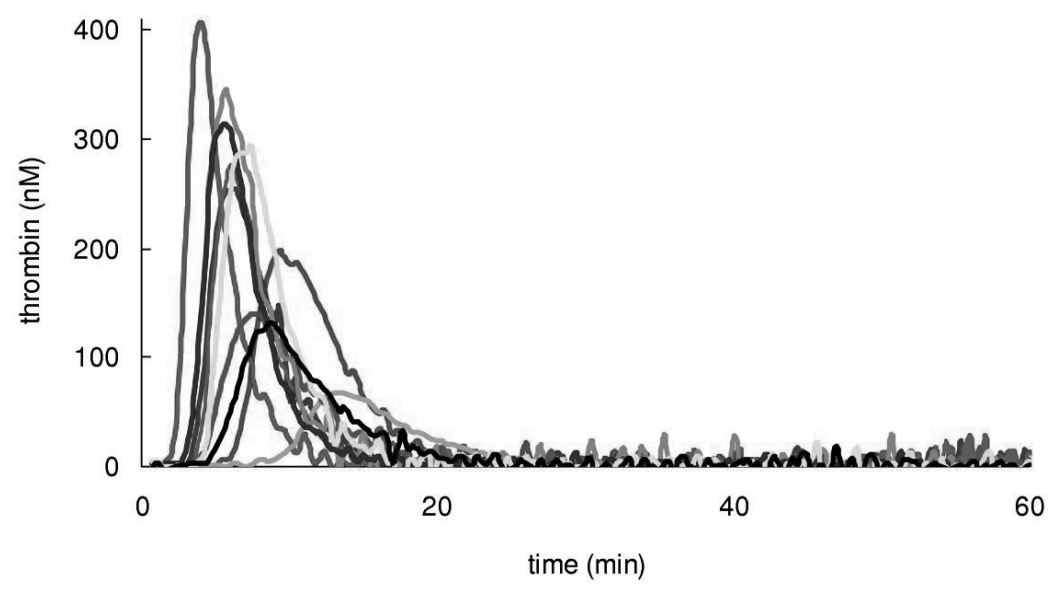

Figure 2 Thrombin generation in plasma, effect of the addition of subretinal fluid in the absence of tissue factor. Ten subretinal fluid samples obtained during scleral buckling surgery for primary rhegmatogenous retinal detachment provoked thrombin generation to a different extent in severe FXII deficient plasma. 


\section{Western Blot Analysis}

Protein concentrations were determined using Bradford reagent (BioRad). Ten $\mu \mathrm{g}$ of total protein was separated on a Novex 4-12\% Bis-Tris Gel (Invitrogen), transferred to nitrocellulose and followed by immunodetection with rabbit polyclonal TF specific antibodies. Prior to immunodetection the blot was stained with Ponceau $\mathrm{S}$ to assess equal loading.

\section{Statistical Analysis}

The nonparametric Mann-Whitney $U$-test was used for the comparison of the parameters of the thrombogram between samples collected by the two different techniques and between samples from RRD patients with and without postsurgical PVR. The nonparametric Wilcoxon signed-rank test was used to compare the procoagulant activity of the whole cell samples with the corresponding supernatants. The chi-square test was used to compare nominal variables such as diabetes mellitus. $P$ values $<0.05$ were considered to be statistically significant.

Table 1 Comparison between patients with low TF activity and patients with high TF activity based on the peak height of the thrombogram

\begin{tabular}{|c|c|c|c|}
\hline Clinical variable & $\begin{array}{l}\text { Low TF activity } \\
\qquad(n=10)\end{array}$ & $\begin{array}{l}\text { High TF activity } \\
\qquad(n=10)\end{array}$ & $P$ value \\
\hline \multicolumn{4}{|l|}{ Age (years) } \\
\hline Median (range) & $62(42-79)$ & $62(14-82)$ & $P=0.940$ \\
\hline \multicolumn{4}{|l|}{ Sex $(\%)$} \\
\hline Female & $4(40 \%)$ & $2(20 \%)$ & $P=0.329$ \\
\hline Male & $6(60 \%)$ & $8(80 \%)$ & \\
\hline Diabetes mellitus (\%) & 0 & $1(10 \%)$ & $P=0.305$ \\
\hline Pseudophakia (\%) & $3(30 \%)$ & $4(40 \%)$ & $P=0.639$ \\
\hline \multicolumn{4}{|c|}{ Duration of macular detachment (days) } \\
\hline Median (range) & $2(1-3)$ & $5(4-17)$ & $P=0.008$ \\
\hline \multicolumn{4}{|c|}{ Size of retinal detachment (quadrants) } \\
\hline Median (range) & $2(1-3)$ & $2(2-3)$ & $P=0.788$ \\
\hline \multicolumn{4}{|l|}{ Retinal defects } \\
\hline Median (range) & $2(1-2)$ & $2(0-6)$ & $P=0.796$ \\
\hline \multicolumn{4}{|c|}{ Preoperative visual acuity (logMAR) } \\
\hline Median (range) & $0.61(0-2.52)$ & $1.77(0.60-2.52)$ & $P=0.050$ \\
\hline
\end{tabular}

TF, tissue factor; logMAR, logarithm of minimal angle of resolution. 


\section{Results}

To investigate whether subretinal fluid exerted any procoagulant activity, samples from 10 patients who underwent successful scleral buckling surgery for primary RRD were added to normal and severe factor XII deficient plasma. All patients had an uncomplicated follow-up. These samples were collected by making a small incision into the sclera and choroid. In the absence of TF, the addition of subretinal fluid from patients with primary RRD induced thrombin generation to a different extent in all cases (Fig. 2), whereas no thrombin at all was generated in the absence of subretinal fluid. To confirm that this procoagulant activity was caused by the presence of TF in subretinal fluid, antibodies against human TF were added to these samples. The procoagulant activity on the parameters of CAT (lag time, ETP, peak height, and time to peak) was almost completely neutralized by these antibodies (Fig. 3). Further, the presence of TF in subretinal fluid was confirmed using Western blotting (Fig. 4).

Data from animal studies and clinical studies have shown that blood coagulation components may play key roles in the early stages of PVR. ${ }^{8,9,12,13}$ Therefore, we were interested whether subretinal fluid samples from patients with primary RRD who developed postsurgical PVR showed even higher procoagulant activity. The ten samples from Fig. 2 were compared with ten age- and gender-matched samples from patients who developed PVR within a 2-months period. All PVR samples showed high procoagulant activity but no significant differences between both groups with respect to the various parameters of the thrombogram were detected (Mann-Whitney test; $P>0.05$ for lag time, ETP, peak height, and time to peak).

Table 2 Thrombin generation in subretinal fluid samples; comparison of two collection techniques

\begin{tabular}{|c|c|c|c|}
\hline $\begin{array}{l}\text { Parameter } \\
\text { thrombogram }\end{array}$ & $\begin{array}{l}\text { Incision technique } \\
\qquad(n=10)\end{array}$ & $\begin{array}{l}\text { Pipette technique } \\
\qquad(n=8)\end{array}$ & $P$ value \\
\hline \multicolumn{4}{|l|}{ Lag time } \\
\hline Mean \pm SD & $4.6 \pm 2.0$ & $3.7 \pm 1.4$ & NS \\
\hline \multicolumn{4}{|l|}{ ETP } \\
\hline Mean \pm SD & $1249 \pm 311$ & $1485 \pm 369$ & NS \\
\hline \multicolumn{4}{|l|}{ Peak height } \\
\hline Mean \pm SD & $241 \pm 104$ & $145 \pm 131$ & NS \\
\hline \multicolumn{4}{|l|}{ Time to peak } \\
\hline Mean $\pm S D$ & $7.5 \pm 2.6$ & $11.5 \pm 3.8$ & $P=0.033$ \\
\hline
\end{tabular}

SD, standard deviation; NS, not significant; ETP, endogenous thrombin potential. 


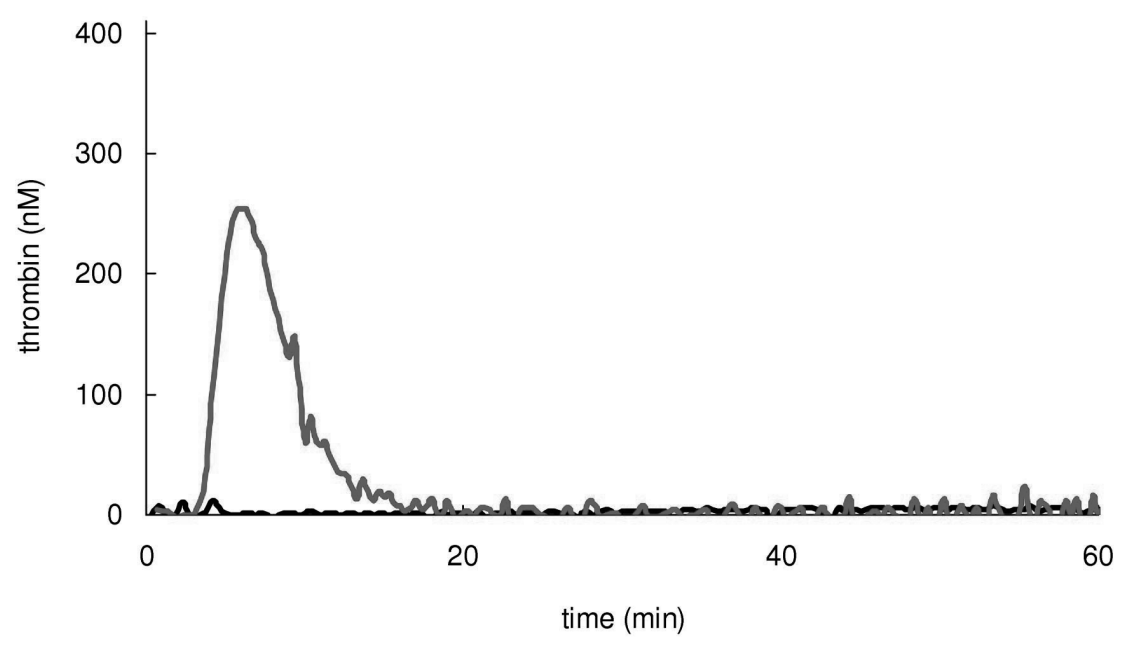

Figure 3 Thrombin generation in plasma, effect of antibodies against human tissue factor after the addition of subretinal fluid. Thrombin was generated in the presence of subretinal fluid (in red), whereas no thrombin at all was generated in the absence of subretinal fluid. Antibodies against human tissue factor almost completely neutralized the procoagulant activity of subretinal fluid (in black). Only one example is shown.

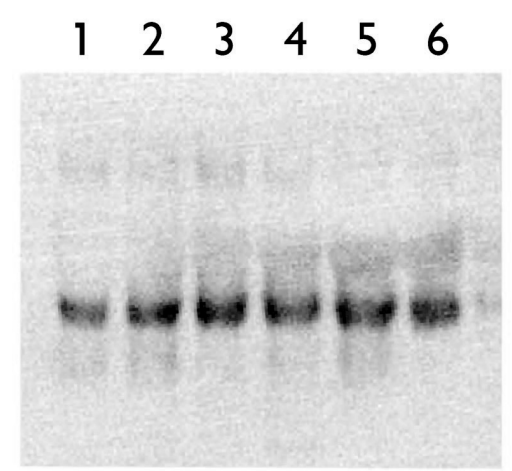

WB: anti-TF

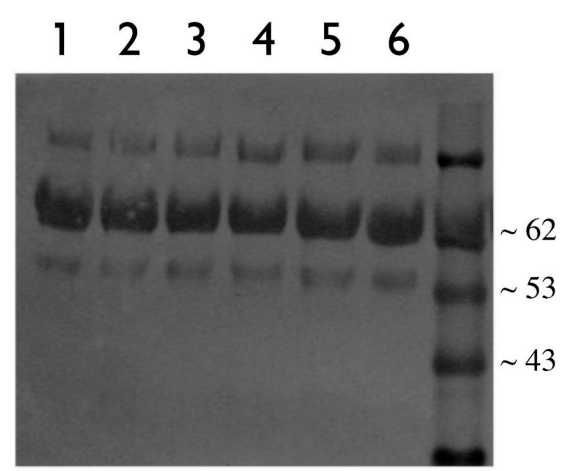

Ponceau

Figure 4 Western blot analysis of subretinal fluid samples using an antibody specifically detecting tissue factor reveals a major band at $\sim 50 \mathrm{kD}$. Samples from 6 patients who underwent scleral buckling surgery for rhegmatogenous retinal detachment were investigated. Samples from patients 1-3 are supernatants; samples from patients 4-6 are whole cell specimens. 
To investigate whether TF is a determinant of the extent of tissue injury following RRD, we made a comparison between patients with low TF activity and patients with high TF activity based on the peak height of the thrombogram. Both RRD patients with an uncomplicated follow-up and patients who developed postsurgical PVR were included in the analysis, since there were no significant differences in thrombogram parameters between both groups. Patients with high TF activity had a significant longer duration of macular detachment than patients with low TF activity $(P=0.008$; Table 1$)$. Moreover, there was a trend that the former group had a worse preoperative visual acuity $(P=0.050)$.

We also determined whether the method of fluid collection influenced our results. Therefore, we investigated 8 subretinal fluid samples from patients with primary RRD which were collected by using a small needle with pipette. All samples investigated clearly showed evident thrombin generation, though to a lesser extent in comparison with the incision technique (Table 2). Statistical analysis showed that only time to peak was significantly different between both groups (Mann-Whitney test; $P=0.033$ ). We also investigated the procoagulant activity of the supernatant of these samples. In comparison with the whole cell specimens, the supernatants showed similar procoagulant activity (Fig. 5), although differences were statistically significant for lag time (Wilcoxon signed-rank test; $P=0.042)$, ETP $(P=0.012)$, peak height $(P=0.012)$, and time to peak $(P=0.017)$.

Further, we were interested whether this procoagulant phenomenon could also be demonstrated in vitreous fluids of various other ocular conditions. Therefore, we compared the procoagulant activity of vitreous fluids collected during pars plana vitrectomy for primary $\operatorname{RRD}(n=12)$, macular pucker $(n=5)$, macular hole $(n=6)$, and proliferative diabetic retinopathy $(n=5)$ with vitreous fluid samples from eye bank eyes $(n=11)$, which served as controls. Interestingly, the addition of vitreous fluids from the non-retinal detachment groups hardly affected the amount of thrombin generated in normal and severe factor XII deficient plasma. In 1/5 (20\%) samples from patients with macular pucker, $0 / 6(0 \%)$ samples from patients with macular hole, and $0 / 5(0 \%)$ samples from patients with proliferative diabetic retinopathy thrombin generation was observed (Fig. 6a-c). In the retinal detachment group and in the eye bank group, in 4/12 (33\%) and 2/11 (18\%) vitreous samples thrombin was generated, respectively (Fig. 6d-e). Again, these effects were neutralized by antibodies against human TF in all vitreous fluid samples in which procoagulant activity was shown (data not shown), indicating that it is the presence of TF causing the thrombin generation. 


\section{Discussion}

To our knowledge, this is the first report showing that subretinal fluid collected during scleral buckling surgery for primary RRD exerts procoagulant activity. TF accounted for almost all procoagulant activity, since thrombin generation was almost completely reduced by neutralizing antibodies. We have hereby confirmed the results from the study of Hollborn et $a^{5}$ in human clinical specimens. Our results using CAT, a functional test that evaluates the biological activity of coagulation factors including TF, were further supported by Western blotting. Interestingly, hardly any procoagulant activity was detected in vitreous fluids from patients with macular pucker, macular hole, or proliferative diabetic retinopathy, whereas vitreous fluids from RRD patients showed TF activity in one third of cases.

In our study, procoagulant activity was demonstrated in only a minority of vitreous fluid samples from patients with RRD, whereas all subretinal fluid samples from patients with the same ocular disorder were able to trigger the clotting cascade. This discrepancy may be explained by the site of sample collection. During vitrectomy the vitreous fluid is collected from the core of the vitreous body. Although we do not know the exact origin of TF in our samples, it may well be that there is less activity in this part of the eye compared with the site very close to the

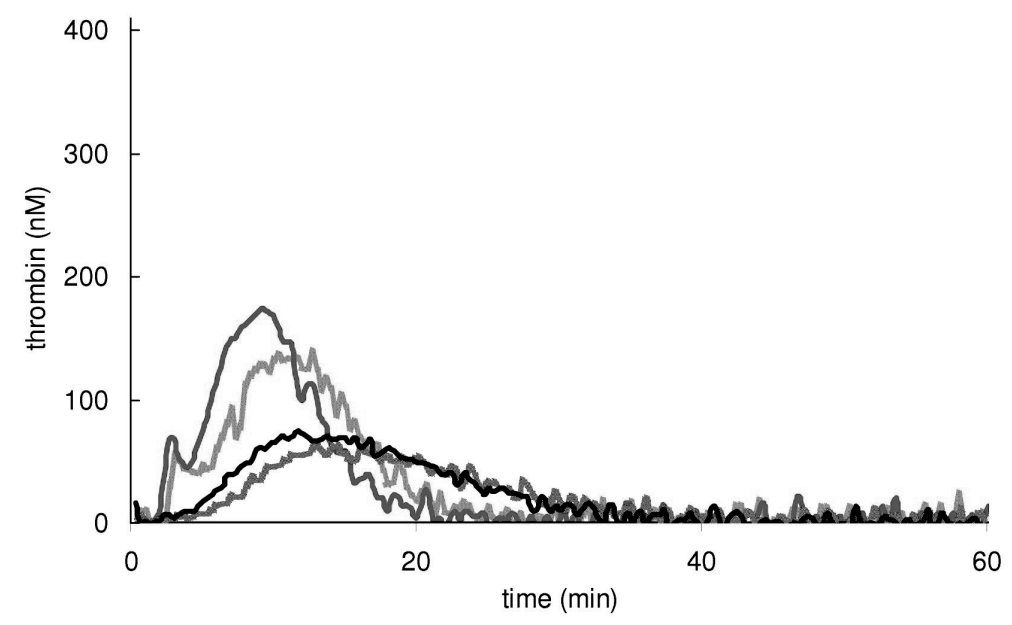

Figure 5 Thrombin generation in plasma, comparison of the addition of the whole cell subretinal fluid samples and its corresponding supernatants. Whole cell specimens and its corresponding supernatants provoked thrombin generation to a similar extent, although differences regarding the various parameters of the thrombogram were statistically significant (Wilcoxon signed-rank test; $P<0.05$ for lag time, ETP, peak height, and time to peak). The solid lines represent the whole cell specimens; the dashed lines represent the supernatants. Only two examples (in red and black) are shown. 

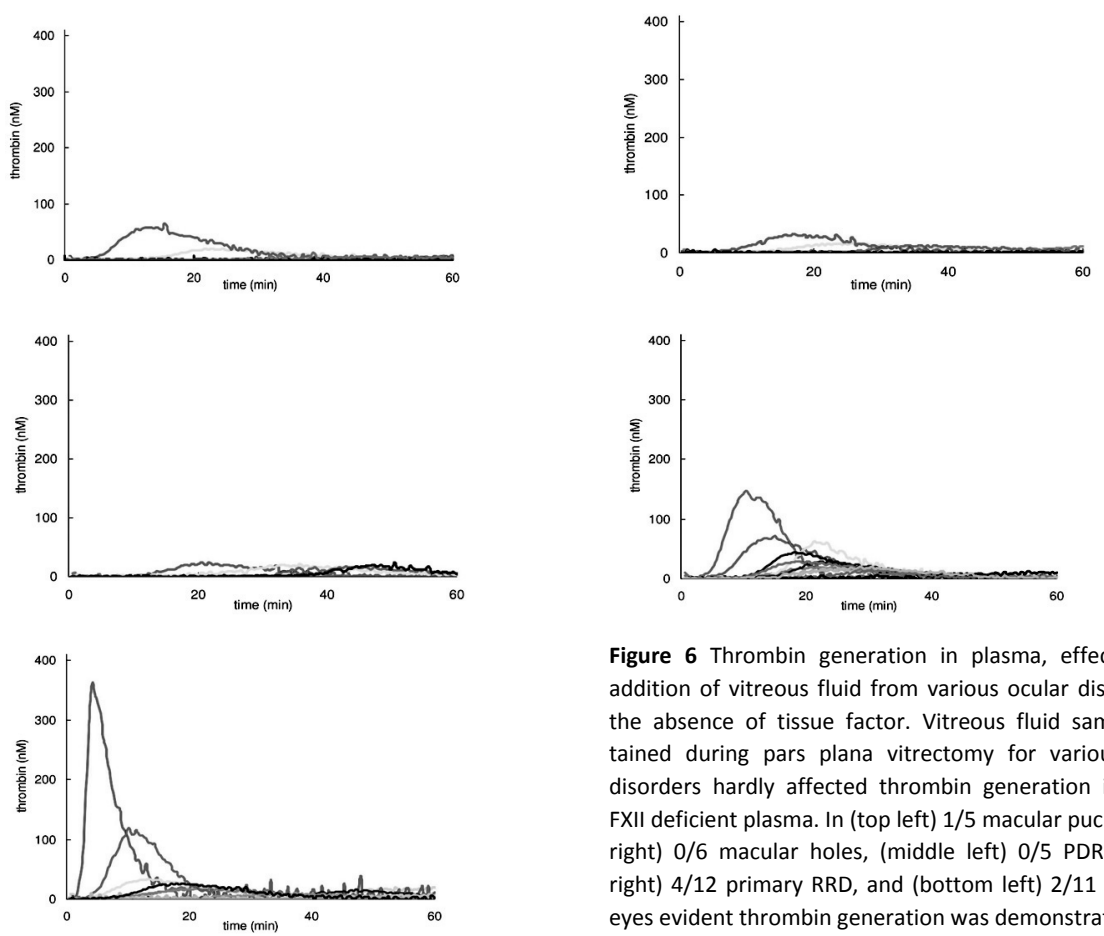

Figure 6 Thrombin generation in plasma, effect of the addition of vitreous fluid from various ocular disorders in the absence of tissue factor. Vitreous fluid samples obtained during pars plana vitrectomy for various ocular disorders hardly affected thrombin generation in severe FXII deficient plasma. In (top left) 1/5 macular puckers, (top right) 0/6 macular holes, (middle left) 0/5 PDR, (middle right) 4/12 primary RRD, and (bottom left) $2 / 11$ eye bank eyes evident thrombin generation was demonstrated.

retinal detachment. Interestingly, in some control samples from eye bank eyes procoagulant activity was detected. This may be due to lysis of cells in the postmortem tissues. However, analysis of data did not show a correlation between postmortem time and thrombin generation (data not shown). Finally, thrombin generation in subretinal fluid samples collected by pipette was lower than by the incision method. Possibly, this was caused by the small incision in the sclera itself whereby small amounts of TF may be released into the subretinal fluid.

TF is historically defined as the coagulation initiation factor, but is now recognized to have additional nonhemostatic functions on different cell populations. TF may induce a broad range of cellular responses, including inflammation and cell migration. This is illustrated by the upregulation of both interleukin (IL)- 6 and IL-8 expression in macrophages and the stimulation of fibroblast migration, following complex formation of TF with factor VIla. ${ }^{14,15}$ On the other hand, it was demonstrated that TF expression was up-regulated by a variety of cell types after stimulation with inflammatory mediators. ${ }^{16}$ Among these cell types were monocytes which have been shown to be ubiquitous in the subretinal space after retinal detachment. $^{17}$ 
It remains to be elucidated, however, what the exact meaning of TF in subretinal fluid is and whether its presence has any clinical implications. There are no reports indicating an increased incidence of thrombotic events in the retinal vasculature after retinal detachment. Nevertheless, retinal blood flow in eyes with rhegmatogenous retinal detachment has been shown to be severely impaired, ${ }^{18,19}$ resulting in prolonged retinal circulation times. Activation of the blood coagulation cascade by TF may have caused this phenomenon. Another interesting possibility is that increased TF expression may reflect tissue injury after retinal detachment. It was shown that TF gene expression is increased after experimental retinal detachment ${ }^{5}$ and that TF was detected in the normal human retina. ${ }^{4}$ We speculate that increased TF levels after RRD may result from breakdown of the blood-retinal barrier whereby retinal pigment epithelial cells and/or other retinal cells release TF into the subretinal space. This hypothesis is further supported by our findings showing that patients with high TF activity had a significant longer duration of macular detachment than those with low TF activity. Moreover, there was a trend that patients in the former group had a worse preoperative visual acuity. A larger prospective study needs to be conducted to draw conclusions concerning the monitoring of tissue damage after RRD by the measurement of TF activity.

Since blood coagulation is the first phase in the wound healing response, it may initiate the early changes that are responsible for the development of fibrotic membranes that are characteristic for PVR. Clinical studies have shown that intraocular hemorrhage during or after surgery are among the most important clinical risk factors for the development of PVR. ${ }^{12,13}$ In addition, several components of the coagulation cascade have been identified in PVR membranes including fibrin. ${ }^{20,21}$ Fibrin clots may provide a scaffold for cellular attachment and for the proliferation of RPE cells and glial cells. ${ }^{22}$ Although many studies have shown the involvement of components of the coagulation cascade in the pathophysiology of PVR, we could not detect any significant differences in TF activity between patients with an uncomplicated RRD and patients who developed postsurgical PVR.

Although some of our clinical findings suggest that tissue injury following RRD may have caused high TF activity, the origin of TF in the subretinal fluid samples may also be plasma-derived. Currently, several sources of blood-borne TF have been proposed. Most reports have focused on circulating TF-containing microparticles, which are circulating cell fragments derived from cells undergoing activation or apoptosis. ${ }^{23}$ These are considered to derive mostly from platelets and activated circulating monocytes. Monocytes themselves have also been claimed as a source of circulating $\mathrm{TF}^{24}$ and are known to invade the subretinal space after RRD. The presence of soluble TF in plasma has also been suggested but has not been generally accepted today. However, we showed that the supernatants of subretinal fluid specimens exerted considerable procoagulant activity by the action of TF. 
In conclusion, we have shown for the first time that subretinal fluid collected from patients with RRD exerts high procoagulant activity, whereas procoagulant activity of vitreous fluids from various ocular conditions was negligible. Our findings indicate that TF activity may reflect tissue damage following RRD, although a large prospective study is needed to evaluate its clinical significance.

\section{References}

1. Østerud B, Rapaport SI. Activation of factor IX by the reaction product of tissue factor and factor VII: additional pathway for initiating blood coagulation. Proc Natl Acad Sci USA 1977; 74:5260-5264.

2. Nemerson Y. Tissue factor and hemostasis. Blood 1988;71:1-8.

3. Koyama T, Nishida K, Ohdama S, et al. Determination of plasma tissue factor antigen and its clinical significance. Br J Haematol 1994;87:343-347.

4. Sakamoto $\mathrm{T}$, Ito $\mathrm{S}$, Yoshikawa $\mathrm{H}$, et al. Tissue factor increases in the aqueous humor of proliferative diabetic retinopathy. Graefes Arch Clin Exp Ophthalmol 2001;239:865-871.

5. Hollborn M, Francke M, landiev I, et al. Early activation of inflammation- and immune responserelated genes after experimental detachment of the porcine retina. Invest Ophthalmol Vis Sci 2008;49:1262-1273.

6. Brozna JP. Cellular regulation of tissue factor. Blood Coagul Fibrinolysis 1990;1:415-426.

7. Koyama T, Nishida K, Ohdama S, et al. Determination of plasma tissue factor antigen and its clinical significance. Br J Haematol 1994;87:343-347.

8. Cleary PE, Ryan SJ. Experimental posterior penetrating eye injury in the rabbit, I: Method of production and natural history. Br J Ophthalmol 1979;63:306-311.

9. García-Layana A, Pastor JC, Saornil MA, Gonzalez G. Porcine model of proliferative vitreoretinopathy with platelets. Curr Eye Res 1997;16:556-563.

10. Hemker HC, Giesen P, Al Dieri R, et al. The calibrated automated thrombogram (CAT): a universal routine test for hyper- and hypocoagulability. Pathophysiol Haemost Thromb 2002;32:249-253.

11. Hemker HC, Giesen P, Al Dieri R, et al. Calibrated automated thrombin generation measurement in clotting plasma. Pathophysiol Haemost Thromb 2003;33:4-15.

12. Yoshino $\mathrm{Y}$, Ideta $\mathrm{H}$, Nagasaki $\mathrm{H}$, Uemura A. Comparative study of clinical factors predisposing patients to proliferative vitreoretinopathy. Retina 1989;9:97-100.

13. Girard P, Mimoun G, Karpouzas I, Montefiore G. Clinical risk factors for proliferative vitreoretinopathy after retinal detachment surgery. Retina 1994;14:417-424.

14. Muth H, Kreis I, Zimmermann R, Tillmanns H, Hölschermann H. Differential gene expression in activated monocyte-derived macrophages following binding of factor VIla to tissue factor. Thromb Haemost 2005;94:1028-1034.

15. Siegbahn A, Johnell M, Rorsman C, Ezban M, Heldin CH, Rönnstrand L. Binding of factor VIla to tissue factor on human fibroblasts leads to activation of phospholipase $\mathrm{C}$ and enhanced PDGF-BBstimulated chemotaxis. Blood 2000;96:3452-3458.

16. Hoffman M. Some things I thought I knew about tissue factor that turn out to be wrong. Thromb Res 2008;122 Suppl 1:S73-77.

17. Feeney L, Burns RP, Mixon RM. Human subretinal fluid. Its cellular and subcellular components. Arch Ophthalmol 1975;93:62-69.

18. Satoh Y. Retinal circulation in rhegmatogenous retinal detachment demonstrated by videofluorescence angiography and image analysis, I: The condition of retinal circulation before retinal detachment surgery. Nippon Ganka Gakkai Zasshi 1989;93:1002-1008. 
19. Tagawa H, Feke GT, Goger DG, McMeel JW, Furukawa H. Retinal blood flow changes in eyes with rhegmatogenous retinal detachment and scleral buckling procedures. Nippon Ganka Gakkai Zasshi 1992;96:259-264.

20. Weller M, Wiedemann P, Bresgen M, Heimann K. Giant preretinal membrane formation behind a silicone oil bubble in a hypotensive eye. Retina 1990;10:86-91.

21. Schwartz D, de la Cruz ZC, Green WR, Michels RG. Proliferative vitreoretinopathy. Ultrastructural study of 20 retroretinal membranes removed by vitreous surgery. Retina 1988;8:275-281.

22. Vidaurri-Leal JS, Glaser BM. Effect of fibrin on morphologic characteristics of retinal pigment epithelial cells. Arch Ophthalmol 1984;102:1376-1379.

23. Østerud B, Bjørklid E. Sources of tissue factor. Semin Thromb Hemost 2006;32:11-23.

24. Egorina EM, Sovershaev MA, Bjørkøy G, et al. Intracellular and surface distribution of monocyte tissue factor: application to intersubject variability. Arterioscler Thromb Vasc Biol 2005;25:14931498. 

Chapter 4

Soluble Apoptotic Factors and Adhesion Molecules in Rhegmatogenous Retinal Detachment 


\section{Abstract}

Purpose: To investigate the association between soluble apoptosis and adhesion molecules and the development of proliferative vitreoretinopathy (PVR) after reattachment surgery for rhegmatogenous retinal detachment (RRD).

Methods: A multiplex immunoassay was used to measure soluble Fas (sFas), sFas ligand (sFasL), soluble intercellular adhesion molecule-1 (sICAM-1), and soluble vascular cell adhesion molecule-1 (sVCAM-1) levels in 55 subretinal fluid samples collected during scleral buckling surgery for primary RRD. Seventeen patients who developed a redetachment due to postoperative PVR after reattachment surgery (PVR group) were compared with age-, sex-, and storage-time-matched RRD samples from 38 patients with an uncomplicated postoperative course (RRD group). Ten vitreous samples from patients with macular hole and ten vitreous samples from eye bank eyes served as additional controls.

Results: A 2- to 3-fold increase in levels of sFas, sFasL, sICAM-1, and SVCAM-1 was found in the PVR group compared with those of the RRD group $(P<0.05$ for all analytes), as well as a 5- to 20-fold increase in the PVR group compared with those of additional control groups $(P<0.001$ for all analytes). Significant associations $(P<$ $0.001)$ were found between sFas and both sICAM-1 $(r=0.84)$ and SVCAM-1 $(r=$ $0.93)$ and between sFasL and both sICAM-1 $(r=0.82)$ and SVCAM-1 $(r=0.85)$. In addition, sFas, sFasL, and sVCAM-1 were significantly correlated $(P<0.05)$ with the extent and duration of retinal detachment.

Conclusions: These findings indicate that an increased expression of soluble apoptosis and adhesion molecules at the time of primary retinal detachment surgery is associated with the future development of PVR. 


\section{Introduction}

Proliferative vitreoretinopathy (PVR), the primary cause of failure of retinal detachment surgery, is an eye-sight-threatening condition that is characterized by intraretinal gliosis and the formation of cellular membranes on both sides of the retina. ${ }^{1,2}$ The retinal pigment epithelial (RPE) cell is considered to be a critical cell type in the formation of PVR membranes. It has been shown that already shortly after onset of rhegmatogenous retinal detachment (RRD) RPE cells beneath a detached retina may leave the monolayer and start proliferating and migrating. ${ }^{3,4}$ The exact mechanism by which only in a small minority of patients with RRD does the growth of RPE cells lead to postoperative PVR is unknown. We have previously suggested that PVR-affected patients lack a mechanism that stimulates apoptosis of uncontrolled RPE cells shortly after RRD onset. ${ }^{5}$ Ligation of the cell surface receptor Fas by its ligand FasL has been shown to induce apoptosis in proliferating RPE cells, whereas nonproliferating RPE cells also express Fas but were resistant to Fas ligation. ${ }^{6}$ The Fas/FasL system may thus play a role in the removal of excessive RPE cells after RRD onset, and it therefore seems plausible that a defective Fas/FasL system may predispose to PVR development.

So far, previous work has focused on the identification of apoptosis in patients with established PVR. Apoptotic cell nuclei were detected in epiretinal membranes of patients with PVR, ${ }^{7}$ and Fas expression has been reported in traction membranes in traumatic PVR. ${ }^{8}$ Furthermore, vitreous Fas and FasL mRNA were detected in patients with retinal detachment with and without PVR. ${ }^{9}$ Interestingly, both Fas and FasL also exist in soluble forms, sFas and sFasL. sFas inhibits Fas-mediated apoptosis, ${ }^{10}$ whereas the function of sFasL is controversial. It has been demonstrated that SFasL is a functional molecule that is capable of inducing apoptosis in presensitized cells. ${ }^{11}$ On the other hand, there is also abundant evidence that $\mathrm{sFasL}$ is antiapoptotic by binding the receptor protein Fas, thereby interfering with the induction of apoptosis by the membrane-bound form of FasL. ${ }^{12-15}$ Whether SFasL is a death promoter or death inhibitor probably depends on various factors such as the microenvironmental context and trimerization of the ligand. ${ }^{11}$

Intraocular levels of sFas and SFasL have been demonstrated to be significantly elevated in patients with active uveitis, ${ }^{16}$ suggesting that both molecules may also have proinflammatory properties. Moreover, in vitro studies have shown that the ligation of Fas resulted in increased expression of intercellular adhesion molecule (ICAM)-1 and vascular cell adhesion molecule (VCAM)-1. ${ }^{17}$ Both ICAM-1 and VCAM-1 mediate the recruitment of inflammatory cells to sites of injury, and their soluble forms have been shown to be increased in patients with PVR. ${ }^{18}$ The Fas/FasL system may thus also be indirectly involved in the exaggerated inflammatory response that underlies PVR development. 
In this study, we have detected and quantified the expression of sFas, sFasL, sICAM1 and SVCAM-1 in subretinal fluid samples of patients who underwent scleral buckling surgery for primary RRD. Patients who developed a redetachment due to PVR were compared with age-, sex-, and storage-time-matched control patients who had an uncomplicated postoperative course during the overall follow-up period. We found that significantly increased levels of sFas, sFasL, sICAM-1 and SVCAM-1 were associated with the future development of PVR.

\section{Methods}

\section{Patients}

In our department subretinal fluid samples are routinely obtained during scleral buckling surgery for primary RRD and transferred to the BioBank Maastricht, where they are aliquoted in $50 \mu \mathrm{L}$ portions. All samples in this study were collected between 2003 and 2008. In this time frame, a total of 232 samples were collected. Of these, 32 samples represented patients who developed a redetachment due to PVR later on during the postoperative course. Of these, we excluded 3 patients with preoperative vitreous hemorrhage, 3 patients with preoperative trauma, and 3 patients because of late PVR development ( $>21 / 2$ months after reattachment surgery). Furthermore, 6 patients were excluded due to low sample volumes $(<50 \mu \mathrm{L})$ or contamination with blood. Finally, 17 samples from patients who developed a redetachment due to PVR within $2 \frac{1}{2}$ months after scleral buckling surgery for primary RRD were included in the study (defined as the PVR group). These were compared with 38 samples from patients who did not develop a redetachment during the total follow-up period, i.e., patients with an uncomplicated postoperative course (defined as the RRD group). The samples from both groups were matched for age, sex, and storage time. None of the included patients had preoperative uveitis or autoimmune disease, whereas none of the diabetics $(n=5)$ had diabetic retinopathy.

For all these patients, we collected demographic variables and potential clinical risk factors for the development of postoperative PVR (Table 1), and the following clinical variables: follow-up time, occurrence of a redetachment, postoperative PVR grade, and preoperative and final postoperative best-corrected Snellen visual acuity. Retinopexy by intraoperative cryotherapy was performed in $64 \%$ of patients. In the majority of patients cryotherapy was applied two to three times around the retinal break. For statistical analysis, Snellen visual acuity was transformed into logMAR (logarithm of minimal angle of resolution) visual acuity. PVR was graded according to the Classification of Retinal Detachment with PVR. ${ }^{19}$ Data were collec- 
Table 1 Demographics and Potential Clinical Risk Factors for PVR

\begin{tabular}{|c|c|c|c|}
\hline Potential Clinical Risk Factor & $\begin{array}{c}\text { RRD } \\
(n=38)\end{array}$ & $\begin{array}{c}\text { PVR } \\
(n=17)\end{array}$ & $\begin{array}{c}\text { Univariate } \\
\text { Testing }\end{array}$ \\
\hline \multicolumn{4}{|l|}{ Age in years } \\
\hline Median (range) & $60(43-72)$ & $59(43-72)$ & NS \\
\hline \multicolumn{4}{|l|}{ Sex, \% } \\
\hline Female & 29 & 29 & NS \\
\hline Male & 71 & 71 & \\
\hline \multicolumn{4}{|l|}{ Size of retinal detachment in quadrants } \\
\hline Median (range) & $2(1-3)$ & $2(1-4)$ & NS \\
\hline \multicolumn{4}{|l|}{ Number of retinal defects } \\
\hline Median (range) & $1.5(1-5)$ & $1(0-4)$ & NS \\
\hline Macular detachment, \% & 70 & 82 & NS \\
\hline \multicolumn{4}{|l|}{ Preoperative logMAR visual acuity } \\
\hline Median (range) & $0.75(0.05-2.52)$ & $1.77(0.10-2.52)$ & $P=0.046$ \\
\hline \multicolumn{4}{|l|}{ Detachment duration in days } \\
\hline Median (range) & $5(1-75)$ & $7(1-58)$ & NS \\
\hline \multicolumn{4}{|l|}{ Preoperative PVR grade } \\
\hline Median (range) & $1(0-3)$ & $2(0-3)$ & NS \\
\hline Diabetes mellitus, \% & 11 & 6 & NS \\
\hline Preoperative myopia > 5D, \% & 17 & 31 & NS \\
\hline \multicolumn{4}{|l|}{ Preoperative lens status, $\%$} \\
\hline Pseudophakia & 16 & 35 & NS \\
\hline Aphakia & 0 & 0 & NS \\
\hline Preoperative uveitis, \% & 0 & 0 & NS \\
\hline Preoperative vitreous hemorrhage, \% & 0 & 0 & NS \\
\hline Preoperative cryotherapy, \% & 0 & 0 & NS \\
\hline Preoperative trauma, \% & 0 & 0 & NS \\
\hline
\end{tabular}

D = Diopters, NS = not significant.

ted as 0 (no PVR), 1 (grade A), 2 (grade B), 3 (grade C), and 4 (grade D). Duration of retinal detachment was defined as the interval between the onset of symptoms and reattachment surgery and was estimated according to a precise history of patients' symptoms.

As a separate control, we also included 10 vitreous samples from 10 patients who underwent pars plana vitrectomy for macular hole and 10 vitreous samples obtained from 10 eye bank eyes with consent for research. The study was performed with the agreement of the University Hospital Maastricht Medical Ethics Committee. All patients gave their informed consent before inclusion in the study and after the nature of the study was explained. The study adhered to the tenets of the Declaration of Helsinki. 


\section{Specimens}

Undiluted subretinal fluid samples were obtained during scleral buckling surgery for primary RRD as described previously. ${ }^{20,21}$ Before the incision, scleral and choroidal vessels were carefully cauterized. A cotton tip was used to remove any macroscopic blood that surrounded the incision opening. Subretinal fluid samples were collected from the surface of the sclera with the use of a 25-gauge bent needle. Undiluted vitreous samples were obtained by conventional three-port, closed vitrectomy by manual suction at the start of the surgical procedure before opening the infusion line. Samples were taken from the core of the vitreous body.

Vitreous samples from eye bank eyes were obtained from the Cornea Bank Amsterdam and were isolated within 24 hours after death. The donors did not have any known eye disease and deceased as the result of trauma, cerebrovascular event, or cardiac or respiratory failure. All samples were collected in sterile tubes, immediately stored at our BioBank at -80 으, and thawed directly before analysis. Samples that were contaminated with macroscopic hemorrhage were discarded. Sample volumes ranged between 50 and $300 \mu \mathrm{L}$ for subretinal fluid and between 50 and $1,300 \mu \mathrm{L}$ for vitreous fluid.

\section{Multiplex Immunoassay}

sFas, sFasL, sVCAM-1, and sICAM-1 were measured with diagnostic process software (Luminex-100 device; Luminex, Austin, TX) using a commercial multiplex immunoassay kit (Millipore, Billerica, MA). The assay was run according to the instructions of the manufacturer. In summary, the premixed beads coated with the target antibodies were incubated for 120 minutes at room temperature with premixed standards or with subretinal fluid or vitreous fluid $(25 \mu \mathrm{L})$. After repeated washings, biotinylated detection antibodies were added for an additional 60 minutes. Subsequently, streptavidin-phycoerythrin was added to the wells. After incubation for $\mathbf{3 0}$ minutes, the wells were washed twice, the beads were resuspended in $100 \mu \mathrm{L}$ sheath fluid, and fluorescence intensity was measured. Data collection and analysis of the data from all assays were performed (software from Bioplex Manager 4.1.1, Bio-Rad, Hercules, CA) using five-parameter curve fitting. Levels of sFasL below the detection limit were assigned the lowest value from the standard curve, whereas sICAM-1 levels above the detection limit were assigned the highest value from the standard curve because remeasurements were not possible, given the limited amount of sample. For statistical analysis, concentrations below or above the detection limit were converted to a value 0.5 -fold the lowest value or 2.0 -fold the highest value of the calibration curve, respectively. 


\section{Statistics}

Samples were divided into 4 groups: patients who developed a redetachment due to PVR within $2 \frac{1}{2}$ months after scleral buckling surgery (the PVR group), patients with an uncomplicated postoperative course after reattachment surgery (the RRD group), patients who underwent pars plana vitrectomy for macular hole, and eye bank eyes. The latter two groups served as additional controls. Since data were not normally distributed, nonparametric tests were used for statistical analysis. Analyte levels between more than two groups were compared using the Kruskal-Wallis test, and levels between two groups were analysed using the Mann-Whitney $U$ test. Correlations were determined by the Spearman rho test. To compare clinical variables between the PVR group and the RRD group, the $X^{2}$ test and the Mann-Whitney $U$ test were used as appropriate. Statistical analysis was performed using an algorithm, input-output module software (SPSS for Windows, version 16.0; SPSS, Chicago, IL). Differences were considered significant at $P<0.05$, with two-tailed testing.

\section{Results}

\section{Demographics and Clinical Results}

sFas, sFasL, sVCAM-1, and sICAM-1 levels were quantified by multiplex immunoassay in subretinal fluid samples of 55 patients who underwent scleral buckling surgery for primary RRD. Initial reattachment was achieved in all 55 cases. Seventeen patients who developed a redetachment due to postoperative PVR were compared with 38 patients with an uncomplicated postoperative course. In the PVR group, there were 5 women (29\%) and 12 men (71\%) with a median age of 59 years (range, $43-72$ years). Of these 17 patients with postoperative PVR, 9 patients were classified with PVR grade $B, 7$ with PVR grade $C$, and 1 with PVR grade $D$. The median time interval between reattachment surgery and redetachment due to postoperative PVR was 35 days (range, 7-80 days) and the median follow-up time was 21 months (range, 3-80 months). The RRD group consisted of 11 women (29\%) and 27 men (71\%) with a median age of 60 years (range, $43-72$ years). Their median follow-up time was 8 months (range, $3-80$ months). With respect to potential preoperative clinical risk factors for the development of PVR (Table 1), only median preoperative $\operatorname{logMAR}$ visual acuity was significantly worse in the PVR group (1.77; range $0.10-$ 2.52) compared with that of the RRD group (0.75; range $0.05-2.52$ ) (MannWhitney $U$ test; $P=0.046)$. There was a trend toward a higher preoperative PVR 

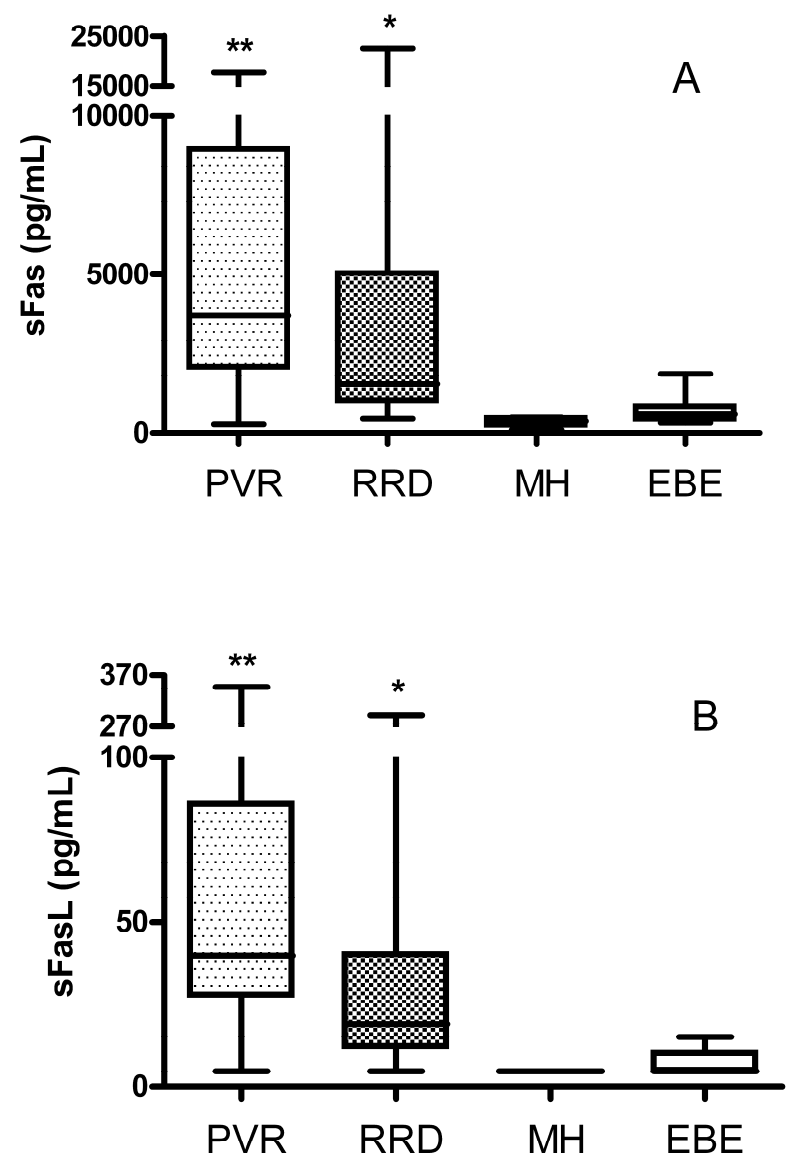

Figure 1 Box-and-whisker plots of (A) sFas and (B) sFasL levels in subretinal fluid samples from patients with primary RRD. Patients who developed a redetachment as a result of postsurgical PVR ( $n=17$, PVR group) were compared with controls who had an uncomplicated retinal detachment during the overall follow-up period ( $n=38$, RRD group). Vitreous fluids from patients with macular hole ( $n=10, \mathrm{MH}$ group) and eye bank eyes ( $n=10$, EBE group) served as additional controls. ${ }^{*}$ PVR versus RRD, $P<0.05$; PVR versus $\mathrm{MH}, P<0.001$; PVR versus EBE, $P<0.001,{ }^{*}$ RRD versus $\mathrm{MH}, P<0.001$; RRD versus EBE, $P<0.001$. Box: lower and upper quartiles; horizontal line: the median. 

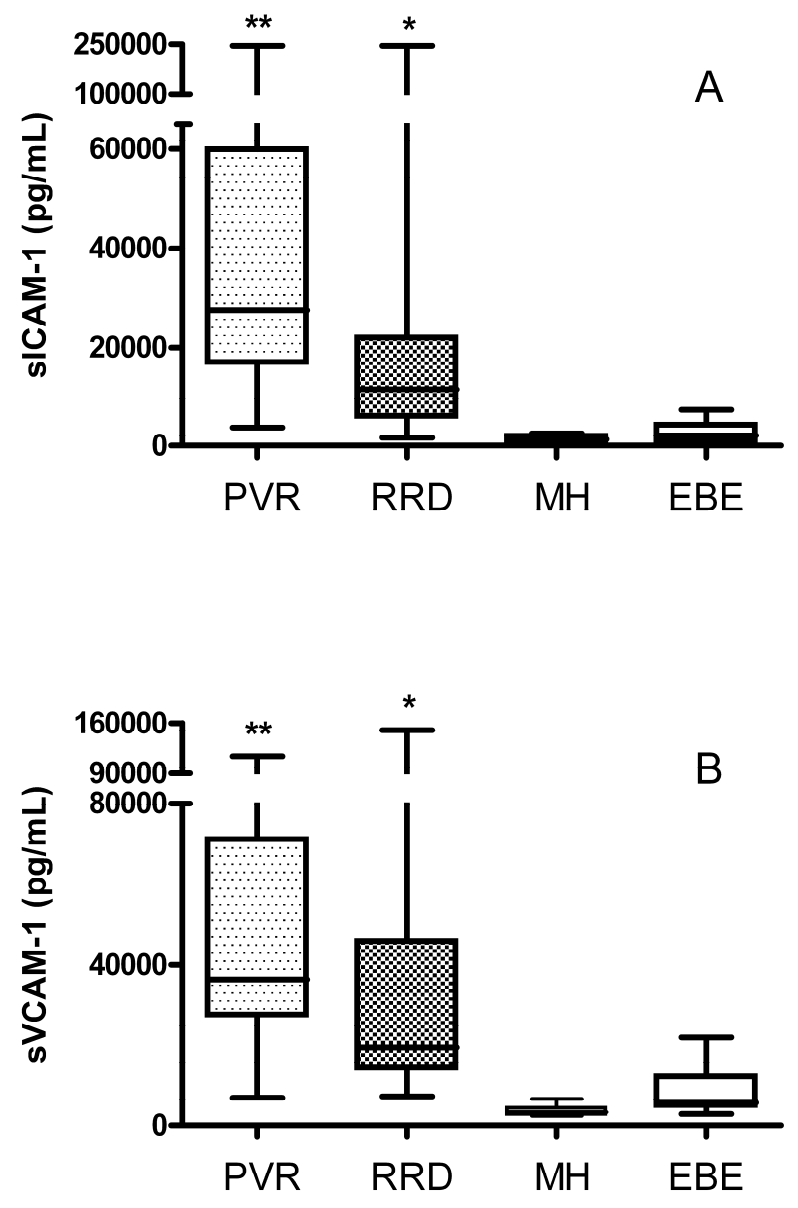

Figure 2 Box-and-whisker plots of (A) SICAM-1 and (B) SVCAM-1 levels in subretinal fluid samples from patients with primary RRD. Patients who developed a redetachment as a result of postsurgical PVR $(n=$ 17 , PVR group) were compared with controls who had an uncomplicated retinal detachment during the overall follow-up period ( $n=38$, RRD group). Vitreous fluids from patients with $\mathrm{MH}$ ( $n=10, \mathrm{MH}$ group) and EBE ( $n=10$, EBE group) served as additional controls. **PVR versus RRD, $P<0.05$; PVR versus $\mathrm{MH}, P$ $<0.001$; PVR versus EBE, $P<0.001,{ }^{*}$ RRD versus $\mathrm{MH}, P<0.001$; RRD versus EBE, $P<0.001$. Box: lower and upper quartiles; horizontal line: the median. 
grade in the PVR group $(P=0.070)$. Detachment duration was similar between the RRD group (5 days; range, $1-75$ days) and the PVR group (7 days; range $1-58$ days) $(P=0.808)$.

\section{sFas and sFasL Levels in Subretinal Fluid}

According to Kruskal-Wallis tests, significant differences between groups were found for both sFas $(P<0.0001)$ and sFasL $(P<0.0001)$. Detectable levels of sFas were determined in all samples investigated. Subretinal fluid levels of sFas from patients who developed a redetachment due to PVR were approximately 2.5-fold higher than those from eyes with RRD and an uncomplicated postoperative course (Mann-Whitney $U$ test; $P=0.0396$ ). In addition, subretinal fluid sFas levels of both the PVR group and the RRD group were significantly elevated compared with the macular hole group ( $P<0.001$ for both comparisons) and the eye bank eye group ( $P$ $<0.001$ for both comparisons) (Fig. 1A).

sFasL was detected in 16/17 (94\%) patients in the PVR group, in 32/38 (84\%) patients in the RRD group, in $0 / 10(0 \%)$ patients with macular hole, and in $3 / 10$ (30\%) vitreous fluids from eye bank eyes. Median subretinal fluid sFasL concentrations were approximately twofold higher in the PVR group than those in the RRD group. This twofold difference between both groups at this early stage of investigation, i.e., at the time of primary RRD when no PVR has manifested yet, was highly significant (Mann-Whitney $U$ test; $P=0.0057$ ). Moreover, levels in samples from both retinal detachment groups were significantly higher compared with those in both the macular hole group and the eye bank eye group ( $P<0.001$ for all comparisons) (Fig. 1B).

\section{sVCAM-1 and sICAM-1 Levels in Subretinal Fluid}

sVCAM-1 and sICAM-1 levels were significantly different between the four groups (Kruskal-Wallis test; $P<0.0001$ for both analytes). For sICAM-1, 2/17 (12\%) PVR samples and 2/38 (5\%) RRD samples were above the upper detection limit, whereas sVCAM-1 was detected in all samples investigated. We found a two- to threefold increase in both sICAM-1 and SVCAM-1 levels in the PVR group compared with levels in the RRD group (Mann-Whitney $U$ test; $P=0.0056$ and $P=0.0414$, respectively). Furthermore, levels of both adhesion molecules in the PVR group and the RRD group were significantly elevated (up to 20-fold) compared with levels in the macular hole group and the eye bank eye group ( $P<0.001$ for all comparisons) (Figs. $2 \mathrm{~A}, 2 \mathrm{~B}$ ). The levels of all soluble factors investigated (sFas, sFasL, sICAM-1, sVCAM-

1) are summarized in Table 2. 


\section{Correlations between Soluble Factors and Clinical Variables}

There was a strong positive correlation between sFas and sFasL (Spearman rho test; $r=0.89 ; P<0.0001)$ and SVCAM-1 and sICAM-1 ( $r=0.75 ; P<0.0001)$ (Figs. 3A, 3B). Moreover, we found significant associations $(P<0.0001)$ between sICAM-1 and both sFas $(r=0.84)$ and SFasL $(r=0.82)$ and between sVCAM-1 and both sFas $(r=$ $0.93)$ and sFasL $(r=0.85)$ (Figs. 3C $-F$ ). When comparing the soluble factors with clinical variables, we found that SFas, sFasL, and SVCAM-1 levels were significantly correlated $(P<0.05)$ with detachment duration $(r=0.45, r=0.31$, and $r=0.39$, respectively), duration of macular detachment $(r=0.55, r=0.37$, and $r=0.54)$, and the number of quadrants involved $(r=0.34, r=0.30$, and $r=0.32)$. Both SFasL and sICAM-1 were not associated with preoperative PVR, whereas its correlations with sFas and SVCAM-1 were low ( $r=0.31$ and $r=0.32$, respectively) $(P<0.05)$. There were no significant correlations between SICAM-1 and other preoperative clinical variables. Final visual acuity was significantly better in the RRD group (median logMAR visual acuity 0.22 ; range $0-1.30$ ) than that in the PVR group (median logMAR visual acuity 1.10; range $0-2.52$ ) (Mann-Whitney $U$ test; $P<0.0001$ ). Preoperative visual acuity $(r=0.41 ; P=0.002)$ and SICAM-1 $(r=0.32 ; P=0.017)$ were significantly associated with final visual outcome, whereas SFas, sFasL, and SVCAM-1 were not ( $r$ $=0.21, r=0.21$, and $r=0.16$, respectively; $P>0.05$ ).

Table 2 Summary of sFas, sFasL, sICAM-1, and sVCAM-1 Levels in Retinal Detachment, Macular Hole, and Eye Bank Eyes

\begin{tabular}{|c|c|c|c|c|}
\hline $\begin{array}{l}\text { Analyte } \\
\text { (pg/mL) }\end{array}$ & $\begin{array}{c}\text { PVR } \\
\text { (SRF; } n=17)\end{array}$ & $\begin{array}{c}\text { RRD } \\
\text { (SRF; } n=38)\end{array}$ & $\begin{array}{l}\text { Macular Hole } \\
\text { (VF; } n=10)\end{array}$ & $\begin{array}{c}\text { Eye Bank Eyes } \\
\text { (VF; } n=10)\end{array}$ \\
\hline \multicolumn{5}{|l|}{ sFas } \\
\hline $\begin{array}{l}\text { Median } \\
\text { (range) }\end{array}$ & $\begin{array}{c}3688^{* *} \\
(271-17677)\end{array}$ & $\begin{array}{c}1524^{*} \\
(446-22600)\end{array}$ & $\begin{array}{c}370 \\
(104-482)\end{array}$ & $\begin{array}{c}576 \\
(321-1864)\end{array}$ \\
\hline \multicolumn{5}{|l|}{ sFasL } \\
\hline $\begin{array}{l}\text { Median } \\
\text { (range) }\end{array}$ & $\begin{array}{c}40 * * \\
(<9.5-347)\end{array}$ & $\begin{array}{c}19 * \\
(<9.5-293)\end{array}$ & $\begin{array}{c}<9.5 \\
(<9.5-<9.5)\end{array}$ & $\begin{array}{c}<9.5 \\
(<9.5-15)\end{array}$ \\
\hline \multicolumn{5}{|l|}{ sICAM-1 } \\
\hline $\begin{array}{l}\text { Median } \\
\text { (range) }\end{array}$ & $\begin{array}{c}27540 * * \\
(3707->245000)\end{array}$ & $\begin{array}{c}11434^{*} \\
(1629->245000)\end{array}$ & $\begin{array}{c}1336 \\
(635-2523)\end{array}$ & $\begin{array}{c}2149 \\
(777-7297)\end{array}$ \\
\hline \multicolumn{5}{|l|}{ sVCAM-1 } \\
\hline $\begin{array}{l}\text { Median } \\
\text { (range) }\end{array}$ & $\begin{array}{c}36436 * * \\
(6883-114189)\end{array}$ & $\begin{array}{c}19347^{*} \\
(7232-149754)\end{array}$ & $\begin{array}{c}3252 \\
(2471-6622)\end{array}$ & $\begin{array}{c}5613 \\
(2836-21862)\end{array}$ \\
\hline
\end{tabular}




\section{Discussion}

In the present study, subretinal fluid levels of sFas, sFasL, sICAM-1, and SVCAM-1 were significantly increased in patients who developed postoperative PVR compared with patients with an uncomplicated follow-up after primary retinal detachment surgery. To illustrate, we found a two- to threefold increase in levels of all soluble factors investigated in the PVR group compared with that in the RRD group, and even a 5- to 20-fold increase compared with the additional control groups (Figs. 1 , 2; Table 2). Furthermore, strong associations $(r \geq 0.75)$ were found between sFas, sFasL, sICAM-1, and sVCAM-1.

Previous studies have implicated an abnormal regulation of apoptosis in the pathogenesis of proliferative vitreoretinal disorders. Research has focused on the detection of apoptotic cells in epiretinal membranes of patients with established PVR. $^{7-9,22,23}$ Most apoptotic cells appeared to be from RPE cell origin, ${ }^{22,23}$ and the Fas/FasL system has been assigned an important role in RPE cell death. ${ }^{9}$ Shifting the balance toward apoptosis in PVR membranes was suggested as a novel therapeutic approach to prevent the uncontrolled proliferation of cells in this disorder.

In contrast to these reports, the time point at which samples were obtained and the sampling specimen (subretinal fluid instead of vitreous) differed in the present study. In retinal detachment, it was shown that within 24 hours after loss of contact between the pigment epithelium and the photoreceptor layer, RPE cells begin to proliferate and dedifferentiate. ${ }^{3}$ Therefore, we believe that sampling at a time close to the onset of primary RRD and in the near vicinity of the RPE may provide clues as to which local factors may initiate the uncontrolled growth of cells that lead to PVR membrane formation. Therefore, a comparison was made between subretinal fluids from patients in whom PVR develops after reattachment surgery and from patients with an uncomplicated follow-up. We used vitreous fluids from donated eyes and from patients with macular hole as additional controls for our subretinal fluid samples, as described earlier. ${ }^{5}$ Although vitreous differs in composition from subretinal fluid, and thus cannot function as an ideal control specimen, it has been suggested that vitreous is the main source of subretinal fluid in recent onset RRD. ${ }^{24}$

Since our goal was to identify soluble mediators that might contribute to the initial stages of PVR development, it was of utmost importance to have similar baseline characteristics between those patients who developed PVR and those who did not. Therefore, we decided to match both groups for age, sex, and storage time of the sample. Although other preoperative variables may also be considered for matching, our subretinal fluid database was not large enough to allow us to do so. Nevertheless, no significant differences with respect to important preoperative clinical characteristics such as extent and duration of retinal detachment were detected between both groups, except for preoperative visual acuity. This may be ex- 

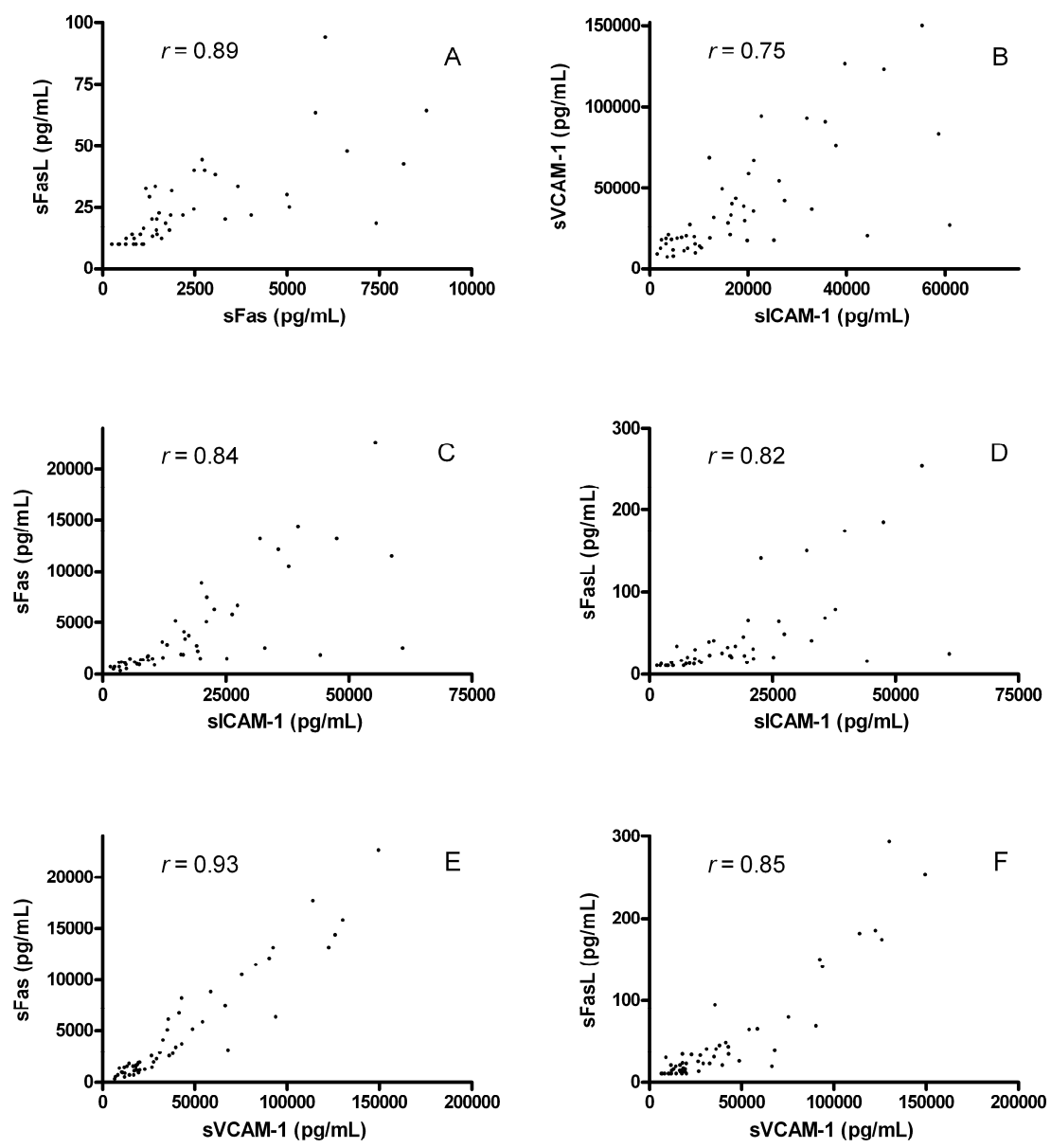

Figure 3 Correlations between various analytes in subretinal fluid samples after primary RRD. Correlation between (A) sFas and sFasL, (B) sICAM-1 and sVCAM-1, (C) SICAM-1 and sFas, (D) SICAM-1 and sFasL, (E) sVCAM-1 and sFas, (F) SVCAM-1 and sFasL. SICAM-1 levels that were above the detection limit are not shown in the figure.

plained in part by the higher percentage of patients with a detached macula in the PVR group compared with the RRD group that, however, did not reach statistical significance $(P=0.347)$. Moreover, the difference in logMAR preoperative visual acuity is less evident when mean levels instead of median levels are taken into account (PVR group 1.62; RRD group 1.10) (data not shown). The introduction of bias was also minimized by exclusion of patients with preoperative conditions known to induce PVR, such as preoperative vitreous hemorrhage and preoperative trauma. 
Furthermore, none of the patients had uveitis or autoimmune disease, and none of the diabetics had signs of diabetic retinopathy. The correlations between increased levels of soluble apoptotic molecules as well as adhesion molecules and PVR development may thus suggest their involvement in the initial stages of this fibrotic eye condition. Of note, the percentage of patients with postoperative PVR in our database $(13.7 \%)$ was somewhat higher than numbers reported in the literature. This higher incidence may be explained by the fact that we did not collect subretinal fluid in patients with small or shallow detachments, i.e., retinal detachments at low risk for developing PVR.

Fas is expressed on a wide variety of cells such as inflammatory cells, which are known to infiltrate the subretinal space after retinal detachment, and resident ocular cells. ${ }^{8,25-27}$ Because all these cells have the potential to transcribe Fas, the source of sFas in our subretinal fluid samples remains to be clarified. It has been postulated that increased shedding of the receptor protein Fas from the cell membrane, which leads to the secretion of the antiapoptotic sFas, may downregulate the killing activity of FasL-bearing cells ${ }^{10}$; however, the surface expression of FasL is limited to resident cells in immune privileged sites and activated immune cells. ${ }^{28-30}$ In the retina, FasL is expressed on RPE cells and throughout the retina. ${ }^{30,31}$ Moreover, RPE cells have been shown to upregulate FasL in areas with subretinal inflammatory infiltrates, whereas cultured RPE cells were capable of releasing both the membrane form of FasL (mFasL) in vesicles and sFasL. ${ }^{32}$ Although FasL expression on epithelial cells appears to be an important mechanism for the maintenance of immune privilege in the eye by inducing apoptosis of infiltrating Fas-positive immune cells, ${ }^{30}$ the exact role of its soluble form remains to be clarified. In contrast to studies that have demonstrated the apoptosis-inducing properties of $\mathrm{SFasL}^{11,33}$ there is abundant evidence that its killing capacity is greatly reduced or even may counteract the induction of apoptosis by mFasL. ${ }^{12-15}$ Taken together, the source and function of both sFas and SFasL in the subretinal space after the neurosensory retina separates from the underlying RPE are unclear and should be determined in future studies.

Because the relationship between increased soluble mediators and PVR development may represent only a correlation, alternative explanations for our findings must be considered. There is a large body of evidence that the separation of photoreceptors from the RPE leads to disruption of normal photoreceptor homeostasis, and the Fas-mediated extrinsic death pathway and the mitochondrial intrinsic death pathway have both been assigned an important role in photoreceptor loss after retinal detachment. ${ }^{31,34-36}$ In addition, these studies have shown that both pathways are activated in a time-dependent fashion after retinal detachment. Even though the correlations between SFas/sFasL and the extent and duration of retinal detachment in our study were weak, these findings may point to a protective role in the survival of photoreceptors after RRD. In line with this hypothesis, the intrinsic pro- 
duction of the antiapoptotic sFas after hypoxic-ischemic events in the brain was suggested to protect central nervous system cells from further damage. ${ }^{37}$

Both sFas and SFasL have also been attributed proinflammatory properties in addition to their roles in apoptosis. The hypothesis that the Fas/FasL system merely confers immune privilege has been challenged by several studies demonstrating that sFasL may induce a granulocytic response. ${ }^{11,38,39}$ Furthermore, sFas has been found in a number of conditions of acute and chronic inflammation, including cardiovascular, respiratory, and autoimmune disease. ${ }^{40-43}$ In the eye, the levels of sFas and SFasL in the vitreous of patients with active uveitis were significantly higher than levels in those with inactive uveitis, ${ }^{16}$ whereas in patients who underwent penetrating keratoplasty the incidence of detectable sFasL was higher in those who had immune reactions than that in those without immune reactions. ${ }^{44}$

Next to the increased levels of sFas and SFasL, we observed significantly elevated levels of the proinflammatory adhesion molecules sICAM-1 and SVCAM-1 in the PVR group compared with the RRD group (Fig. 2). Both adhesion molecules have been shown to be elevated in vitreous of patients with PVR compared with that in patients with macular hole in a prior study, ${ }^{18}$ whereas ICAM-1 expression was found on PVR membranes. ${ }^{45}$ Since ICAM-1 and VCAM- 1 have a role in leukocyte adhesion and migration into the injured tissue, both molecules may be involved in the early events that elicit an inflammatory response that is associated with the future development of PVR. Elevated sICAM-1 levels in the present study confirm the results of a noncommercial sICAM-1 multiplex assay that we performed elsewhere in a similar population (data submitted). The local production of adhesion molecules by resident ocular cells has been suggested since serum levels in patients with PVR were not increased. ${ }^{46}$ Retinal endothelial cells and RPE cells are possible sources of sCAMs in patients with retinal detachment; in vitro studies have demonstrated the increased expression of both ICAM-1 and VCAM- 1 in these cell types in the presence of inflammatory cytokines. ${ }^{47,48}$ Moreover, retinas separated from the RPE in experimental retinal detachment showed increased ICAM-1 and VCAM-1 gene transcription. ${ }^{49}$

Interestingly, we found strong correlations between sFas/sFasL and both adhesion molecules (Fig. 3). There is scarce evidence that Fas activation may lead to the upregulation of adhesion molecules. In vitro studies have shown that the ligation of Fas resulted in the increased expression of ICAM-1 and VCAM-1 on endothelial cells. ${ }^{17}$ The Fas/FasL system may thus be indirectly involved in the recruitment of inflammatory cells to sites of injury, although in vitro studies are needed to investigate whether resident ocular cells are capable of secreting ICAM-1 and VCAM-1 after activation of the Fas/FasL system. Alternatively, the strong correlations between apoptotic and adhesion molecules may also be explained by the activation of resident ocular cells after RRD onset, leading to the simultaneous secretion of sFas, sFasL, sICAM-1, and sVCAM-1. 
To summarize, our findings show that levels of sFas, sFasL, sICAM-1, and sVCAM-1 are significantly higher in patients who developed PVR compared with levels in patients with an uncomplicated RRD. The elevated levels of soluble apoptotic factors and soluble adhesion molecules may point to their involvement in the cellular processes that occur in the subretinal space after retinal detachment. The exact roles of the soluble forms of Fas/FasL as death promoters, death inhibitors, or inducers of inflammation need further clarification.

\section{Acknowledgments}

We thank Elisabeth Pels and co-workers of the Corneabank Amsterdam for providing the vitreous fluids from donor eyes.

\section{References}

1. Pastor JC, de la Rúa ER, Martín F. Proliferative vitreoretinopathy: risk factors and pathobiology. Prog Retin Eye Res 2002;21:127-144.

2. Pastor JC, Méndez MC, de la Fuente MA, et al. Intraretinal immunohistochemistry findings in proliferative vitreoretinopathy with retinal shortening. Ophthalmic Res 2006;38:193-200.

3. Anderson DH, Stern WH, Fisher SK, Erickson PA, Borgula GA. The onset of pigment epithelial proliferation after retinal detachment. Invest Ophthalmol Vis Sci 1981;21:10-16.

4. Del Priore LV, Hornbeck R, Kaplan HJ, et al. Débridement of the pig retinal pigment epithelium in vivo. Arch Ophthalmol 1995;113:939-944.

5. Dieudonné SC, La Heij EC, Diederen R, et al. High TGF- $\beta 2$ levels during primary retinal detachment may protect against proliferative vitreoretinopathy. Invest Ophthalmol Vis Sci 2004;45:4113-4118.

6. Chang JH, Kang SW, Ham DI. Sensitivity of CD95-induced apoptosis in different proliferative status of human retinal pigment epithelial cells. Korean J Ophthalmol 2001;15:74-80.

7. Esser P, Bartz-Schmidt KU, Walter P, Kaszli F, Heimann K, Weller M. Apoptotic cell death in proliferative vitreoretinopathy. German J Ophthalmol 1996;5:73-78.

8. Weller M, Heimann K, Bartz-Schmidt KU, Fontana A, Esser P. CD95 expression in traumatic proliferative vitreoretinopathy: a target for the induction of apoptosis. German J Ophthalmol 1997;5:332337.

9. El Ghrably I, Powe DG, Orr G, et al. Apoptosis in proliferative vitreoretinopathy. Invest Ophthalmol Vis Sci 2004;45:1473-1479.

10. Cheng J, Zhou T, Liu C, et al. Protection from Fas-mediated apoptosis by a soluble form of the Fas molecule. Science 1994;263:1759-1762.

11. Janssen O, Qian J, Linkermann A, Kabelitz D. CD95 ligand - death factor and costimulatory molecule? Cell Death Differ 2003;10:1215-1225.

12. Hohlbaum AM, Moe S, Marshak-Rothstein A. Opposing effects of transmembrane and soluble Fas ligand expression on inflammation and tumor cell survival. J Exp Med 2000;191:1209-1219.

13. Suda T, Hashimoto H, Tanaka M, Ochi T, Nagata S. Membrane Fas ligand kills human peripheral blood T lymphocytes, and soluble Fas ligand blocks the killing. J Exp Med 1997;186:2045-2050.

14. Tanaka M, Itai T, Adachi M, Nagata S. Downregulation of Fas ligand by shedding. Nat Med 1998;4:31-36. 
15. Schneider P, Holler N, Bodmer JL, et al. Conversion of membrane-bound Fas (CD95) ligand to its soluble form is associated with downregulation of its proapoptotic activity and loss of liver toxicity. J Exp Med 1998;187:1205-1213.

16. Sugita S, Taguchi $\mathrm{C}$, Takase $\mathrm{H}$, et al. Soluble Fas ligand and soluble Fas in ocular fluid of patients with uveitis. Br J Ophthalmol 2000;84:1130-1134.

17. Cardier JE, Schulte T, Kammer H, Kwak J, Cardier M. Fas (CD95, APO-1) antigen expression and function in murine liver endothelial cells: implications for the regulation of apoptosis in liver endothelial cells. FASEB J 1999;13:1950-1960.

18. Barile GR, Chang S, Park L, Reppucci VS, Schiff WM, Schmidt AM. Soluble cellular adhesion molecules in proliferative vitreoretinopathy and proliferative diabetic retinopathy. Curr Eye Res 1999;19:219-227.

19. Retina Society Terminology Committee. The classification of retinal detachment with proliferative vitreoretinopathy. Ophthalmology 1983;90:121-125.

20. Ricker LAG, Kijlstra A, de Jager W, Liem ATA, Hendrikse F, La Heij EC. Chemokine levels in subretinal fluid obtained during scleral buckling surgery after rhegmatogenous retinal detachment. Invest Ophthalmol Vis Sci 2010;51:4143-4150.

21. Ricker LJAG, Dieri RA, Beckers GJ, et al. High subretinal fluid procoagulant activity in rhegmatogenous retinal detachment. Invest Ophthalmol Vis Sci 2010;51:5234-5239.

22. Zhang $X$, Barile $G$, Chang $S$, et al. Apoptosis and cell proliferation in proliferative retinal disorders: PCNA, Ki-67, caspase-3, and PARP expression. Curr Eye Res 2005;30:395-403.

23. Esser $P$, Heimann $K$, Bartz-Schmidt KU, et al. Apoptosis in proliferative vitreoretinal disorders: possible involvement of TGF- $\beta$ - induced RPE cell apoptosis. Exp Eye Res 1997;65:365-378.

24. Quintyn JC, Brasseur G. Subretinal fluid in primary rhegmatogenous retinal detachment: physiopathology and composition. Surv Ophthalmol 2004;49:96-108.

25. Watanabe-Fukunaga R, Brannan C, Itoh N, et al. The cDNA structure, expression, and chromosomal assignment of the mouse Fas antigen. J Immunol 1992;148:1274-1279.

26. Liles W, Kiener P, Ledbetter J, Aruffo A, Klebanoff S. Differential expression of Fas (CD95) and Fas ligand on normal human phagocytes: implications for the regulation of apoptosis in neutrophils. $J$ Exp Med 1996;184:429-440.

27. Richardson B, Lalwani N, Johnson K, Marks R. Fas ligation triggers apoptosis in macrophages but not endothelial cells. Eur J Immunol 1994;24:2640-2645.

28. Bellgrau D, Gold D, Selawry H, Moore J, Franzusoff A, Duke RC. A role for CD95 ligand in preventing graft rejection. Nature 1995;377:630-632.

29. Suda T, Okazaki T, Naito Y, et al. Expression of the Fas ligand in cells of the T cell lineage. $J$ Immunol 1995;154:3806-3813.

30. Griffith TS, Brunner T, Fletcher SM, Green DR, Ferguson TA. Fas ligand-induced apoptosis as a mechanism of immune privilege. Science 1995;270:1189-1192.

31. Zacks DN, Zheng QD, Han Y, Bakhru R, Miller JW. Fas-mediated apoptosis and its relation to intrinsic pathway activation in an experimental model of retinal detachment. Invest Ophthalmol Vis Sci 2004;45:4563-4569.

32. McKechnie NM, King BCR, Fletcher E, Braun G. Fas-ligand is stored in secretory lysosomes of ocular barrier epithelia and released with microvesicles. Exp Eye Res 2006;83:304-314.

33. Jiang S, Wu MWH, Sternberg P, Jones DP. Fas mediates apoptosis and oxidant-induced cell death in cultured hRPE cells. Invest Ophthalmol Vis Sci 2000;41:645-655.

34. Zacks DN, Boehlke C, Richards AL, Zheng QD. Role of the Fas-signaling pathway in photoreceptor neuroprotection. Arch Ophthalmol 2007;125:1389-1395.

35. Hisatomi T, Sakamoto T, Goto Y, et al. Critical role of photoreceptor apoptosis in functional damage after retinal detachment. Curr Eye Res 2002;24:161-172.

36. Besirli CG, Chinskey ND, Zheng QD, Zacks DN. Inhibition of retinal detachment-induced apoptosis in photoreceptors by a small peptide inhibitor of the Fas receptor. Invest Ophthalmol Vis Sci 2010;51:2177-2184. 
37. Tarkowski E, Rosengren L, Blomstrand C, Jensen C, Ekholm S, Tarkowski A. Intrathecal expression of proteins regulating apoptosis in acute stroke. Stroke 1999;30:321-327.

38. Dupont PJ, Warrens AN. Fas ligand exerts its pro-inflammatory effects via neutrophil recruitment but not activation. Immunology 2006;120:133-139.

39. Allison J, Georgiou HM, Strasser A, Vaux DL. Transgenic expression of CD95 ligand on islet beta cells induces a granulocytic infiltration but does not confer immune privilege upon islet allografts. Proc Natl Acad Sci USA 1997;94:3943-3947.

40. Toyozaki T, Hiroe M, Saito $T$, et al. Levels of soluble Fas in patients with myocarditis, heart failure of unknown origin, and in healthy volunteers. Am J Cardiol 1998;81:798-800.

41. Yasuda N, Gotoh K, Minatoguchi S, et al. An increase of soluble Fas, an inhibitor of apoptosis, associated with progression of COPD. Respir Med 1998;92:993-999.

42. Chen DY, Lan JL, Lin FJ, Hsieh TY. Elevated levels of soluble Fas (APO-1, CD95), soluble Fas ligand, and matrix metalloproteinase- 3 in sera from patients with active untreated adult onset Still's disease. Clin Rheumatol 2007;26:393-400.

43. El-Agroudy AE, El-Baz A. Soluble Fas: a useful marker of inflammation and cardiovascular diseases in uremic patients. Clin Exp Nephrol 2010;14:152-157.

44. Reinhard T, Bönig H, Mayweg S, Böhringer D, Göbel U, Sundmacher R. Soluble Fas ligand and transforming growth factor $\beta 2$ in the aqueous humor of patients with endothelial immune reactions after penetrating keratoplasty. Arch Ophthalmol 2002;120:1630-1635.

45. Limb GA, Franks WA, Munasinghe KR, Chignell AH, Dumonde DC. Proliferative vitreoretinopathy: an examination of the involvement of lymphocytes, adhesion molecules and HLA-DR antigens. Graefes Arch Clin Exp Ophthalmol 1993;231:331-336.

46. Limb GA, Chignell AH, Cole $\mathrm{CJ}$, et al. Intercellular adhesion molecule-1 in proliferative vitreoretinopathy. Invest Ophthalmol Vis Sci 1997;38:1043-1048.

47. Leeuwenberg JFM, Smeets EF, Neefjes JJ, et al. E-selectin and intercellular adhesion molecule-1 are released by activated human endothelial cells in vitro. Immunology 1992;77:543-549.

48. Platts KE, Benson MT, Rennie IG, Sharrard RM, Rees RC. Cytokine modulation of adhesion molecule expression on human retinal pigment epithelial cells. Invest Ophthalmol Vis Sci 1995;36:2262-2269.

49. Zacks DN. Gene transcription profile of the detached retina (An AOS Thesis). Trans Am Ophthalmol Soc 2009;107:343-382. 

Chapter 5

Anti-angiogenic Isoforms of VEGF

Predominate in Subretinal Fluid of

Patients with Rhegmatogenous Retinal

Detachment and Proliferative

Vitreoretinopathy

Retina 2012;32(1):54-59

L.J.A.G. Ricker, S.C. Dieudonné, E.S. Rennel, T.T.J.M. Berendschot, F. Hendrikse, A. Kijlstra, E.C. La Heij 


\section{Abstract}

Background: In proliferative vitreoretinopathy (PVR), a non-angiogenic eye disease that is characterized by the formation of mainly avascular membranes, vascular endothelial growth factor (VEGF) levels are found to be up-regulated. Recently, it was discovered that VEGF is alternatively spliced to form the angiogenic $\left(V_{E G F} F_{x x x}\right)$ and anti-angiogenic $\left(V_{E G F} F_{x x} b\right)$ family of isoforms. Previous studies on expression of VEGF in PVR samples have not distinguished between the two families of isoforms.

Methods: We measured total VEGF and $V_{E G F} \times$ xb levels in subretinal fluid of patients with PVR $(n=10)$ and patients with uncomplicated rhegmatogenous retinal detachment (RRD) ( $n=27)$ using enzyme-linked immunosorbent assay.

Results: We found total VEGF levels to be 2- to 3-fold elevated in the PVR group as compared to the RRD group $(P=0.047)$. Anti-angiogenic $V_{E G F}$ bx $b$ isoforms predominated ( $>60 \%$ of total VEGF) in the majority of RRD and PVR samples investigated, although a wide variability of isoform ratios was observed within both groups.

Conclusions: The absence of an increased ratio of $V_{E G F} F_{x x}$ to $V_{E G F} b$ in patients with PVR as compared to patients with uncomplicated RRD may explain a lack of blood vessels in PVR membranes. Elevated VEGF levels indicate that this cytokine may play a role in the pathogenesis of PVR that is not related to angiogenesis. 


\section{Introduction}

In human eye disease, vascular endothelial growth factor (VEGF) has been attributed an important role in ocular angiogenesis, such as in diabetic retinopathy, retinopathy of prematurity, and wet age-related macular degeneration. ${ }^{1}$ Surprisingly, it has also been demonstrated in non-angiogenic ocular diseases. The association of VEGF with the pathogenesis of proliferative vitreoretinopathy (PVR), a proliferative disorder that is characterized by the formation of avascular epiretinal membranes (ERMs) and subretinal membranes, has been investigated by several groups. VEGF levels were found to be higher in PVR subretinal fluid and vitreous fluid samples compared to uncomplicated rhegmatogenous retinal detachment (RRD) controls. ${ }^{2,3}$ Contradictory results have been reported for the association between VEGF levels and the duration of retinal detachment, ${ }^{2,4,5}$ whereas no correlations were demonstrated between VEGF and the extent of retinal detachment., ${ }^{2,4}$ Retinal pigmented epithelial (RPE) cells and retinal glia, which constitute the major components of PVR membranes and membranes in ischemic retinopathies, ${ }^{6}$ each produce VEGF. ${ }^{7,8}$ Interestingly, ERMs in ischemic retinopathies, such as proliferative diabetic retinopathy (PDR), are vascularized, while those associated with PVR are mainly avascular. This finding raises the question why PVR membranes lack blood vessels if VEGF is present.

The mRNA encoding VEGF is differentially spliced from eight exons to encode at least six different proteins. ${ }^{9}$ These proteins are named according to the amino acid number of the monomer $\left(V_{E G F} F_{121}, V_{E G F} G_{165}, V_{E G F} 189\right.$, etc), generically termed VEGF $_{\mathrm{xxx} \cdot} \cdot{ }^{10}$ Recently, it was discovered that VEGF splicing in the terminal exon results in an almost identical family of sister isoforms, which leads to the production of proteins of the same length as the other forms, but with a different C-terminal amino acid sequence. ${ }^{11}$ This family has been termed VEGF $F_{x x x} b$. The receptor-binding domains and dimerisation domains are still intact in these new isoforms. The dominant VEGF $\mathrm{Fxx}_{\mathrm{xx}}$ isoform in most angiogenic states is $\mathrm{VEGF}_{165}$, whereas the dominant $V E G F_{x x x}$ b isoform appears to be $V_{E G F} F_{165} b$, which binds to its receptor with the same affinity as $\mathrm{VEGF}_{165}$. However, instead of stimulating angiogenesis signaling, VEGF $\mathrm{F}_{\mathrm{xx}} \mathrm{b}$ is actively anti-angiogenic due to the inhibition of the proliferative, migratory, and vasodilator effects of $\mathrm{VEGF}_{165 .}{ }^{12}$

It was the aim of this study to investigate the protein expression of VEGF and its pro-angiogenic and anti-angiogenic isoforms in subretinal fluid samples of patients with PVR compared to patients with uncomplicated RRD. 


\section{Methods}

Subretinal fluid samples of 37 patients who underwent scleral buckling surgery for primary RRD were collected for this study. Ten subretinal fluid samples from patients with preoperative PVR and 27 subretinal fluid samples from patients with uncomplicated RRD were obtained. None of the included patients had undergone previous vitreoretinal surgery. All samples were collected between May 2005 and January 2007. Undiluted subretinal fluid samples were obtained after scleral puncture with a 25-gauge bent needle and before cryotherapy, as we described earlier. ${ }^{13}$ Samples that were contaminated with macroscopic hemorrhage were discarded. All samples were collected in sterile Eppendorf tubes, immediately stored at $-80^{\circ} \mathrm{C}$, and thawed immediately before analysis. Sample volumes ranged between 50 and 500 $\mu \mathrm{L}$.

For all 37 patients, we recorded age, sex, preoperative best corrected Snellen visual acuity, macular involvement, duration and extent of detachment, diabetes mellitus, and the number and size of retinal defects. PVR was graded using the 1991 classification of the Retina Society Terminology Committee. ${ }^{14}$ All PVR cases were grade $\mathrm{B}(n=9)$ or grade $\mathrm{C}(n=1)$ and were secondary to rhegmatogenous retinal detachments. The study adhered to the tenets of the Declaration of Helsinki and was performed with the agreement of the University Hospital ethics committee. All patients gave written informed consent before the surgical procedure and after the nature of the study was explained.

All materials were provided by Sigma-Aldrich (Gillingham, UK), unless otherwise specified. VEGF ELISAs, VEGF 165 b protein and $V_{E G F_{165}}$ protein were provided by R\&D Systems (Minneapolis, MN, USA). Total VEGF and VEGF $F_{x x} b$ concentrations in subretinal fluid were measured using a standard VEGF Duoset ELISA (\#DY293) or a VEGF $_{x x x}$ b ELISA (\#DY3045), as described earlier. ${ }^{15}$ Immulon $2 \mathrm{HB}$ plate (Thermo Life Sciences, Basingstoke, UK) were coated with $2 \mu \mathrm{g} \mathrm{ml}{ }^{-1}$ mouse monoclonal antiVEGF $_{x x x}$ b antibody (R\&D \#MAb 3045) overnight. The plate was washed three times in phosphate-buffered saline $+0.05 \%$ Tween after each step. Plates were blocked in Super block (Pierce Biotechnology, Rockford, IL, USA \#37515) overnight. Subretinal fluids were diluted 2-10 times in 3\% bovine serum albumin and incubated for 2 hours and detected using $100 \mathrm{ng} / \mathrm{ml}$ goat polyclonal anti-VEGF biotinylated detection antibody (R\&D \#BAF 293) for 2 hours followed by streptavidin conjugated horse radish peroxidase and read at $450 \mathrm{~nm}$ after addition of $1 \mathrm{M} \mathrm{H}_{2} \mathrm{SO}_{4}$. Regarding specificity, the anti-VEGF $\mathrm{xxx}_{\mathrm{b}}$ antibody showed no cross-reactivity with rhVEGF$_{206}$, rhVEGF-B ${ }_{167}$, rhVEGF-B ${ }_{186}$, rhVEGF-C, or rhVEGF-D, whereas the detection limit for the antibody was $12 \mathrm{pg} / \mathrm{mL}$. Since a commercial ELISA for $\mathrm{VEGF}_{\mathrm{xxx}}$ was not available, its concentrations were calculated by subtracting VEGF $_{x x x}$ b from total VEGF.

For statistical analysis, Snellen visual acuity was transformed into logMAR (logarithm of minimal angle of resolution) acuity. Patients with PVR were compared to 
patients with uncomplicated RRD. The nonparametric Mann-Whitney $U$ test was used for ordinal variables such as growth factor level and duration of retinal detachment. The chi-square test was used to compare nominal variables such as diabetes mellitus and sex. The Spearman's rho test was used to test the correlation between the levels of total VEGF, VEGF $\mathrm{Fxx}_{\mathrm{xx}} \mathrm{b}$, and $\mathrm{VEGF}_{\mathrm{xx} x}$, with ordinal clinical variables. Moreover, we investigated the role of macular involvement and the extent of retinal detachment as possible confounding variables with respect to the association between VEGF levels and the presence or absence of PVR. Differences were considered significant at $P<0.05$, with two-tailed testing.

\section{Results}

Subretinal fluid samples from 37 patients were analyzed for total VEGF levels and VEGF isoform levels. Ten samples were obtained from patients with preoperative PVR. This group included 6 men (60\%) and 4 women (40\%) with a median age of 68 years (range $22-83$ ). Nine patients had PVR grade B and one patient had PVR grade $\mathrm{CP} 2$. The group of patients with uncomplicated RRD $(n=27)$ consisted of 18 men (67\%) and 9 women (33\%) with a mean age of 63 years (range $23-85$ ). Between the two groups, there were no statistically significant differences with respect to age, sex, number and size of retinal defects and detachment duration. However, there was a significant difference in the median number of quadrants involved between the PVR group and the uncomplicated RRD group $(P=0.021$; Mann-Whitney $U$ test) (Table 1). Moreover, the macula was more often involved ( $90 \%$ vs. $48 \%)(P=$ 0.021 ; chi-square test) and the median preoperative logMAR visual acuity was worse (1.77 vs. 0.60) ( $P=0.007$; Mann-Whitney $U$ test) in the PVR group as compared to the RRD group without PVR (Table 1). A negative correlation between $V_{E G F}$ levels and the size of the retinal defect was found, although the correlation coefficient was low $(r=-0.41)(P=0.012$; Spearman's rho test). For the other clinical variables, we did not find any correlation with total VEGF or VEGF $\mathrm{xxx}_{\mathrm{x}}$ b levels.

Total VEGF levels were detected in all but one patient in the RRD group. We found total VEGF levels in the PVR group to be two- to threefold elevated as compared to the RRD group. The median concentration of total VEGF in patients with PVR was $418 \mathrm{pg} / \mathrm{mL}$ (Q1, $180 \mathrm{pg} / \mathrm{mL}$; Q3, $1306 \mathrm{pg} / \mathrm{mL}$ ) and $186 \mathrm{pg} / \mathrm{mL}$ (Q1, 54 $\mathrm{pg} / \mathrm{mL}$; $\mathrm{Q} 3,417 \mathrm{pg} / \mathrm{mL}$ ) in patients with uncomplicated RRD. Analysis of these data revealed that the difference in total VEGF between these two groups reached statistical significance ( $P=0.047$; Mann-Whitney $U$ test) (Fig. 1$)$. In addition, we investigated whether there was a significant relationship between VEGF levels and presence versus absence of PVR after adjusting for baseline differences between both groups. In contrast to the extent of retinal detachment (i.e., the number of quadrants involved), macular involvement may be considered as a confounding variable 
Table 1 Demographics and Clinical Variables

\begin{tabular}{|c|c|c|c|}
\hline Clinical Variable & $\begin{array}{c}\text { RRD } \\
(n=27)\end{array}$ & $\begin{array}{c}\text { PVR } \\
(n=10)\end{array}$ & $P$ value \\
\hline \multicolumn{4}{|l|}{ Age (years) } \\
\hline Median (range) & $63(23-85)$ & $68(22-83)$ & NS \\
\hline \multicolumn{4}{|l|}{ Sex } \\
\hline Female & $9(33 \%)$ & $4(40 \%)$ & NS \\
\hline Male & $18(67 \%)$ & $6(60 \%)$ & NS \\
\hline Diabetes mellitus & $4(15 \%)$ & 0 & NS \\
\hline \multicolumn{4}{|l|}{ Quadrants involved } \\
\hline Median (range) & $2(1-3)$ & $2(2-3)$ & $P=0.021$ \\
\hline \multicolumn{4}{|c|}{ Number of retinal defects } \\
\hline Median (range) & $1(0-3)$ & $1.5(0-3)$ & NS \\
\hline \multicolumn{4}{|c|}{$\begin{array}{l}\text { Size of retinal defects (optic disc diame- } \\
\text { ters) }\end{array}$} \\
\hline Median (range) & $1.5(0-3)$ & $1.25(0-3)$ & NS \\
\hline \multicolumn{4}{|c|}{ Duration of macular detachment (days) } \\
\hline Median (range) & $7(2-180)$ & $6(3-65)$ & NS \\
\hline Macular detachment & $13(48 \%)$ & $9(90 \%)$ & $P=0.021$ \\
\hline \multicolumn{4}{|c|}{$\begin{array}{l}\text { Preoperative logMAR visual } \\
\text { acuity }\end{array}$} \\
\hline Median (range) & $0.60(0-2.52)$ & $1.77(0.52-2.52)$ & $P=0.007$ \\
\hline
\end{tabular}

RRD, rhegmatogenous retinal detachment; PVR, proliferative vitreoretinopathy; NS, not significant; logMAR, logarithm of the minimum angle of resolution.

because it influences the coefficient of VEGF. After multivariate analysis, however, the association between elevated VEGF concentrations and presence of PVR remained statistically significant $(P=0.024)$.

We also determined the concentrations of $V_{E G F} F_{x x x} b$ and $V_{E G F} F_{x x}$ to find out whether the development of PVR resulted in an alteration in the balance of VEGF isoforms. In 22/26 (85\%) RRD samples and 10/10 (100\%) PVR samples the antiangiogenic $\operatorname{VEGF}_{\mathrm{xxx}} \mathrm{b}$ was detected $(P=0.188$; chi-square test). The pro-angiogenic VEGF $_{x x x}$ was present in 10/26 (38\%) RRD samples and 5/10 (50\%) PVR samples ( $P=$ 0.529 ; chi-square test). Median levels of $\mathrm{VEGF}_{\mathrm{xxx}} \mathrm{b}$ and $\mathrm{VEGF}_{\mathrm{xxx}}$ were $290 \mathrm{pg} / \mathrm{mL}$ and $169 \mathrm{pg} / \mathrm{mL}$ in the PVR group, respectively, and $93 \mathrm{pg} / \mathrm{mL}$ and $<12 \mathrm{pg} / \mathrm{mL}$ in the RRD group, respectively. When comparing the ratio between pro-angiogenic and antiangiogenic VEGF isoforms, we found that the mean percentages of VEGF $F_{x x x} b$ were similar between the RRD samples and the PVR samples $(P=0.937)$. Although there was a predominance of the anti-angiogenic isoforms in both groups, it is important to note that there was a wide variability between anti-angiogenic:pro-angiogenic VEGF ratios in both the RRD group (mean percentage $\mathrm{VEGF}_{\mathrm{xxx}} \mathrm{b} 69 \%$, range $0-100 \%$ ) and the PVR group (mean percentage VEGF $_{x x x}$ b 64\%, range $11-100 \%$ ). This wide 
distribution can be explained by very low VEGF $x$ xx b levels $\left(<30 \% \operatorname{VEGF}_{x x x}\right.$ b) in $7 / 26$ (27\%) RRD samples and in 3/10 (30\%) PVR samples.

\section{Discussion}

This is the first study that determined VEGF splice variants in subretinal fluid samples of patients with RRD and patients with PVR. We found that total VEGF protein levels were significantly higher in patients with preoperative PVR as compared to patients with uncomplicated RRD. Moreover, the ratios of anti-angiogenic VEGF $_{x x x}$ b:pro-angiogenic VEGF $_{x x x}$ were found to be similar between both groups, with a predominance of the anti-angiogenic isoforms (RRD group, 69\%:31\%; PVR group, $64 \%: 36 \%$ ), although a wide variability of these ratios was observed within both groups.

VEGF splicing in the terminal exon results in an almost identical family of sister isoforms. The anti-angiogenic $V_{E G F}$ xxx isoforms have about $96 \%$ homology with the pro-angiogenic $\mathrm{VEGF}_{\mathrm{xxx}}$ isoforms and were therefore not detectable by commercially available antibodies used in previous studies. ${ }^{9}$ This means that studies describing VEGF expression in epiretinal membranes, vitreous fluid samples, or subretinal fluid samples of patients with PVR published so far could not make the distinction between the pro- and anti-angiogenic VEGF isoforms. As a result, some studies concluded that it was surprising that VEGF levels were high in an eye disease that is characterized by the formation of avascular membranes. ${ }^{16}$

VEGF $_{x x x} b$ isoforms are endogenously produced in normal human tissues. ${ }^{12}$ They form over $50 \%$ of the total VEGF protein in lung (82\%), colon (>95\%), and skin $(>95 \%)^{7}$. Over-expression of $\mathrm{VEGF}_{165} \mathrm{~b}$ inhibited tumor cell-mediated migration and proliferation of endothelial cells in three different tumor types, ${ }^{17}$ suggesting that the mechanism of inhibition is caused by inhibiting angiogenesis rather than by a direct effect on tumor cell growth. It is thus the angiogenic switch from antiangiogenic $\mathrm{VEGF}_{\mathrm{xxx}} \mathrm{b}$ isoforms to pro-angiogenic $\mathrm{VEGF}_{\mathrm{xxx}}$ isoforms that allows tumors to develop their own blood supply.

Perrin et al. ${ }^{18}$ measured VEGF splice variants in vitreous fluid from patients who underwent vitrectomy for various ocular conditions. They found that $\mathrm{VEGF}_{\mathrm{xxx}} \mathrm{b}$ isoforms accounted for $65 \%$ of total VEGF in the vitreous of patients with retinal detachment and macular hole. In addition, in 6/18 (33\%) vitreous samples obtained from this group of patients pro-angiogenic isoforms accounted for the majority of the total VEGF protein. Both observations are consistent with the data reported in our current study. In contrast to patients with retinal detachment or macular hole, the aforementioned study showed that the percentage of total VEGF in the vitreous that was inhibitory (i.e. VEGF $\mathrm{xxx}_{\mathrm{x}}$ ) was significantly lower in patients with proliferative diabetic retinopathy. ${ }^{18}$ In the latter group, an angiogenic switch was observed 
with VEGF $x x x$ b levels dropping to only $12.5 \%$ of the total VEGF. We report that the anti-angiogenic $V_{E G F_{x x}} b$ isoforms comprise more than half of the total VEGF protein in subretinal fluid samples of both patients with PVR and patients with uncomplicated RRD. The absence of an angiogenic switch in these patients may explain a lack of blood vessels in PVR membranes. This hypothesis should however be treated with caution given the predominance of pro-angiogenic VEGF isoforms in a subset of our study population. On the other hand, there are several immunohistochemical studies confirming the presence of vascularisation in a substantial portion of PVR membranes. ${ }^{19,20}$ To illustrate, a vascular component, which consisted mostly of capillary-sized vessels that were clinically inapparent, was demonstrated in $28.6 \%$ of all PVR membranes investigated in one study. ${ }^{21}$ Further study with combined assessment of a vascular component in PVR membranes and VEGF isoforms in corresponding PVR samples is therefore warranted.

Various studies have investigated whether VEGF played a role in the pathogenesis of PVR. In line with our study, VEGF was found to be up-regulated in vitreous or subretinal fluid samples of patients with PVR. ${ }^{2,3}$ Furthermore, VEGF staining was prominent in all or almost all PVR membranes investigated. ${ }^{16,22}$ The role of an imbalance between VEGF and pigment epithelium-derived factor (PEDF) in thepathogenesis of PVR has not been elucidated yet. Ogata et al. ${ }^{3}$ found increased VEGF concentrations and decreased PEDF concentrations in vitreous of PVR eyes,

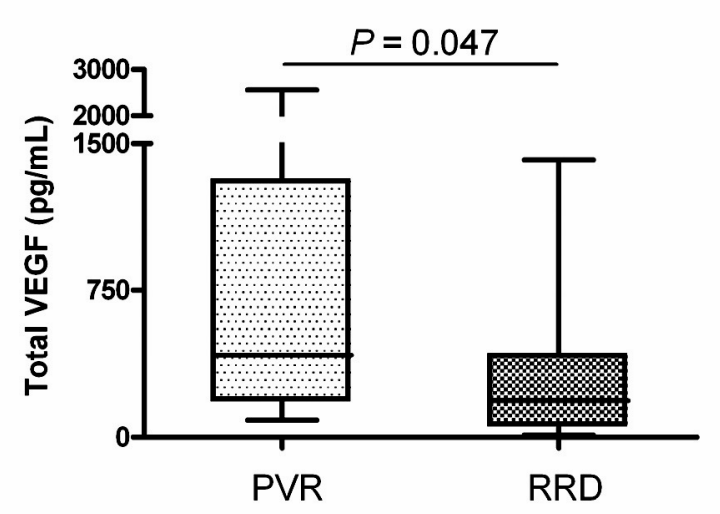

Figure 1 Box-and-whisker plot of total VEGF levels in subretinal fluid of patients with PVR (the PVR group) and patients with uncomplicated RRD (the RRD group). It is shown that total VEGF levels in the PVR group are significantly elevated as compared to the RRD group $(P=0.047)$. Box: lower and upper quartiles; horizontal line: the median. 
similar to the inversion found in the vascularized form of fibrosis, i.e. PDR. ${ }^{23}$ However, our group could not confirm this inversion, since the VEGF-PEDF balance was found to be similar between PVR and controls. ${ }^{24}$

Since specific antibodies were not available, none of these earlier studies have investigated VEGF splice variants, and it was hypothesized that VEGF may have functions other than inducing angiogenesis. ${ }^{16}$ This hypothesis is supported by growing evidence of a possible interaction of VEGF with non-endothelial cells in the eye. It was shown that RPE cells in situ, as well as RPE cells in epiretinal membranes and in culture, express VEGF receptors. In many ERMs, VEGF and its receptors were colocalized, suggesting that an autocrine and/or paracrine mechanism may exist. ${ }^{16}$ Other studies identified VEGF receptors on other non-endothelial cells in the eye such as on adult photoreceptor cells and Müller cells. ${ }^{25}$ The authors concluded that endogenous VEGF is implicated in the maintenance of the adult neural retina by supporting cell survival of these retinal cells. Interestingly, VEGF has also been shown to induce monocyte activation manifested by the induction of tissue factor and monocyte chemotaxis. ${ }^{26}$ The influx of a high number of macrophages in most PVR subjects in the first stage of the disease compared with PVR negative RRD patients underlines their importance in the pathogenesis of PVR, as was shown by Martin et al. ${ }^{27}$ Thus, VEGF probably exerts pleiotropic effects on diverse cell types such as RPE cells and monocytes, which are assumed to play major roles in the development of PVR.

In the current study, we only included patients with relatively mild, preoperative PVR and found total VEGF levels to be significantly elevated in this group of patients as compared to patients without PVR. The only patient with PVR grade C had the highest total VEGF protein of all patients included (data not shown). Therefore, there may be an even larger difference with more advanced PVR cases. Since our study is somewhat limited by small sample size, a study on VEGF isoforms in a larger series of PVR cases should elucidate the robustness of our data. Moreover, the availability of an antibody against the pro-angiogenic VEGF isoforms is needed to verify whether the pro- and anti-angiogenic isoforms add up.

In conclusion, total VEGF levels were significantly higher in subretinal fluid samples of patients with PVR compared to patients with uncomplicated RRD without PVR. Even though several studies have shown an up-regulation of VEGF, its exact role remains unknown. We may have provided an explanation for a lack of blood vessels in PVR membranes by the identification of a predominance of antiangiogenic $V_{E G F} F_{x x} b$ isoforms in RRD and PVR samples. Further investigations are however required to elucidate the high levels of pro-angiogenic VEGF isoforms in some of these patients. 


\section{References}

1. Witmer AN, Vrensen GF, Van Noorden CJ, Schlingemann RO. Vascular endothelial growth factors and angiogenesis in eye disease. Prog Retin Eye Res 2003;22:1-29.

2. Su CY, Chen MT, Wu WS, Wu WC. Concentration of vascular endothelial growth factor in the subretinal fluid of retinal detachment. J Ocul Pharmacol Ther 2000;16:463-9.

3. Ogata N, Nishikawa M, Nishimura T, Mitsuma Y, Matsumura M. Inverse levels of pigment epithelium-derived factor and vascular endothelial growth factor in the vitreous of eyes with rhegmatogenous retinal detachment and proliferative vitreoretinopathy. Am J Ophthalmol 2002;133:851-2.

4. Moromizato $\mathrm{Y}$, Hayashi $\mathrm{H}$, Kato $\mathrm{H}$, Ozaki H, Oshima K. Concentration of vascular endothelial growth factor within the subretinal space and vitreous fluid in rhegmatogenous retinal detachment. J Jpn Ophthalmol Soc 1997;101:498-502.

5. Aiello LP, Avery RL, Arrigg PG, et al. Vascular endothelial growth factor in ocular fluid of patients with diabetic retinopathy and other retinal disorders. N Engl J Med 1994;331:1480-7.

6. Vinores SA, Campochiaro PA, Conway BP. Ultrastructural and electron-immunocytochemical characterization of cells in epiretinal membranes. Invest Ophthalmol Vis Sci 1990;31:14-28.

7. Adamis AP, Shima DT, Yeo KT, et al. Synthesis and secretion of vascular permeability factor/vascular endothelial growth factor by human retinal pigment epithelial cells. Biochem Biophys Res Commun 1993;193:631-8.

8. Hata Y, Nakagawa K, Ishibashi T, Inomata H, Ueno H, Sueishi K. Hypoxia-induced expression of vascular endothelial growth factor by retinal glial cells promotes in vitro angiogenesis. Virchows Arch 1995;426:479-86.

9. Ladomery MR, Harper SJ, Bates DO. Alternative splicing in angiogenesis: the vascular endothelial growth factor paradigm. Cancer Lett 2007;249:133-42.

10. Ferrara N. Vascular endothelial growth factor: basic science and clinical progress. Endocr Rev 2004;25:581-611.

11. Bates DO, Cui TG, Doughty JM, et al. VEGF165b, an inhibitory splice variant of vascular endothelial growth factor, is down-regulated in renal cell carcinoma. Cancer Res 2002;62:4123-31.

12. Woolard J, Wang WY, Bevan HS, et al. VEGF165b, an inhibitory vascular endothelial growth factor splice variant: mechanism of action, in vivo effect on angiogenesis and endogenous protein expression. Cancer Res 2004;64:7822-35.

13. Ricker LJAG, Kijlstra A, de Jager W, et al. Chemokine levels in subretinal fluid obtained during scleral buckling surgery after rhegmatogenous retinal detachment. Invest Ophthalmol Vis Sci 2010;51:4143-50.

14. Machemer R, Aaberg TM, Freeman HM, Irvine AR, Lean JS, Michels RM. An updated classification of retinal detachment with proliferative vitreoretinopathy. Am J Ophthalmol 1991;112:159-65.

15. Varey AH, Rennel ES, Qiu Y, et al. VEGF 165 b, an antiangiogenic VEGF-A isoform, binds and inhibits bevacizumab treatment in experimental colorectal carcinoma: balance of pro- and antiangiogenic VEGF-A isoforms has implications for therapy. Br J Cancer 2008;98:1366-79.

16. Chen YS, Hackett SF, Schoenfeld CL, Vinores MA, Vinores SA, Campochiaro PA. Localisation of vascular endothelial growth factor and its receptors to cells of vascular and avascular epiretinal membranes. Br J Ophthalmol 1997;81:919-26.

17. Rennel E, Waine $E$, Guan $\mathrm{H}$, et al. The endogenous anti-angiogenic VEGF isoform, VEGF165b inhibits human tumour growth in mice. Br J Cancer 2008;98:1250-7.

18. Perrin RM, Konopatskaya O, Qiu Y, Harper S, Bates DO, Churchill AJ. Diabetic retinopathy is associated with a switch in splicing from anti- to pro-angiogenic isoforms of vascular endothelial growth factor. Diabetologia 2005;48:2422-7.

19. Tsanou E, loachim E, Stefaniotou M, et al. Immunohistochemical study of angiogenesis and proliferative activity in epiretinal membranes. Int J Clin Pract 2005;59:1157-61.

20. Dawczynski J, Janz S, Kasper M, et al. Histologische und immunhistologische Untersuchungen humaner epiretinaler Membranen. Klin Monatsbl Augenheilkd 2006;223:687-90. 
21. Asiyo-Vogel MN, El-Hifnawi ES, Bopp S, Laqua $\mathrm{H}$. The vascular component of proliferative vitreoretinopathy membranes: an immunohistochemical and ultrastructural study. Retina 1998;18:56-61.

22. Armstrong D, Augustin AJ, Spengler R, et al. Detection of vascular endothelial growth factor and tumor necrosis factor alpha in epiretinal membranes of proliferative diabetic retinopathy, proliferative vitreoretinopathy and macular pucker. Ophthalmologica 1998;212:410-4.

23. Ogata N, Nishikawa M, Nishimura T, Mitsuma Y, Matsumura M. Unbalanced vitreous levels of pigment epithelium-derived factor and vascular endothelial growth factor in diabetic retinopathy. Am J Ophthalmol 2002;134:348-53.

24. Dieudonne SC, La Heij EC, Diederen RM, et al. Balance of vascular endothelial growth factor and pigment epithelial growth factor prior to development of proliferative vitreoretinopathy. Ophthalmic Res 2007;39:148-54.

25. Saint-Geniez M, Maharaj AS, Walshe TE, et al. Endogenous VEGF is required for visual function: evidence for a survival role on Müller cells and photoreceptors. PLOS ONE 2008;3:e3554.

26. Clauss M, Gerlach M, Gerlach $H$, et al. Vascular permeability factor: a tumor-derived polypeptide that induces endothelial cell and monocyte procoagulant activity, and promotes monocyte migration. J Exp Med 1990;172:1535-45.

27. Martin F, Pastor JC, De La Rua ER, et al. Proliferative vitreoretinopathy: cytologic findings in vitreous samples. Ophthalmic Res 2003;35:232-8. 

Chapter 6

Chemokine Levels in Subretinal Fluid Obtained during Scleral Buckling Surgery after Rhegmatogenous Retinal Detachment 


\section{Abstract}

Purpose: Interleukin (IL)-6, a multifunctional cytokine with regulatory functions in wound healing, and several chemokines have been implicated in the pathogenesis of proliferative vitreoretinopathy (PVR) following rhegmatogenous retinal detachment (RRD). The exact role of these chemokines, their correlation with IL-6 after primary RRD and their association with the future development of PVR are not yet known.

Methods: A multiplex immunoassay was used to determine 15 different chemokines and IL-6 in subretinal fluid samples obtained during scleral buckling surgery for primary RRD. Samples from patients with preoperative uveitis, preoperative trauma, or preoperative vitreous hemorrhage were excluded. Patients who developed a redetachment due to postsurgical PVR within $2 \frac{1}{2}$ months $(n=21)$ were compared with controls who had an uncomplicated retinal detachment during the overall follow-up period $(n=54)$. Controls were matched for gender, age, and storage time.

Results: Levels of IL-6 $(P=0.001)$, MIF $(P=0.016), \operatorname{CCL} 2(P=0.041), \operatorname{CCL} 11(P=$ $0.012), \operatorname{CCL} 17(P=0.003), \operatorname{CCL} 18(P=0.007), \operatorname{CCL} 19(P<0.001), \operatorname{CCL} 22(P<0.001)$, CXCL8 $(P=0.027), \operatorname{CXCL9}(P=0.007)$, and $\operatorname{CXCL10~}(P=0.002)$ were significantly higher in patients who developed postoperative PVR after primary RRD than in patients with uncomplicated retinal detachment. A significant positive correlation was observed between IL- 6 and both CCL22 ( $r=0.538 ; P<0.0001)$ and CXCL8 $(r=$ 0.645; $P<0.0001)$.

Conclusions: Various chemokines and IL- 6 are up-regulated in patients that develop fibrotic membranes following primary RRD-repair and may therefore be involved in the future development of postoperative PVR. 


\section{Introduction}

Failure to reattach the retina after surgical repair of rhegmatogenous retinal detachment (RRD) is mostly due to proliferative vitreoretinopathy (PVR). ${ }^{1}$ This eyesight threatening disease is characterized by the formation of fibrotic membranes that usually ensue within 3 months after reattachment surgery. The biological processes that lead to the development of these contractile membranes show many similarities with the normal wound healing response, in which inflammation plays a pivotal role. $^{2}$

Abundant evidence is available showing that inflammatory cytokines and inflammatory cells may underlie the pathological changes that ultimately lead to the development of PVR. Several immunohistochemical studies have demonstrated the presence of macrophages and lymphocytes in PVR membranes. ${ }^{3-6}$ A possible role of these immune cells in the PVR process is supported by cytological studies showing their presence in vitreous specimens from patients with PVR. ${ }^{7-8}$ Taken together, chemokines must be operative in order to elicit a vast influx of immune cells into the subretinal space after RRD.

Chemokines are small proteins that regulate migration of various types of leukocytes to sites of inflammation. ${ }^{9}$ Based on their chemotactic activity and the arrangement of cysteine residues, chemokines can be divided into two major subfamilies. Generally, CC chemokines potently attract monocytes, T lymphocytes, eosinophils, and basophils, whereas CXC chemokines are known to recruit neutrophils and activated T lymphocytes to the site of injury. ${ }^{10}$ Two of the most extensively studied chemokines in PVR specimens include CCL2 and CXCL8. ${ }^{11-16}$ Both chemokines have been detected in PVR vitreous and levels of these chemokines were shown to be higher than in vitreous specimens from patients with proliferative diabetic retinopathy or idiopathic epiretinal membranes. ${ }^{17}$ In the same study, many other inflammatory mediators were detected including the chemokines CCL4 and CCL11, showing that a complex mix of chemokines may play a role in the pathogenesis of PVR. Interleukin (IL)-6, a multifunctional cytokine with regulatory functions in wound healing, has also been shown to be elevated in PVR specimens ${ }^{16,18-20}$ and has been implicated in the induction of several chemokines. ${ }^{21}$

We hypothesized that chemokines play an important role in the pathogenesis of PVR, in particular in the very early stages when no fibrotic membranes have formed yet. In most studies, a limited number of chemokines were measured per sample and samples were obtained when the patient had already developed PVR. ${ }^{12-16} \mathrm{Re}-$ cently developed multiplex bead-based immunoassays allow for the simultaneous detection of many analytes in a very small sample volume. ${ }^{22}$ Using this technique, we investigated protein expression of 15 different chemokines in subretinal fluid samples obtained while performing routine scleral buckling surgery for primary 
RRD. The results showed that several chemokines as well as IL-6 may play a role in the development of PVR.

\section{Methods}

\section{Subjects}

In our department, subretinal fluid samples are routinely collected during scleral buckling surgery for primary RRD. Based on a medical record study, we made a selection of subretinal fluid samples stored in the BioBank Maastricht. Samples from patients who had preoperative uveitis, preoperative trauma, preoperative vitreous hemorrhage, or preoperative cryotherapy were excluded from this study. After exclusion, we were able to identify 21 samples from patients who developed a redetachment due to PVR within $2 \frac{1}{2}$ months after scleral buckling surgery for primary RRD. This disease group, defined as the PVR positive group, was compared with patients who did not develop a redetachment during the overall follow-up period. Samples from these patients served as controls and were defined as the PVR negative group. To improve statistical power, we selected two to three age-, sex-, and storage time-matched controls without a redetachment during follow-up. This resulted in 54 patients with uncomplicated retinal detachment. All subretinal fluid samples were collected between 2001 and 2008. The study followed the tenets of the Declaration of Helsinki and was performed with the agreement of the University Hospital ethics committee. All patients gave written informed consent before the surgical procedure and after the nature of the study was explained.

\section{Sample Collection}

Undiluted subretinal fluid samples were obtained during scleral buckling surgery for primary RRD by making a small incision through the sclera and choroid. Scleral and choroidal vessels were carefully cauterized before the incision. Any macroscopic blood surrounding the incision opening was removed with a cotton tip. Subretinal fluid was collected from the surface of the sclera with a 25-gauge bent needle. Samples showing macroscopic hemorrhage were discarded. All samples were collected in sterile polypropylene tubes, immediately stored at $-80^{\circ} \mathrm{C}$, and thawed directly before analysis. Sample volumes ranged between $50-250 \mu \mathrm{L}$.

\section{Multiplex Bead-based Immunoassay}

Chemokines were measured by the Luminex Core Facility (Utrecht, The Netherlands) with expertise in the simultaneous measurement of proteins in a wide range 
of biological fluids including aqueous humor, human plasma, and synovial fluid using a multiplex immunoassay (Luminex, Austin, TX). ${ }^{23,24}$ Immunoassays were validated for the detection of proteins using in house developed assays. In summary, the antibody-coated microspheres were incubated for 60 minutes with standards or subretinal fluid $(50 \mu \mathrm{l})$ in $96-w e l l, 1.2-\mu \mathrm{m}$ filter plates (Millipore, Amsterdam, The Netherlands). Plates were washed, and a cocktail of biotinylated detection antibodies was added for 60 minutes. After repeated washings, streptavidinphycoerythrin was added for an additional 10 minutes. Beads were washed twice, and the fluorescence intensity was measured. Measurements and analysis of the data from all assays were performed using the Bio-Plex system in combination with Bio-Plex Manager software, version 4.1, using 5-parametric curve fitting (Bio-Rad,

Table 1 Demographics and Potential Clinical Risk Factors for PVR

\begin{tabular}{|c|c|c|c|}
\hline Risk factor & $\begin{array}{l}\text { Postoperative PVR } \\
\text { Negative }(n=54)\end{array}$ & $\begin{array}{l}\text { Postoperative PVR } \\
\text { Positive }(n=21)\end{array}$ & $\begin{array}{l}\text { Univariate } \\
\text { Testing }\end{array}$ \\
\hline \multicolumn{4}{|l|}{ Age (years) } \\
\hline Median (range) & $61(43-79)$ & $62(43-76)$ & NS \\
\hline \multicolumn{4}{|l|}{ Sex (\%) } \\
\hline Female & 26 & 29 & NS \\
\hline Male & 74 & 71 & \\
\hline \multicolumn{4}{|l|}{$\begin{array}{l}\text { Size of retinal detachment } \\
\text { (quadrants) }\end{array}$} \\
\hline Median (range) & $2(1-3)$ & $2(1-4)$ & NS \\
\hline \multicolumn{4}{|l|}{$\begin{array}{l}\text { Total size of retinal defects } \\
\text { (optic disc diameters) }\end{array}$} \\
\hline Median (range) & $2(0-5.5)$ & $1(0-4)$ & NS \\
\hline Macular detachment (\%) & 64 & 86 & NS \\
\hline \multicolumn{4}{|l|}{ Preoperative logMAR VA } \\
\hline Median (range) & $0.75(0.05-2.52)$ & $1.77(0.10-2.52)$ & $P=0.045$ \\
\hline \multicolumn{4}{|l|}{ Detachment duration (days) } \\
\hline Median (range) & $5(1-75)$ & $6(1-90)$ & NS \\
\hline Diabetes mellitus (\%) & 11 & 10 & NS \\
\hline Preoperative myopia >5D (\%) & 17 & 24 & NS \\
\hline \multicolumn{4}{|l|}{ Preoperative lens status (\%) } \\
\hline Pseudophakia & 19 & 33 & NS \\
\hline Aphakia & 0 & 0 & NS \\
\hline Preoperative uveitis (\%) & 0 & 0 & NS \\
\hline \multicolumn{4}{|l|}{ Preoperative vitreous } \\
\hline hemorrhage (\%) & 0 & 0 & NS \\
\hline Preoperative cryotherapy (\%) & 0 & 0 & NS \\
\hline Preoperative trauma (\%) & 0 & 0 & NS \\
\hline
\end{tabular}

PVR, proliferative vitreoretinopathty; NS, not significant; logMAR, logarithm of minimal angle of resolution; VA, visual acuity; D, diopters. 
Table 2 IL-6 and Chemokine Levels and the Development of Postoperative PVR

\begin{tabular}{|c|c|c|c|}
\hline Analyte (pg/mL) & $\begin{array}{l}\text { Postoperative PVR } \\
\text { Negative }(n=54)\end{array}$ & $\begin{array}{c}\text { Postoperative PVR } \\
\text { Positive }(n=21)\end{array}$ & $\begin{array}{c}\text { Univariate } \\
\text { Testing }\end{array}$ \\
\hline \multicolumn{4}{|l|}{ IL-6 } \\
\hline Median (range) & $59.5(8.33-1211)$ & $149(36.3-2656)$ & $P=0.001$ \\
\hline Mean (SD) & $139(202)$ & $483(712)$ & \\
\hline \multicolumn{4}{|l|}{ MIF } \\
\hline Median (range) & $3618(997-15020)$ & $6691(1691-12900)$ & $P=0.016$ \\
\hline Mean (SD) & $4484(2880)$ & $6682(3638)$ & \\
\hline \multicolumn{4}{|l|}{ CCL2 } \\
\hline Median (range) & 849 (442 - 1139) & $930(629-1134)$ & $P=0.041$ \\
\hline Mean (SD) & $822(153)$ & $900(132)$ & \\
\hline \multicolumn{4}{|l|}{ CCL3 } \\
\hline Median (range) & $359(237-491)$ & $391(268-662)$ & NS \\
\hline Mean (SD) & $362(53.6)$ & $398(89.3)$ & \\
\hline \multicolumn{4}{|l|}{ CCL5 } \\
\hline Median (range) & $151(49.0-630)$ & $186(50.4-619)$ & NS \\
\hline Mean (SD) & $179(96.3)$ & $205(151)$ & \\
\hline \multicolumn{4}{|l|}{ CCL11 } \\
\hline Median (range) & $8.58(5.32-12.0)$ & $9.18(6.90-15.0)$ & $P=0.012$ \\
\hline Mean (SD) & $8.49(1.45)$ & $10.0(2.16)$ & \\
\hline \multicolumn{4}{|l|}{ CCL17 } \\
\hline Median (range) & $2.04(1.41-4.31)$ & $2.59(1.76-5.84)$ & $P=0.003$ \\
\hline Mean (SD) & $2.16(0.48)$ & $2.97(1.24)$ & \\
\hline \multicolumn{4}{|l|}{ CCL18 } \\
\hline Median (range) & $4305(184-14344)$ & $6897(434-14967)$ & $P=0.007$ \\
\hline Mean (SD) & 4791 (3091) & $7049(3480)$ & \\
\hline \multicolumn{4}{|l|}{ CCL19 } \\
\hline Median (range) & $115(21.4-705)$ & $309(76.8-570)$ & $P<0.001$ \\
\hline Mean (SD) & $144(117)$ & $290(160)$ & \\
\hline \multicolumn{4}{|l|}{ CCL21 } \\
\hline Median (range) & $752(454-2453)$ & $777(614-2221)$ & NS \\
\hline Mean (SD) & $822(286)$ & $917(371)$ & \\
\hline \multicolumn{4}{|l|}{ CCL22 } \\
\hline Median (range) & $18.2(11.7-44.1)$ & $31.9(10.9-92.5)$ & $P<0.001$ \\
\hline Mean (SD) & $20.4(6.75)$ & $34.3(18.5)$ & \\
\hline \multicolumn{4}{|l|}{ CXCL8 } \\
\hline Median (range) & $83.5(28.4-728)$ & $131(42.4-1324)$ & $P=0.027$ \\
\hline Mean (SD) & $155(166)$ & $259(296)$ & \\
\hline \multicolumn{4}{|l|}{ CXCL9 } \\
\hline Median (range) & $15.1(8.47-91.1)$ & $17.3(12.3-55.0)$ & $P=0.007$ \\
\hline Mean (SD) & $17.0(11.1)$ & $22.2(11.0)$ & \\
\hline \multicolumn{4}{|l|}{ CXCL10 } \\
\hline Median (range) & $206(42.6-875)$ & $377(128-1002)$ & $P=0.002$ \\
\hline Mean (SD) & $239(166)$ & $425(275)$ & \\
\hline \multicolumn{4}{|l|}{ CXCL12 } \\
\hline Median (range) & $12254(5773-16759)$ & $10991(7005-17286)$ & NS \\
\hline Mean (SD) & $11610(2775)$ & $11376(2897)$ & \\
\hline \multicolumn{4}{|l|}{ CX3CL1 } \\
\hline Median (range) & $229(140-318)$ & $228(147-465)$ & NS \\
\hline Mean (SD) & $231(35.2)$ & $231(63.4)$ & \\
\hline
\end{tabular}

PVR, proliferative vitreoretinopathy; IL-6, interleukin-6; MIF, macrophage migration inhibitory factor. 
Hercules, CA). The concentrations of IL- 6 and the following chemokines were measured: the chemokine-like macrophage migration inhibitory factor (MIF); the CC chemokines CCL2, CCL3, CCL5, CCL11, CCL17, CCL18, CCL19, CCL21, CCL22; the CXC chemokines CXCL8, CXCL9, CXCL10, CXCL12; and $\mathrm{CX}_{3} \mathrm{CL} 1$. The above set represented all chemokines present in the chemokine package of the Luminex Core Facility.

\section{Clinical Variables}

For all patients we collected demographic variables, potential clinical risk factors for the development of PVR (Table 1) and the following clinical variables: follow-up time, occurrence of a redetachment, postoperative PVR grade, and preoperative and final postoperative best corrected Snellen visual acuity. PVR was graded according to the Classification of Retinal Detachment with PVR. ${ }^{25}$ Data were collected as 0 (no PVR), 1 (grade A), 2 (grade B), 3 (grade C), and 4 (grade D). Duration of retinal detachment was defined as the interval between the onset of symptoms and surgery and was estimated according to a precise history of patients' symptoms. For statistical analysis, Snellen visual acuity was transformed into logMAR (logarithm of minimal angle of resolution) visual acuity. Net visual outcome was calculated by subtracting logMAR visual acuity at final follow-up from logMAR visual acuity preoperatively.

\section{Statistical Analysis}

Patients who developed a redetachment due to PVR within $2 \frac{1}{2}$ months after reattachment surgery were compared with patients with an uncomplicated follow-up. Further, we investigated whether chemokine levels were different in patients who developed early postoperative PVR (within one month) and whether differences in chemokine expression were related to PVR grade. The non-parametric MannWhitney $U$-test was used for ordinal variables such as chemokine levels, since data were not normally distributed. The chi-square test was used to compare nominal variables such as diabetes mellitus. Correlations were determined by the Spearman's Rho test. Statistical analysis of the data was performed using SPSS version 16.0 (SPSS for Windows; SPSS, Chicago, IL, USA). Differences were considered significant at $P<0.05$, with two-tailed testing.

\section{Results}

Subretinal fluids from 75 patients with primary RRD undergoing scleral buckling surgery for primary RRD were analyzed for chemokine content. Twenty one patients 
Table 3 The Spearman Correlation Coefficients for Significantly

Up-regulated Chemokines

\begin{tabular}{ll}
\hline Chemokine & $\begin{array}{l}\text { Correlation } \\
\text { coefficient }\end{array}$ \\
\hline MIF - CCL2 & $r=0.596$ \\
CCL11 - CCL17 & $r=0.693$ \\
CCL11 - CCL22 & $r=0.513$ \\
CCL17 - CCL22 & $r=0.668$ \\
CCL17 - CXCL9 & $r=0.515$ \\
CCL18 - CCL19 & $r=0.594$ \\
CCL18 - CXCL9 & $r=0.502$ \\
CCL18 - CXCL10 & $r=0.592$ \\
CCL19 - CXCL10 & $r=0.628$ \\
\hline
\end{tabular}

All correlations listed are significant at the $P<0.001$ level.

who developed postoperative PVR were compared with 54 patients who had an uncomplicated follow-up. In the PVR positive group, 10 patients were classified with PVR grade $B, 10$ with PVR grade $C$, and one with PVR grade $D$. The median time interval between the scleral buckling procedure and redetachment due to PVR was 37 days (range, 7-80) and the median follow-up time was 21 months (range, 3-80). The group consisted of 6 women (29\%) and 15 men (71\%) with a median age of 62 years (range, 43-76). The PVR negative patients included 14 women (26\%) and 40 men (74\%) with a median age of 61 years (range, 43-79). Their median follow-up time was 6 months (range, 2-80). Potential clinical risk factors for the development of postoperative PVR were available for all 75 patients included in this study. Except for a worse preoperative visual acuity in the PVR positive group $(P=0.045)$, there were no statistically significant differences between the two groups (Table 1).

Median and mean subretinal fluid IL-6 levels were approximately three times higher in patients with a redetachment due to postoperative PVR compared with those with an uncomplicated follow-up $(P=0.001)$. Simultaneous measurement of 15 different chemokines in every single sample using a multiplex bead-based immunoassay revealed the following results (Table 2). Using univariate testing, subretinal fluid levels of MIF $(P=0.016), \operatorname{CCL} 2(P=0.041), \operatorname{CCL} 11(P=0.012), \operatorname{CCL} 17(P=0.003)$, $\operatorname{CCL18}(P=0.007), \operatorname{CCL19}(P<0.001), \operatorname{CCL} 22(P<0.001), \operatorname{CXCL8}(P=0.027), \operatorname{CXCL9}(P$ $=0.007)$, and CXCL10 $(P=0.002)$ were significantly higher in the PVR positive group as compared to the PVR negative group. Median levels of CCL3, CCL5, and CCL21 were higher in the PVR positive group but did not reach statistical significance $(P>$ 0.05).

There was a low to moderate positive correlation between IL-6 and CCL2 ( $r=$ 0.232), CCL11 ( $r=0.326)$, CCL17 $(r=0.428)$, CCL18 $(r=0.460)$, CCL19 $(r=0.340)$, CXCL9 $(r=0.267)$, and CXCL10 ( $r=0.322)(P<0.05$ for all), whereas the correlation between IL- 6 and both CCL22 and CXCL8 was moderate to strong $(r=0.538$ and $r=$ 0.645 , respectively) $(P<0.0001$ for both; Fig 1$)$. When comparing the various chemo 

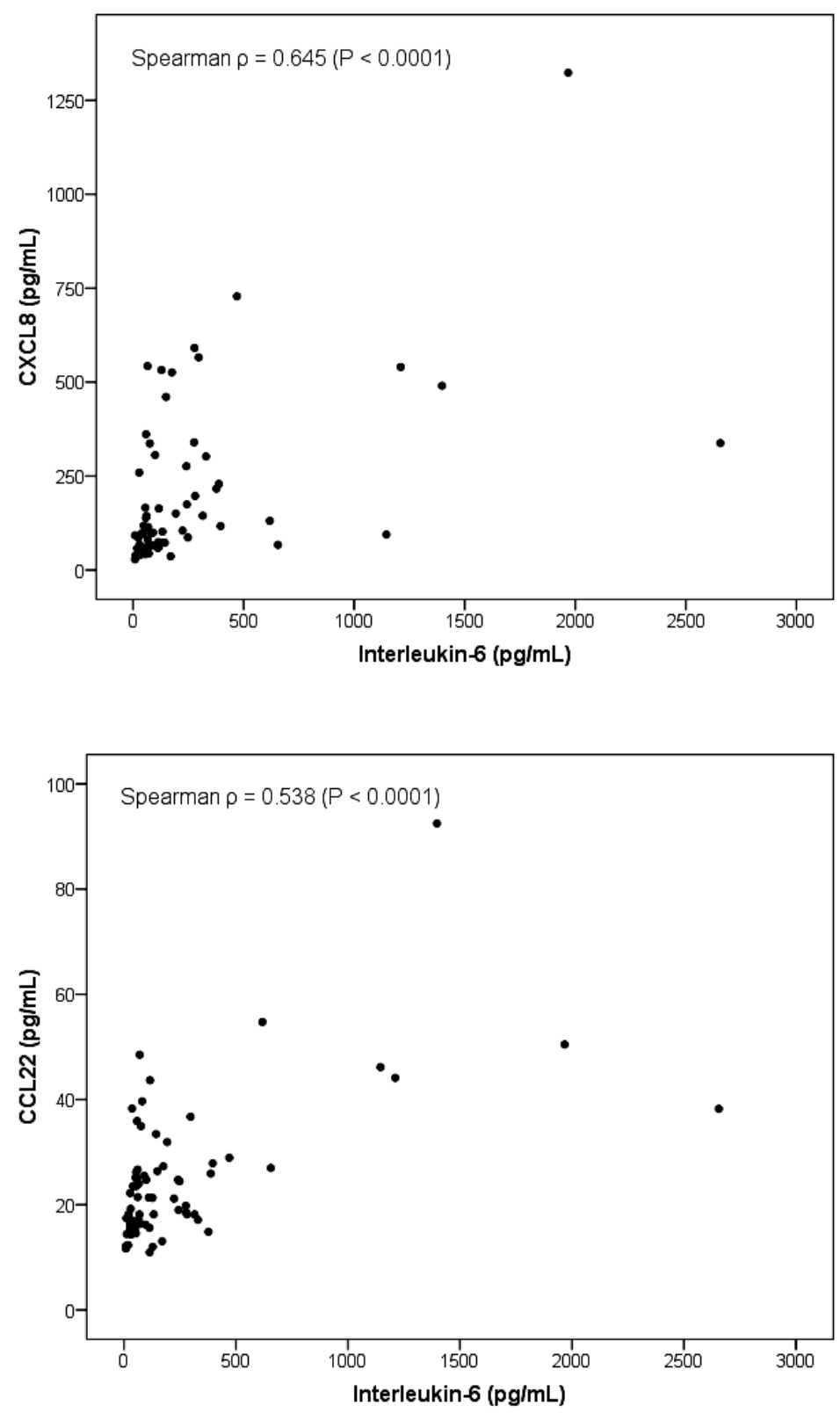

Figure 1 Correlation of IL- 6 with chemokine levels in subretinal fluid after primary rhegmatogenous retinal detachment. (Top) Correlation of IL-6 with CXCL8; (Bottom) Correlation of IL-6 with CCL22. 
kines that were significantly up-regulated after univariate testing, we found several moderate to strong correlations $(r>0.5 ; P<0.001)$ (Table 3$)$. Significant correlations between biochemical variables and clinical variables were low $(r<0.4)$. For example, we found a negative correlation between the total size of retinal defects and levels of IL-6 ( $r=-0.289)$, CCL11 ( $r=-0.296)$, CCL18 $(r=-0.384)$, CXCL9 $(r=-0.369)$, and CXCL10 $(r=-0.253)(P<0.05$ for all).

Preoperative visual acuity correlated moderately but significantly with final and net visual acuity ( $r=0.428$ and $r=0.633$, respectively) $(P<0.001$ for both). As expected, the postoperative and net visual acuities of the PVR positive group were significantly worse than those of the PVR negative group at final follow-up $(P<$ 0.001 and $P=0.003$, respectively). Correlations between clinical variables and final and net visual acuities were very low $(r<0.3)$. However, we found moderate correlations between final visual acuity and both CCL19 $(r=0.418 ; P<0.001)$ and CXCL10 ( $r=0.475 ; P<0.001)$.

Eight patients developed a redetachment due to PVR within one month after reattachment surgery. We compared chemokine levels of these patients with those who had a redetachment due to postoperative PVR between 1 and $2 \frac{1}{2}$ months after ocular surgery $(n=13)$. Except for a lower median level of CXCL10 in the latter group $(P=0.036)$, we were not able to find any significant differences between both groups. To find out whether there were differences in chemokine expression between patients with different PVR grades, we compared chemokine levels of 10 patients with PVR grade $B$ with 11 patients with PVR grade $\mathrm{C}$ or higher. IL-6 $(P=$ $0.024)$ and CCL3 $(P=0.017)$ were significantly lower in patients with higher PVR grades, whereas no significant differences were detected between both groups concerning the other analytes.

\section{Discussion}

The present study shows that levels of MIF, CCL2, CCL11, CCL17, CCL18, CCL19, CCL22, CXCL8, CXCL9, and CXCL10 were significantly higher in patients with a redetachment due to postoperative PVR than in patients with an uncomplicated retinal detachment. IL-6, with a threefold increase in the PVR positive group, was positively correlated with several chemokines. Demographic variables and potential clinical risk factors for the development of PVR, except for preoperative visual acuity, were not significantly different between the two groups. Moreover, patients with preoperative uveitis and patients with conditions that may induce an inflammatory response such as preoperative trauma and vitreous hemorrhage, were excluded from this study. Therefore, our findings indicate that there is an association between a wide range of chemokines that are elevated briefly after the onset of RRD and the future development of postsurgical PVR. 
Previous studies that have investigated chemokine content in PVR specimens have focused particularly on a few chemokines using enzyme-linked immunosorbent assays (ELISAs). Two of the most extensively studied chemokines are CCL2 and CXCL8. Several investigations have shown an up-regulation of these chemokines in PVR patients. ${ }^{11-16}$ We confirmed the findings of these earlier studies in our subretinal fluid samples, although we were only able to show a slight but significant increase in CCL2 levels briefly after the onset of RRD. For example, Elner et al. ${ }^{13}$ demonstrated a six-fold increase in CCL2 levels in PVR vitreous compared to samples from patients with uncomplicated RRD. These results implicate a more profound role for CCL2 in later stages after RRD and when PVR membranes have already developed.

Our study, however, differed from previous reports on some crucial points. Most studies have dealt with vitreous samples, whereas we studied chemokine content in subretinal fluid. This may be more appropriate since this is the ocular fluid that surrounds the resident retinal cells after initial retinal detachment. Another important difference with earlier studies is the time point at which the ocular samples were obtained. Sampling at a time close to the onset of the primary RRD may provide clues to the local triggers initiating the PVR process. ${ }^{26}$ Our patient population served this purpose, since the median overall delay between reported onset of RRD and surgery was only 5 to 6 days. Moreover, the multiplex bead-based immunoassay allowed us to detect a large number of chemokines simultaneously, with comparable performance in sensitivity, accuracy, and reproducibility to ELISAs performed in previous studies. ${ }^{27}$ Consequently, detection of a whole spectrum of chemokines briefly after the onset of RRD may provide new insight into the pathological mechanisms leading to the formation of PVR membranes and may thus be important for future prophylaxis or treatment purposes. Differences between our study and previous studies, chemokine function, and chemokine levels are summarized in Table 4. Prior to the study presented here 13 different chemokines had been analysed in ocular fluids in relation to PVR development. Our data set expanded the number to a total of 21 and it is evident that several novel chemokines will be discovered in the near future. The precise role of each of these individual chemokines after the onset of RRD remains to be elucidated. It has been postulated that many CC and CXC chemokines share a common function and tend to act on a broad range of leukocytes including monocytes, lymphocytes, and neutrophils (Table 4). ${ }^{10}$ This concept is further supported by redundancy and binding promiscuity between many chemokine ligands and receptors. ${ }^{28}$

For some chemokines, however, a specific role in the development of PVR has been suggested. CCL2 is mainly known for its induction of monocyte chemotaxis in areas of injury. ${ }^{29}$ It was shown that CCL2 is critical for the infiltration of macrophages/microglia to the subretinal space after retinal detachment. ${ }^{30}$ Although a wide variety of cells can express CCL2, local production by resident ocular cells inclu- 


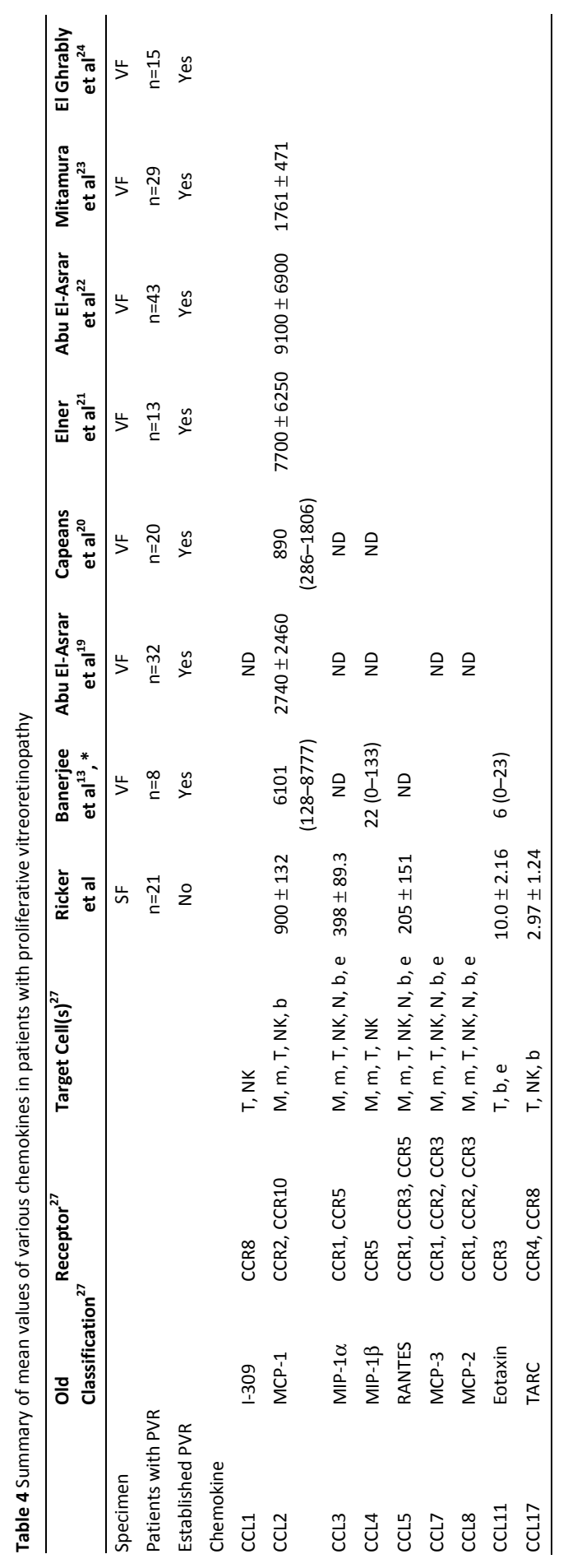




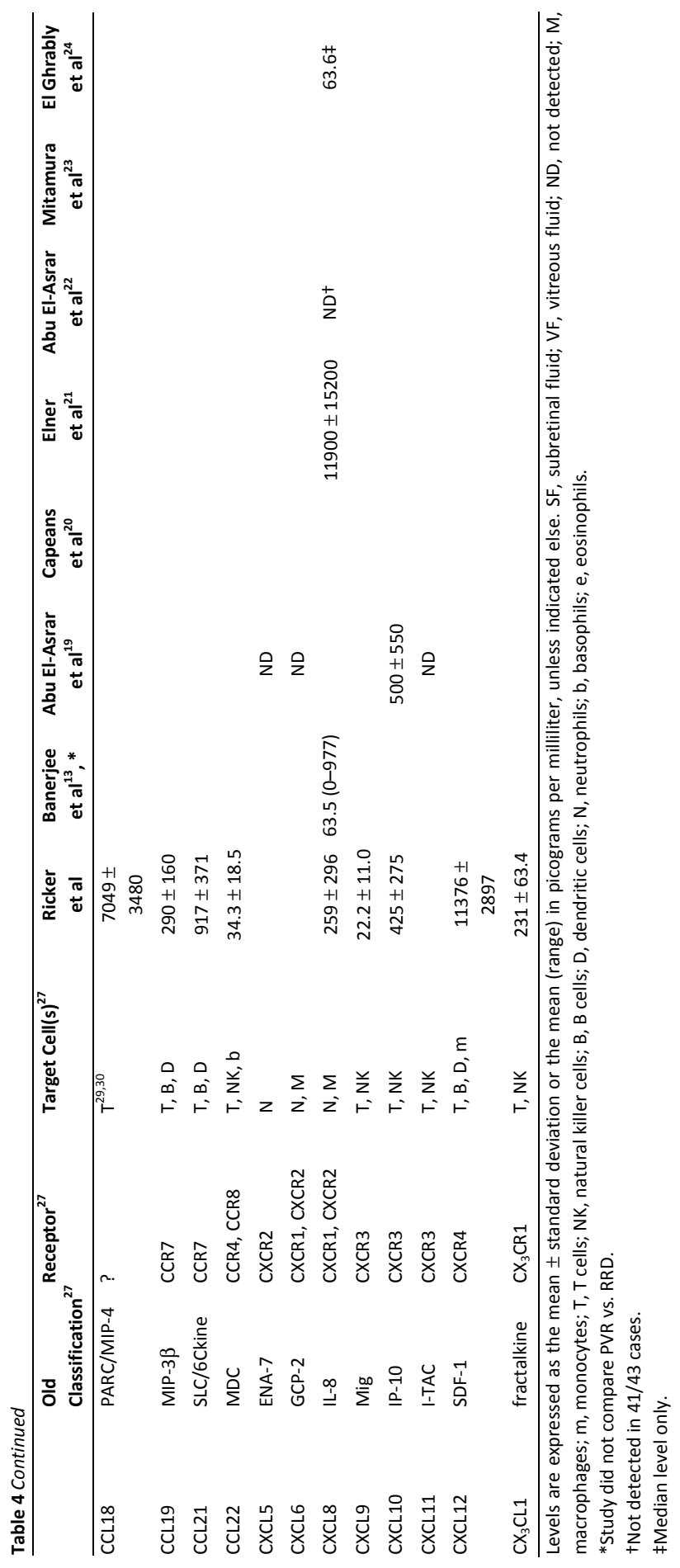


ding retinal pigment epithelial (RPE) cells has been suggested. For example, in vitro studies have shown that IL-1 or TNF- $\alpha$ stimulated RPE cells may express CCL2. ${ }^{31,32}$ Moreover, CCL2 has been shown to stimulate RPE cell migration, ${ }^{33}$ suggesting a role for this chemokine in PVR development. Further, monocytes/macrophages have been shown to have a potentiating effect on RPE cell proliferation. ${ }^{34}$ Similarly, CXCL8 may be secreted by many different cell types in response to inflammatory stimuli. ${ }^{35}$ CXCL8 exerts many functions depending on cell type and tissue. Nevertheless, its main function is the recruitment of neutrophils to inflammatory sites in response to injury. ${ }^{35}$ Goczalik et al. ${ }^{36}$ showed that microglial cells may contribute to increased intraocular levels of CXCL8 in retinal detachment and PVR, and CXCL8 receptor expression in glial cells of PVR retinas and PVR membranes suggested a role for CXCL8 in the initiation of reactive gliosis.

Some chemokines can exhibit high cell and receptor specificity. Interestingly, CXCL9 and CXCL10 are highly specific for T lymphocytes. ${ }^{37}$ CXCR3, the receptor for CXCL9 and CXCL10, is preferentially expressed on T lymphocytes, which are responsible for a number of $\mathrm{T}$ lymphocyte-mediated diseases including autoimmune uveitis and vernal keratoconjunctivitis. ${ }^{38-40}$ Moreover, cytokine-stimulated RPE cells are capable of producing CXCL9 and CXCL10, whereas pre-treatment of RPE cells with the anti-inflammatory cytokine IFN- $\beta$ resulted in the elimination of CXCL9 production. ${ }^{41}$ The CC chemokines CCL17, CCL18, and CCL22 have also been shown to play a role in trafficking and activation of T lymphocytes. ${ }^{42-45}$ Together with the presence of T lymphocytes in subretinal fluid, vitreous fluid, ${ }^{7}$ and epiretinal membranes ${ }^{4,6}$ from patients with PVR, these findings warrant further investigations concerning a role for T lymphocytes in the pathogenesis of PVR.

IL- 6 is a cytokine with a wide range of functions in inflammation and wound healing. For instance, IL-6 was found to induce chemokines and to recruit leukocytes in an animal model. ${ }^{21}$ On the other hand, IL- 6 may be produced by inflammatory cells invading the subretinal space after RRD due to chemotactic signalling. ${ }^{46}$ Previous studies have detected increased levels of IL- 6 in RRD patients ${ }^{47,48}$ and PVR patients, ${ }^{16,18-20}$ whereas others have demonstrated a correlation between IL-6 and several chemokines. ${ }^{14,47}$ Our study confirmed the findings of these previous studies. Whether IL- 6 plays a role in the induction of chemokines or is secreted by cells invading the subretinal space after RRD remains to be elucidated.

So far, it is not clear which cells are responsible for the secretion of chemokines into the subretinal space after retinal detachment. Previous studies have demonstrated that increased chemokine levels are most likely due to the intraocular production by resident ocular cells. ${ }^{13,15}$ The RPE cell is believed to be an important candidate cell type, since RPE cells are able to produce many chemokines after an appropriate stimulus. Contact with vitreous ${ }^{49}$ or monocytes, ${ }^{50}$ stimulation by proinflammatory cytokines, ${ }^{51}$ and mechanical injury ${ }^{52}$ have all been shown to be an appropriate trigger for the production and secretion of chemokines by RPE cells. 
Other resident cell types or inflammatory cells may however also contribute to the subretinal fluid content of chemokines following retinal detachment. Correlations between some chemokines in our study may indicate that a common pathway is involved.

To conclude, our findings indicate that a number of chemokines are upregulated briefly after the onset of RRD in patients who develop postoperative PVR following primary RRD-repair. Increased chemotactic signalling in these patients may be the underlying phenomenon leading to a vast and immediate influx of inflammatory cells after the onset of RRD and may cause an inflammatory response that is associated with the future development of PVR. Moreover, the results identify some specific chemokines as potential therapeutic targets for patients who are at risk for developing a redetachment due to PVR.

\section{Acknowledgments}

The authors are grateful to the Algemene Nederlandse Vereniging ter Voorkoming van Blindheid for financial support.

\section{References}

1. Charteris DG. Proliferative vitreoretinopathy: pathobiology, surgical management, and adjunctive treatment. Br J Ophthalmol 1995;79:953-960.

2. Pastor JC, de la Rúa ER, Martín F. Proliferative vitreoretinopathy: risk factors and pathobiology. Prog Retin Eye Res 2002;21:127-144.

3. Weller M, Heimann K, Wiedemann P. Demonstration of mononuclear phagocytes in a human epiretinal membrane using a monoclonal anti-human macrophage antibody. Graefes Arch Clin Exp Ophthalmol 1988;226:252-254.

4. Charteris DG, Hiscott P, Robey HL, Gregor ZJ, Lightman SL, Grierson I. Inflammatory cells in proliferative vitreoretinopathy subretinal membranes. Ophthalmology 1993;100:43-6.

5. Esser $\mathrm{P}$, Heimann $\mathrm{K}$, Wiedemann $\mathrm{P}$. Macrophages in proliferative vitreoretinopathy and proliferative diabetic retinopathy: differentiation of subpopulations. Br J Ophthalmol 1993;77:731-733.

6. Proença R, Carvalho M, Proença D, Verissimo J, Regadas I, Travassos A. HLA antigens and lymphocytes in proliferative vitreoretinopathy. Graefes Arch Clin Exp Ophthalmol 1994;232:25-32.

7. Baudouin C, Hofman P, Brignole F, Bayle J, Loubière R, Gastaud P. Immunocytology of cellular components in vitreous and subretinal fluid from patients with proliferative vitreoretinopathy. Ophthalmologica 1991;203:38-46.

8. Canataroglu H, Varinli I, Ozcan AA, Canataroglu A, Doran F, Varinli S. Interleukin (IL)-6, interleukin (IL)-8 levels and cellular composition of the vitreous humor in proliferative diabetic retinopathy, proliferative vitreoretinopathy, and traumatic proliferative vitreoretinopathy. Ocul Immunol Inflamm 2005;13:375-381.

9. Struyf $S$, Proost $P$, Van Damme J. Regulation of the immune response by the interaction of chemokines and proteases. Adv Immunol 2003;81:1-44.

10. Wallace GR, Curnow SJ, Wloka K, Salmon M, Murray PI. The role of chemokines and their receptors in ocular disease. Prog Retin Eye Res 2004;23;435-448. 
11. Abu El-Asrar AM, Struyf S, Kangave D, Geboes K, Van Damme J. Chemokines in proliferative diabetic retinopathy and proliferative vitreoretinopathy. Eur Cytokine Netw 2006;17:155-165.

12. Capeans C, De Rojas MV, Lojo S, Salorio MS. C-C chemokines in the vitreous of patients with proliferative vitreoretinopathy and proliferative diabetic retinopathy. Retina 1998;18:546-550.

13. Elner SG, Elner VM, Jaffe GJ, Stuart A, Kunkel SL, Strieter RM. Cytokines in proliferative diabetic retinopathy and proliferative vitreoretinopathy. Curr Eye Res 1995;14:1045-1053.

14. Abu El-Asrar AM, Van Damme J, Put W, et al. Monocyte chemotactic protein-1 in proliferative vitreoretinal disorders. Am J Ophthalmol 1997;123:599-606.

15. Mitamura Y, Takeuchi S, Yamamoto S, et al. Monocyte chemotactic protein-1 levels in the vitreous of patients with proliferative vitreoretinopathy. Jpn J Ophthalmol 2002;46:218-221.

16. El-Ghrably IA, Dua HS, Orr GM, Fischer D, Tighe PJ. Intravitreal invading cells contribute to vitreal cytokine milieu in proliferative vitreoretinopathy. Br J Ophthalmol 2001;85:461-470.

17. Banerjee S, Savant V, Scott RAH, Curnow SJ, Wallace GR, Murray PI. Multiplex bead analysis of vitreous humor of patients with vitreoretinal disorders. Invest Ophthalmol Vis Sci 2007;48:22032207.

18. Kauffmann DJH, Van Meurs JC, Mertens DAE, Peperkamp E, Master C, Gerritsen ME. Cytokines in vitreous humor: interleukin-6 is elevated in proliferative vitreoretinopathy. Invest Ophthalmol Vis Sci 1994;35:900-906.

19. La Heij EC, Van de Waarenburg MP, Blaauwgeers HG, et al. Basic fibroblast growth factor, glutamine synthetase, and interleukin- 6 in vitreous fluid from eyes with retinal detachment complicated by proliferative vitreoretinopathy. Am J Ophthalmol 2002;134:367-375.

20. Kon CH, Occleston NL, Aylward GW, Khaw PT. Expression of vitreous cytokines in proliferative vitreoretinopathy: a prospective study. Invest Ophthalmol Vis Sci 1999;40:705-712.

21. Romano M, Sironi M, Toniatti C, et al. Role of IL-6 and its soluble receptor in induction of chemokines and leukocyte recruitment. Immunity 1997;6:315-325.

22. Vignali DA. Multiplexed particle-based flow cytometric assays. J Immunol Methods 2000;243:243255.

23. De Jager W, Prakken BJ, Bijlsma JW, Kuis W, Rijkers GT. Improved multiplex immunoassay performance in human plasma and synovial fluid following removal of interfering heterophilic antibodies. J Immunol Methods 2005;300:124-135.

24. Sijssens KM, Rijkers GT, Rothova A, Stilma JS, Schellekens PA, De Boer JH, et al. Cytokines, chemokines and soluble adhesion molecules in aqueous humor of children with uveitis. Exp Eye Res 2007;85:443-449.

25. Retina Society Terminology Committee. The classification of retinal detachment with proliferative vitreoretinopathy. Am J Ophthalmol 1983;90:121-125.

26. Dieudonné SC, La Heij EC, Diederen R, et al. High TGF- $\beta 2$ levels during primary retinal detachment may protect against proliferative vitreoretinopathy. Invest Ophthalmol Vis Sci 2004;45:4113-4118.

27. De Jager W, Te Velthuis H, Prakken BJ, Kuis W, Rijkers GT. Simultaneous detection of 15 human cytokines in a single sample of stimulated peripheral blood mononuclear cells. Clin Diagn Lab Immunol 2003;10:133-139.

28. Zlotnik A, Yoshie O. Chemokines: a new classification system and their role in immunity. Immunity 2000;12:121-127.

29. Haelens A, Wuyts A, Proost P, et al. Leukocyte migration and activation by murine chemokines. Immunobiology 1996;195:499-521.

30. Nakazawa T, Hisatomi T, Nakazawa C, et al. Monocyte chemoattractant protein 1 mediates retinal detachment-induced photoreceptor apoptosis. Proc Natl Acad Sci USA 2007;104:2425-2430.

31. Elner SG, Strieter RM, Elner VM, et al. Monocyte chemotactic protein gene expression by cytokinetreated human retinal pigment epithelial cells. Lab Invest 1991;64:819-825.

32. Elner SG, Elner VM, Bian ZM, et al. Human retinal pigment epithelial cell interleukin-8 and monocyte chemotactic protein-1 modulation by T-lymphocyte products. Invest Ophthalmol Vis Sci 1997;38:446-455. 
33. Han QH, Hui YN, Du HJ, Zhang WJ, Ma JX, Wang SY. Migration of retinal pigment epithelial cells in vitro modulated by monocyte chemotactic protein-1: enhancement and inhibition. Graefes Arch Clin Exp Ophthalmol 2001;239:531-538.

34. Osusky R, Ryan SJ. Retinal pigment epithelial cell proliferation: potentiation by monocytes and serum. Graefes Arch Clin Exp Ophthalmol 1996;234 Suppl 1:S76-82.

35. Baggiolini $\mathrm{M}$, Clark-Lewis I. Interleukin-8, a chemotactic and inflammatory cytokine. FEBS Lett 1992;307:97-101.

36. Goczalik I, Ulbricht E, Hollborn M, et al. Expression of CXCL8, CXCR1, and CXCR2 in neurons and glial cells of the human and rabbit retina. Invest Ophthalmol Vis Sci 2008;49:4578-4589.

37. Farber JM. Mig and IP-10: CXC chemokines that target lymphocytes. J Leukoc Biol 1997;61:246-257.

38. Chen J, Vistica BP, Takase H, et al. A unique pattern of up- and down-regulation of chemokine receptor CXCR3 on inflammation-inducing Th1 cells. Eur J Immunol 2004;34:2885-2894.

39. Ohta K, Yamagami S, Wiggert B, Dana MR, Streilein JW. Chemokine gene expression in iris-ciliary body during experimental autoimmune uveoretinitis. Curr Eye Res 2002;24:451-457.

40. Abu El-Asrar AM, Struyf S, Al-Kharashi SA, Missotten L, Van Damme J, Geboes K. The T-lymphocyte chemoattractant Mig is highly expressed in vernal keratoconjunctivitis. Am J Ophthalmol 2003;136:853-860.

41. Hooks JJ, Nagineni CN, Hooper LC, Hayashi K, Detrick B. IFN- $\beta$ provides immuno-protection in the retina by inhibiting ICAM-1 and CXCL9 in retinal pigment epithelial cells. J Immunol 2008;180:37893796.

42. lellem A, Mariani M, Lang $R$, et al. Unique chemotactic response profile and specific expression of chemokine receptors CCR4 and CCR8 by CD4(+)CD25(+) regulatory T cells. J Exp Med 2001;194:847853.

43. Kang S, Xie J, Ma S, Liao W, Zhang J, Luo R. Targeted knock down of CCL22 and CCL17 by siRNA during DC differentiation and maturation affects the recruitment of $\mathrm{T}$ subsets. Immunobiology 2010;215:153-162.

44. Hieshima K, Imai T, Baba M, et al. A novel human CC chemokine PARC that is most homologous to macrophage-inflammatory protein-1 $\alpha /$ LD78 $\alpha$ and chemotactic for T lymphocytes, but not for monocytes. J Immunol 1997;159:1140-1149.

45. Luzina IG, Papadimitriou JC, Anderson R, Pochetuhen K, Atamas SP. Induction of prolonged infiltration of $\mathrm{T}$ lymphocytes and transient $\mathrm{T}$ lymphocyte-dependent collagen deposition in mouse lungs following adenoviral gene transfer of CCL18. Arthritis Rheum 2006;54:2643-2655.

46. De Vos AF, Hoekzema R, Kijlstra A. Cytokines and uveitis, a review. Curr Eye Res 1992;11:581-597.

47. Yoshimura $\mathrm{T}$, Sonoda $\mathrm{KH}$, Sugahara $\mathrm{M}$, et al. Comprehensive analysis of inflammatory immune mediators in vitreoretinal diseases. PLOS ONE 2009;4:e8158.

48. La Heij EC, Van de Waarenburg MP, Blaauwgeers HG, et al. Levels of basic fibroblast growth factor, glutamine synthetase, and interleukin- 6 in subretinal fluid from patients with retinal detachment. Am J Ophthalmol 2001;132:544-550.

49. Fan W, Zheng JJ, Peiper SC, McLaughlin BJ. Changes in gene expression of ARPE-19 cells in response to vitreous treatment. Ophthalmic Res 2002;34:357-365.

50. Yoshida A, Elner SG, Bian ZM, Kunkel SL, Lukacs NW, Elner VM. Differential chemokine regulation by Th2 cytokines during human RPE-monocyte coculture. Invest Ophthalmol Vis Sci 2001;42:16311638.

51. Hollborn M, Enzmann V, Barth W, Wiedemann P, Kohen L. Changes in the mRNA expression of cytokines and chemokines by stimulated RPE cells in vitro. Curr Eye Res 2000;20:488-495.

52. Yoshida A, Elner SG, Bian ZM, Elner VM. Induction of interleukin-8 in human retinal pigment epithelial cells after denuding injury. Br J Ophthalmol 2001;85:872-876. 



\section{Chapter 7}

Interleukin and Growth Factor Levels in Subretinal Fluid in Rhegmatogenous Retinal Detachment: a Case-control Study

L.J.A.G. Ricker, A. Kijlstra, A.G.H. Kessels, W. de Jager, A.T.A. Liem, F. Hendrikse, E.C. La Heij 


\section{Abstract}

Purpose: Rhegmatogenous retinal detachment (RRD) is a major cause of visual loss in developed countries. Proliferative vitreoretinopathy (PVR), an eye-sight threatening complication of RRD surgery, resembles a wound-healing process with inflammation, scar tissue formation, and membrane contraction. This study was performed to determine the possible involvement of a wide range of cytokines in the future development of PVR, and to identify predictors of PVR and visual outcome.

Methods: A multiplex immunoassay was used for the simultaneous detection of 29 different cytokines in subretinal fluid samples from patients with primary RRD. Of 306 samples that were collected and stored in our BioBank between 2001 and 2008, 21 samples from patients who developed postoperative PVR were compared with 54 age-, sex-, and storage-time-matched RRD control patients who had an uncomplicated postoperative course during the overall follow-up period.

Results: Levels of IL-1 $\alpha$, IL-2, IL-3, IL-6, VEGF, and ICAM- 1 were significantly higher $(P<0.05)$ in patients who developed postoperative PVR after reattachment surgery than in patients with an uncomplicated postoperative course, whereas levels of IL$1 \beta$, IL-4, IL-5, IL-7, IL-9, IL-10, IL-11, IL-12p70, IL-13, IL-15, IL-17, IL-18, IL-21, IL-22, IL23, IL-25, IL-33, TNF- $\alpha$, IFN- $\gamma$, IGF-1, bFGF, HGF, and NGF were not $(P>0.05)$. Multivariate logistic regression analysis revealed that IL-3 $(P=0.001)$, IL-6 $(P=0.047)$, ICAM-1 $(P=0.010)$, and preoperative visual acuity $(P=0.026)$ were independent predictors of postoperative PVR. Linear regression analysis showed that ICAM-1 $(P=$ $0.005)$ and preoperative $\log M A R$ visual acuity $(P=0.001)$ were predictive of final visual outcome after primary RRD repair.

Conclusions: Our findings indicate that after RRD onset an exaggerated response of certain cytokines may predispose to PVR. Sampling at a time close to the onset of primary RRD may thus provide clues as to which biological events may initiate the development of PVR and, most importantly, may provide a means for therapeutic control. 


\section{Introduction}

Rhegmatogenous retinal detachment (RRD) is an ophthalmologic emergency that occurs in approximately 12.6 cases per 100,000 persons per year. ${ }^{1}$ Although an increasingly number of retinal detachments is successfully repaired with a single procedure, proliferative vitreoretinopathy (PVR) is still the primary cause of failure of reattachment surgery. ${ }^{1}$ This eye-sight threatening condition is characterized by the formation of cellular membranes on both sides of the retina that upon contraction may cause a redetachment with often a permanent drop in visual acuity. The development of these fibrotic membranes is reminiscent of the normal woundhealing response with inflammation, migration and proliferation of resident ocular cells and invading immune cells. ${ }^{2}$ In all these biological processes, cytokines function as signalling molecules between these cells in order to bring about the events that ultimately lead to the formation and contraction of PVR membranes. ${ }^{2}$

Several studies have been undertaken to unravel the role of these cytokines in the pathogenesis of PVR by determining their expression in PVR vitreous and PVR membranes. ${ }^{2-12}$ Resident ocular cells including retinal pigment epithelial (RPE) cells and glial cells, and invading immune cells such as macrophages and lymphocytes are all capable of producing and secreting these cytokines. ${ }^{2}$ Immunohistochemical studies have demonstrated the presence of fibroblast growth factor (FGF), insulin growth factor (IGF), and vascular endothelial growth factor (VEGF) in PVR membranes. ${ }^{3,4}$ For example, FGF and IGF have been implicated in the migration and proliferation of RPE cells, ${ }^{5,6}$ whereas VEGF may play a role in monocyte chemotaxis. ${ }^{7}$ Moreover, levels of interleukin (IL)-1, IL-6, interferon (IFN)- $\gamma$, and intercellular adhesion molecule (ICAM)-1 have been shown to be elevated in PVR vitreous, ${ }^{8-12}$ suggesting an inflammatory component in PVR pathogenesis. These data also indicate that not a single cytokine but a complex network of cytokines may underlie the development of contractile fibrotic membranes that are characteristic of PVR.

So far, the use of intravitreal pharmacological agents to prevent the occurrence of PVR has shown disappointing results. ${ }^{13,14}$ Although the intraoperative application of daunorubicin demonstrated some effect by reducing the number of reoperations, its use failed to show a significant increase in reattachment rate in patients with preoperative PVR. ${ }^{15} \mathrm{~A}$ better understanding of the early biological alterations after primary RRD that may lead to postoperative PVR is therefore needed to develop new therapeutic strategies. Previous animal studies have demonstrated an increase in gene and protein expression of proinflammatory cytokines hours and days after the creation of experimental retinal detachment when no PVR membranes have formed yet. ${ }^{16,17}$ However, previous studies have mainly focused on cytokines in ocular fluids of patients with established PVR. ${ }^{11,12,18-21}$ Further, only a limited number of cytokines have been determined in each patient in these studies. Since PVR is the resultant of an inflammatory process in which a multitude of cytokines is in- 
volved, the measurement of a single cytokine seems rather unsatisfactory. Therefore, examining a whole cytokine profile in patients after primary RRD provides not only clues as to which cytokines may play a role in PVR pathogenesis, it may also indicate which cytokines are most predictive of its development.

In a previous study on early biological alterations after primary RRD, we used recently developed multiplex bead-based immunoassays for the simultaneous detection of several chemokines and their correlation with IL-6. ${ }^{22}$ In the study presented here we report the protein expression of 29 different interleukins and growth factors in subretinal fluid samples from the same population. Our findings indicate that an exaggerated response of certain cytokines occurring after RRD onset may predispose to PVR development.

\section{Methods}

\section{Patients}

The research followed the tenets of the Declaration of Helsinki and the Medical Ethics Committee of University Hospital Maastricht, which approved all the protocols used in this study. All enrolled patients gave written informed consent before the surgical procedure and after the nature of the study was explained.

Subretinal fluid samples are routinely collected during scleral buckling surgery for primary RRD in our department, except in patients with small (less than one quadrant) or shallow detachments. Between 2001 and 2008, a total of 306 patients underwent subretinal fluid sampling. Upon collection, samples were transferred and stored in the BioBank Maastricht. A thorough medical record study revealed that 45 of these patients developed a redetachment due to PVR later on during the postoperative follow-up period. Of these, 9 samples were excluded due to low sample volume $(<75 \mu \mathrm{L})$ or contamination with blood, whereas 6 samples were excluded because of late PVR development (more than $2 \frac{1}{2}$ months after subretinal fluid collection). Further, we excluded 4 patients with preoperative vitreous hemorrhage, 4 patients with preoperative trauma, and 1 patient with preoperative cryotherapy. Finally, 21 samples from patients who developed a redetachment due to PVR within $2 \frac{1}{2}$ months after scleral buckling surgery for primary RRD were included in the study. This disease group, defined as the PVR group, was compared with patients who did not develop a redetachment during the overall follow-up period (at least 3 months), i.e. patients with an uncomplicated follow-up after primary RRD repair. Samples from these patients served as controls and were defined as the RRD group. We compared every single PVR sample with two to three age-, sex-, and storagetime-matched controls, which resulted in 54 control patients with an uncomplicated follow-up following primary retinal detachment surgery. 


\section{Sample Collection}

Undiluted subretinal fluid samples were obtained during scleral buckling surgery for primary RRD. Scleral and choroidal vessels were carefully cauterized before the incision. Any macroscopic blood surrounding the incision opening was removed with a cotton tip. Subretinal fluid was collected from the surface of the sclera with a 25gauge bent needle. All samples were collected in sterile polypropylene tubes, stored at $-80^{\circ} \mathrm{C}$, and thawed directly before analysis. Sample volumes ranged between 100 $-700 \mu \mathrm{L}$.

\section{Multiplex Bead-Based Immunoassay}

Cytokines were measured at the Luminex Core Facility (Utrecht, The Netherlands) with a multiplex immunoassay (Luminex, Austin, TX, USA) using an in-housevalidated panel which incorporates an appropriate Quality Control Program, as previously described. ${ }^{23}$ In summary, the antibody-coated microspheres were incubated for 60 minutes with standards or subretinal fluid $(50 \mu \mathrm{L})$ in 96-well, 1.2- $\mu \mathrm{m}$ filter plates (Millipore, Amsterdam, The Netherlands). Plates were washed (Bio-Plex pro II wash station, Bio-Rad, Hercules, CA, USA), and a cocktail of biotinylated detection antibodies was added for an additional 60 minutes. After repeated washings streptavidin-phycoerythrin was added and incubated for 10 minutes. Next, after 2 additional washes fluorescence intensity was measured. Data collection and analysis of the data from all assays were performed (Bio-Plex system in combination with Bio-Plex Manager software, ver. 4.1; Bio-Rad, Hercules, CA, USA), by using fiveparameter curve fitting. The concentrations of the following cytokines were measured: the interleukins IL- $1 \alpha$, IL-1 $\beta$, IL-2, IL-3, IL-4, IL-5, IL-6, IL-7, IL-9, IL-10, IL-11, IL12p70, IL-13, IL-15, IL-17, IL-18, IL-21, IL-22, IL-23, IL-25, and IL-33; the proinflammatory cytokines tumor necrosis factor (TNF)- $\alpha$ and IFN- $\gamma$; the growth factors IGF-1, basic (b)FGF, VEGF, nerve growth factor (NGF), and hepatocyte growth factor (HGF); and the cell adhesion molecule ICAM-1. The lower limit of detection of the cytokines ranged between 0.1 and $19.5 \mathrm{pg} / \mathrm{mL}$. Concentrations below the detection limit were assigned the lowest value from the respective standard curve. For statistical analysis, concentrations below the detection limit were converted to a value of 0.5 times the lowest value of the calibration curve.

\section{Clinical Variables}

For all patients, demographic variables, potential clinical risk factors for the development of PVR (Table 1) and the following clinical variables were collected: followup time, occurrence of a redetachment, postoperative PVR grade, and preoperative and final postoperative best corrected Snellen visual acuity. PVR was graded according to the Classification of Retinal Detachment with PVR. ${ }^{24}$ Data were collected as 0 
(no PVR), 1 (grade A), 2 (grade B), 3 (grade C), and 4 (grade D). Duration of retinal detachment was defined as the interval between the onset of symptoms and surgery and was estimated according to a precise history of patients' symptoms. Duration of macular detachment was evaluated separately and was defined as the interval between the onset of a sudden drop in visual acuity and reattachment surgery. The refraction of pseudophakic patients was evaluated based on historical data. For statistical analysis, Snellen visual acuity was transformed into logMAR visual acuity.

\section{Statistical Analysis}

Patients who developed a redetachment due to PVR within $2 \frac{1}{2}$ months after the scleral buckling procedure (the PVR group) were compared with patients with an uncomplicated follow-up (the RRD group). Further, we investigated whether cytokine concentrations were different in patients who developed early postoperative PVR (within 30 days after reattachment surgery) compared to patients with late postoperative PVR (more than 30 days after reattachment surgery) and whether differences in cytokine expression were related to PVR grade. The nonparametric Mann-Whitney $U$ test was used for ordinal variables such as analyte levels, since data were not normally distributed. The chi-square test was used to compare nominal variables such as diabetes mellitus. Correlations were determined by the Spearman's rho test. As we expected that preoperative PVR, duration of retinal detachment, and macular involvement were not equally distributed between both groups, we investigated the role of these clinical parameters as possible confounding variables with respect to the association between cytokine levels and the development of postoperative PVR, using multivariate logistic regression analysis. Statistical analysis of the data was performed using SPSS version 16.0 (SPSS for Windows; SPSS, Chicago, IL, USA). Differences were considered significant at $P<0.05$, with two-tailed testing.

Stepwise logistic regression analysis was used to assess the data's predictive ability in determining the occurrence of a redetachment due to postoperative PVR. Since the choice of $P<0.05$ is often too stringent in this analysis and may exclude important variables from the model, choosing a higher $P$ value is highly recommended. ${ }^{25}$ Therefore, clinical and biological variables that reached $P$ values $<0.15$ in univariate tests were further analyzed with forward stepwise logistic regression analysis. Linear regression analysis was used to assess the data's predictive value in determining postoperative visual acuity. 


\section{Results}

\section{Demographics and Clinical Results}

Subretinal fluid samples from 75 patients who underwent scleral buckling surgery were analyzed. Twenty one patients with primary RRD who developed postoperative PVR within $2 \frac{1}{2}$ months after the surgical procedure were compared with 54 patients with primary RRD who had an uncomplicated follow-up. The PVR group consisted of 6 women (29\%) and 15 men (71\%) with a median age of 62 years (range $43-76)$. The median time interval between the scleral buckling procedure and redetachment due to PVR was 37 days (range $13-80$ ) and the median followup time was 21 months (range $3-80$ ). Ten patients developed a redetachment due to postoperative PVR grade $B, 10$ patients due to postoperative PVR grade $C$, and one patient due to postoperative PVR grade $D$. In comparison, the RRD group included 14 women (26\%) and 40 men (74\%) with a median age of 61 years (range 43 - 79). Their median follow-up time was 6 months (range 3-80).

Potential preoperative clinical risk factors for the development of postoperative PVR were available for all 75 patients included in this study (Table 1). There were no statistically significant differences between both groups regarding these parameters, except for a worse median preoperative logMAR visual acuity in the PVR group (1.77; range $0.10-2.52$ ) as compared to the RRD group $(0.75$; range $0.05-2.52)(P$ $=0.045)$. Although not statistically significant, median preoperative PVR grades were higher in the PVR group (grade $B$ ) than in the RRD group (grade A) $(P=0.218$ ), as well as the median duration of retinal detachment (PVR, 6 days; RRD, 5 days) $(P=$ $0.650)$ and the percentage of patients with macular involvement (PVR, 86\%; RRD 64\%) $(P=0.067)$.

\section{Interleukin and Growth Factor Levels in Subretinal Fluid}

Among the interleukins analyzed, levels of IL-1 $\alpha(P=0.025)$, IL-2 $(P=0.044)$, IL-3 $(P$ $=0.008)$, IL-6 $(P<0.001)$, IL-15 $(P=0.013)$, and IL-18 $(P=0.008)$ were significantly higher in patients with primary RRD who developed a redetachment due to PVR than in patients with primary RRD and an uncomplicated follow-up. Since small nonsignificant differences in baseline characteristics between both groups may have influenced our results, we decided to correct for preoperative PVR grade, duration of retinal detachment, and macular involvement using multivariate logistic regression analysis. After correction, levels of IL-1 $\alpha(P=0.011)$, IL-2 $(P=0.021)$, IL-3 $(P=$ $0.006)$, and IL-6 $(P=0.021)$ remained significantly elevated in the PVR group as compared to the RRD group, whereas both IL-15 $(P=0.392)$ and IL-18 $(P=0.281)$ lost their significance. 
Table 1 Demographics and Potential Clinical Risk Factors for PVR

\begin{tabular}{|c|c|c|c|c|}
\hline $\begin{array}{l}\text { Potential Clinical } \\
\text { Risk Factor }\end{array}$ & $\begin{array}{l}\text { RRD Group } \\
(n=54)\end{array}$ & $\begin{array}{l}\text { PVR Group } \\
(n=21)\end{array}$ & $\begin{array}{l}\text { Univariate } \\
\text { Testing }\end{array}$ & $\begin{array}{c}\text { Stepwise Logistic } \\
\text { Regression }\end{array}$ \\
\hline Age (years) & $61(43-79)$ & $62(43-76)$ & NS & NS \\
\hline Sex, Female (\%) & 26 & 29 & NS & NS \\
\hline $\begin{array}{l}\text { Size of retinal detachment } \\
\text { (quadrants) }\end{array}$ & $2(1-3)$ & $2(1-4)$ & NS & NS \\
\hline $\begin{array}{l}\text { Total size of retinal defects } \\
\text { (optic disc diameters) }\end{array}$ & $2(0-5.5)$ & $1(0-4)$ & NS & NS \\
\hline Macular detachment (\%) & 64 & 86 & NS & NS \\
\hline Preoperative logMAR VA & $\begin{array}{c}0.75 \\
(0.05-2.52)\end{array}$ & $\begin{array}{c}1.77 \\
(0.10-2.52)\end{array}$ & $P=0.045$ & $P=0.026$ \\
\hline Detachment duration (days) & $5(1-75)$ & $6(1-90)$ & NS & NS \\
\hline Preoperative PVR grade & $1(0-3)$ & $2(0-3)$ & NS & NS \\
\hline Diabetes mellitus (\%) & 11 & 10 & NS & NS \\
\hline Preoperative myopia >5D (\%) & 17 & 24 & NS & NS \\
\hline Pseudophakia (\%) & 19 & 33 & NS & NS \\
\hline Aphakia (\%) & 0 & 0 & NS & NS \\
\hline Preoperative uveitis (\%) & 0 & 0 & NS & NS \\
\hline Preoperative cryotherapy (\%) & 0 & 0 & NS & NS \\
\hline $\begin{array}{l}\text { Preoperative vitreous } \\
\text { hemorrhage (\%) }\end{array}$ & 0 & 0 & NS & NS \\
\hline Preoperative trauma (\%) & 0 & 0 & NS & NS \\
\hline
\end{tabular}

Data are expressed as median (range) or in percentages. Abbreviations: RRD = rhegmatogenous retinal detachment; PVR = proliferative vitreoretinopathy; NS = not significant; logMAR = logarithm of minimal angle of resolution; $\mathrm{VA}=$ visual acuity; $\mathrm{D}=$ diopters.

Levels of IGF-1, bFGF, NGF, and HGF were similar between both groups $(P>0.05)$, whereas median VEGF levels were approximately two to three times higher in the PVR group as compared to the RRD group $(P=0.012)$. After correction for the aforementioned preoperative clinical parameters, this difference remained statistically significant $(P=0.049)$. In the current study, we found wide variations in the levels of both IL-6 and VEGF with approximately a 100-fold increase of the highest levels compared to the lowest levels in both the PVR and RRD group.

IFN- $\gamma$ was detected in 9 of 54 (17\%) subretinal fluid samples from patients in the RRD group and in 3 of 21 (14\%) samples from patients in the PVR group ( $P>0.05)$. There were no significant differences in the median levels of IFN- $\gamma$ and TNF- $\alpha$ be tween the two groups $(P>0.05)$. The median levels of the cell adhesion molecule ICAM-1 were significantly elevated in the PVR group as compared to the RRD group $(P=0.002)$, even after having corrected for differences in preoperative PVR grade, duration of retinal detachment, and macular involvement $(P=0.016)$. Levels of all 
Table 2 Cytokine Levels and the Development of Postoperative PVR

\begin{tabular}{|c|c|c|c|c|}
\hline $\begin{array}{l}\text { Cytokine } \\
\text { (pg/mL) }\end{array}$ & $\begin{array}{l}\text { RRD Group } \\
(n=54)\end{array}$ & $\begin{array}{l}\text { PVR Group } \\
(n=21)\end{array}$ & $\begin{array}{l}\text { Univariate } \\
\text { testing }\end{array}$ & $\begin{array}{c}\text { Stepwise } \\
\text { Logistic Re- } \\
\text { gression }\end{array}$ \\
\hline IL-1 $\alpha$ & $5.8(2.9-11)$ & $7.0(4.1-20)$ & $P=0.025$ & NS \\
\hline IL-1 $\beta$ & $6.4(2.5-12)$ & $6.8(3.1-20)$ & NS & NS \\
\hline IL-2 & $5.9(3.7-12)$ & $6.6(3.4-18)$ & $P=0.044$ & NS \\
\hline IL-3 & $101(24-348)$ & $144(47-464)$ & $P=0.008$ & $P=0.001$ \\
\hline IL-4 & $1.5(0.5-2.8)$ & $1.7(1.0-4.5)$ & NS & NS \\
\hline $\mathrm{IL}-5$ & $2.3(0.8-4.5)$ & $2.2(0.9-6.3)$ & NS & NS \\
\hline IL-6 & $60(8.3-1211)$ & $149(36-2656)$ & $P<0.001$ & $P=0.047$ \\
\hline IL-7 & $16(6.2-63)$ & $17(6.7-53)$ & NS & NS \\
\hline IL-9 & $103(49-185)$ & $96(54-288)$ & NS & NS \\
\hline IL-10 & $3.5(1.7-8.4)$ & $3.8(2.3-8.5)$ & NS & NS \\
\hline IL-11 & $23(7.3-59)$ & $25(12-89)$ & NS & NS \\
\hline IL-12p70 & $32(15-58)$ & $30(19-78)$ & NS & NS \\
\hline IL-13 & $59(27-191)$ & $57(37-162)$ & NS & NS \\
\hline IL-15 & $0.8(0.1-15)$ & $1.8(0.3-11)$ & $P=0.013$ & NS \\
\hline IL-17 & $37(11-76)$ & $32(14-119)$ & NS & NS \\
\hline IL-18 & $24(5.8-262)$ & $36(12-144)$ & $P=0.008$ & NS \\
\hline $\mathrm{IL}-21$ & $3524(2291-5481)$ & $3421(1981-7135)$ & NS & NS \\
\hline IL-22 & $30(6.6-81)$ & $35(9.4-98)$ & NS & NS \\
\hline IL-23 & $133(63-857)$ & $135(80-435)$ & NS & NS \\
\hline IL-25 & $2349(1253-65737)$ & $2458(1516-26189)$ & NS & NS \\
\hline IL-33 & $14(4.8-64)$ & $17(5.4-55)$ & NS & NS \\
\hline TNF- $\alpha$ & $6.2(2.9-8.8)$ & $6.6(2.1-30)$ & NS & NS \\
\hline $\mathrm{IFN}-\gamma$ & $<0.3(<0.3-16)$ & $<0.3(<0.3-18)$ & NS & NS \\
\hline IGF-1 & $1548(1086-2344)$ & $1607(1106-3401)$ & NS & NS \\
\hline bFGF & $1137(715-2051)$ & $1154(767-2869)$ & NS & NS \\
\hline NGF & $7.0(2.8-9.6)$ & $7.5(2.8-31)$ & NS & NS \\
\hline HGF & $3413(413-9987)$ & 3949 (971 - 10769) & NS & NS \\
\hline VEGF & $64(21-1421)$ & $153(40-3308)$ & $P=0.012$ & NS \\
\hline ICAM-1 & $19927(4529-40489)$ & $28276(6780-44606)$ & $P=0.002$ & $P=0.010$ \\
\hline
\end{tabular}

Data are expressed as median (range) in $\mathrm{pg} / \mathrm{mL}$. Abbreviations: RRD = rhegmatogenous retinal detachment; PVR = proliferative vitreoretinopathy; IL = interleukin; NS = not significant; TNF- $\alpha=$ tumor necrosis factor- $\alpha$; IFN- $\gamma=$ interferon- $\gamma$; IGF-1 = insulin growth factor-1; bFGF = basic fibroblast growth factor; NGF = nerve growth factor; HGF = hepatocyte growth factor; VEGF = vascular endothelial growth factor; ICAM-1 = intercellular adhesion molecule-1.

cytokines are summarized in Table 2; levels of cytokines that were significantly different between both groups are illustrated in Fig. 1. 
To find out whether there were differences in cytokine levels between patients with different postoperative PVR grades within the PVR group, we compared patients with postoperative PVR grade $\mathrm{B}(n=10)$ to patients with postoperative PVR grade $\mathrm{C}$ or higher $(n=11)$. Median IL-6 levels were significantly higher in the PVR grade $B$ group (245 pg/mL, range $116-2656)$ as compared to the PVR grade $C$ group (114 $\mathrm{pg} / \mathrm{mL}$, range $36-1398)(P=0.024)$. No other significant differences in cytokine levels were detected between both groups. Comparison of cytokines between patients who developed postoperative PVR within 30 days $(n=8)$ and those who developed PVR after 30 days following surgery $(n=13)$ did not reveal any significant differences.

\section{Correlations of Biological Variables and Clinical Variables}

There were moderate to strong correlations between IL-1 $\alpha$ and both IL-2 and IL-3 ( $r$ $=0.83$ and $r=0.64$, respectively) $(P<0.001)$ and between IL-2 and IL-3 $(r=0.47)(P<$ $0.001)$. Further, we found a strong correlation between VEGF and ICAM-1 $(r=0.61)$. When comparing cytokine levels with clinical variables, we generally found low correlations $(r<0.4)$ except between duration of macular detachment and ICAM-1 $(r=0.40)(P<0.01)$. With respect to preoperative PVR grade, we only found a very weak association with ICAM-1 levels $(r=0.25)(P=0.030)$. Preoperative visual acuity correlated moderately but significantly with final visual acuity $(r=0.43)(P<0.001)$. Correlations between other preoperative clinical variables (i.e. duration of retinal detachment, duration of macular detachment, the extent of retinal detachment in quadrants, and the number of retinal breaks) and final visual acuity were very low ( $r$ $<0.3$ ), whereas patients with macular detachment at the time of primary retinal detachment surgery had worse final visual outcome (median logMAR VA 0.52, range $0-3.00$ ) as compared to patients without involvement of the macula (median logMAR VA 0.30 , range $0-0.80)(P=0.013)$.

\section{Predictors of Postoperative PVR and Visual Outcome}

Variables that were significantly different between the RRD group and the PVR group or were close to significance in univariate tests $(P<0.15)$ were selected for stepwise logistic regression analysis. The selected variables were IL-1 $\alpha$, IL-2, IL-3, IL6, IL-15, IL-18, IL-25, NGF, VEGF, ICAM-1, preoperative logMAR visual acuity and presence of macular detachment. This analysis revealed that IL-3 $(P=0.001)$, IL-6 ( $P$ $=0.047), \operatorname{ICAM}-1(P=0.010)$, and preoperative logMAR visual acuity $(P=0.026)$ were independent predictors of postoperative PVR after primary RRD. On the other hand, linear regression analysis showed that ICAM-1 $(P=0.005)$ and preoperative logMAR visual acuity $(P=0.001)$ were predictive of final visual outcome after primary $R R D$ repair. 


\section{Discussion}

In the current study, we found levels of IL-1 $\alpha$, IL-2, IL-3, IL-6, VEGF, and ICAM-1 to be significantly higher in patients who developed a redetachment due to postoperative PVR than in patients with an uncomplicated follow-up after primary RRD. Correction for possible confounding variables including preoperative PVR, duration of retinal detachment, and macular involvement was necessary due to small differences in baseline characteristics between the PVR group and the RRD group. Stepwise forward logistic regression analysis revealed that IL-3, IL-6, ICAM-1, and preoperative visual acuity were independent predictors of postoperative PVR, whereas ICAM-1 and preoperative visual acuity were predictive of final visual acuity after primary RRD repair. Samples from patients with preoperative conditions known to
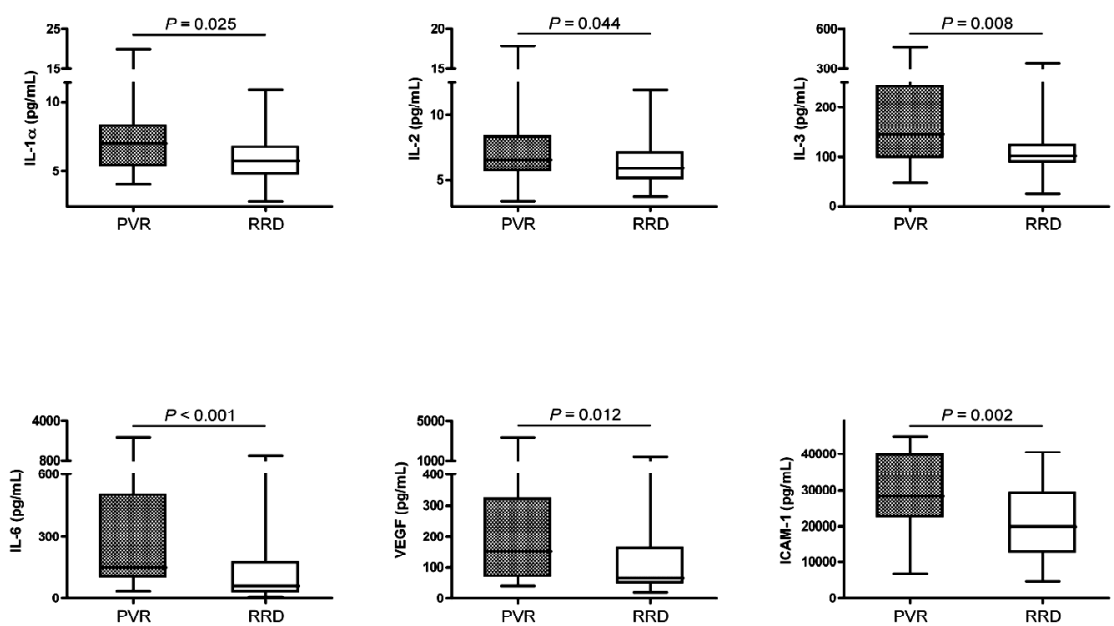

Figure 1 Box-and-whisker plots of significantly elevated cytokine levels in patients with primary rhegmatogenous retinal detachment. A multiplex immunoassay was used to determine 29 different cytokines in subretinal fluid samples obtained during scleral buckling surgery for rhegmatogenous retinal detachment. Patients who developed a redetachment due to postsurgical PVR within $2 \frac{1}{2}$ months after reattachment surgery ( $n=21$, 'PVR' group) were compared with controls who had an uncomplicated retinal detachment during the overall follow-up period ( $n=54$, 'RRD' group). Levels of IL-1 $\alpha$, IL-2, IL-3, IL-6, VEGF, and ICAM-1 were significantly higher $(P<0.05)$ in patients who developed postoperative PVR than in patients with an uncomplicated postoperative course. After correction for possible confounding variables including preoperative PVR, duration of retinal detachment, and macular involvement, these factors remained significantly different between both groups (see text). Box: lower and upper quartiles; horizontal line: the median. Abbreviations: PVR = proliferative vitreoretinopathy; RRD = rhegmatogenous retinal detachment; IL = interleukin; VEGF = vascular endothelial growth factor; ICAM-1 = intercellular adhesion molecule-1. 
induce PVR were excluded from the study, since these would have yielded high cytokine levels that were directly related to that condition (e.g., uveitis). In addition, we excluded samples from patients with late PVR development, considering it would be more likely that in patients who have PVR developed after 3 months, a new event caused the recurrence rather than the stimulus that was of our interest. ${ }^{26}$ Hence, our findings indicate that there is an association between certain cytokines (IL-1 $\alpha$, IL-2, IL-3, IL-6, VEGF, and ICAM-1) and the development of postsurgical PVR after primary RRD repair. Whether an unknown clinical event may have triggered the exaggerated cytokine response in the PVR group or whether differences in the genetic control of this cytokine response are involved remains to be clarified.

Animal studies have shown an upregulation of proinflammatory genes already very soon (hours to days) after the induction of retinal detachment together with a time dependency of certain cytokines. ${ }^{16,17}$ These animal studies are certainly far more well-controlled than our clinical study and a time dependency could not be analyzed due to insufficient time points. Nevertheless, we demonstrated that sampling after the onset of primary RRD but before the development of postoperative PVR may provide clues as to which biological events initiate the formation of PVR membranes, and may therefore provide a means for therapeutic control before postoperative PVR has been established. In the scope of developing a preventive strategy, a study by Bali et $\mathrm{al}^{27}$ showed that a single preoperative subconjunctival injection of dexamethasone prior to scleral buckling retinal detachment surgery resulted in a significant decrease in laser flare measurements at one week postoperatively, reflecting less blood-retina barrier breakdown. Whether steroid priming via these injections leads to a lower incidence of postoperative PVR has not yet been investigated.

Multiplex bead-based immunoassay allowed us to detect a large number of cytokines simultaneously, with comparable performance in sensitivity, accuracy, and reproducibility to enzyme-linked immunosorbent assays (ELISAs) performed in previous studies. ${ }^{28}$ With the use of ELISAs, earlier studies could only focus on a few cytokines and mostly studied patients with already established PVR following earlier reattachment surgery. Moreover, most studies have dealt with vitreous samples, whereas our study addressed subretinal fluid specimens. To discover early biological alterations that may lead to PVR development, analysis of subretinal fluid may be more appropriate because of its close proximity to the RPE cell layer after initial retinal detachment.

The source of the cytokines in our subretinal fluid specimens remains speculative although it is most likely that they are simultaneously produced by resident ocular cells and infiltrating inflammatory cells. Even though the blood-retina barrier may be broken down, the levels of plasma cytokines do not reach high enough levels to significantly contribute to the cytokine milieu in the subretinal space after retinal detachment. ${ }^{18,19,29}$ 
A large number of ocular fluid cytokines has been investigated previously in RRD patients with or without PVR, including IL-1, IL-6, TNF- $\alpha$, IFN- $\gamma$, VEGF, FGF, HGF, and ICAM-1 (Table S1). ${ }^{8-12,18-21,29-33}$ Of this group of cytokines, we confirmed earlier findings showing elevated levels of IL- $1 \alpha$, IL-6, VEGF, and ICAM-1 in our specimens. Comparison of the levels reported in these studies is however difficult due to significant differences in sampling time, sampling size, sampling specimen, laboratory methods, and baseline characteristics of the study population. A correlation between increased levels of IL-2 and IL-3 and the development of postoperative PVR as we describe in the current study has not yet been reported earlier.

The proinflammatory cytokines IL-1 $\alpha$ and IL-1 $\beta$ have similar biological properties and have been implicated in the pathogenesis of PVR. ${ }^{8,9}$ Since IL-1 induces RPE cell migration ${ }^{34}$ and its intravitreal injection leads to breakdown of the blood-ocular barrier, ${ }^{35}$ IL-1 has been suggested to be an important candidate in the activation processes that ultimately lead to PVR development. Although our findings showed that IL-1 $\alpha$ levels were significantly elevated in the PVR group, the difference with the control group was only small. The same holds for IL-2 with median levels of less than $7 \mathrm{pg} / \mathrm{mL}$. On the other hand, many cytokines have redundant properties and even small elevations in a number of cytokines may lead to synergistic effects.

IL-6 reached very high levels in some patients and median levels were approximately 2.5 times higher in the PVR group as compared to the RRD group. IL- 6 is a pleiotropic cytokine with a wide range of activities in inflammation and immune reactions. ${ }^{36}$ Various groups have reported IL- 6 gene expression and secretion by cytokine-stimulated human RPE cells, ${ }^{37,38}$ whereas IL- 6 may also be produced by several inflammatory cells invading the subretinal space after RRD due to chemotactic signalling. ${ }^{39}$ In addition, IL-6 itself was found to induce chemokines and to amplify the recruitment of leukocytes in an animal model. ${ }^{40}$ Consistent with these data, we reported the correlation between IL- 6 and a wide range of chemokines in subretinal fluid samples from patients with retinal detachment. ${ }^{22}$ IL-6, in contrast, may also serve as a photoreceptor neuroprotectant, as was shown in an experimental model of retinal detachment. ${ }^{41}$ Results of our current study were in line with those of Kon et al ${ }^{8}$ and El-Ghrably et al, ${ }^{9}$ suggesting a role for IL- 6 in the early alterations that may induce postoperative PVR (Table S1). Interestingly, we found significantly lower IL-6 levels in patients with higher postoperative PVR grades, for which we have no sound explanation.

Similar to IL-6, we found median VEGF levels to be two to three times elevated in subretinal fluid samples of patients with PVR. Since PVR is characterized by the formation of mainly avascular membranes, it was hypothesized that VEGF may have functions other than inducing angiogenesis. ${ }^{4}$ This hypothesis was supported by growing evidence of a possible interaction of VEGF with non-endothelial cells in the eye. A previous study has shown that RPE cells in situ, as well as RPE cells in epiretinal membranes and in culture, express VEGF receptors. ${ }^{4}$ In the majority of these 


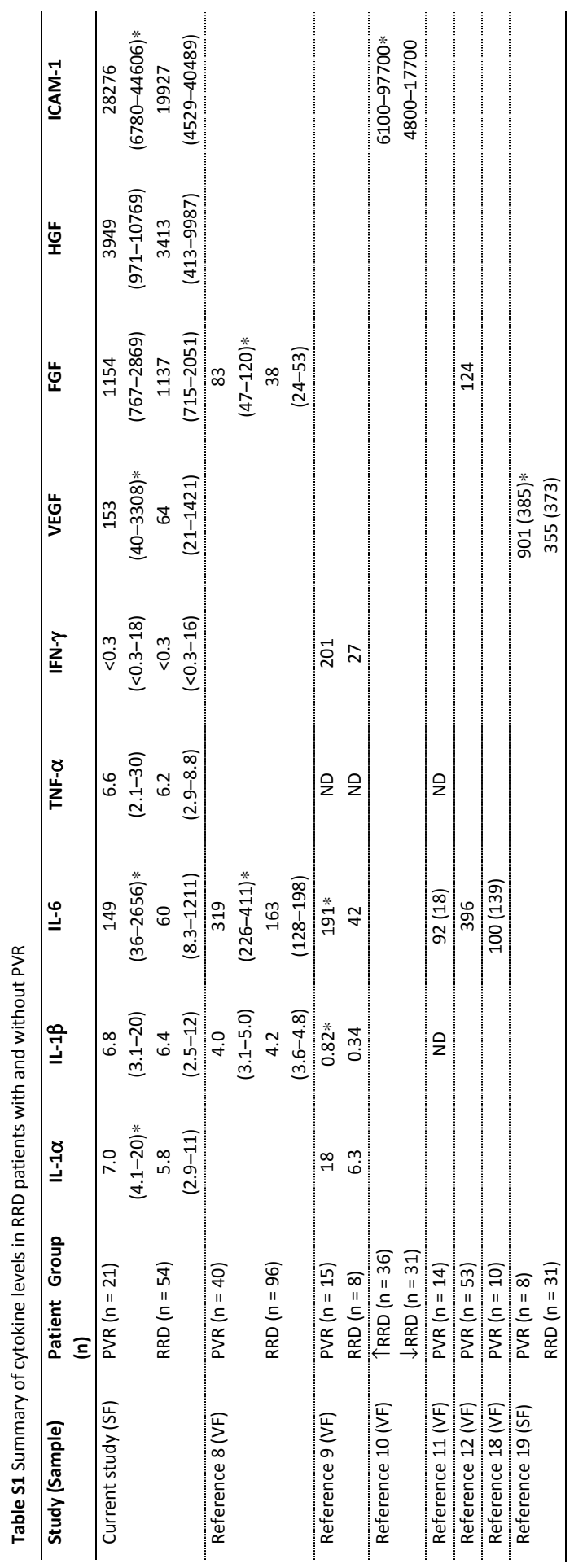




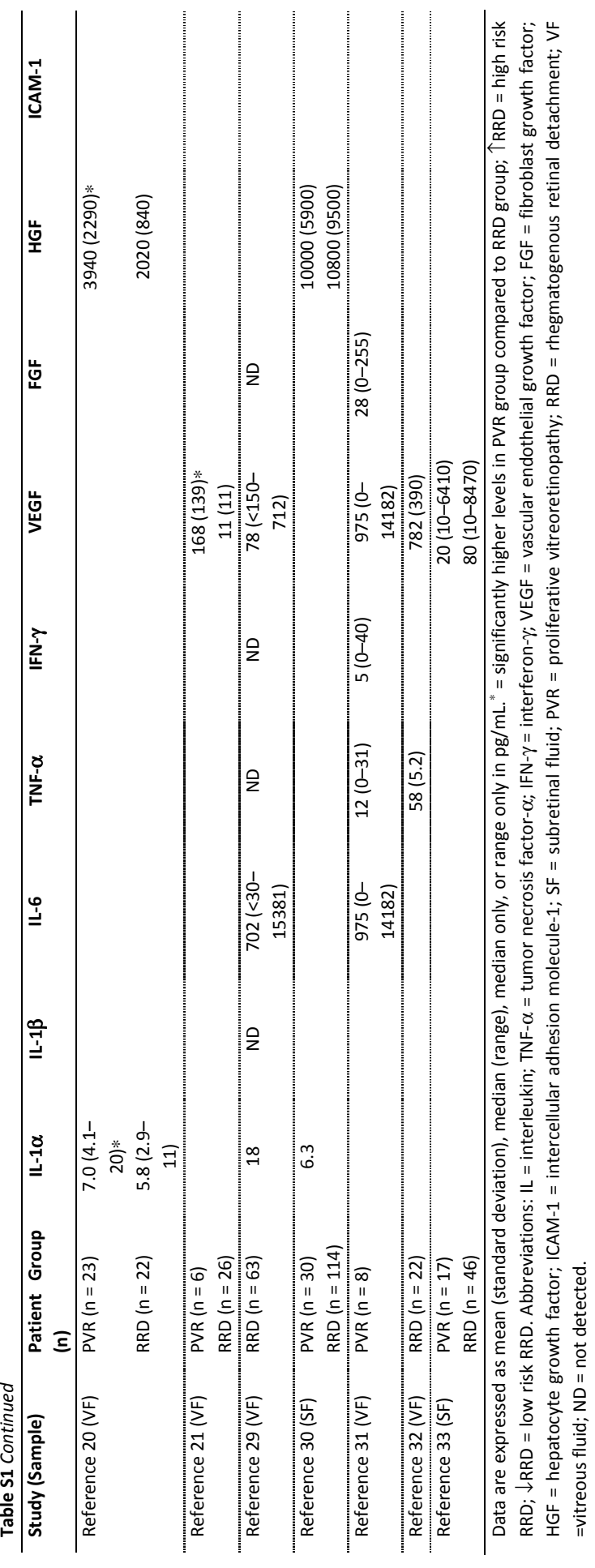


membranes, VEGF and its receptors were co-localized, indicating that an autocrine and/or paracrine mechanism may exist. Other studies identified VEGF receptors on other non-endothelial cells in the eye such as on adult photoreceptor cells and Müller cells, implicating a role for VEGF in the maintenance of the adult neural retina by supporting cell survival of these retinal cells. ${ }^{42}$ Interestingly, VEGF has also been shown to induce monocyte activation manifested by the induction of monocyte chemotaxis. ${ }^{7}$ Thus, VEGF probably exerts pleiotropic effects on diverse cell types such as RPE cells and monocytes, which play major roles in the development of PVR.

The presence of ICAM-1 in epiretinal membranes and vitreous of patients with PVR has been demonstrated earlier in a few studies. ${ }^{43,44}$ In addition, ICAM-1 expression has been found on cultured human RPE cells and was upregulated after stimulation with IL-1, TNF- $\alpha$, or IFN- $\gamma .{ }^{45}$ ICAM- 1 has an important role in regulating leukocyte migration into sites of inflammation, thereby enhancing cytokine-mediated inflammatory reactions after retinal detachment. Limb and Chigne $\|^{10}$ showed that high levels of ICAM-1 may constitute an additional risk factor to known clinical risk factors for the development of PVR. Our study confirmed these results, and we showed that ICAM-1 is not only an independent predictor of postoperative PVR, but also of visual outcome after reattachment surgery.

The use of multiplex immunoassays entails research that is basically hypothesisgenerating. We identified IL-2 and IL-3 as novel candidates in the activation of PVR development. Elevated concentrations of these cytokines in our samples suggest their involvement in the initial stages of PVR pathogenesis. IL-3, which was shown to be the best predictor of postoperative PVR in our study population, exerts proinflammatory actions by the activation of hematopoietic cells of various lineages including macrophages, ${ }^{46}$ and is mainly synthesized by T-lymphocytes. ${ }^{47}$ Together with studies showing their presence in ocular fluids and epiretinal membranes from patients with PVR, ${ }^{48,49}$ our results underscore a possible role for T lymphocytes in the pathogenesis of PVR. Since microglial cells have also been shown to express IL-3, ${ }^{50}$ its cellular source and function after retinal detachment remain unknown.

So far, the use of intravitreal pharmacologic agents has not been proven to be efficacious in the prevention or treatment of PVR and most efforts have been dedicated to modulate the clinical risk factors. ${ }^{13,14}$ Despite these efforts PVR is still the primary cause of failure of retinal detachment surgery and a frequent cause of legal blindness in developed countries. Therefore, more insight in its pathogenesis is needed to develop further prevention strategies. The identification of laboratory predictors of PVR (IL-3, IL-6, ICAM-1) may help us to treat only those patients at greatest risk. On the other hand, the identification of preoperative visual acuity as an independent predictor of postoperative PVR should be viewed with caution since it is merely a result of statistical analysis and is most likely due to a higher proportion of patients with macular involvement in the PVR group. Future prospective 
studies are necessary to test the validity of our study. Since we only assessed cytokine content in subretinal fluid samples from patients who underwent scleral buckling surgery for primary RRD, predictors of postoperative PVR derived from our study results may not be applicable to other patient populations (e.g., patients who undergo a vitrectomy). The present study did not include known PVR associated factors such as platelet-derived growth factor (PDGF) or transforming growth factor (TGF)- $\beta .^{30,51}$ The PDGF assay has not yet been developed by the Luminex Core Facility, whereas the TGF- $\beta$ assay needs a prior acid activation to convert the latent into the activated form, which prevents its simultaneous detection with other cytokines in the multiplex bead immunoassay.

In summary, our findings show that several cytokines are upregulated after the onset of RRD in patients in whom postoperative PVR develops after primary RRD repair. An exaggerated inflammatory response in this subset of patients may thus be the underlying phenomenon that ultimately leads to the formation of PVR membranes. Moreover, we report that IL-3, IL-6, ICAM-1, and preoperative visual acuity were independent predictors of PVR and may be useful in identifying those patients at greatest risk. Importantly, elevated levels of IL-3 may shed new light on PVR pathogenesis and may suggest $\mathrm{T}$ cell and/or microglial cell involvement in the early events of PVR development.

\section{References}

1. D'Amico DJ. Clinical practice. Primary retinal detachment. N Engl J Med 2008;359:2346-2354.

2. Pastor JC, de la Rúa ER, Martín F. Proliferative vitreoretinopathy: risk factors and pathobiology. Prog Retin Eye Res 2002;21:127-144.

3. Fredj-Reygrobellet D, Baudouin C, Nègre F, Caruelle JP, Gastaud P, et al. Acidic FGF and other growth factors in preretinal membranes from patients with diabetic retinopathy and proliferative vitreoretinopathy. Ophthalmic Res 1991;23:154-161.

4. Chen YS, Hackett SF, Schoenfeld CL, Vinores MA, Vinores SA, et al. Localisation of vascular endothelial growth factor and its receptors to cells of vascular and avascular epiretinal membranes. $\mathrm{Br} J$ Ophthalmol 1997;81:919-926.

5. Spraul CW, Kaven C, Lang GK, Lang GE. Effect of growth factors on bovine retinal pigment epithelial cell migration and proliferation. Ophthalmic Res 2004;36:166-171.

6. Grant MB, Guay C, Marsh R. Insulin-like growth factor I stimulates proliferation, migration, and plasminogen activator release by human retinal pigment epithelial cells. Curr Eye Res 1990;9:323335.

7. Clauss M, Gerlach M, Gerlach H, Brett J, Wang F, et al. Vascular permeability factor: a tumorderived polypeptide that induces endothelial cell and monocyte procoagulant activity, and promotes monocyte migration. J Exp Med 1990;172:1535-1545.

8. Kon CH, Occleston NL, Aylward GW, Khaw PT. Expression of vitreous cytokins in proliferative vitreoretinopathy: a prospective study. Invest Ophthalmol Vis Sci 1999;40:705-712.

9. El-Ghrably IA, Dua HS, Orr GM, Fischer D, Tighe PJ. Intravitreal invading cells contribute to vitreal cytokine milieu in proliferative vitreoretinopathy. Br J Ophthalmol 2001;85:461-470.

10. Limb GA, Chignell AH. Vitreous levels of intercellular adhesion molecule 1 (ICAM-1) as a risk indicator of proliferative vitreoretinopathy. Br J Ophthalmol 1999;83:953-956. 
11. Kauffmann DJH, Van Meurs JC, Mertens DAE, Peperkamp E, Master C, et al. Cytokines in vitreous humor: interleukin-6 is elevated in proliferative vitreoretinopathy. Invest Ophthalmol Vis Sci 1994;35:900-906.

12. La Heij EC, Van de Waarenburg MP, Blaauwgeers HG, Kessels AGH, Liem ATA, et al. Basic fibroblast growth factor, glutamine synthetase, and interleukin- 6 in vitreous fluid from eyes with retinal detachment complicated by proliferative vitreoretinopathy. Am J Ophthalmol 2002;134:367-375.

13. Wickham L, Bunce C, Wong D, McGurn D, Charteris DG. Randomized controlled trial of combined 5fluorouracil and low-molecular-weight heparin in the management of unselected rhegmatogenous retinal detachments undergoing primary vitrectomy. Ophthalmology 2007;114:698-704.

14. Ahmadieh H, Feghhi M, Tabatabaei H, Shoeibi N, Ramezani A, et al. Triamcinolone acetonide in silicone-filled eyes as adjunctive treatment for proliferative vitreoretinopathy: a randomized clinical trial. Ophthalmology 2008;115:1938-1943.

15. Wiedemann P, Hilgers RD, Bauer P, Heimann K. Adjunctive daunorubicin in the treatment of proliferative vitreoretinopathy: results of a multicenter clinical trial. Daunomycin Study Group. Am J Ophthalmol 1998;126:550-559.

16. Hollborn M, Francke M, landiev I, Bühner E, Foja C, et al. Early activation of inflammation- and immune response-related genes after experimental detachment of the porcine retina. Invest Ophthalmol Vis Sci 2008;49:1262-1273.

17. Nakazawa T, Matsubara A, Noda K, Hisatomi T, She H, et al. Characterization of cytokine responses to retinal detachment in rats. Mol Vis 2006;12:867-878.

18. Canataroglu H, Varinli I, Ozcan AA, Canataroglu A, Doran F, et al. Interleukin (IL)-6, interleukin (IL)-8 levels and cellular composition of the vitreous humor in proliferative diabetic retinopathy, proliferative vitreoretinopathy, and traumatic proliferative vitreoretinopathy. Ocul Immunol Inflamm 2005;13:375-381.

19. Su CY, Chen MT, Wu WS, Wu WC. Concentration of vascular endothelial growth factor in the subretinal fluid of retinal detachment. J Ocul Pharmacol Ther 2000;16:463-469.

20. Mitamura Y, Takeuchi S, Matsuda A, Tagawa Y, Mizue Y, et al. Hepatocyte growth factor levels in the vitreous of patients with proliferative vitreoretinopathy. Am J Ophthalmol 2000;129:678-680.

21. Ogata N, Nishikawa M, Nishimura T, Mitsuma Y, Matsumura M. Inverse levels of pigment epithelium-derived factor and vascular endothelial growth factor in the vitreous of eyes with rhegmatogenous retinal detachment and proliferative vitreoretinopathy. Am J Ophthalmol 2002;133:851852.

22. Ricker LAG, Kijlstra A, De Jager W, Liem ATA, Hendrikse $H$, et al. Chemokine levels in subretinal fluid obtained during scleral buckling surgery after rhegmatogenous retinal detachment. Invest Ophthalmol Vis Sci 2010;51:4143-4150.

23. de Jager W, Bourcier K, Rijkers GT, Prakken BJ, Seyfert-Margolis V. Prerequisites for cytokine measurements in clinical trials with multiplex immunoassays. BMC Immunol 2009;10:52.

24. Retina Society Terminology Committee. The classification of retinal detachment with proliferative vitreoretinopathy. Ophthalmology 1983;90:121-125.

25. Hosmer DW, Lemeshow S. Model-building strategies and methods for logistic regression. In: Shewhart WA, Wilks SS, editors. Applied logistic regression. New York: Wiley, 1989:82-134.

26. Mietz $\mathrm{H}$, Heimann $\mathrm{K}$. Onset and recurrence of proliferative vitreoretinopathy in various vitreoretinal diseases. Br J Ophthalmol 1995;79:874-877.

27. Bali E, Feron EJ, Peperkamp E, Veckeneer M, Mulder PG, et al. The effect of a preoperative subconjunctival injection of dexamethasone on blood-retinal barrier breakdown following scleral buckling retinal detachment surgery: a prospective randomized placebo-controlled double blind clinical trial. Graefes Arch Clin Exp Ophthalmol 2010;248:957-962.

28. De Jager W, Te Velthuis H, Prakken BJ, Kuis W, Rijkers GT. Simultaneous detection of 15 human cytokines in a single sample of stimulated peripheral blood mononuclear cells. Clin Diagn Lab Immunol 2003;10:133-139. 
29. Yoshimura $T$, Sonoda $\mathrm{KH}$, Sugahara M, Mochizuki $\mathrm{Y}$, Enaida $\mathrm{H}$, et al. Comprehensive analysis of inflammatory immune mediators in vitreoretinal diseases. PLOS ONE 2009;4:e8158.

30. Dieudonné SC, La Heij EC, Diederen R, Kessels AGH, Liem ATA, et al. High TGF- $\beta 2$ levels during primary retinal detachment may protect against proliferative vitreoretinopathy. Invest Ophthalmol Vis Sci 2004;45:4113-4118.

31. Banerjee S, Savant V, Scott RAH, Curnow SJ, Wallace GR, et al. Multiplex bead analysis of vitreous humor of patients with vitreoretinal disorders. Invest Ophthalmol Vis Sci 2007;48:2203-2207.

32. Rasier R, Gormus U, Artunay O, Yuzbasioglu E, Oncel M, et al. Vitreous levels of VEGF, IL-8, and TNFalpha in retinal detachment. Curr Eye Res 2010;35:505-509.

33. Dieudonné SC, La Heij EC, Diederen RMH, Kessels AGH, Liem ATA, et al. Balance of vascular endothelial growth factor and pigment epithelial growth factor prior to development of proliferative vitreoretinopathy. Ophthalmic Res 2007;39:148-154.

34. Kirchhof B, Kirchhof E, Ryan SJ, Dixon JF, Barton BE, et al. Macrophage modulation of retinal pigment epithelial cell migration and proliferation. Graefes Arch Clin Exp Ophthalmol 1989;227:60-66.

35. Ferrick MR, Thurau SR, Oppenheim MH, Herbort CP, Ni M, et al. Ocular inflammation stimulated by intravitreal interleukin-8 and interleukin-1. Invest Ophthalmol Vis Sci 1991;32:1534-1539.

36. Kishimoto T. Interleukin-6: discovery of a pleiotropic cytokine. Arthritis Res Ther 2006;8(Suppl 2):S2.

37. Kuppner MC, McKillop-Smith S, Forrester JV. TGF-beta and IL-1 beta act in synergy to enhance IL-6 and IL-8 mRNA levels and IL-6 production by human retinal pigment epithelial cells. Immunology 1995;84:265-271.

38. Holtkamp GM, Van Rossem M, de Vos AF, Willekens B, Peek R, et al. Polarized secretion of IL-6 and IL-8 by human retinal pigment epithelial cells. Clin Exp Immunol 1998;112:34-43.

39. de Vos AF, Hoekzema R, Kijlstra A. Cytokines and uveitis, a review. Curr Eye Res 1992;11:581-597.

40. Romano M, Sironi M, Toniatti C, Polentarutti N, Fruscella P, et al. Role of IL-6 and its soluble receptor in induction of chemokines and leukocyte recruitment. Immunity 1997;6:315-325.

41. Chong DY, Boehlke CS, Zheng QD, Zhang L, Han Y, et al. Interleukin-6 as a photoreceptor neuroprotectant in an experimental model of retinal detachment. Invest Ophthalmol Vis Sci 2008;49:31933200.

42. Saint-Geniez M, Maharaj AS, Walshe TE, Tucker BA, Sekiyama E, et al. Endogenous VEGF is required for visual function: evidence for a survival role on Müller cells and photoreceptors. PLOS ONE 2008;3:e3554.

43. Limb GA, Franks WA, Munasinghe KR, Chignell AH, Dumonde DC. Proliferative vitreoretinopathy: an examination of the involvement of lymphocytes, adhesion molecules and HLA-DR antigens. Graefes Arch Clin Exp Ophthalmol 1993;231:331-336.

44. Esser P, Bresgen M, Fischbach R, Heimann K, Wiedemann P. Intercellular adhesion molecule-1 levels in plasma and vitreous from patients with vitreoretinal disorders. Ger J Ophthalmol 1995;4:269-274.

45. Elner SG, Elner VM, Pavilack MA, Todd RF 3rd, Mayo-Bond L, et al. Modulation and function of intercellular adhesion molecule-1 (CD54) on human retinal pigment epithelial cells. Lab Invest 1992;66:200-211.

46. Frendl G, Beller DI. Regulation of macrophage activation by IL-3. I. IL-3 functions as a macrophageactivating factor with unique properties, inducing la and lymphocyte function-associated antigen-1 but not cytotoxicity. J Immunol 1990;144:3392-3399.

47. Lindemann A, Mertelsmann R. Interleukin-3: structure and function. Cancer Invest 1993;11:609623.

48. Charteris DG, Hiscott P, Robey HL, Gregor ZJ, Lightman SL, et al. Inflammatory cells in proliferative vitreoretinopathy subretinal membranes. Ophthalmology 1993;100:43-46.

49. Baudouin C, Hofman P, Brignole F, Bayle J, Loubière R, et al. Immunocytology of cellular components in vitreous and subretinal fluid from patients with proliferative vitreoretinopathy. Ophthalmologica 1991;203:38-46. 
50. Gebicke-Haerter PJ, Appel K, Taylor GD, Schobert A, Rich IN, et al. Rat microglial interleukin-3. J Neuroimmunol 1994;50:203-214.

51. Lei H, Rheaume MA, Kazlauskas A. Recent developments in our understanding of how plateletderived growth factor (PDGF) and its receptors contribute to proliferative vitreoretinopathy. Exp Eye Res 2010;90:376-381. 

Chapter 8

\section{Adipokine Levels in Subretinal Fluid from Patients with Rhegmatogenous Retinal Detachment}

Exp Eye Res. In press (in revised form).

L.J.A.G. Ricker, A. Kijlstra, A.G.H. Kessels, W. de Jager, F. Hendrikse, E.C. La Heij 


\section{Abstract}

Purpose: Adipokines have recently emerged as a novel group of mediators with important roles in inflammatory and immune responses and in the process of wound healing. This study investigated the involvement of several adipokines in the future development of proliferative vitreoretinopathy (PVR) following reattachment surgery for rhegmatogenous retinal detachment (RRD).

Methods: A multiplex immunoassay was used to measure 6 different adipokines in 75 subretinal fluid samples collected during reattachment surgery for primary RRD. Twenty-one patients who developed a redetachment due to postoperative PVR after scleral buckling surgery (PVR group) were compared with age-, sex-, and storage-time-matched RRD samples from 54 patients with an uncomplicated postoperative course (RRD group).

Results: Levels of adiponectin $(P=0.006)$, cathepsin $\mathrm{S}(P=0.001)$, and leptin $(P=$ 0.041 ) were significantly elevated in the PVR group as compared to the RRD group. Levels of tissue inhibitor of metalloproteinase (TIMP)-1 were significantly lower in the PVR group than in the RRD group $(P=0.044)$. After correction for diabetes, body mass index (BMI), macular involvement, and preoperative PVR, the association between postoperative PVR development and adiponectin, cathepsin S, and TIMP-1 remained statistically significant $(P<0.05)$, whereas the significant correlation between PVR and elevated leptin levels was lost $(P=0.068)$. There were no significant differences in levels of chemerin $(P=0.351)$ and adipsin $(P=0.915)$. Of all adipokines investigated, multivariate logistic regression analysis showed that adiponectin was the exclusive predictor of the development of postoperative PVR after scleral buckling surgery $(P=0.003)$.

Conclusions: Our findings indicate that, at the time of surgery for primary RRD, an altered expression of certain adipokines is associated with the future development of postoperative PVR. 


\section{Introduction}

Although the success rate of rhegmatogenous retinal detachment (RRD) surgery has improved significantly over the past few decades, the development of proliferative vitreoretinopathy (PVR) remains the primary cause of failure of reattachment strategies. ${ }^{1}$ PVR comprises a series of events which show similarities with the normal wound-healing cascade involving inflammation, migration and proliferation of cells, extracellular matrix deposition, and contraction. Several cytokines and growth factors are involved in these complex processes that ultimately lead to PVR membrane formation. ${ }^{2}$

Adipose tissue has been found to produce a wide range of cytokines, named adipokines, that participate in physiological and pathological processes such as food intake, body mass control, insulin sensitivity, and vascular sclerotic processes. ${ }^{3}$ Recently, adipokines have emerged as a novel group of mediators with important roles in inflammatory and immune responses and in the process of wound healing. ${ }^{3}$ They are mainly produced by adipocytes but may as well originate from a wide variety of other cell types in various body tissues. For example, adipokines and their receptors have been detected in the gastric mucosa, liver, intestine, bone, skeletal muscle, and placenta, indicating that they also have other biological functions besides their roles in appetite, metabolism, and adipogenesis. ${ }^{4-6}$

One of the most extensively studied adipokines in the eye is leptin. Leptin levels have been shown to be significantly elevated in the vitreous of patients with proliferative diabetic retinopathy as well as in patients with retinal detachment, and leptin and its receptor have also been detected in fibrovascular and idiopathic epiretinal membranes. ${ }^{7}$ In addition, leptin expression was increased in the retina, choroid, and sclera in experimental uveitis. ${ }^{8}$ These studies suggest a role for this cytokine in inflammatory and fibrotic processes within the eye. Similar to leptin, the adipokines adiponectin, cathepsin S, and tissue inhibitor of metalloproteinase (TIMP)-1 have been detected in the eye and have been implicated in inflammatory disease or in wound healing and remodelling processes of the retina. ${ }^{9-14}$

In previous studies on biological alterations after primary RRD, we used recently developed multiplex immunoassays for the detection of a wide range of chemokines, interleukins, and growth factors. ${ }^{15,16}$ In the present study, we investigated the expression of adiponectin, cathepsin S, TIMP-1, leptin, chemerin, and adipsin in subretinal fluid samples obtained during scleral buckling surgery in patients from the same population. Patients who developed a redetachment due to postoperative PVR were compared to patients with an uncomplicated postoperative course. We found that altered levels of adiponectin, cathepsin S, and TIMP-1 were associated with the future development of postoperative PVR. 


\section{Material and methods}

\section{Patients}

Between 2001 and 2008, we collected 306 subretinal fluid samples obtained from 302 patients with primary RRD, and stored them in our Biobank. According to a thorough medical record study, 45 samples represented patients who developed a redetachment due to PVR later on during the postoperative course. Of these, 24 samples were not investigated in the present study after applying the following exclusion criteria: low sample volume $(<75 \mu \mathrm{L})$ or contamination with blood $(n=9)$; late PVR development, i.e. more than $2 \frac{1}{2}$ months after reattachment surgery $(n=6)$; preoperative vitreous hemorrhage $(n=4)$; preoperative trauma $(n=4)$; and preoperative cryotherapy $(n=1)$. The remaining 21 samples from 21 patients who developed a redetachment due to PVR within $2 \frac{1}{2}$ months after scleral buckling surgery for primary RRD were included in the study (the PVR group). We compared this group of patients with age-, sex-, and storage-time-matched RRD samples from 54 patients who did not develop a redetachment during the overall follow-up period of at least 3 months, i.e. patients with an uncomplicated postoperative course after primary RRD repair (the RRD group). The same exclusion criteria applied to the RRD group.

The study was performed with the agreement of the University Hospital Maastricht Medical Ethics Committee. All patients gave their informed consent before inclusion in the study and after the nature of the study was explained. The study adhered to the tenets of the Declaration of Helsinki.

\section{Clinical variables}

For all 75 patients who underwent reattachment surgery for primary RRD demographic variables and potential clinical risk factors for PVR development were collected (Table 1). The median follow-up time was 21 months in the PVR group (range $3-80$ ) and 6 months in the RRD group (range 3-80). PVR was graded according to the 1983 Classification of Retinal Detachment with PVR. ${ }^{17}$ Data were collected as " 0 " in the absence of PVR, " 1 " for PVR grade A, " 2 " for PVR grade $B$, " 3 " for PVR grade $C$, and " 4 " for PVR grade D. Duration of retinal detachment was defined as the interval between the onset of symptoms and surgery and was estimated according to a precise history of patients' symptoms. Duration of macular detachment was evaluated separately and was defined as the interval between the onset of a sudden drop in visual acuity and reattachment surgery. The refraction of pseudophakic patients was evaluated based on historical data, i.e. before these patients underwent cataract surgery. 
Table 1 Demographics and Potential Clinical Risk Factors for PVR

\begin{tabular}{|c|c|c|c|}
\hline $\begin{array}{l}\text { Potential Clinical } \\
\text { Risk Factor }\end{array}$ & $\begin{array}{l}\text { RRD Group } \\
(n=54)\end{array}$ & $\begin{array}{l}\text { PVR Group } \\
(\mathbf{n}=\mathbf{2 1})\end{array}$ & $\begin{array}{l}\text { Univariate } \\
\text { Testing }\end{array}$ \\
\hline \multicolumn{4}{|l|}{ Age (years) } \\
\hline Median (range) & $61(43-79)$ & $62(43-76)$ & $N S^{a}$ \\
\hline \multicolumn{4}{|l|}{ Sex (\%) } \\
\hline Female & 26 & 29 & NS \\
\hline Male & 74 & 71 & \\
\hline \multicolumn{4}{|l|}{ BMI } \\
\hline Median (range) & $25.9(17.8-33.0)$ & $25.6(19.5-31.9)$ & NS \\
\hline \multicolumn{4}{|l|}{$\begin{array}{l}\text { Size of retinal detachment } \\
\text { (quadrants) }\end{array}$} \\
\hline Median (range) & $2(1-3)$ & $2(1-4)$ & NS \\
\hline \multicolumn{4}{|l|}{$\begin{array}{l}\text { Total size of retinal defects } \\
\text { (optic disc diameters) }\end{array}$} \\
\hline Median (range) & $2(0-5.5)$ & $1(0-4)$ & NS \\
\hline Macular detachment (\%) & 64 & 86 & NS \\
\hline \multicolumn{4}{|l|}{ Detachment duration (days) } \\
\hline Median (range) & $5(1-75)$ & $6(1-90)$ & NS \\
\hline \multicolumn{4}{|l|}{ Preoperative PVR grade } \\
\hline Median (range) & $1(0-3)$ & $2(0-3)$ & NS \\
\hline Diabetes mellitus (\%) & 11 & 10 & NS \\
\hline Preoperative myopia $>5 \mathrm{D}^{\mathrm{a}}(\%)$ & 17 & 24 & NS \\
\hline \multicolumn{4}{|l|}{ Preoperative lens status (\%) } \\
\hline Pseudophakia & 19 & 33 & NS \\
\hline Aphakia & 0 & 0 & NS \\
\hline Preoperative uveitis (\%) & 0 & 0 & NS \\
\hline Preoperative cryotherapy (\%) & 0 & 0 & NS \\
\hline \multicolumn{4}{|l|}{ Preoperative vitreous } \\
\hline hemorrhage (\%) & 0 & 0 & NS \\
\hline Preoperative trauma (\%) & 0 & 0 & NS \\
\hline
\end{tabular}

${ }^{\mathrm{a}} \mathrm{NS}=$ not significant; $\mathrm{D}=$ diopters.

\section{Specimens}

Undiluted subretinal fluid samples are routinely obtained during scleral buckling surgery for primary RRD in our department, except in cases with shallow detachments or small detachments involving less than one quadrant. Before the incision, scleral and choroidal vessels were carefully cauterized. A cotton tip was used for the removal of any macroscopic blood that surrounded the incision opening. Samples were collected from the surface of the sclera with the use of a 25-gauge bent needle. Upon collection, these samples were transferred to the Biobank Maastricht, where they were aliquoted in $50 \mu \mathrm{L}$ portions and stored at $-80^{\circ} \mathrm{C}$. 


\section{Multiplex immunoassay}

An in-house-validated panel of 6 different adipokines was measured at the Luminex Core Facility (Utrecht, The Netherlands) with a multiplex immunoassay (Luminex, Austin, TX, USA), as described previously. ${ }^{18}$ In summary, the antibody-coated microspheres were incubated for 60 minutes with standards or subretinal fluid $(50 \mu \mathrm{L})$ in 96-well, 1.2- $\mu \mathrm{m}$ filter plates (Millipore, Amsterdam, The Netherlands). Plates were washed (Bio-Plex pro II wash station, Bio-Rad, Hercules, CA, USA), and a cocktail of biotinylated detection antibodies was added for an additional 60 minutes. After repeated washings streptavidin-phycoerythrin was added and incubated for 10 minutes. Next, after 2 additional washes fluorescence intensity was measured. Data collection and analysis of the data from all assays were performed (Bio-Plex system in combination with Bio-Plex Manager software, ver. 4.1; Bio-Rad, Hercules, CA, USA), by using five-parameter curve fitting. The concentrations of the following adipokines were measured: adiponectin, cathepsin S, TIMP-1, leptin, chemerin, and adipsin. The lower limit of detection of the adipokines ranged between 1.0 and 109 $\mathrm{pg} / \mathrm{mL}$. Concentrations above the upper detection limit were assigned the highest value from the respective standard curve.

\section{Statistics}

Since data were not normally distributed, the nonparametric Mann Whitney $U$ test was used to compare ordinal variables such as adipokine levels between the PVR group and the RRD group. Accordingly, the chi-square test was used for the comparison of nominal variables such as sex and diabetes mellitus. Correlations were determined by the Spearman's rho test. Multivariate logistic regression analysis was used to investigate the role of confounding variables with respect to the association between adipokine levels and postoperative PVR development. The following variables were tested as possible confounders: sex, body mass index (BMI), presence of diabetes, involvement of the macular area in the retinal detachment, detachment duration, and preoperative PVR. To reduce the number of possible confounding variables and to prevent overfitting of the model, we first tested the influence of each individual possible confounder on the value of the coefficient of each specific adipokine. A change in the coefficient of more than $10 \%$ was chosen as a cut-off point to enter the variable in the final multivariate regression model. Forward stepwise logistic regression analysis was used to assess the data's predictive ability in determining the occurrence of a redetachment due to postoperative PVR. SPSS 16.0 and GraphPad Prism 4.00 were used for statistical analysis. Differences between groups were considered significant at $P<0.05$, with two-tailed testing. 


\section{Results}

\section{Demographics and clinical variables}

Demographics and potential clinical risk factors for PVR are summarized in Table 1. In total, 75 subretinal fluid samples from 75 patients with primary RRD were analyzed for adipokine content. Twenty-one patients who developed a redetachment due to PVR (PVR group) were compared with 54 patients with an uncomplicated postoperative course after reattachment surgery (RRD group). Both groups were matched for age, sex, and storage time of the sample. The median age was 62 years in the PVR group (range $43-76$ ) and 61 years in the RRD group (range $43-79$ ), and the majority of patients was male in both groups ( $71 \%$ vs. $74 \%$, respectively). The median time interval between scleral buckling surgery and redetachment due to PVR was 37 days (range $13-80$ ). In this group of patients, 10 patients had a redetachment due to postoperative PVR grade $B, 10$ patients due to postoperative PVR grade $C$, and one patient due to postoperative PVR grade $D$. Differences between the PVR group and the RRD group with respect to baseline characteristics were nonsignificant, including involvement of the macula in the detachment $(P=0.067)$, the duration of symptoms between onset and reattachment surgery $(P=0.650)$, preoperative PVR $(P=0.218), \mathrm{BMI}(P=0.630)$, and the number of patients with diabetes $(P=0.842)$ (Table 1$)$.

\section{Adipokine levels in subretinal fluid}

Levels of adiponectin, cathepsin S, leptin, chemerin, and adipsin were detected in all 75 samples investigated, whereas TIMP-1 levels were above the upper detection limit in 23/75 (31\%) samples. Adipokine levels in the RRD group and the PVR group are summarized in Table 2 and illustrated in Fig. 1.

The median levels of adiponectin were significantly elevated in the PVR group (26877 pg/mL; range $7810-46132$ ) as compared to the RRD group (17699 pg/mL; range $2300-38737)(P=0.006)$. After correction for $\mathrm{BMI}$, which was the only variable that influenced the coefficient of adiponectin, a bivariate analysis still showed a significant association between elevated adiponectin levels and postoperative PVR development $(P=0.002)$. Adiponectin levels were similar between those with and without diabetes $(P=0.643)$, and no significant association was found between adiponectin levels and BMI $(r=-0.15 ; P=0.25)$. On the other hand, a trend toward higher median levels in females $(26872 \mathrm{pg} / \mathrm{mL}$ ) as compared to males (17549 $\mathrm{pg} / \mathrm{mL})$ was observed $(P=0.052)$. 
Table 2 Adipokine Levels and the Development of Postoperative PVR

\begin{tabular}{|c|c|c|c|}
\hline $\begin{array}{l}\text { Adipokine } \\
\text { (pg/mL) }\end{array}$ & $\begin{array}{l}\text { RRD Group } \\
(n=54)\end{array}$ & $\begin{array}{l}\text { PVR Group } \\
(n=21)\end{array}$ & $\begin{array}{c}\text { Univariate } \\
\text { testing }\end{array}$ \\
\hline \multicolumn{4}{|l|}{ Adiponectin } \\
\hline Median & 17699 & 26877 & $P=0.006$ \\
\hline (range) & $(2300-38737)$ & $(7810-46132)$ & \\
\hline \multicolumn{4}{|l|}{ Cathepsin S } \\
\hline Median & 4592 & 6119 & $P=0.001$ \\
\hline (range) & $(1230-10151)$ & $(2326-9453)$ & \\
\hline \multicolumn{4}{|l|}{ TIMP-1 } \\
\hline Median & 16356 & 14401 & $P=0.044$ \\
\hline (range) & $(8581->26200)$ & $(8724->26200)$ & \\
\hline \multicolumn{4}{|l|}{ Leptin } \\
\hline Median & 1136 & 2357 & $P=0.041$ \\
\hline (range) & $(693.6-7397)$ & $(817.9-13067)$ & \\
\hline \multicolumn{4}{|l|}{ Chemerin } \\
\hline Median & 21361 & 18995 & $P=0.351$ \\
\hline (range) & $(6496-42930)$ & $(11768-36001)$ & \\
\hline \multicolumn{4}{|l|}{ Adipsin } \\
\hline Median & 94.9 & 85.8 & $P=0.915$ \\
\hline (range) & $(35.7-145.8)$ & $(39.2-270.0)$ & \\
\hline
\end{tabular}

A highly significant difference was also noted for cathepsin $\mathrm{S}$ with median levels of $6119 \mathrm{pg} / \mathrm{mL}$ (range 2326 - 9453) in the PVR group and $4592 \mathrm{pg} / \mathrm{mL}$ in the RRD group (range $1230-10151)(P=0.001)$. Macular involvement in the primary retinal detachment and $\mathrm{BMI}$ were considered confounding variables due to their influence on the coefficient of cathepsin S. After multivariate analysis, the association between elevated cathepsin S concentrations and development of PVR remained statistically significant $(P=0.029)$. Sex, presence of diabetes, and BMI were not associated with cathepsin S levels $(P>0.05)$.

For TIMP-1, 2/21 (9.5\%) PVR samples and 21/54 (38.9\%) RRD samples were above the upper detection limit. The number of samples that was detected by our multiplex immunoassay was significantly different between both groups ( $P=0.013$ ). Moreover, median levels of TIMP-1 were significantly lower in the PVR group (14401 $\mathrm{pg} / \mathrm{mL}$; range $8724->26200)$ than in the RRD group (16356 pg/mL; range 8581 $>26200)(P=0.044)$. None of the possible confounding variables (sex, BMI, diabetes, macular involvement, detachment duration, and preoperative PVR) influenced the coefficient of TIMP-1. No significant associations were found between TIMP-1 levels and sex, diabetes, or BMI $(P>0.05)$.

We found a 2-fold elevation of median leptin levels in patients who developed postoperative PVR (2357 pg/mL; range 818 - 13067) as compared to RRD patients with an uncomplicated postoperative course after reattachment surgery (1136 
$\mathrm{pg} / \mathrm{mL}$; range 694 - 7397) $(P=0.041)$. Preoperative PVR, BMI, and presence of diabetes may be considered as confounding variables since they influenced the coefficient of leptin. After correction for these variables in a multivariate analysis, the association between elevated leptin levels and PVR development lost significance ( $P$ $=0.068$ ). Median leptin levels were significantly elevated in female patients (2196 $\mathrm{pg} / \mathrm{mL} ; n=20)$ as compared to male patients $(1118 \mathrm{pg} / \mathrm{mL} ; n=55)(P=0.003)$, whereas a trend was shown toward increased levels in patients with diabetes (2900 $\mathrm{pg} / \mathrm{mL} ; n=8)$ as compared to those without diabetes $(1214 \mathrm{pg} / \mathrm{mL} ; n=67)(P=$ 0.091). Furthermore, subretinal fluid leptin levels correlated significantly with body mass index (BMI) $(r=0.40)(P=0.001)$. There were no significant differences in levels of chemerin $(P=0.351)$ and adipsin $(P=0.915)$ between the PVR group and the RRD group.

\section{Correlations between adipokines and clinical variables}

There was a positive correlation $(P<0.001)$ between adiponectin and both cathep$\sin \mathrm{S}(r=0.57)$ and leptin $(r=0.49)$, and between cathepsin $\mathrm{S}$ and leptin $(r=0.46)$. A negative correlation was found between TIMP-1 and each adiponectin $(r=-0.41)(P$ $<0.001)$, cathepsin S $(r=-0.53)(P<0.001)$, and leptin $(r=-0.36)(P=0.002)$. In general, correlations between adipokines and clinical variables were low $(r<0.4)$. For example, both adiponectin and leptin were correlated $(P<0.05)$ with the duration of macular detachment ( $r=0.34$ and $r=0.30$, respectively), and cathepsin $\mathrm{S}$ was found to be correlated with the number of quadrants involved $(r=0.34)$. We found TIMP-1 to be negatively associated $(P<0.05)$ with the duration of macular detachment and the number of quadrants involved ( $r=-0.31$ and $r=-0.35$, respectively). There were no significant correlations between preoperative PVR and levels of any adipokine.

Of all adipokines investigated, logistic regression analysis showed that adiponectin was the exclusive predictor of the development of a redetachment due to PVR after scleral buckling surgery $(P=0.003)$. We found that for each $10000 \mathrm{pg} / \mathrm{mL}$ increase in adiponectin content, the probability of the occurrence of postoperative PVR increased with an odds ratio of 2.3.

\section{Discussion}

The current study showed an association between increased levels of adiponectin and cathepsin S as well as decreased levels of TIMP-1 and the development of postoperative PVR after reattachment surgery for primary RRD. Stepwise logistic regression analysis revealed that adiponectin was an independent predictor of postoperative PVR. 
Recent animal studies have demonstrated an altered expression of genes and proteins related to inflammation already 24 hours after creation of experimental retinal detachment. ${ }^{19,20}$ Elevated levels of some of these mediators may lead to an aberrant wound healing response and predispose an individual to the future development of complications such as PVR. Analysis of subretinal fluid soon after the onset of primary RRD but before the development of postoperative PVR may shed light on the initial alterations that underlie the pathogenesis of PVR by comparison of those who develop a future redetachment due to postoperative PVR (within $2 \frac{1}{2}$ months after sampling) and those who have an uncomplicated follow-up. Since it is most likely that a new event causes a recurrence in patients who have PVR developed after 3 months rather than the stimulus that is of our interest, ${ }^{21}$ patients with late PVR development were excluded from our study. Moreover, we excluded the samples from patients with preoperative conditions that possibly induce PVR, since these would have yielded high cytokine levels that were directly related to that condition.

We used bead-based multiplex immunoassays for the simultaneous measurement of 6 different adipokines. Compared to enzyme-linked immunosorbent assay (ELISA), this technique combines similar performance with limited sample volume requirements. ${ }^{22}$ Although multiplex immunoassays have a very wide range of standard curves, TIMP-1 levels were above the upper detection limit in almost one-third of samples. Due to the limited amount of sample volumes being collected during scleral buckling procedures, a dilution step could not be performed. To identify factors that may induce the development of postoperative PVR, analysis of subretinal fluid rather than vitreous fluid may be more appropriate because of its close proximity to the retinal pigment epithelium (RPE) monolayer after initial retinal detachment.

Baseline characteristics in both the PVR group and the RRD group appeared similar. Nevertheless, testing for possible confounding variables and correction for some of these were necessary due to small differences in several important preoperative parameters including macular involvement, duration of detachment, and preoperative PVR. Furthermore, sex, BMI, and diabetes were considered possible confounding variables since these have been shown to be associated with adipokine serum levels in previous studies. ${ }^{23-27}$ After correction for preoperative confounding variables, levels of adiponectin, cathepsin S, and TIMP-1 remained significantly different between both groups.

Adiponectin has been attributed anti-inflammatory properties next to its roles in the regulation of insulin sensitivity and hepatic glucose metabolism. ${ }^{28,29}$ In particular, adiponectin has been shown to stimulate the secretion of anti-inflammatory cytokines such as interleukin-10, inhibits the expression of adhesion molecules and reduces nuclear factor kappa $B$ (NFkB) levels in endothelial cells, and promotes the differentiation of monocytes into the anti-inflammatory M2 macrophage pheno- 
type. ${ }^{30,31}$ However, some controversy in the literature exists on adiponectin's role in attenuating excessive inflammatory responses, since increased levels of adiponectin have been observed in patients with ulcerative colitis (serum), multiple sclerosis (cerebrospinal fluid), and rheumatoid arthritis (serum and synovial fluid). ${ }^{27,32-34}$ Moreover, in vitro studies have shown that adiponectin induces the production of pro-inflammatory cytokines in synovial fibroblasts. ${ }^{35}$ In the rat eye, adiponectin and its receptors have been demonstrated in various locations including the choroid, iris, ciliary body, and cornea. ${ }^{36}$ In a rodent model of laser-induced choroidal neovas cularization, treatment with adiponectin resulted in decreased levels of vascular endothelial growth factor (VEGF) and inhibition of choroidal angiogenesis, suggesting a therapeutic role for adiponectin in wet age-related macular degeneration (AMD). ${ }^{9}$ Whether adiponectin may help induce the development of PVR or counteracts an excessive inflammatory response after retinal detachment needs to be addressed in future studies.
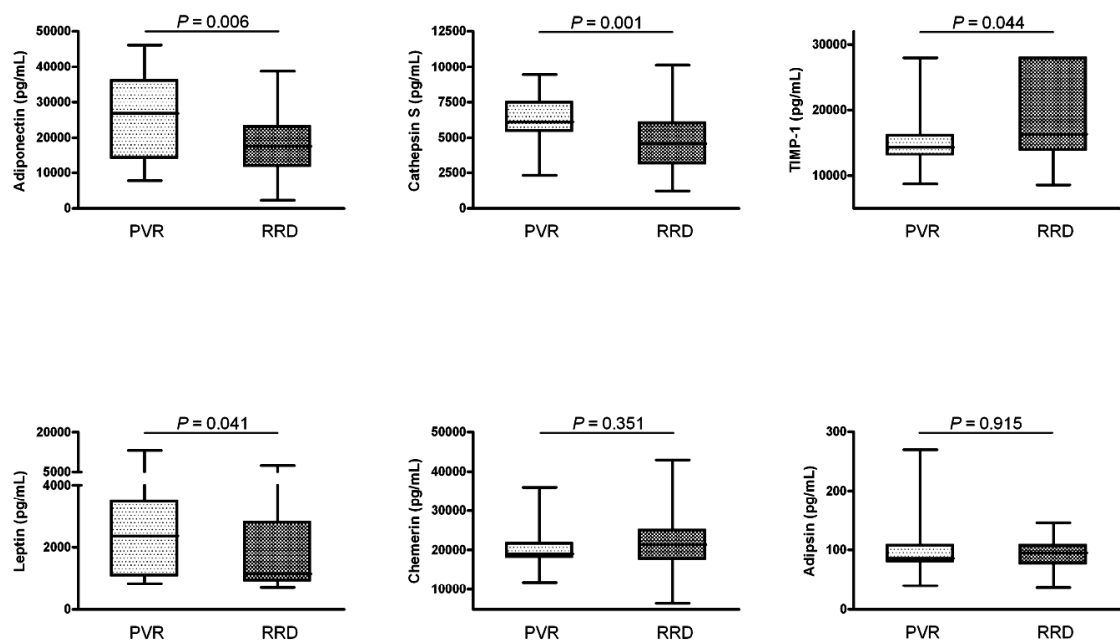

Figure 1 Box-and-whisker plots of adipokine levels in patients with primary rhegmatogenous retinal detachment. A multiplex immunoassay was used to determine 6 different adipokines in subretinal fluid samples obtained during scleral buckling surgery for rhegmatogenous retinal detachment. Patients who developed a redetachment due to postsurgical PVR within $2 \frac{1}{2}$ months after reattachment surgery $(n=21$, 'PVR' group) were compared with controls who had an uncomplicated retinal detachment during the overall follow-up period ( $n=54$, 'RRD' group). Levels of adiponectin, cathepsin S, and leptin were significantly higher $(P<0.05)$, whereas levels of TIMP-1 were significantly lower $(P<0.05)$ in patients in the PVR group as compared to patients in the RRD group. After correction for confounding variables, the significant difference in leptin levels between the PVR group and the RRD group was lost $(P=0.068)$ (see text). Box: lower and upper quartiles; horizontal line: the median. 
The cysteine protease cathepsin $\mathrm{S}$ is involved in extracellular matrix degradation and has a key role in antigen presentation. ${ }^{26}$ Although serum cathepsin $S$ levels are strongly correlated with adipose tissue size, we could not find an association between our subretinal fluid levels and $\mathrm{BMI}$, indicating the local production of this protease in the eye. Within the eye, cathepsin S predominates in the RPE and choroid, and plays an important role in the maintenance of photoreceptor cells via lysosomal digestion of outer segments. ${ }^{12,37,38}$ Also the natural inhibitors of proteases, like TIMP-1, may have a role in normal retinal homeostasis. Not surprisingly, an altered expression of TIMP-1 is believed to play a role in ocular fibrosis. RPE cells, among other cells, have been shown to produce TIMP-1 in vitro, ${ }^{39}$ and TIMP-1 has been demonstrated in epiretinal and subretinal membranes. ${ }^{14}$ Moreover, elevated vitreous TIMP-1 levels were associated with PVR development. ${ }^{40}$ In contrast to this latter report, we found decreased levels in patients who developed PVR as compared to patients who did not. These conflicting results may be explained by differences in sampling specimen, sampling size, baseline characteristics of the study population, and most importantly, timing of sampling (preclinical stage versus end-stage PVR). As tissue remodelling plays a pivotal role in tissue repair, an imbalance in the proteolytic environment has been implicated in fibrotic disorders and scar tissue formation following injury. ${ }^{11}$ Therefore, the altered expression of TIMP-1 and cathepsin S in the PVR group in the current study and their correlations with the extent and duration of retinal detachment may indicate their involvement in wound healing processes in the detached retina.

Besides its roles in lipid metabolism, energy use, and satiety, leptin has emerged as a pleiotropic molecule with involvement in a broad range of biological functions. ${ }^{4,41}$ In both ob/ob and $\mathrm{db} / \mathrm{db}$ mice, defective in leptin and leptin receptor, respectively, a dysregulation of immune and inflammatory responses and an impaired wound healing has been observed. ${ }^{42-47}$ Leptin levels have been shown to be elevated in inflammatory bowel disease, rheumatoid arthritis, multiple sclerosis, Behçet's disease, and Vogt-Koyanagi-Harada disease, ${ }^{48-52}$ underlining its possible pro-inflammatory properties. Although we found a twofold elevation of median leptin levels in the PVR group as compared to the RRD group, this difference lost statistical significance $(P=0.068)$ after correction for preoperative PVR, BMI, and diabetes. Taken together, it appears that increased levels of leptin do not predispose to PVR development after primary retinal detachment. Previous studies on leptin in retinal detachment have not distinguished between those who develop postoperative PVR and those with an uncomplicated follow-up. ${ }^{7,53}$

Adipokines have recently emerged as novel mediators in inflammatory responses and wound healing processes in several disease entities. In this report we have shown the altered expression of adiponectin, cathepsin S, and TIMP-1 in subretinal fluid specimens obtained from patients who developed a redetachment due to PVR. Together with the significant correlations between these adipokines 
and the extent and/or duration of retinal detachment, our findings indicate that these mediators may contribute to the early cellular processes that ultimately lead to the development of postoperative PVR.

\section{References}

1. D'Amico DJ. Clinical practice. Primary retinal detachment. N Engl J Med 2008;359:2346-2354.

2. Pastor JC, de la Rúa ER, Martín F. Proliferative vitreoretinopathy: risk factors and pathobiology. Prog Retin Eye Res 2002;21:127-144.

3. Lago F, Dieguez C, Gómez-Reino J, Gualillo O. The emerging role of adipokines as mediators of inflammation and immune responses. Cytokine Growth Factor Rev 2007;18:313-325.

4. Frübeck G. Intracellular signalling pathways activated by leptin. Biochem J 2006;393:7-20.

5. Maheshwari A, Kurundkar AR, Shaik SS, et al. Epithelial cells in fetal intestine produce chemerin to recruit macrophages. Am J Physiol Gastrointest Liver Physiol 2009;297:G1-G10.

6. Presle $\mathrm{N}$, Pottie $\mathrm{P}$, Dumond $\mathrm{H}$, et al. Differential distribution of adipokines between serum and synovial fluid in patients with osteoarthritis. Contribution of joint tissues to their articular production. Osteoarthritis Cartilage 2006;14:690-695.

7. Gariano RF, Nath AK, D'Amico DJ, Lee T, Sierra-Honigmann MR. Elevation of vitreous leptin in diabetic retinopathy and retinal detachment. Invest Ophthalmol Vis Sci 2000;41:3576-3581.

8. Kükner A, Colakoglu N, Serin D, Alagöz G, Celebi S, Kükner AS. Effects of intraperitoneal vitamin E, melatonin and aprotinin on leptin expression in the guinea pig eye during experimental uveitis. Acta Ophthalmol Scand 2006;84:54-61.

9. Bora PS, Kaliappan S, Lyzogubov VV, et al. Expression of adiponectin in choroidal tissue and inhibition of laser induced choroidal neovascularization by adiponectin. FEBS Lett 2007;581:1977-1982.

10. Im E, Kazlauskas A. The role of cathepsins in ocular physiology and pathology. Exp Eye Res 2007;84:383-388.

11. Sethi CS, Bailey TA, Luthert PJ, Chong NHV. Matrix metalloproteinase biology applied to vitreoretinal disorders. Br J Ophthalmol 2000;84:654-666.

12. Sugano $E$, Tomita $H$, Ishiguro A, Isago $H$, Tamai M. Nitric oxide-induced accumulation of lipofuscinlike materials is caused by inhibition of cathepsin S. Curr Eye Res 2006;31:607-616.

13. Symeonidis C, Diza E, Papakonstantinou E, Souliou E, Dimitrakos SA, Karakiulakis G. Correlation of the extent and duration of rhegmatogenous retinal detachment with the expression of matrix metalloproteinases in the vitreous. Retina 2007;27:1279-1285.

14. Webster L, Chignell AH, Limb GA. Predominance of MMP-1 and MMP-2 in epiretinal and subretinal membranes of proliferative vitreoretinopathy. Exp Eye Res 1999;68:91-98.

15. Ricker LJAG, Kijlstra A, De Jager W, Liem ATA, Hendrikse F, La Heij EC. Chemokine levels in subretinal fluid obtained during scleral buckling surgery after rhegmatogenous retinal detachment. Invest Ophthalmol Vis Sci 2010;51:4143-4150.

16. Ricker LJAG, Kijlstra A, Kessels AGH, et al. Interleukin and growth factor levels in subretinal fluid in rhegmatogenous retinal detachment: a case-control study. PLOS ONE, in press.

17. Retina Society Terminology Committee. The classification of retinal detachment with proliferative vitreoretinopathy. Ophthalmology 1983;90:121-125.

18. De Jager W, Bourcier K, Rijkers GT, Prakken BJ, Seyfert-Margolis V. Prerequisites for cytokine measurements in clinical trials with multiplex immunoassays. BMC Immunol 2009;10:52.

19. Hollborn M, Francke M, landiev I, et al. Early activation of inflammation- and immune responserelated genes after experimental detachment of the porcine retina. Invest Ophthalmol Vis Sci 2008;49:1262-1273.

20. Nakazawa T, Matsubara A, Noda K, et al. Characterization of cytokine responses to retinal detachment in rats. Mol Vis 2006;12:867-878. 
21. Mietz $\mathrm{H}$, Heimann $\mathrm{K}$. Onset and recurrence of proliferative vitreoretinopathy in various vitreoretinal diseases. Br J Ophthalmol 1995;79:874-877.

22. De Jager W, Rijkers GT. Solid-phase and bead-based cytokine immunoassay: a comparison. Methods 2006;38:294-303.

23. Considine RV, Caro JF. Leptin and the regulation of body weight. Int J Biochem Cell Biol 1997;29:1255-1272.

24. Friedman JM, Halaas JL. Leptin and the regulation of body weight. Nature 1998;395:763-770.

25. Rasouli N, Kern PA. Adipocytokines and the metabolic complications of obesity. J Clin Endocrinol Metab 2008;93:S64-S73.

26. Taleb S, Clément K. Emerging role of cathepsin S in obesity and its associated diseases. Clin Chem Lab Med 2007;45:328-332.

27. Weigert J, Obermeier F, Neumeier $\mathrm{M}$, et al. Circulating levels of chemerin and adiponectin are higher in ulcerative colitis and chemerin is elevated in Crohn's disease. Inflamm Bowel Dis 2010;16:630-637.

28. Antoniades C, Antonopoulos AS, Tousoulis D, Stefanadis C. Adiponectin: from obesity to cardiovascular disease. Obes Rev 2009;10:269-279.

29. Juge-Aubry CE, Henrichot E, Meier CA. Adipose tissue: a regulator of inflammation. Best Pract Res Clin Endocrinol Metab 2005;19:547-566.

30. Lovren F, Pan Y, Quan A, et al. Adiponectin primes human monocytes into alternative antinflammatory M2 macrophages. Am J Physiol Heart Circ Physiol 2010;299:H656-H663.

31. Tilg $\mathrm{H}$, Moschen AR. Adipocytokines: mediators linking adipose tissue, inflammation and immunity. Nat Rev Immunol 2006;6:772-783.

32. Hietaharju A, Kuusisto H, Nieminen R, Vuolteenaho K, Elovaara I, Moilanen E. Elevated cerebrospinal fluid adiponectin and adipsin levels in patients with multiple sclerosis: a Finnish co-twin study. Eur J Neurol 2010;17:332-334.

33. Otero $M$, Lago R, Gomez R, et al. Changes in plasma levels of fat-derived hormones adiponectin, leptin, resistin and visfatin in patients with rheumatoid arthritis. Ann Rheum Dis 2006;65:11981201.

34. Schäffler A, Ehling A, Neumann E, et al. Adipocytokines in synovial fluid. JAMA 2003;290:17091710.

35. Ehling $\mathrm{A}$, Schäffler $\mathrm{A}$, Herfarth $\mathrm{H}$, et al. The potential of adiponectin in driving arthritis. $J$ Immunol 2006;176:4468-4478.

36. Bora PS, Kaliappan S, Xu Q, et al. Alcohol linked to enhanced angiogenesis in rat model of neovascularization. FEBS J 2006;273:1403-1414.

37. Lai CM, Shen WY, Constable I, Rakoczy PE. The use of adenovirus-mediated gene transfer to develop a rat model for photoreceptor degeneration. Invest Ophthalmol Vis Sci 2000;41:580-584.

38. Rakoczy PE, Mann K, Cavaney DM, Robertson T, Papadimitreou J, Constable IJ. Detection and possible functions of a cysteine protease involved in digestion of rod outer segments by retinal pigment epithelial cells. Invest Ophthalmol Vis Sci 1994;35:4100-4108.

39. Alexander JP, Bradley JMB, Gabourel JD, Acott TS. Expression of matrix metalloproteinases and inhibitor by human retinal pigment epithelium. Invest Ophthalmol Vis Sci 1990;31:2520-2528.

40. Matsuo T, Okada Y, Shiraga F, Yanagawa T. TIMP-1 and TIMP-2 levels in vitreous and subretinal fluid. Jpn J Ophthalmol 1998;42:377-380.

41. Murad A, Nath AK, Cha ST, Demir E, Flores-Riveros J, Sierra-Honigmann MR. Leptin is an autocrine/paracrine regulator of wound healing. FASEB J 2003;17:1895-1897.

42. Busso N, So A, Chobaz-Peclat V, et al. Leptin signaling deficiency impairs humoral and cellular immune responses and attenuates experimental arthritis. J Immunol 2002;168:875-882.

43. Frank S, Stallmeyer B, Kampfer H, Kolb N, Pfeilschifter J. Leptin enhances wound re-epithelialization and constitutes a direct function of leptin in skin repair. J Clin Invest 2000;106:501-509.

44. Lord GM, Matarese G, Howard JK, Baker RJ, Bloom SR, Lechler RI. Leptin modulates the T-cell immune response and reverses starvation-induced immunosuppression. Nature 1998;394:897-901. 
45. Sanna V, Di Giacomo A, La Cava A, et al. Leptin surge precedes onset of autoimmune encephalomyelitis and correlates with development of pathogenic $\mathrm{T}$ cell responses. J Clin Invest 2003;111:241-250.

46. Siegmund B, Lehr HA, Fantuzzi G. Leptin: a pivotal mediator of intestinal inflammation in mice. Gastroenterology 2002;122:2011-2025.

47. Stallmeyer B, Kampfer H, Podda M, Kaufmann R, Pfeilschifter J, Frank SA. Novel keratinocyte mitogen: regulation of leptin and its functional receptor in skin repair. J Invest Dermatol 2001;117:98105.

48. Barbier $M$, Vidal $H$, Desreumaux $P$, et al. Overexpression of leptin mRNA in mesenteric adipose tissue in inflammatory bowel diseases. Gastroenterol Clin Biol 2003;27:987-991.

49. Bokarewa M, Bokarew D, Hultgren O, Tarkowski A. Leptin consumption in the inflamed joints of patients with rheumatoid arthritis. Ann Rheum Dis 2003;62:952-956.

50. Evereklioglu C, Inalöz HS, Kirtak N, et al. Serum leptin concentration is increased in patients with Behçet's syndrome and is correlated with disease activity. Br J Dermatol 2002;147:331-336.

51. Liu L, Yang P, He H, et al. Leptin increases in Vogt-Koyanagi-Harada (VKH) disease and promotes cell proliferation and inflammatory cytokine secretion. Br J Ophthalmol 2008;92:557-561.

52. Matarese G, Carrieri PB, La Cava A, et al. Leptin increase in multiple sclerosis associates with reduced number of CD4 (+) CD25+ regulatory T cells. Proc Natl Acad Sci USA 2005;102:5150-5155.

53. Maberley D, Cui JZ, Matsubara JA. Vitreous leptin levels in retinal disease. Eye 2006;20:801-804. 

Chapter 9

Prediction of Proliferative Vitreoretinopathy after Retinal

Detachment Surgery: Potential of Biomarker Profiling 


\section{Abstract}

Purpose: To investigate the potential of a combined assessment of clinical risk factors and biomarker profiling in the prediction of proliferative vitreoretinopathy (PVR) after retinal detachment surgery.

Methods: Multiplex bead-based immunoassays were used for the simultaneous measurement of 50 biomarkers in subretinal fluid samples obtained from patients who underwent scleral buckling surgery for primary rhegmatogenous retinal detachment (RRD). Of 306 samples that were collected and stored in our BioBank, we selected 21 samples from patients who developed a redetachment due to PVR within 3 months after reattachment surgery for primary RRD (PVR group). These were compared with age-, sex-, and storage-time-matched RRD samples from 54 patients with an uncomplicated postoperative course after primary RRD repair (RRD group).

Results: Preoperative PVR was the only clinical variable that was an independent predictor of postoperative PVR development $(P=.035)$, and resulted in an area under the receiver operating characteristic curve (AUC) of 0.67 (95\% confidence interval $(\mathrm{Cl}) 0.51-0.83$ ). The addition of the biomarkers chemokine ( $\mathrm{C}-\mathrm{C}$ motif) ligand 22 ( $C \mathrm{CL} 22)$, interleukin-3, and macrophage migration inhibitory factor improved the model significantly $(P<.001)$ and resulted in an AUC of $0.93(95 \% \mathrm{Cl} 0.82$ $-1.04)$. A sensitivity of $94.1 \%$ and a specificity of $94.2 \%$ were reached, using a cutoff value of $32 \%$.

Conclusions: In combination with preoperative PVR grade, the measurement of a single biomarker or a small multibiomarker panel shows great potential and may predict postoperative PVR development after primary RRD in a highly sensitive and specific manner. 


\section{Introduction}

Proliferative vitreoretinopathy (PVR) is a common cause of failure of reattachment surgery after primary rhegmatogenous retinal detachment (RRD). It is characterized by intraretinal fibrosis and the formation of cellular membranes on both sides of the retina. In fact, the PVR process is reminiscent of an aberrant wound healing response in which several stages can be distinguished, including the influx of inflammatory cells, migration and proliferation of cells, and deposition and remodelling of extracellular matrix. ${ }^{1}$ To improve anatomic or visual success rates of reattachment strategies, research has focused on the use of intravitreal pharmacological agents directed against one or more of these stages. ${ }^{2}$ So far, none of these is used in clinical practice on a routine basis because of lack of efficacy or concerns about retinal toxicity. ${ }^{3-6}$ For example, the combined intravitreal use of 5-fluorouracil and heparin did not show an improved outcome of vitreoretinal surgery for established PVR or unselected RRD cases. ${ }^{5,6}$ More promising results were however demonstrated for selected RRD patients at high risk for developing postoperative PVR. ${ }^{7}$ These studies have emphasized the need for the identification of high-risk subgroups to improve the risk-benefit ratio of pharmacological adjunct strategies. If the development of postoperative PVR is predictable, only patients at high risk may be targeted with drugs that are potentially detrimental to retinal tissues. Moreover, these clinical trials have underscored the importance of research that focuses on the pre-clinical stages of PVR rather than on patients with established PVR.

Although several studies have identified clinical risk factors for the development of PVR, ${ }^{8,9}$ attempts to evaluate the potential of biomarker profiling have been scarce until now. ${ }^{10,11}$ Since a wide range of cytokines has been suggested to play a role in the pathogenesis of $P V R,{ }^{10-14}$ it is likely that specific cytokines could serve as PVR biomarkers that can be used as prognostic factors in patients with primary RRD. Pathological processes such as the breakdown of the blood-retinal barrier, the migration and proliferation of retinal pigment epithelial cells and glial cells, and the influx of inflammatory cells into the subretinal space may produce PVR-specific cytokine profiles. In previous studies on early biological alterations after primary $\mathrm{RRD}$, we have demonstrated a possible causal relation between some cytokines and the development of postoperative PVR. ${ }^{14,15}$ In the present study, we have extended the biomarker panel in the same patient population and have addressed the potential of these biomarkers in a clinical setting. So far, prediction models have been constructed based on clinical parameters only. ${ }^{16,17}$ The aim of the present study was to identify biological markers that in conjunction with clinical factors are able to predict the future development of postoperative PVR with high sensitivity and high specificity. 


\section{Methods}

\section{Patients}

Undiluted subretinal fluid samples were obtained in patients who underwent scleral buckling surgery for primary RRD. In our department, this surgical procedure was only used in patients with retinal detachments up to PVR grade C1 according to the 1983 classification. ${ }^{18}$ Subretinal fluid was not collected in relatively simple cases, i.e. patients with small retinal detachments ( $<1$ quadrant involved) and patients with shallow detachments. All patients were operated on by three experienced vitreoretinal surgeons. Of 306 samples that were collected between 2001 and 2008, 45 patients developed a redetachment due to PVR during the postoperative course requiring repeat surgery, as was revealed by a thorough medical record study. Twenty-four of those were excluded because of the following reasons: low sample volume or contamination with blood $(n=9)$ ), late PVR development ( $>3$ months after the primary surgical procedure) $(n=6)$, preoperative vitreous hemorrhage $(n=4)$, preoperative trauma $(n=4)$, and preoperative cryotherapy $(n=1)$. None of the patients who developed postoperative PVR had preoperative uveitis. The remaining 21 samples comprised the PVR group and these were compared with control subretinal fluid samples from the RRD group, i.e. patients who had an uncomplicated follow-up after scleral buckling surgery for primary RRD. Every single PVR sample was compared with 2 to 3 age-, sex-, and storage-time-matched RRD samples, which resulted in 54 control samples. The same exclusion criteria applied to the RRD group.

\section{Clinical Risk Factors for the Prediction of Proliferative Vitreoretinopathy}

The following preoperative and intraoperative variables with the potential to induce or influence PVR development were collected for all 75 patients: age, sex, size of retinal detachment, number of retinal defects, macular detachment, detachment duration, preoperative PVR grade, presence of diabetes, pseudophakia, intraoperative gas use, intraoperative cryotherapy, and intraoperative minor hemorrhage. The median follow-up time was 21 months in the PVR group (range $3-80$ ) and 6 months in the RRD group (range $3-80$ ). PVR was graded according to the 1983 Classification of Retinal Detachment with PVR. ${ }^{18}$ For statistical purposes, data were collected as " 0 " in the absence of PVR, " 1 " for PVR grade A, " 2 " for PVR grade B, " 3 " for PVR grade C, and " 4 " for PVR grade D. Duration of retinal detachment was defined as the interval between the onset of symptoms and surgery and was estimated according to a precise history of patients' symptoms. Duration of macular detachment was evaluated separately and was defined as the interval between the onset of a sudden drop in visual acuity and reattachment surgery. 


\section{Biomarkers for the Prediction of Proliferative Vitreoretinopathy}

Biomarkers were measured in subretinal fluid samples obtained during scleral buckling surgery for primary RRD. Upon collection, undiluted samples were transferred to the BioBank Maastricht where they were aliquoted in $50 \mu \mathrm{L}$ portions and stored at $-80^{\circ} \mathrm{C}$ until assayed, as described previously..$^{19}$ Multiplex immunoassays (Luminex, Austin, TX, USA) were performed at the Luminex Core Facility (Utrecht, The Netherlands) using an in-house-validated panel which incorporates an appropriate Quality Control Program. ${ }^{20}$ In summary, the antibody-coated microspheres were incubated for 60 minutes with standards or subretinal fluid $(50 \mu \mathrm{L})$. Plates were washed (BioPlex pro II wash station, Bio-Rad, Hercules, CA, USA) and a cocktail of biotinylated detection antibodies was added for an additional 60 minutes. After repeated washings, streptavidin-phycoerythrin was added and incubated for 10 minutes. Next, fluorescence intensity was measured and analysis of the data from all assays was performed (Bio-Plex system in combination with Bio-Plex Manager software, ver. 4.1; Bio-Rad, Hercules, CA, USA) using five-parameter curve fitting. The concentrations of 50 biomarkers were measured (Table 1). Concentrations above the upper detection limit were assigned the highest value from the respective standard curve, whereas concentrations below the lower detection limit were assigned the lowest value from the respective standard curve.

\section{Statistical Analysis}

The outcome variable in the present study was postoperative PVR development (yes or no). Blockwise logistic regression analysis was used to identify clinical factors and

Table 1 Biomarkers studied with the use of multiplex immunoassays

\begin{tabular}{ll}
\hline Biological Group & Proteins \\
\hline Interleukins & IL-1 $\alpha$, IL-1 $\beta$, IL-2, IL-3, IL-4, IL-5, IL-6, IL-7, IL-9, IL-10, IL-11, IL-12p70, \\
& IL-13, IL-15, IL-17, IL-18, IL-21, IL-22, IL-23, IL-25, IL-33 \\
Growth factors & IGF-1, bFGF, NGF, HGF, VEGF \\
Chemokines & MIF, CCL2, CCL3, CCL5, CCL11, CCL17, CCL18, CCL19, CCL21, CCL22, \\
& CXCL8, CXCL9, CXCL10, CXCL12, CX3CL1 \\
Adhesion molecules & ICAM-1 \\
Adipokines & Adiponectin, leptin, chemerin, adipsin \\
Proteases/inhibitors & Cathepsin S, TIMP-1 \\
Others & TNF- $\alpha$, IFN- $\gamma$ \\
\hline
\end{tabular}

$\mathrm{IL}=$ interleukin; IGF = insulin growth factor; bFGF = basic fibroblast growth factor; NGF = nerve growth factor; $\mathrm{HGF}=$ hepatocyte growth factor; $\mathrm{VEGF}=$ vascular endothelial growth factor; $\mathrm{MIF}=$ macrophage migration inhibitory factor; $\mathrm{CCL}=$ chemokine $(\mathrm{C}-\mathrm{C}$ motif) ligand; $\mathrm{CXCL}=$ chemokine $(\mathrm{C}-\mathrm{X}-\mathrm{C}$ motif) ligand; $\mathrm{CX} 3 \mathrm{CL}=$ chemokine $(\mathrm{C}-\mathrm{X} 3-\mathrm{C}$ motif) ligand; ICAM = intercellular adhesion molecule; $\mathrm{TIMP}=$ tissue inhibitor of metalloproteinase; TNF = tumor necrosis factor; IFN = interferon. 
Table 2 Demographics and Potential Clinical Risk Factors for Proliferative Vitreoretinopathy

\begin{tabular}{|c|c|c|c|}
\hline $\begin{array}{l}\text { Potential Clinical } \\
\text { Risk Factor }\end{array}$ & $\begin{array}{l}\text { RRD Group } \\
(n=54)\end{array}$ & $\begin{array}{l}\text { PVR Group } \\
(n=21)\end{array}$ & $\begin{array}{c}\text { Univariate } \\
\text { Testing }\end{array}$ \\
\hline \multicolumn{4}{|l|}{ Age (years) } \\
\hline Median (range) & $61(43-79)$ & $62(43-76)$ & NS \\
\hline \multicolumn{4}{|l|}{ Sex (\%) } \\
\hline Female & 26 & 29 & NS \\
\hline Male & 74 & 71 & \\
\hline \multicolumn{4}{|l|}{$\begin{array}{l}\text { Size of retinal detachment } \\
\text { (quadrants) }\end{array}$} \\
\hline Median (range) & $2(1-3)$ & $2(1-4)$ & NS \\
\hline \multicolumn{4}{|l|}{ Number of retinal defects } \\
\hline Median (range) & $1(0-7)$ & $1.5(0-5)$ & NS \\
\hline Macular detachment (\%) & 64 & 86 & NS \\
\hline \multicolumn{4}{|l|}{ Detachment duration (days) } \\
\hline Median (range) & $5(1-75)$ & $6(1-90)$ & NS \\
\hline \multicolumn{4}{|l|}{ Preoperative PVR grade } \\
\hline Median (range) & $1(0-3)$ & $2(0-3)$ & NS \\
\hline Diabetes mellitus (\%) & 11 & 10 & NS \\
\hline Pseudophakia (\%) & 19 & 33 & NS \\
\hline Intraoperative gas use (\%) & 83 & 81 & NS \\
\hline Intraoperative cryotherapy (\%) & 65 & 71 & NS \\
\hline \multicolumn{4}{|l|}{ Intraoperative minor } \\
\hline hemorrhage (\%) & 2 & 19 & $P=0.007$ \\
\hline
\end{tabular}

$\mathrm{RRD}=$ rhegmatogenous retinal detachment; $\mathrm{PVR}$ = proliferative vitreoretinopathy; NS = not significant.

biomarkers that were associated with this dichotomous outcome variable. In the first step (block one), all clinical preoperative and intraoperative factors, regardless their $P$ value, were considered as potential predictors for PVR development. In the second step (block two), all biomarkers that reached $P$ values $<.05$ in univariate logistic regression were considered as potential predictors for PVR development. Variables in both steps were entered with a forward procedure using a criterion of $P$ $<.10$ for entering a variable in the model. The ability of the constructed model to discriminate between those with a nonfavorable outcome (PVR group) and those with a favorable outcome (RRD group) was estimated by the area under the receiver operating characteristic curve (AUC). Cutoff values that yielded highest sensitivity and specificity were chosen. Analyses were performed using SPSS Version 16.0 (SPSS for Windows; SPSS, Chicago, IL, USA). 


\section{Results}

\section{Clinical Risk Factors for the Prediction of Proliferative Vitreoretinopathy}

Clinical data and biomarker concentrations were available for all 75 included patients who underwent scleral buckling surgery for primary RRD. Twenty-one patients who developed a redetachment due to postoperative PVR were compared with 54 age-, sex-, and storage-time-matched RRD control patients who had an uncomplicated postoperative course during the overall follow-up period. There were 15 men (71\%) and 6 women (29\%) in the PVR group, with a median age of 62 years (range $43-76)$. The RRD group consisted of 40 men (74\%) and 14 women $(26 \%)$, with a median age of 61 years (range $43-79$ ). The median storage time of the sample was 3.1 years in both groups. With respect to preoperative clinical parameters there were no significant differences between the PVR group and the RRD group. Similar rates of intraoperative gas use $(P=.807)$ and intraoperative cryotherapy $(P=.585)$ were observed in both groups. The percentage of patients with minor intraoperative hemorrhage was significantly higher in patients who developed postoperative PVR (4/21 patients, $19 \%$ ) as compared with those who had an uncomplicated postoperative course $(1 / 54$ patients, $2 \%)(P=.007)$. Since this difference in baseline characteristics in this small number of patients may have jeopardized the robustness of the prediction model, we excluded these 5 cases from the blockwise logistic regression analysis. All preoperative and intraoperative clinical variables are summarized in Table 2.

\section{Biomarkers for the Prediction of Proliferative Vitreoretinopathy}

Subretinal fluid levels of 50 different biomarkers including interleukins, growth factors, chemokines, and adipokines were measured using multiplex immunoassays. Univariate logistic regression analysis showed that levels of interleukin (IL)-1 $\alpha$, IL-2, IL-3, IL-6, IL-11, macrophage migration inhibitory factor (MIF), chemokine (C-C motif) ligand 2 (CCL2), CCL3, CCL11, CCL17, CCL18, CCL19, CCL22, chemokine (C-X-C motif) ligand 10 (CXCL10), cathepsin S, adiponectin, and intercellular adhesion molecule (ICAM)-1 were significantly elevated in the PVR group as compared to the RRD group, whereas levels of tissue inhibitor of metalloproteinase (TIMP)-1 were significantly lower $(P<.05)$ (Table 3$)$.

\section{Prediction Model for Postoperative PVR}

All clinical parameters except minor intraoperative hemorrhage and the 18 biomarkers that were shown to be significantly different between the PVR group and the RRD group on univariate tests were analyzed for their potential to predict the 
development of postoperative PVR. After the first step using blockwise multiple logistic regression analysis, preoperative PVR was the only clinical variable that was an independent predictor of postoperative PVR development $(P=.035)$. The area under the receiver operating characteristic curve was 0.67 (95\% confidence interval (CI) $0.51-0.83)$. The addition of the biomarkers in step 2 improved the model significantly $(P<.001)$ and yielded a set of three analytes, i.e. CCL22, IL-3, and MIF, that together with preoperative PVR resulted in the best predictive model for postoperative PVR development. To illustrate, CCL22 was, in conjunction with preoperative PVR, the best predictor and yielded an AUC of $0.89(95 \% \mathrm{Cl} 0.77-1.00)(P<$ $.001)$. The addition of IL-3 improved the model significantly $(P=.020)$ and resulted in an AUC of $0.91(95 \% \mathrm{Cl} 0.79-1.02)$. A further improvement of the model was achieved with the addition of MIF $(P=.059)$, yielding a final AUC of $0.93(95 \% \mathrm{Cl}$ 0.82 - 1.04). The ROC curves of each single step are illustrated in the Figure.

The risk of having PVR developed after scleral buckling surgery for primary RRD can be quantified for every individual patient in our study population using preoperative PVR grade and the concentrations of CCL22, IL-3, and MIF:

Estimated probability of postoperative PVR development $=$

$1 /\left(1+\mathrm{e}^{9.53-1.23 *[\text { preopPVR }]-0.138 *[\mathrm{CCL} 22]-0.0104 *[\mathrm{LL}-3]-0.000245 *[\mathrm{MIF}]}\right)$

where preopPVR represents preoperative PVR grade (no PVR $=0, \mathrm{PVR} A=1, \mathrm{PVR} B=$ $2, P V R C=3$ ) and $C C L 22, I L-3$, and MIF are depicted in $\mathrm{pg} / \mathrm{mL}$. This formula predicted the outcome correctly in $94 \%$ of cases in our study population, with a sensitivity of $94.1 \%$ and a specificity of $94.2 \%$ using a cutoff value of $32 \%$. This means that the model allocates a patient to the PVR group if the estimated probability of developing postoperative PVR is $>32 \%$ and to the RRD group if the estimated probability of developing postoperative PVR is $<32 \%$. For patient \#21 for example, who developed PVR (PVR group), the estimated probability of postoperative PVR development was

$1 /\left(1+e^{9.53-1.23 * 2-0.138 * 24.44-0.0104 * 464.26-0.000245 * 4927.33}\right)=91 \%$

The model predicted the outcome of this patient correctly, i.e. the estimated probability was above the cutoff value of $32 \%$. For patient \#22, who did not develop PVR (RRD group), the estimated probability of PVR development was

$1 /\left(1+\mathrm{e}^{9.53-1.23 * 2-0.138 * 17.11-0.0104 * 113.34-0.000245 * 2508.49}\right)=5 \%$

The estimated probability was thus below the cutoff value of $32 \%$, indicating that the prediction model allocated this patient to the appropriate group. 
Table 3 Concentrations of biomarkers that were differentially expressed between the RRD group and the PVR group

\begin{tabular}{|c|c|c|c|}
\hline Biomarker & $\begin{array}{l}\text { RRD group } \\
\quad(n=54)\end{array}$ & $\begin{array}{l}\text { PVR group } \\
(\mathrm{n}=21)\end{array}$ & $\begin{array}{c}\text { Univariate } \\
\text { Testing }\end{array}$ \\
\hline IL-1 $\alpha$ & $5.8(2.9-11)$ & $7.0(4.1-20)$ & $P=0.006$ \\
\hline IL-2 & $5.9(3.7-12)$ & $6.6(3.4-18)$ & $P=0.023$ \\
\hline IL-3 & $101(24-348)$ & $144(47-464)$ & $P=0.001$ \\
\hline IL-6 & $60(8.3-1211)$ & $149(36-2656)$ & $P=0.002$ \\
\hline IL-11 & $23(7.3-59)$ & $25(12-89)$ & $P=0.018$ \\
\hline MIF & $3618(997-15020)$ & $6691(1691-12900)$ & $P=0.008$ \\
\hline $\mathrm{CCL} 2$ & $849(442-1139)$ & $930(629-1134)$ & $P=0.044$ \\
\hline CCL3 & $359(237-491)$ & $391(268-662)$ & $P=0.035$ \\
\hline CCL11 & $8.58(5.32-12.0)$ & $9.18(6.90-15.0)$ & $P=0.001$ \\
\hline CCL17 & $2.04(1.41-4.31)$ & $2.59(1.76-5.84)$ & $P<0.001$ \\
\hline CCL18 & $4305(184-14344)$ & $6897(434-14967)$ & $P=0.008$ \\
\hline CCL19 & $115(21.4-705)$ & $309(76.8-570)$ & $P<0.001$ \\
\hline CCL22 & $18.2(11.7-44.1)$ & $31.9(10.9-92.5)$ & $P<0.001$ \\
\hline CXCL10 & $206(42.6-875)$ & $377(128-1002)$ & $P=0.001$ \\
\hline TIMP-1 & $16356(8581->26200)$ & $14401(8724->26200)$ & $P=0.017$ \\
\hline Adiponectin & $17699(2300-38737)$ & $26877(7810-46132)$ & $P=0.002$ \\
\hline Cathepsin S & $4592(1230-10151)$ & $6119(2326-9453)$ & $P=0.001$ \\
\hline ICAM-1 & $19927(4529-40489)$ & $28276(6780-44606)$ & $P=0.002$ \\
\hline
\end{tabular}

$\mathrm{RRD}=$ rhegmatogenous retinal detachment; $\mathrm{PVR}=$ proliferative vitreoretinopathy; $\mathrm{IL}=$ interleukin; $\mathrm{MIF}=$ macrophage migration inhibitory factor; $\mathrm{CCL}=$ chemokine ( $\mathrm{C}-\mathrm{C}$ motif) ligand; $\mathrm{CXCL}=$ chemokine $(\mathrm{C}-\mathrm{X}-\mathrm{C}$ motif) ligand; TIMP = tissue inhibitor of metalloproteinase; ICAM = intercellular adhesion molecule.

\section{Discussion}

By the identification of clinical risk factors and the analysis of 50 different biomarkers in subretinal fluid samples from patients with primary RRD we were able to discriminate patients with a favorable outcome (uncomplicated follow-up) from patients with an unfavorable outcome (postoperative PVR). The presented data demonstrate that, in combination with preoperative PVR grade, the assessment of a single biomarker (CCL22) or a multibiomarker panel (CCL22, IL-3, MIF) may be a promising approach for the prediction of this fibrotic eye disease.

Results from studies that have investigated the use of intraoperative adjuvant treatments in patients with established PVR have been very disappointing. ${ }^{3-6}$ Treatment of these patients may not be successful because of a too advanced disease process and the irreversible nature of fibrotic sequelae. We believe that sampling after the onset of primary RRD but before the development of postoperative PVR may provide clues as to which biological events initiate the formation of PVR membranes, and also may indicate which cytokines are most predictive of its devel- 
opment. Therefore, we compared patients who developed postoperative PVR with those with an uncomplicated postoperative course after primary RRD. Using this design, we have shown a possible causal relation between PVR development and certain chemokines, interleukins, adhesion molecules, and apoptotic factors in previous studies. ${ }^{14,15,19}$ Samples from patients with preoperative conditions known to increase the risk of PVR (preoperative vitreous hemorrhage, preoperative cryotherapy, and trauma) were excluded from those studies, since these would have yielded high cytokine levels that were directly related to that condition. Moreover, we excluded samples from patients with late PVR development, considering it would be more likely that in patients who have PVR developed after 3 months, a new event caused the recurrence rather than the stimulus that was of our interest. ${ }^{21}$ In the current study, we have evaluated the predictive value of a combined assessment of biomarkers and clinical parameters.

The identification of clinical risk factors for the development of PVR has been studied extensively in the past decades. ${ }^{8,9}$ The current study showed that significantly more patients had minor intraoperative hemorrhage in the PVR group as compared to the RRD group. We did not foresee that even a very small bleeding would have influenced PVR outcome, and it perhaps would have been better to have these cases excluded initially. On the other hand, these data underline the importance to prevent even small bleedings during primary retinal detachment surgery. Of all clinical parameters entered in the model, we found that only preoperative PVR was an independent predictor of postoperative PVR development. The association between preoperative PVR and postoperative PVR has been reported several times in previous reports. ${ }^{22,23}$ In a study that estimated the risk of failure due to PVR based on clinical parameters only, a set of 3 clinical variables, including preoperative PVR grade, was shown to yield a reasonable AUC of $0.84 .{ }^{17}$ The associations that we found between clinical factors and postoperative PVR were however too weak to predict an unfavorable outcome with high sensitivity and specificity.

Multiplex immunoassays have recently emerged as excellent screening tools that allow for the simultaneous detection of multiple cytokines in a single sample. Moreover, these assays require smaller quantities of sample volume but show similar performance to well-established enzyme-linked immunosorbent assays (ELISAs) in terms of sensitivity, accuracy, and reproducibility. ${ }^{20,24}$ This technique enabled us to measure 50 biomarkers simultaneously and to evaluate their potential in the prediction of postoperative PVR development after retinal detachment surgery. Since inflammatory processes play an important role in wound healing, it is not surprising that the majority of 18 mediators that were differentially expressed in the PVR group and the RRD group was immune- or inflammation-related. We demonstrated that the assessment of preoperative PVR status and the measurement of one single biomarker, i.e. CCL22, resulted in a large AUC of 0.89 . Further analysis of our data enabled us to identify several sets of biomarkers with comparable perfor- 


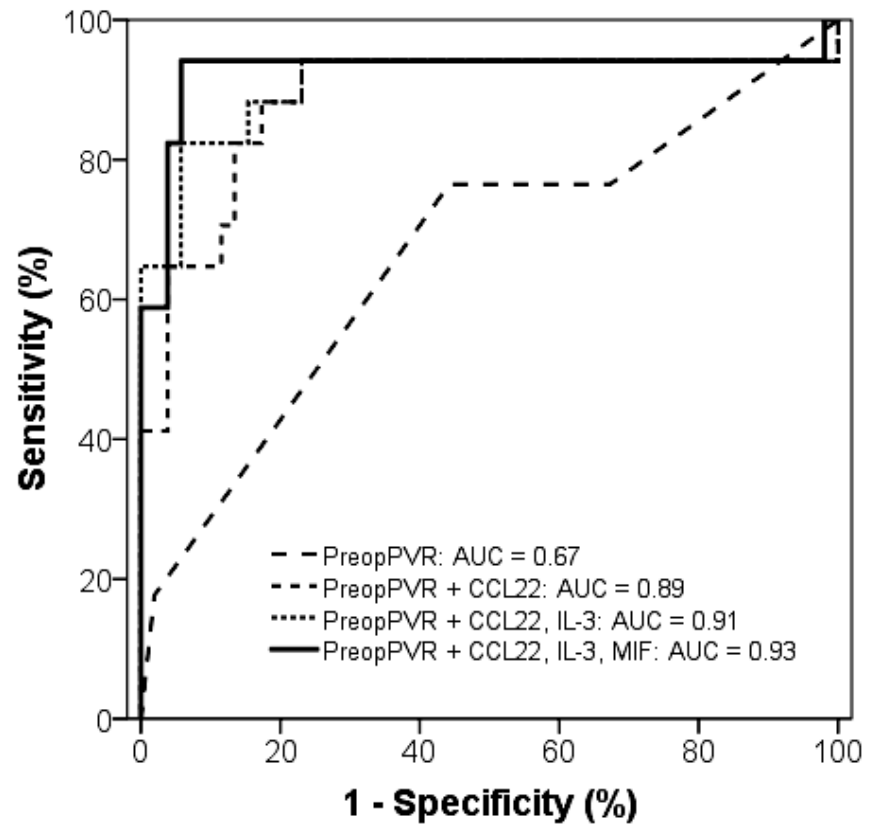

Figure 1 Receiver operating characteristic curves for preoperative proliferative vitreoretinopathy with and without biomarkers. The addition of chemokine (C-C motif) ligand 22, interleukin-3 and macrophage migration inhibitory factor to the prediction model resulted in a final area under the receiver operating characteristic curve of 0.93 (95\% confidence interval $0.82-1.04)$, and a maximal sensitivity and specificity of $94.1 \%$ and $94.2 \%$, respectively, were reached.

mance (data not shown), of which the set including CCL22, IL-3, and MIF yielded the largest AUC of 0.93 , with a very high sensitivity and specificity.

Since PVR has a low incidence after primary RRD, ${ }^{9}$ and retinal toxicity following intraoperative adjunctive treatment may be of real concern, ${ }^{6}$ prognostic or diagnostic tests should have high specificity in the first place. With respect to biomarker assays, cutoff values can be chosen to increase or decrease the specificity of a certain test. If a pharmacologic prophylaxis for PVR becomes available and retinal toxicity problems are negligible, it is possible to be less specific in selecting the treatment group. Because the suspended beads in our immunoassays allow for assay flexibility, refinement of the biomarker panel to further increase the diagnostic power is possible. The predictive value of PVR-associated factors such as platelet-derived growth factor (PDGF) ${ }^{25}$ or transforming growth factor (TGF) $-\beta^{26}$ may therefore be subject of future investigations. 
Regardless of the great potential of biomarker profiling, our study was somewhat limited by small sample size. Our findings warrant a prospective study in an unselected and large cohort of patients with primary RRD to determine the diagnostic value of a biomarker profile including CCL22, IL-3, and MIF. Whether the identification of this set of inflammatory cytokines in subretinal fluid is also applicable to vitreous fluid obtained from patients undergoing pars plana vitrectomy for primary RRD should also be evaluated. An individualized approach with the use of biomarkers requires the development of a postoperative treatment strategy, since the measurement of biomarker levels takes longer than the surgical procedure.

We have demonstrated that the use of multiplex immunoassays shows great potential for screening of biomarkers in ocular samples obtained from patients with primary RRD. We conclude that biomarker profiling, in combination with the assessment of preoperative PVR status, may distinguish patients at high risk of developing PVR from those who have an uncomplicated postoperative course in a highly sensitive and specific manner. The prediction model may be of value in the prognosis, follow-up, and treatment of high-risk cases and in the stratification of cases in clinical trials.

\section{References}

1. Kirchhof B. Strategies to influence PVR development. Graefes Arch Clin Exp Ophthalmol 2004;242:699-703.

2. Guidetti B, Azéma J, Malet-Martino M, Martino R. Delivery systems for the treatment of proliferative vitreoretinopathy: materials, devices and colloidal carriers. Curr Drug Deliv 2008;5:7-19.

3. Ahmadieh $\mathrm{H}$, Feghhi $\mathrm{M}$, Tabatabaei $\mathrm{H}$, et al. Triamcinolone acetonide in silicone-filled eyes as adjunctive treatment for proliferative vitreoretinopathy: a randomized clinical trial. Ophthalmology 2008;115:1938-43.

4. Wiedemann P, Hilgers RD, Bauer P, Heimann K. Adjunctive daunorubicin in the treatment of proliferative vitreoretinopathy: results of a multicenter clinical trial. Daunomycin Study Group. Am J Ophthalmol 1998;126:550-9.

5. Charteris DG, Aylward GW, Wong D, et al. PVR Study Group. A randomized controlled trial of combined 5-fluorouracil and low-molecular-weight heparin in management of established proliferative vitreoretinopathy. Ophthalmology 2004;111:2240-5.

6. Wickham L, Bunce C, Wong D, et al. Randomized controlled trial of combined 5-fluorouracil and low-molecular-weight heparin in the management of unselected rhegmatogenous retinal detachments undergoing primary vitrectomy. Ophthalmology 2007;114:698-704.

7. Asaria $\mathrm{RHY}$, Kon $\mathrm{CH}$, Bunce $\mathrm{C}$, et al. Adjuvant 5-fluorouracil and heparin prevents proliferative vitreoretinopathy. Results from a randomized, double-blind, controlled clinical trial. Ophthalmology 2001;108:1179-83.

8. Nagasaki H, Shinagawa K, Mochizuki M. Risk factors for proliferative vitreoretinopathy. Prog Retin Eye Res 1998;17:77-98.

9. Pastor JC, de la Rúa ER, Martín F. Proliferative vitreoretinopathy: risk factors and pathobiology. Prog Retin Eye Res 2002;21:127-144.

10. Kon $\mathrm{CH}$, Occleston NL, Aylward GW, Khaw PT. Expression of vitreous cytokines in proliferative vitreoretinopathy: a prospective study. Invest Ophthalmol Vis Sci 1999;40:705-12. 
11. Limb GA, Chignell AH. Vitreous levels of intercellular adhesion molecule 1 (ICAM-1) as a risk indicator of proliferative vitreoretinopathy. Br J Ophthalmol 1999;83:953-6.

12. El-Ghrably IA, Dua HS, Orr GM, et al. Intravitreal invading cells contribute to vitreal cytokine milieu in proliferative vitreoretinopathy. Br J Ophthalmol 2001;85:461-70.

13. Banerjee S, Savant V, Scott RAH, et al. Multiplex bead analysis of vitreous humor of patients with vitreoretinal disorders. Invest Ophthalmol Vis Sci 2007;48:2203-7.

14. Ricker LJAG, Kijlstra A, De Jager W, et al. Chemokine levels in subretinal fluid obtained during scleral buckling surgery after rhegmatogenous retinal detachment. Invest Ophthalmol Vis Sci 2010;51:4143-50.

15. Ricker LJAG, Kijlstra A, Kessels AGH, et al. Interleukin and growth factor levels in subretinal fluid in rhegmatogenous retinal detachment: a case-control study. PLOS ONE 2011;6:e19141.

16. Kon $\mathrm{CH}$, Asaria RHY, Occleston NL, et al. Risk factors for proliferative vitreoretinopathy after primary vitrectomy: a prospective study. Br J Ophthalmol 2000;84:506-11.

17. Wickham L, Bunce C, Wong D, Charteris DG. Retinal detachment repair by vitrectomy: simplified formulae to estimate the risk of failure. Br J Ophthalmol. In press.

18. Retina Society Terminology Committee. The classification of retinal detachment with proliferative vitreoretinopathy. Ophthalmology 1983;90:121-5.

19. Ricker LJAG, Altara R, Goezinne F, et al. Soluble apoptotic factors and adhesion molecules in rhegmatogenous retinal detachment. Invest Ophthalmol Vis Sci. In press.

20. De Jager W, Bourcier K, Rijkers GT, et al. Prerequisites for cytokine measurements in clinical trials with multiplex immunoassays. BMC Immunol 2009;10: 52.

21. Mietz $\mathrm{H}$, Heimann $\mathrm{K}$. Onset and recurrence of proliferative vitreoretinopathy in various vitreoretinal diseases. Br J Ophthalmol 1995;79:874-7.

22. Girard P, Mimoun G, Karpouzas I, Montefiore G. Clinical risk factors for proliferative vitreoretinopathy after retinal detachment surgery. Retina 1994;14:417-24.

23. Duquesne N, Bonnet M, Adeleine P. Preoperative vitreous hemorrhage associated with rhegmatogenous retinal detachment: a risk factor for postoperative proliferative vitreoretinopathy? Graefes Arch Clin Exp Ophthalmol 1996;234:677-82.

24. De Jager $\mathbf{W}$, Te Velthuis $\mathrm{H}$, Prakken BJ, et al. Simultaneous detection of 15 human cytokines in a single sample of stimulated peripheral blood mononuclear cells. Clin Diagn Lab Immunol 2003;10:133-9.

25. Lei H, Rheaume MA, Kazlauskas A. Recent developments in our understanding of how plateletderived growth factor (PDGF) and its receptors contribute to proliferative vitreoretinopathy. Exp Eye Res 2010;90:376-81.

26. Dieudonné SC, La Heij EC, Diederen R, et al. High TGF- $\beta 2$ levels during primary retinal detachment may protect against proliferative vitreoretinopathy. Invest Ophthalmol Vis Sci 2004;45:4113-8. 

Chapter 10

General Discussion 


\section{Rhegmatogenous retinal detachment and proliferative vitreoretinopathy}

Rhegmatogenous retinal detachment (RRD) is an ophthalmologic condition that occurs in 8 to 18 cases per 100,000 persons per year. ${ }^{1-5}$ The degree of functional recovery after retinal detachment surgery is strongly associated with preoperative involvement of the macula. ${ }^{6}$ Even though an increasingly number of retinal detachments is successfully repaired with a single procedure, proliferative vitreoretinopathy (PVR) is still the primary cause of failure of reattachment surgery. This eye-sight threatening condition is characterized by the formation of cellular membranes on both sides of the retina that upon contraction may cause a recurrent detachment, with often a poor visual prognosis. The development of these fibrotic membranes is reminiscent of the normal wound-healing response with inflammation, migration and proliferation of retinal cells, and extracellular matrix deposition. ${ }^{7}$ In all these biological processes, cytokines function as signalling molecules that bring about the events that lead to the formation and contraction of PVR membranes

\section{Optical coherence tomography}

Optical coherence tomography (OCT) is a non-invasive in vivo examination of crosssectional images of tissues based on the reflectivity of backscattered light. OCT is nowadays widely used in clinical practice and has been an important subject of ophthalmic research since its introduction in the early $1990 \mathrm{~s}^{8-10}$ Today it is a wellestablished tool in the diagnosis and follow-up of retinal conditions, glaucoma, and anterior segment disease. Because anatomical results of retinal detachment surgery have not run parallel with improvements in visual outcome, it is not surprising that OCT parameters have been a matter of investigation in recent years to find anatomical clues for incomplete functional recovery. Postoperative assessment using OCT has shown persistent submacular fluid in a substantial number of patients who underwent scleral buckling surgery for retinal detachment, and it usually requires several months before this fluid has resolved. ${ }^{11}$ Some studies did not find any influence on postoperative visual acuity, ${ }^{12,13}$ whereas the delayed absorption of subretinal fluid was found to be associated with a worse visual outcome by others. ${ }^{14-17}$ The latter studies have however not quantified the association between persistent submacular fluid and vision loss. We demonstrated that - besides preoperative foveal thickness - persistent submacular fluid was associated with a worse visual prognosis in macula-off RRD patients, although the effect on visual outcome was only small (Chapter 2). The development of spectral-domain or Fourier-domain OCT technology has shifted the scientific interest towards the delineation of selected layers in the retina. Postoperative visual acuity after retinal detachment was shown to be 
correlated with disruption of the photoreceptor inner/outer segment junction line and the external limiting membrane in recent studies. ${ }^{18-21}$ Although insight in the intraretinal changes after retinal detachment has increased in the past years, the usefulness of these OCT parameters in everyday clinical practice needs to be determined in the near future.

\section{Coagulation factors and PVR}

Since blood coagulation is the first phase in the wound healing response, it may initiate the early changes that are responsible for the development of fibrotic membranes that are characteristic for PVR. Several components of the coagulation cascade have been identified in PVR membranes including fibrin. ${ }^{22,23}$ Moreover, human RPE cells in culture lose, on exposure to fibrin, their normal epithelial morphologic characteristics and dedifferentiate into fibrocyte-like cells. ${ }^{24}$ Although the mechanism of interaction between RPE cells and fibrin is unknown, it was suggested that fibrin clots may provide a scaffold for cellular attachment and subsequent proliferation of RPE cells and glial cells, providing an explanation for a relatively high PVR rate in RRD patients with vitreous hemorrhage. A possible role for blood coagulation components in the pathogenesis of PVR was further emphasized by some experimental retinal detachment models. ${ }^{25-27}$ We have shown for the first time that subretinal fluid collected from RRD patients exerts high procoagulant activity by the action of tissue factor (TF), although we were not able to demonstrate a higher TF activity in eyes of patients who developed PVR (Chapter 3 ). It remains to be elucidated, however, what the exact meaning of TF in subretinal fluid is and whether its presence could have any clinical implications. There are no reports indicating an increased incidence of thrombotic events in the retinal vasculature after retinal detachment. An interesting possibility is that increased TF expression may reflect tissue injury after retinal detachment. We speculate that increased TF levels after RRD may result from breakdown of the blood-retinal barrier whereby retinal pigment epithelial cells and/or other retinal cells release TF into the subretinal space. This hypothesis is further supported by our findings showing that patients with high TF activity had a significant longer duration of retinal detachment including the macula than those with low TF activity. Moreover, there was a trend that patients in the former group had a worse preoperative visual acuity. A larger prospective study needs to be conducted to draw conclusions concerning the monitoring of tissue damage after RRD by the measurement of TF activity. 


\section{Apoptosis and PVR}

Previous studies have implicated an abnormal regulation of apoptosis in the pathogenesis of proliferative vitreoretinal disorders. Various studies have investigated the presence of apoptotic cells in epiretinal membranes of patients with established PVR. ${ }^{28-32}$ In PVR specimens, most apoptotic cells appeared to be from RPE cell origin. ${ }^{31,32}$ Shifting the balance toward apoptosis in PVR membranes was suggested to be a novel therapeutic approach to prevent the uncontrolled proliferation of RPE cells in this disorder. In contrast to these reports, we believe that sampling at a time close to the onset of primary RRD (i.e. the pre-clinical stages of PVR) and in the near vicinity of the RPE (i.e. subretinal fluid) may provide clues as to which local factors may initiate the uncontrolled growth of cells or the induction of apoptosis. We have previously analyzed TGF- $\beta$ levels in subretinal fluids aspirated during primary retinal detachment surgery, since proapoptotic effects of TGF- $\beta$ were demonstrated in cultured human RPE cells. ${ }^{32}$ We found significantly decreased levels of TGF- $\beta$ in patients who developed PVR as compared with those with an uncomplicated followup, suggesting that high levels at the time of primary retinal detachment may protect against subsequent development of PVR. ${ }^{33}$

The Fas/FasL system has also been assigned an important role in RPE cell death. ${ }^{30}$ Ligation of the membrane form of Fas (mFas) by its ligand mFasL - both proapoptotic molecules - has been shown to induce apoptosis in proliferating RPE cells. ${ }^{34}$ We have demonstrated that significantly increased levels of the antiapoptotic soluble Fas (sFas) and SFasL were associated with the future development of PVR (Chapter 4), supporting the hypothesis that PVR-affected individuals may have an impaired removal mechanism of excessive RPE cells after RRD onset. Importantly, the mFas-mediated extrinsic death pathway has also been shown to play a pivotal role in photoreceptor loss after retinal detachment, ${ }^{35-38}$ whereas the antiapoptotic sFas was suggested to protect central nervous system cells from further damage after an hypoxic-ischemic event. ${ }^{39}$ It thus seems that there is a delicate balance between proapoptotic and antiapoptotic molecules after retinal detachment, and we hypothesize that an imbalance toward an upregulation of antiapoptotic molecules may predispose patients to PVR.

\section{VEGF and PVR}

In human eye disease, vascular endothelial growth factor (VEGF) has been attributed an important role in ocular angiogenesis. ${ }^{40}$ The association of VEGF with the pathogenesis of PVR, a proliferative disorder that is characterized by the formation of mainly avascular epiretinal membranes, was somewhat surprising. ${ }^{41,42}$ In Chapter 5 , we have shown that the anti-angiogenic $V_{E G F}$ bx $b$ isoforms comprise more than 
half of the total VEGF protein in samples of both patients with PVR and patients with uncomplicated RRD. The absence of an angiogenic switch in these patients may explain a lack of blood vessels in PVR membranes. This hypothesis should however be treated with caution given the predominance of pro-angiogenic VEGF isoforms in a subset of our study population. On the other hand, there are several immunohistochemical studies confirming the presence of vascularisation in a substantial portion of PVR membranes. ${ }^{43,44}$ To illustrate, a vascular component, which consisted mostly of capillary-sized vessels that were clinically inapparent, was demonstrated in $28.6 \%$ of all PVR membranes investigated. ${ }^{45}$ Further study with combined assessment of a vascular component in PVR membranes and VEGF isoforms in corresponding PVR samples is therefore warranted.

It has also been hypothesized that VEGF may have functions other than inducing angiogenesis. ${ }^{46}$ This hypothesis is supported by growing evidence of a possible interaction of VEGF with non-endothelial cells in the eye. It was shown that RPE cells in situ, as well as RPE cells in epiretinal membranes and in culture, express VEGF receptors. In many epiretinal membranes, VEGF and its receptors were colocalized, suggesting that an autocrine and/or paracrine mechanism may exist. ${ }^{46}$ Other studies identified VEGF receptors on other non-endothelial cells in the eye such as on adult photoreceptor cells and Müller cells, suggesting a role for VEGF in the maintenance of the adult neural retina. ${ }^{47}$ Interestingly, VEGF has also been shown to induce monocyte activation and monocyte migration. ${ }^{48}$ Thus, VEGF probably exerts pleiotropic effects on diverse cell types that are implicated in the pathogenesis of PVR.

\section{Cytokines/growth factors and PVR}

The use of intravitreal pharmacological agents to treat the development of existing PVR membranes has shown disappointing results so far, and it seems to be impossible to reverse the process of tissue fibrosis in the eye. ${ }^{49} \mathrm{~A}$ better understanding of the early biological alterations after primary RRD is therefore needed to develop new strategies that prevent the occurrence of postoperative PVR. With respect to the treatment of PVR, it is important to recognize that the most promising results were demonstrated in selected patients with primary retinal detachment at high risk for developing postoperative PVR, ${ }^{50}$ whereas the same treatment was not efficacious in patients with established PVR. ${ }^{51}$ In the former group, a cocktail of heparin and 5-FU was initially thought to be a successful attempt to prevent the development of PVR until concerns about retinal toxicity emerged. ${ }^{52}$ Results from this study have emphasized the need for the identification of high-risk subgroups to improve the risk-benefit ratio of pharmacological adjunct strategies. If the development of postoperative PVR is predictable, only patients at high risk may be targeted with 
drugs that are potentially detrimental to retinal tissues. Moreover, these clinical trials have underscored the importance of research that focuses on the pre-clinical stages of PVR rather than on patients with established PVR. Animal studies have demonstrated an increase in gene and protein expression of proinflammatory cytokines hours and days after the creation of experimental retinal detachment when no PVR membranes have formed yet. ${ }^{53,54}$ Therefore, we believe that sampling after the onset of primary RRD but before the development of postoperative PVR may provide more insight in the initial processes that lead to PVR membrane formation, and also may indicate which cytokines are most predictive of its development.

In line with the above, our studies outlined in Chapter 6-8 differed from most previous reports on this crucial point, i.e. the time point at which the ocular samples were obtained. We compared samples from primary RRD patients who developed postoperative PVR later on with those from patients with an uncomplicated postoperative course. Using this design, we have shown a possible causal relation between PVR development and certain chemokines, interleukins, growth factors, adhesion molecules, and adipokines. Moreover, most studies have dealt with vitreous samples, whereas we studied cytokine content in subretinal fluid. This may be more appropriate since this is the ocular fluid that surrounds the resident retinal cells after initial retinal detachment. The precise role and source of each of the individual cytokines that we found to be elevated after the onset of RRD remain to be elucidated. It has been postulated that several cytokines share a common function and tend to act on a broad range of cells. ${ }^{55}$ This concept is further supported by redundancy and binding promiscuity between some cytokines and their receptors. ${ }^{56} \mathrm{Fu}$ ture research should therefore focus on the identification of relevant cytokines and relevant inflammatory mechanisms in the pathogenesis of PVR. Our studies do not indicate that there is a single key target within the pathogenesis of PVR. As a consequence, it will be a challenge to selectively target the aberrant cellular proliferation seen in PVR while not interfering with physiological ocular processes. As it seems more likely that a combination of drugs is needed and/or several stages of the disease process need to be attacked simultaneously, the treatment of PVR becomes more complicated and the possibility of drug-induced retinal toxicity increases.

\section{Prediction of PVR}

The identification of risk factors for the development of PVR may be useful for the prognosis, follow-up, and treatment of high-risk cases and for the stratification of cases in clinical trials. Potentially toxic adjunct treatments should be targeted solely at patients at greatest risk. Many studies have investigated and identified a wide range of preoperative and perioperative clinical risk factors for PVR. Findings presented in these studies appear to be contradictory and inconclusive, ${ }^{57,58}$ and there- 
fore their significance in everyday clinical practice is difficult to assess. The associations that we and others found between clinical factors and postoperative PVR were too weak to predict an unfavorable outcome with high sensitivity and specificity. ${ }^{59,60}$

In Chapter 9, we have demonstrated that the use of multiplex immunoassays shows great potential for screening of biomarkers in ocular samples obtained from patients with primary RRD. We conclude that biomarker profiling, in combination with the assessment of clinical risk factors, may distinguish patients at high risk of developing PVR from those who have an uncomplicated postoperative course in a highly sensitive and specific manner. Our findings warrant a prospective study in an unselected and large cohort of patients with primary RRD to determine the diagnostic value of a specific biomarker profile (i.e. CCL22, IL-3, and MIF). Whether the identification of this set of inflammatory cytokines in subretinal fluid is also applicable to vitreous fluid obtained from patients undergoing pars plana vitrectomy for primary RRD should also be evaluated. This is an important issue since a shift towards vitrectomy has been observed in recent years.

\section{Cytology and PVR}

Analysis of cytologic specimens after retinal detachment may provide insight into the cellular composition of pre-clinical stages of PVR. Since cytologic samples are difficult to handle and cells are often identified using unreliable morphological criteria, data are scarce and often inconclusive. ${ }^{61,62}$ Although some studies used immunohistochemical markers, the exact origin of cells is often difficult to ascertain. ${ }^{63,64}$ As stated earlier in the General Introduction (Chapter 1), different cell types can assume various phenotypes in PVR specimens. Therefore, the identification and application of novel specific markers and results from double-labelling experiments are required so that cytologic studies may contribute to a better understanding of the disease process and may produce valuable information regarding the prophylaxis of PVR.

\section{Value of PVR models}

As a multitude of antiproliferative and anti-inflammatory drugs showed great promise in experimental PVR and cell cultures, but failed in human clinical trials, the value of these models in the development of new pharmacotherapeutical adjuncts must be questioned. Most models bypass the crucial first steps in the early pathogenesis of PVR by the intravitreal injection of substances or cells. More than 25 animal models of PVR have been developed throughout years, ${ }^{65}$ suggesting that the quest for a model that does not undermine the natural course of PVR is still ongo- 
ing. In fact, the same is true for the evaluation of antiproliferative drugs and antimetabolites in culture studies. It will be a challenge to investigate and to understand their impact on cultured RPE cells and fibroblasts, not in isolation, but in relation to the environmental context of PVR.

\section{Drug delivery in PVR}

The treatment of PVR with pharmacological adjuncts is difficult as a result of the anatomical, physiological, and immunological barriers that preclude the achievement of therapeutic drug levels in the posterior segment of the eye. Moreover, most drugs that have been proposed in the treatment of PVR have a narrow therapeutic window, carry the risk of local toxicity, and have a short half-life in the vitreous cavity. ${ }^{66}$ The most important route of drug delivery that is currently applied to treat retinal disease is the intraocular route using intravitreal injections. ${ }^{67}$ Although this route of administration achieves the highest intraocular bioavailability in retinal tissues, it also carries the risk of a multitude of injection-related complications, including raised intraocular pressure, vitreous or retinal hemorrhage, retinal tears, retinal detachment, infectious endophthalmitis, and cataracts. ${ }^{68,69}$ Since the median time interval between the onset of retinal disease and the development of PVR is approximately 2 months $^{70}$ and treatment would require multiple injections, sustained drug delivery systems are more than welcome. Silicone oil as a vehicle for drug delivery, implantable devices, and injectable particulates such as biodegradable microspheres and encapsulated liposomes may all provide adequate drug levels in retinal tissues and are currently under investigation. ${ }^{66}$

\section{Final conclusions}

PVR is still the primary cause of failure of retinal detachment surgery. As functional results have not run parallel to the improvements in surgical outcome and recurrent detachment after an initially successful surgical procedure is still a major problem, research has focused on the development of pharmacological adjuncts. Attempts to treat the presence of established PVR membranes with antiproliferative or antiinflammatory agents have been very disappointing so far, and none of them is nowadays used in everyday clinical practice on a routine basis. As it appears that the process of fibrosis is irreversible, future research should aim at the identification of relevant inflammatory mechanisms in the pre-clinical stages of PVR, allowing the development of a medical prophylactic strategy for this severe and intriguing fibrotic condition. 


\section{References}

1. Wong TY, Tielsch JM, Schein OD. Racial difference in the incidence of retinal detachment in Singapore. Arch Ophthalmol 1999;117:379-83.

2. Tornquist R, Stenkula S, Tornquist P. Retinal detachment: a study of a population-based patient material in Sweden 1971-1981. I. Epidemiology. Acta Ophthalmol (Copenh) 1987;65:213-22.

3. Algvere PV, Jahnberg P, Textorius O. The Swedish Retinal Detachment Register, I: a database for epidemiological and clinical studies. Graefes Arch Clin Exp Ophthalmol 1999;237:137-44.

4. Li X. Incidence and epidemiological characteristics of rhegmatogenous retinal detachment in Beijng, China. Ophthalmology 2003;110:2413-7.

5. Mitry D, Charteris DG, Yorston D, Siddiqui MA, Campbell H, Murphy AL, et al. The epidemiology and socioeconomic associations of retinal detachment in Scotland: a two-year prospective populationbased study. Invest Ophthalmol Vis Sci 2010;51:4963-8.

6. Salicone A, Smiddy WE, Ventkatraman A, Feuer W. Visual recovery after scleral buckling procedure for retinal detachment. Ophthalmology 2006;113:1734-42.

7. Pastor JC. Proliferative vitreoretinopathy: an overview. Surv Ophthalmol 1998;43:3-18.

8. Huang D, Swanson EA, Lin CP, et al. Optical coherence tomography. Science 1991;254:1178-81.

9. Fercher AF, Hitzenberger CK, Drexler W, et al. In vivo optical coherence tomography. Am J Ophthalmol 1993;116:113-4.

10. Swanson EA, Izatt JA, Hee MR, et al. In-vivo retinal imaging by optical coherence tomography. Opt Lett 1993;18:1864-6.

11. D’Amico DJ. Clinical practice. Primary retinal detachment. N Engl J Med 2008;359:2346-54.

12. Baba $T$, Hirose A, Moriyama M, Mochizuki M. Tomographic image and visual recovery of acute macula-off rhegmatogenous retinal detachment. Graefes Arch Clin Exp Ophthalmol 2004;242:57681.

13. Seo JH, Woo SJ, Park KH, Yu YS, Chung H. Influence of persistent submacular fluid on visual outcome after successful scleral buckle surgery for macula-off retinal detachment. Am J Ophthalmol 2008;145:915-22.

14. Wolfensberger TJ, Gonvers M. Optical coherence tomography in the evaluation of incomplete visual acuity recovery after macula-off retinal detachments. Graefes Arch Clin Exp Ophthalmol 2002;240:85-9.

15. Theodossiadis PG, Georgalas IG, Emfietzoglou J, et al. Optical coherence tomography findings in the macula after treatment of rhegmatogenous retinal detachments with spared macula preoperatively. Retina 2003;23:69-75.

16. Benson SE, Schlottmann PG, Bunce C, Xing W, Charteris DG. Optical coherence tomography analysis of the macula after scleral buckle surgery for retinal detachment. Ophthalmology 2007;114:108-12.

17. Cavallini GM, Masini C, Volante V, Pupino A, Campi L, Pelloni S. Visual recovery after scleral buckling for macula-off retinal detachments: an optical coherence tomography study. Eur J Ophthalmol 2007;17:790-6.

18. Shimoda $\mathrm{Y}$, Sano M, Hashimoto H, Yokota Y, Kishi S. Restoration of photoreceptor outer segment after vitrectomy for retinal detachment. Am J Ophthalmol 2010;149:284-90.

19. Theodossiadis PG, Theodossiadis GP, Charonis A, Emfietzoglou I, Grigoropoulos VG, Liarakos VS. The photoreceptor layer as a prognostic factor for visual acuity in the secondary epiretinal membrane after retinal detachment surgery: imaging analysis by spectral-domain optical coherence tomography. Am J Ophthalmol 2011;151:973-80.

20. Wakabayashi T, Oshima Y, Fujimoto H, Murakami Y, Sakaguchi H, Kusaka S, Tano Y. Foveal microstructure and visual acuity after retinal detachment repair; imaging analysis by Fourier-domain optical coherence tomography. Ophthalmology 2009;116:519-28.

21. Gharbiya M, Grandinetti F, Scavella V, et al. Correlation between spectral-domain optical coherence tomography findings and visual outcome after primary rhegmatogenous retinal detachment repair. Retina. In press. 
22. Weller M, Wiedemann P, Bresgen M, Heimann K. Giant preretinal membrane formation behind a silicone oil bubble in a hypotensive eye. Retina 1990;10:86-91.

23. Schwartz D, de la Cruz ZC, Green WR, Michels RG. Proliferative vitreoretinopathy. Ultrastructural study of 20 retroretinal membranes removed by vitreous surgery. Retina 1988;8:275-81.

24. Vidaurri-Leal JS, Glaser BM. Effect of fibrin on morphologic characteristics of retinal pigment epithelial cells. Arch Ophthalmol 1984;102:1376-9.

25. Hollborn M, Francke M, landiev I, et al. Early activation of inflammation- and immune responserelated genes after experimental detachment of the porcine retina. Invest Ophthalmol Vis Sci 2008;49:1262-73.

26. Cleary PE, Ryan SJ. Experimental posterior penetrating eye injury in the rabbit, I: Method of production and natural history. Br J Ophthalmol 1979;63:306-11.

27. García-Layana A, Pastor JC, Saornil MA, Gonzalez G. Porcine model of proliferative vitreoretinopathy with platelets. Curr Eye Res 1997;16:556-63.

28. Esser P, Bartz-Schmidt KU, Walter P, Kaszli F, Heimann K, Weller M. Apoptotic cell death in proliferative vitreoretinopathy. German J Ophthalmol 1996;5:73-78.

29. Weller M, Heimann K, Bartz-Schmidt KU, Fontana A, Esser P. CD95 expression in traumatic proliferative vitreoretinopathy: a target for the induction of apoptosis. German J Ophthalmol 1997;5:332-337.

30. El Ghrably I, Powe DG, Orr G, et al. Apoptosis in proliferative vitreoretinopathy. Invest Ophthalmol Vis Sci 2004;45:1473-1479.

31. Zhang $X$, Barile $G$, Chang $S$, et al. Apoptosis and cell proliferation in proliferative retinal disorders: PCNA, Ki-67, caspase-3, and PARP expression. Curr Eye Res 2005;30:395-403.

32. Esser $\mathrm{P}$, Heimann $\mathrm{K}$, Bartz-Schmidt $\mathrm{KU}$, et al. Apoptosis in proliferative vitreoretinal disorders: possible involvement of TGF- $\beta$ - induced RPE cell apoptosis. Exp Eye Res 1997;65:365-378.

33. Dieudonné SC, La Heij EC, Diederen R, Kessels AGH, Liem ATA, et al. High TGF- $\beta 2$ levels during primary retinal detachment may protect against proliferative vitreoretinopathy. Invest Ophthalmol Vis Sci 2004;45:4113-8.

34. Chang JH, Kang SW, Ham DI. Sensitivity of CD95-induced apoptosis in different proliferative status of human retinal pigment epithelial cells. Korean J Ophthalmol 2001;15:74-80.

35. Zacks DN, Zheng QD, Han Y, Bakhru R, Miller JW. Fas-mediated apoptosis and its relation to intrinsic pathway activation in an experimental model of retinal detachment. Invest Ophthalmol Vis Sci 2004;45:4563-4569.

36. Zacks DN, Boehlke C, Richards AL, Zheng QD. Role of the Fas-signaling pathway in photoreceptor neuroprotection. Arch Ophthalmol 2007;125:1389-1395.

37. Hisatomi T, Sakamoto T, Goto Y, et al. Critical role of photoreceptor apoptosis in functional damage after retinal detachment. Curr Eye Res 2002;24:161-172.

38. Besirli CG, Chinskey ND, Zheng QD, Zacks DN. Inhibition of retinal detachment-induced apoptosis in photoreceptors by a small peptide inhibitor of the Fas receptor. Invest Ophthalmol Vis Sci 2010;51:2177-2184.

39. Tarkowski E, Rosengren L, Blomstrand C, Jensen C, Ekholm S, Tarkowski A. Intrathecal expression of proteins regulating apoptosis in acute stroke. Stroke 1999;30:321-327.

40. Witmer AN, Vrensen GF, Van Noorden CJ, Schlingemann RO. Vascular endothelial growth factors and angiogenesis in eye disease. Prog Retin Eye Res 2003;22:1-29.

41. Su CY, Chen MT, Wu WS, Wu WC. Concentration of vascular endothelial growth factor in the subretinal fluid of retinal detachment. J Ocul Pharmacol Ther 2000;16:463-9.

42. Ogata N, Nishikawa M, Nishimura T, Mitsuma Y, Matsumura M. Inverse levels of pigment epithelium-derived factor and vascular endothelial growth factor in the vitreous of eyes with rhegmatogenous retinal detachment and proliferative vitreoretinopathy. Am J Ophthalmol 2002;133:851-2.

43. Tsanou E, loachim E, Stefaniotou M, et al. Immunohistochemical study of angiogenesis and proliferative activity in epiretinal membranes. Int J Clin Pract 2005;59:1157-61. 
44. Dawczynski J, Janz S, Kasper M, et al. Histologische und immunhistologische Untersuchungen humaner epiretinaler Membranen. Klin Monatsbl Augenheilkd 2006;223:687-90.

45. Asiyo-Vogel MN, El-Hifnawi ES, Bopp S, Laqua $\mathrm{H}$. The vascular component of proliferative vitreoretinopathy membranes: an immunohistochemical and ultrastructural study. Retina 1998;18:56-61.

46. Chen YS, Hackett SF, Schoenfeld CL, Vinores MA, Vinores SA, Campochiaro PA. Localisation of vascular endothelial growth factor and its receptors to cells of vascular and avascular epiretinal membranes. Br J Ophthalmol 1997;81:919-26.

47. Saint-Geniez M, Maharaj AS, Walshe TE, et al. Endogenous VEGF is required for visual function: evidence for a survival role on Müller cells and photoreceptors. PLOS ONE 2008;3:e3554.

48. Clauss M, Gerlach M, Gerlach H, et al. Vascular permeability factor: a tumor-derived polypeptide that induces endothelial cell and monocyte procoagulant activity, and promotes monocyte migration. J Exp Med 1990;172:1535-45.

49. Kirchhof B. Strategies to influence PVR development. Graefes Arch Clin Exp Ophthalmol 2004;242:699-703.

50. Asaria $\mathrm{RHY}$, Kon $\mathrm{CH}$, Bunce $\mathrm{C}$, et al. Adjuvant 5-fluorouracil and heparin prevents proliferative vitreoretinopathy. Results from a randomized, double-blind, controlled clinical trial. Ophthalmology 2001;108:1179-83.

51. Charteris DG, Aylward GW, Wong D, et al. PVR Study Group. A randomized controlled trial of combined 5-fluorouracil and low-molecular-weight heparin in management of established proliferative vitreoretinopathy. Ophthalmology 2004;111:2240-5.

52. Wickham L, Bunce C, Wong D, et al. Randomized controlled trial of combined 5-fluorouracil and low-molecular-weight heparin in the management of unselected rhegmatogenous retinal detachments undergoing primary vitrectomy. Ophthalmology 2007;114:698-704.

53. Hollborn M, Francke M, landiev I, Bühner E, Foja C, et al. Early activation of inflammation- and immune response-related genes after experimental detachment of the porcine retina. Invest Ophthalmol Vis Sci 2008;49:1262-73.

54. Nakazawa T, Matsubara A, Noda K, Hisatomi T, She H, et al. Characterization of cytokine responses to retinal detachment in rats. Mol Vis 2006;12:867-78.

55. Wallace GR, Curnow SJ, Wloka K, Salmon M, Murray PI. The role of chemokines and their receptors in ocular disease. Prog Retin Eye Res 2004;23;435-448.

56. Zlotnik A, Yoshie O. Chemokines: a new classification system and their role in immunity. Immunity 2000;12:121-127.

57. Pastor JC, Rodriguez de la Rua E, Martin F. Proliferative vitreoretinopathy: risk factors and pathobiology. Prog Retin Eye Res 2002;21:127-44.

58. Nagasaki H, Shinagawa K, Mochizuki M. Risk factors for proliferative vitreoretinopathy. Prog Retin Eye Res 1998;17:77-98.

59. Kon $\mathrm{CH}$, Asaria RHY, Occleston NL, et al. Risk factors for proliferative vitreoretinopathy after primary vitrectomy: a prospective study. Br J Ophthalmol 2000;84:506-11.

60. Wickham L, Bunce C, Wong D, Charteris DG. Retinal detachment repair by vitrectomy: simplified formulae to estimate the risk of failure. Br J Ophthalmol. In press.

61. Toti P, Morocutti A, Sforzi C, De Santi MM, Catella AM, Baiocchi S. The subretinal fluid in retinal detachment. A cytologic study. Doc Ophthalmol 1991;77:39-46.

62. Martín F, Pastor JC, de la Rua ER, et al. Proliferative vitreoretinopathy: cytologic findings in vitreous samples. Ophthalmic Res 2003;35:232-8.

63. Baudouin C, Hofman P, Brignole F, Bayle J, Loubiere R, Gastaud P. Immunocytology of cellular components in vitreous and subretinal fluid from patients with proliferative vitreoretinopathy. Ophthalmologica 1991;203:38-46.

64. Canataroglu H, Varinli I, Ozcan AA, Canataroglu A, Doran F, Varinli S. Interleukin (IL)-6, interleukin (IL)-8 levels and cellular composition of the vitreous humor in proliferative diabetic retinopathy, proliferative vitreoretinopathy, and traumatic proliferative vitreoretinopathy. Ocul Immunol Inflamm 2005;13:375-381. 
65. Lei $\mathrm{H}$, Rheaume MA, Kazlauskas A. Recent developments in our understanding of how plateletderived growth factor (PDGF) and its receptors contribute to proliferative vitreoretinopathy. Exp Eye Res 2010;90:376-81.

66. Guidetti B, Azéma J, Malet-Martino M, Martino R. Delivery systems for the treatment of proliferative vitreoretinopathy: materials, devices and colloidal carriers. Current Drug Delivery 2008;5:7-19.

67. Edelhauser HF, Rowe-Rendleman CL, Robinson MR, et al. Ophthalmic drug delivery systems for the treatment of retinal diseases: basic research to clinical applications. Invest Ophthalmol Vis Sci 2010;51:5403-20.

68. Ghate D, Edelhauser HF. Ocular drug delivery. Expert Opin Drug Deliv 2006;3:275-87.

69. Jager RD, Aiello LP, Patel SC, Cunningham ET. Risks of intravitreous injection: a comprehensive review. Retina 2004;24:676-98.

70. Mietz $\mathrm{H}$, Heimann $\mathrm{K}$. Onset and recurrence of proliferative vitreoretinopathy in various vitreoretinal diseases. Br J Ophthalmol 1995;79:874-7. 

Summary 


\section{Summary}

In this thesis we set out to investigate a number of clinical and biochemical factors that have been implicated in the pathogenesis of rhegmatogenous retinal detachment (RRD) and proliferative vitreoretinopathy (PVR). An introduction on both topics and the questions and hypotheses that we have addressed in this thesis are outlined in Chapter 1.

In Chapter 2, we investigated the influence of subfoveal fluid and foveal thickness on visual outcome in patients who underwent scleral buckling surgery for primary RRD. In a prospective study on 53 patients, optical coherence tomography (OCT) scanning was performed preoperatively and during all subsequent follow-up visits at $1,3,6,9,12$, and 24 months postoperatively. Persistent subfoveal fluid postoperatively and increased foveal thickness preoperatively were associated with a worse visual prognosis in macula-off RRD patients, although the effect was small in the majority of patients. We also found that - without the performance of preoperative OCT - one-third of our patient population would have been misclassified as having a macula-on RRD based on clinical assessment only.

Chapter $\mathbf{3}$ presents the results of a study on the procoagulant activity of ocular fluids obtained from patients with vitreoretinal disease. An increased mRNA expression of genes related to blood coagulation, including the procoagulant tissue factor, was demonstrated in experimental retinal detachment but was not yet confirmed in human clinical specimens. Calibrated automated thrombography (CAT) was used to investigate the thrombogenic properties of 28 subretinal fluids from retinal detachment and of 39 vitreous fluids from several ocular conditions, including retinal detachment, macular pucker, macular hole, and proliferative diabetic retinopathy. The addition of subretinal fluid from all retinal detachment patients induced thrombin generation in normal and severe factor XII deficient plasma, whereas the addition of vitreous fluids from various ocular disorders hardly provoked thrombin generation. The procoagulant activity in subretinal fluid was almost completely neutralized by antibodies against human tissue factor and its presence was confirmed by Western blot analysis. Our results indicate that only subretinal fluid from patients with RRD exerts high procoagulant activity by the action of tissue factor. We were not able to demonstrate a higher tissue factor activity in subretinal fluid samples from patients who developed PVR after primary RRD compared with those with an uncomplicated follow-up.

Chapter $\mathbf{4}$ describes the association between levels of soluble Fas (sFas), soluble Fas ligand (sFasL), soluble intercellular adhesion molecule (sICAM)-1, and soluble vascular adhesion molecule (sVCAM)-1 and the development of postoperative PVR. Patients who developed a redetachment due to postoperative PVR after reattachment surgery (PVR group; $n=17$ ) were compared with age-, sex-, and storage-timematched RRD samples from patients with an uncomplicated postoperative course 
(RRD group; $n=38$ ). The apoptosis-related factors sFas and SFasL and the proinflammatory adhesion molecules SICAM-1 and SVCAM-1 were all significantly elevated in the PVR group as compared with the RRD group, suggesting a role in PVR pathogenesis. The strong correlations between the apoptosis-related factors and adhesion molecules may point to a common pathway.

In Chapter 5, we investigated the protein expression of vascular endothelial growth factor (VEGF) and its pro-angiogenic and anti-angiogenic isoforms in subretinal fluid samples of patients with PVR and patients with an uncomplicated retinal detachment. VEGF levels were found to be significantly elevated in the PVR group as compared with the uncomplicated RRD group. Anti-angiogenic VEGF isoforms predominated in the majority of RRD and PVR samples investigated, although a wide variability of isoform ratios was observed within both groups. These results may provide an explanation for a lack of blood vessels in the majority of PVR membranes. Elevated VEGF levels indicate that this cytokine may play a role in the pathogenesis of PVR that is not related to angiogenesis.

In the following chapters, we compared cytokine content in subretinal fluid samples from patients who developed a redetachment due to postsurgical PVR (PVR group; $n=21$ ) with controls who had an uncomplicated retinal detachment during the overall follow-up period (RRD group; $n=54$ ). Chapter 6 describes the association between postoperative PVR development and a multitude of chemokines, i.e. macrophage migration inhibitory factor (MIF), chemokine (C-C motif) ligand 2 (CCL2), CCL11, CCL17, CCL18, CCL19, CCL22, chemokine (C-X-C motif) ligand (CXCL8), CXCL9, and CXCL10. These results indicate that increased chemotactic signalling may be the underlying phenomenon leading to a vast and immediate influx of inflammatory cells after the onset of retinal detachment and may cause an inflammatory response that is associated with the future development of PVR. Chapter 7 again shows that sampling at a time close to the onset of primary retinal detachment may provide clues as to which biological factors may initiate the development of PVR. Of the 29 different interleukins, growth factors and adhesion molecules that were studied, six showed to be significantly associated with PVR development, i.e. interleukin (IL)-1 $\alpha$, IL-2, IL-3, IL-6, VEGF, and sICAM-1. In Chapter 8, we have investigated the association between certain adipokines and the occurrence of postoperative PVR. Adipokines have recently emerged as a novel group of mediators with important roles in inflammation and wound healing. Levels of adiponectin, cathepsin S, leptin, and tissue inhibitor of metalloproteinase (TIMP)-1 were significantly different in the PVR group in comparison with the RRD group, suggesting their involvement in the future development of postoperative PVR after retinal detachment surgery. The significant correlation between PVR and elevated leptin levels was however lost after having corrected for the presence of diabetes, body mass index, and preoperative PVR. 
In Chapter 9, we investigated the potential of a combined assessment of clinical risk factors and biomarker profiling in the prediction of proliferative vitreoretinopathy (PVR) after retinal detachment surgery. A prediction model was constructed based on blockwise stepwise logistic regression with clinical variables and selected biomarkers. Preoperative PVR was the only clinical variable that was an independent predictor of postoperative PVR development, and resulted in an area under the receiver operating characteristic curve (AUC) of 0.67 (95\% confidence interval (CI) $0.51-0.83$ ). The addition of the biomarkers CCL22, IL-3, and MIF resulted in a final AUC of 0.93 (95\% Cl $0.82-1.04)$. A sensitivity of $94.1 \%$ and a specificity of $94.2 \%$ were reached, using a cutoff value of $32 \%$. RRD or PVR outcome was correctly predicted in $94 \%$ of cases in the study population. These results indicate that, in combination with preoperative PVR grade, the measurement of a small multibiomarker panel shows great potential and may predict postoperative PVR development after primary RRD in a highly sensitive and specific manner.

In Chapter 10, the findings presented in this thesis are discussed and directions for further research in the area of retinal detachment and PVR are briefly summarized. 

Samenvatting 


\section{Samenvatting}

In dit proefschrift hebben we een aantal klinische en biochemische factoren onderzocht die mogelijkerwijs een rol spelen in de pathogenese van rhegmatogene ablatio retinae en proliferatieve vitreoretinopathie. In Hoofdstuk 1 worden deze aandoeningen uitgebreid toegelicht en worden de onderwerpen die aan bod komen in dit proefschrift uiteengezet.

In Hoofdstuk 2 hebben we de invloed van de aanwezigheid van subfoveaal vocht en de foveadikte op de gezichtsscherpte onderzocht in patiënten die een cerclage plombe operatie ondergingen vanwege een netvliesloslating. In een prospectieve studie werd vóór de operatie en 1, 3, 6, 9, 12 en 24 maanden ná de operatie een optical coherence tomography (OCT) scan gemaakt bij 53 patiënten. In patiënten met een netvliesloslating waarbij de macula betrokken was zagen we dat persisterend subfoveaal vocht ná de operatie en een verdikte fovea vóór de operatie geassocieerd waren met een verminderde gezichtsscherpte, hoewel in de meerderheid van de patiënten dit effect vrij klein was. Bovendien bleek dat de OCT scan betrouwbaarder was dan het oordeel van de oogarts bij het beoordelen of de macula betrokken was bij de netvliesloslating.

In Hoofdstuk $\mathbf{3}$ hebben we de stollingsactiviteit in oogvochten van patiënten met netvliesaandoeningen bestudeerd. In dierexperimentele studies was reeds eerder aangetoond dat een verhoogde expressie van genen die een rol spelen in de bloedstolling, waaronder tissue factor, verhoogd waren bij een netvliesloslating. Echter, dit is nooit eerder aangetoond in humane studies. Calibrated automated thrombography (CAT) werd gebruikt om de thrombogene eigenschappen te bepalen in 28 subretinale oogvochten van patiënten met een netvliesloslating en in 39 glasvochten van allerlei netvliesaandoeningen, waaronder een netvliesloslating, macula pucker, maculagat en proliferatieve diabetische retinopathie. Het toevoegen van subretinaal vocht van alle patiënten met een netvliesloslating induceerde thrombine generatie in normaal en factor XII deficiënt plasma, terwijl het toevoegen van glasvochten van allerlei oogaandoeningen nauwelijks thrombine generatie induceerde. De stollingsactiviteit in subretinale oogvochten kon geneutraliseerd worden met antilichamen tegen humaan tissue factor en werd bevestigd met Western blot analyse. Onze resultaten laten zien dat alleen subretinaal vocht van patiënten met een netvliesloslating een hoge pro-coagulante activiteit heeft door toedoen van het humaan tissue factor. We konden niet aantonen dat patiënten die proliferatieve vitreoretinopathie ontwikkelden na een netvliesloslating een hogere stollingsactiviteit in het subretinale oogvocht hadden dan patiënten zonder proliferatieve vitreoretinopathie.

Hoofdstuk 4 beschrijft de associatie tussen het krijgen van proliferatieve vitreoretinopathie na een netvliesloslating en bepaalde factoren in het subretinale oogvocht, zoals soluble Fas (sFas), soluble Fas ligand (sFasL), soluble intercellular adhe- 
sion molecule (sICAM)-1, en soluble vascular adhesion molecule (sVCAM)-1. Zeventien patiënten die proliferatieve vitreoretinopathie ontwikkelden (de PVR groep) werden vergeleken met 38 patiënten die geen proliferatieve vitreoretinopathie ontwikkelden (de RRD groep). Zowel de factoren die een rol spelen in de geprogrammeerde celdood (apoptose) - sFas en sFasL - als de factoren die een rol spelen in het ontstekingsproces - sICAM-1 en SVCAM-1 - waren verhoogd in de PVR groep in vergelijking met de RRD groep en spelen dus mogelijkerwijs een rol in de pathogenese van proliferatieve vitreoretinopathie. De sterke correlaties tussen deze factoren suggereren dat apoptose en inflammatie sterk met elkaar verbonden zijn na een netvliesloslating.

In Hoofdstuk $\mathbf{5}$ hebben we de eiwitexpressie van vascular endothelial growth factor (VEGF) en zijn pro-angiogene en anti-angiogene isovormen onderzocht in het subretinale vocht van patiënten met PVR en patiënten met een ongecompliceerde netvliesloslating. We zagen dat het VEGF verhoogd aanwezig was in de patiënten met proliferatieve vitreoretinopathie. Het waren vooral de anti-angiogene isovormen die aanwezig waren in zowel patiënten met PVR als patiënten zonder PVR, hoewel in een minderheid de pro-angiogene vormen de overhand hadden. Dit zou een verklaring kunnen zijn voor het ontbreken van bloedvaten in PVR membranen. Het VEGF, waarvan de waarden verhoogd waren in patiënten met proliferatieve vitreoretinopathie, speelt dus mogelijk een rol die niet gerelateerd is aan de bloedvatvorming in dit ziektebeeld.

In de Hoofdstukken $6 \mathrm{t} / \mathrm{m} 8$ hebben we een groot aantal factoren tegelijkertijd bepaald in subretinale vochten van patiënten met een netvliesloslating. Eenentwintig patiënten die proliferatieve vitreoretinopathie ontwikkelden na een netvliesloslating werden vergeleken met 54 patiënten die geen proliferatieve vitreoretinopathie ontwikkelden. Hoofdstuk 6 beschrijft de associatie tussen het krijgen van proliferatieve vitreoretinopathie en een groot aantal chemokines, te weten macrophage migration inhibitory factor (MIF), chemokine (C-C motif) ligand 2 (CCL2), CCL11, CCL17, CCL18, CCL19, CCL22, chemokine (C-X-C motif) ligand (CXCL8), CXCL9, and CXCL10. Onze resultaten laten zien dat de verhoogde waarden van een aantal chemokines ten grondslag kunnen liggen aan de aanwezigheid van ontstekingscellen in oogvochten bij patiënten met een netvliesloslating en dat deze mogelijk een rol spelen in het ontstaan van proliferatieve vitreoretinopathie. In Hoofdstuk 7 beschrijven we de resultaten van eenzelfde studie naar de aanwezigheid van 29 verschillende interleukines en groeifactoren in oogvochten van patiënten met een netvliesloslating. We vonden dat 6 factoren (IL-1 $\alpha$, IL-2, IL-3, IL-6, VEGF en sICAM-1) verhoogd aanwezig waren bij patiënten die proliferatieve vitreoretinopathie ontwikkelden. Deze factoren spelen dus mogelijk een rol in de ontstekingsprocessen en wondgenezingsreactie die kenmerkend is voor proliferatieve vitreoretinopathie. De associatie tussen proliferatieve vitreoretinopathie en enkele adipokines wordt beschreven in Hoofdstuk 8. Adipokines spelen een belangrijke rol bij ziekten die geas- 
socieerd zijn met obesitas, suikerziekte en atherosclerose. Recent is aangetoond dat deze ook in het oog kunnen voorkomen waar ze - net als de chemokines, interleukines en groeifactoren - een rol spelen in ontsteking en wondgenezing. In onze studie hebben we een relatie gevonden tussen een viertal adipokines (adiponectine, cathepsine $\mathrm{S}$, leptine en tissue inhibitor of metalloproteinase (TIMP)-1) en de ontwikkeling van proliferatieve vitreoretinopathie na een netvliesloslating. Nadat gecorrigeerd was voor diabetes, body mass index en preoperatieve PVR bleek de correlatie tussen verhoogde waarden van het leptine en het postoperatief ontstaan van PVR niet stand te houden.

In Hoofdstuk 9 hebben we onderzocht of we het krijgen van proliferatieve vitreoretinopathie na een netvliesloslating kunnen voorspellen aan de hand van klinische factoren en de factoren die hierboven beschreven staan. Een model werd gemaakt op basis van blockwise stepwise logistische regressie analyse met enkele geselecteerde klinische en biochemische factoren. We zagen dat het optreden van proliferatieve vitreoretinopathie vóór de operatie gerelateerd was aan het krijgen van proliferatieve vitreoretinopathie ná de operatie, en samen met het bepalen van slechts een drietal biochemische factoren (CCL22, IL-3 en MIF) in oogvochten kon in $94 \%$ van de patiënten met een netvliesloslating het optreden van proliferatieve vitreoretinopathie juist voorspeld worden. De maximale sensitiviteit en specificiteit van deze test was respectievelijk $94.1 \%$ en $94.2 \%$, bij een afkappunt van $32 \%$. Deze resultaten tonen aan dat het bepalen van factoren in oogvochten veelbelovend is om patiënten die een groot risico hebben op het ontwikkelen van PVR te onderscheiden van patiënten met een laag risico. Dit kan van belang zijn bij de prognose en behandeling van patiënten met een netvliesloslating.

In Hoofdstuk 10 worden de belangrijkste bevindingen van dit promotieonderzoek bediscussieerd en komen onderwerpen voor toekomstig onderzoek aan bod. 



\section{Dankwoord}




\section{Dankwoord}

Graag wil ik iedereen bedanken die op enigerlei wijze heeft bijgedragen tot de totstandkoming van dit proefschrift. Een aantal personen wil ik in het bijzonder bedanken.

Prof. dr. F. Hendrikse wil ik bedanken voor alle mogelijkheden die ik heb gekregen om me gedurende 4 jaar op wetenschappelijk gebied te ontplooien. Op uw afdeling zijn alle randvoorwaarden aanwezig of ze worden onmiddellijk gecreëerd om op een zo aangenaam mogelijke manier onderzoek te doen. Ook ben ik dank verschuldigd aan prof. dr. H. Steinbusch voor het adopteren van een "buitenbeentje" op de afdeling Mental Health and Neuroscience (MHeNS).

Veel dank gaat uiteraard uit naar mijn dagelijkse begeleiders prof. dr. E.C. La Heij en prof. dr. A. Kijlstra. Beste Ellen, hoewel je niet bij mijn sollicitatiegesprek aanwezig was, hadden we toch al gauw een klik. Zowel op wetenschappelijk als persoonlijk vlak was je voor mij een uitstekende mentor. Je gaf me het vertrouwen en de vrijheid om te excelleren. Ik hoop van harte dat het PVR-onderzoek - dat bij jou in uitstekende handen is - een passend vervolg krijgt. Beste Aize, jij was van onschatbare waarde wat betreft het fundamentele oftewel het niet-klinische deel van dit project. Ik heb ontzettend veel geleerd van onze brainstormsessies en heb genoten van je nimmer aflatende enthousiasme en je verbazingwekkend brede kennis. Ook de master class paling roken zal ik niet snel vergeten!

Alle vitreoretinale chirurgen (waaronder dr. A.T.A. Liem, drs. I.J. Lundqvist en drs. F. Goezinne) en oogheelkundig OK-personeel (waaronder Tony, Mariette en Nicky) wil ik bedanken voor het afnemen en opslaan van de glasvochten en subretinale vochten. Ik realiseer me terdege dat de kracht van het onderzoek zoals beschreven in dit proefschrift vooral het resultaat is van het jarenlang verzamelen van deze oogvochten.

Ing. Astrid Hacking en de dames van het secretariaat wil ik graag bedanken voor het werk achter de schermen. Jullie maakten altijd meteen werk van al mijn vragen en verzoeken.

Drs. A.G.H. Kessels wil ik graag bedanken voor alle hulp met de statistiek. Beste Fons, nadat we elkaars gebruiksaanwijzing kenden, bleken onze amusante statistiek bijeenkomsten ook nog eens zeer vruchtbaar. Binnen 5 minuten begreep je de vraagstelling én had je het antwoord al klaar, waardoor regelmatig tijd overbleef voor de meer sociale dingen des levens. En gelukkig was je met stressballen gemakkelijk omkoopbaar. 
Mijn kamergenoten bij MHeNS wil ik bedanken voor enkele plezierige jaren. Marlien, wat heb ik gelachen om je ongezouten en ongenuanceerde uitspraken. Frank, jij was ook meer van het avondritme, en bovendien heb je mij - digibeet - een keer of vijftig geholpen met mijn computer die nimmer naar mij maar wel naar jou wilde luisteren. Ivona, we had loads of fun (remember the Serbian hub) and congratulations with the fact that you did not manage to speak more than four words of Dutch during those 6 years that you spent in the Netherlands. Kim en later Nienke, gelukkig hadden we jullie om de boel een beetje in toom te houden; anders was het geheid misgegaan.

Ook de (ex)-onderzoekers bij de oogheelkunde wil ik natuurlijk bedanken voor een gezellige onderzoekstijd: Annelie, Aukje, Elton, Frank, Frenne, Margriet, Mari, Muriel, Nienke, Paul, Rob en Yanny. En nog bedankt dat jullie mij de EK-poule lieten winnen;-).

Dennis en Jules, jullie wisten allebei niet van het bestaan van paranimfen. Ten tijde van de promotieplechtigheid is jullie functie louter ceremonieel; later op de avond zijn de verwachtingen uitermate hooggespannen.

The Usual Suspects en de Rabano's wil ik bedanken voor de welkome afwisseling op een leven vol Pubmed en Web of Science. Ik heb genoten van alle avonturen en memorabele avonden. Gelukkig hebben we de foto's en de video's nog!

Mijn ouders en mijn broer wil ik bedanken voor jarenlang vertrouwen. Tom, ik wens je heel veel succes met je nieuwe studie in Peru.

Lieve Lauretta, ik ben je heel dankbaar voor alle liefde en geloof in me. 

Curriculum Vitae

List of Publications 


\section{Curriculum Vitae (English)}

Lukas Ricker was born on January 21, 1981 in Heerlen, The Netherlands. He attended Trichtercollege in Maastricht between 1993 - 1999. He started his medical training in 2000 at Maastricht University where he received his medical doctor degree in 2006 (Cum Laude). After having performed clinical work in the field of neurology, he started his $\mathrm{PhD}$ research in June 2007 on retinal detachment and proliferative vitreoretinopathy at the department of Ophthalmology, University Hospital Maastricht (under supervision of prof. dr. F. Hendrikse, prof. dr. E.C. La Heij, and prof. dr. A. Kijlstra). The research described in this thesis was in part performed at the School of Mental Health and Neuroscience (MHeNS) at Maastricht University, which is part of the European Graduate School of Neuroscience (EURON; Head: prof. dr. H. Steinbusch). In 2009 he won a travel grant to attend the 2010 Annual Meeting from the Association for Research in Vision and Ophthalmology (ARVO) in Fort Lauderdale, Florida, for his best presentation at ARVO-NED, the Dutch affiliate chapter of ARVO. The results of his PhD research are described in this thesis. 


\section{Curriculum Vitae (Nederlands)}

Lukas Ricker werd geboren op 21 januari 1981 in Heerlen. Na het behalen van het eindexamen VWO aan het Trichtercollege in Maastricht in 1999 startte hij in 2000 met de studie geneeskunde aan de Universiteit van Maastricht, waar hij in 2006 zijn arts-examen behaalde (Cum Laude). Na klinische werkzaamheden bij de neurologie is hij in juni 2007 begonnen met zijn promotieonderzoek naar netvliesloslatingen en proliferatieve vitreoretinopathie bij de afdeling oogheelkunde van het academisch ziekenhuis Maastricht (onder supervisie van prof. dr. F. Hendrikse, prof. dr. E.C. La Heij en prof. dr. A. Kijlstra). Het onderzoek zoals beschreven in dit proefschrift is ten dele uitgevoerd bij de afdeling Mental Health and Neuroscience (MHeNS) aan de Universiteit Maastricht, onderdeel van de European Graduate School of Neuroscience (EURON; Hoofd: prof. dr. H. Steinbusch). In 2009 ontving hij een reisbeurs om in 2010 het congres van de Association for Research in Vision and Ophthalmology (ARVO) in Fort Lauderdale (Florida) te bezoeken naar aanleiding van zijn winnende onderzoekspresentatie tijdens de jaarlijkse bijeenkomst van ARVO-NED, de Nederlandse tegenhanger van ARVO. De resultaten van zijn promotieonderzoek zijn te lezen in dit proefschrift. 


\section{List of publications}

Bootsma HP, Ricker L, Diepman L, Gehring J, Hulsman J, Lambrechts D, et al. Levetiracetam in clinical practice: long-term experience in patients with refractory epilepsy referred to a tertiary epilepsy centre.

Epilepsy Behav 2007;10(2):296-303

Bootsma HP, Ricker L, Diepman L, Gehring J, Hulsman J, Lambrechts D, et al. Longterm effects of levetiracetam and topiramate in clinical practice: a head-to-head comparison.

Seizure 2008;17(1):19-26

Bootsma HP, Ricker L, Hekster C, Hulsman J, Lambrechts D, Majoie M, et al. The impact of side effects on long-term retention in three new antiepileptic drugs.

Seizure 2009;18(5):327-31

Ricker LJAG, Kijlstra A, de Jager W, Liem ATA, Hendrikse F, La Heij EC. Chemokine levels in subretinal fluid obtained during scleral buckling surgery following rhegmatogenous retinal detachment.

Invest Ophthalmol Vis Sci 2010;51(8):4143-4150

Ricker LJAG, Al Dieri R, Beckers GJM, Pels E, Liem ATA, Hendrikse F, Kijlstra A, Hemker HC, La Heij EC. High Subretinal Fluid Procoagulant Activity in Rhegmatogenous Retinal Detachment.

Invest Ophthalmol Vis Sci 2010;51(10):5234-5239

Ricker LJAG, Noordzij LJ, Goezinne F, Cals DWJK, Berendschot TTJM, Liem ATA, Hendrikse F, La Heij EC. Persistent Subfoveal Fluid and Increased Preoperative Foveal Thickness Impair Visual Outcome after Macula-off Retinal Detachment Repair.

Retina 2011;31(8):1505-1512

Ricker LAG, Kijlstra A, de Jager W, Liem ATA, Hendrikse F, La Heij EC. Interleukin and Growth Factor Levels in Subretinal Fluid Obtained during Scleral Buckling Surgery after Rhegmatogenous Retinal Detachment.

PLOS ONE 2011;6(4):e19141 
Ricker LAG, Altara R, Goezinne F, Hendrikse F, Kijlstra A, La Heij EC. Soluble Apoptotic Factors and Adhesion Molecules in Rhegmatogenous Retinal Detachment. Invest Ophthalmol Vis Sci 2011;52(7):4256-4262

Ricker LJAG, Dieudonné SC, Rennel ES, Berendschot TTJM, Hendrikse F, Kijlstra A, La Heij EC. Anti-angiogenic Isoforms of VEGF Predominate in Subretinal Fluid of Patients with Rhegmatogenous Retinal Detachment and Proliferative Vitreoretinopathy.

Retina 2012;32(1):54-59

Ricker LJAG, de Jager W, Kessels AGH, Hendrikse F, Kijlstra A, La Heij EC. Adipokine Levels in Subretinal Fluid from Patients with Rhegmatogenous Retinal Detachment.

Exp Eye Res. In press

Ricker LJAG, Kessels AGH, de Jager W, Hendrikse F, Kijlstra A, La Heij EC. Prediction of Proliferative Vitreoretinopathy after Retinal Detachment Surgery: Potential of Biomarker Profiling.

Submitted

Ricker LAG, Kijlstra A, Mooij CM, Hendrikse F, La Heij EC. Immunocytology of cellular components in subretinal fluid from patients with rhegmatogenous retinal detachment.

Manuscript in preparation 